Check for updates

Cite this: RSC Adv., 2020, 10, 30314

\title{
Applications of alkyl orthoesters as valuable substrates in organic transformations, focusing on reaction media
}

\begin{abstract}
Zahra Khademi and Kobra Nikoofar (iD *
In this review we focus on applications of alkyl orthoesters as valuable and efficient substrates to perform various classes of two-component and multi-component organic reactions. The article has classified them according to two aspects, which are: (i) a focus on the reaction medium (solvent-free conditions, aqueous media, and organic solvents); and (ii) an examination of product structures. Reaction accomplishment under solvent-free conditions is an eco-friendly process with the absence of volatile toxic solvents, which puts it in line with green chemistry goals. Water is an interesting choice in organic transformations due to its inexpensiveness and safety. The authors hope their assessment will help chemists to attain new approaches for utilizing alkyl orthoesters in various organic synthetic methods. The review covers the corresponding literature up to the beginning of 2020.
\end{abstract}

Received 16th June 2020

Accepted 27th July 2020

DOI: $10.1039 / \mathrm{dOra05276k}$

rsc.li/rsc-advances

(e) 3,3,3-Triethoxy-1-propyne ( $\left.\mathrm{HCC}(\mathrm{OEt})_{3}, \mathbf{8}\right)$.

\section{Introduction}

Orthoester (1,1,1-triorganyloxyalkane) (1) is the general name for a functional group containing three alkoxy groups attached to one central carbon atom, with the general formula $\mathrm{RC}(\mathrm{OR})_{3}$. In fact they are the esters of orthoacids which do not exist in a free state. ${ }^{\mathbf{1 , 2}}$ Orthoesters were first synthesized via nucleophilic the substitution reaction of chloroform (2) with alkoxides (3) by Williamson and Kay in 1854 (Scheme 1). ${ }^{3}$ There are several examples of acyclic alkylorthoesters such as: ${ }^{4}$

(a) Trimethyl orthoformate (TMOF) is the simplest orthoester in organic chemistry, which is also called trimethoxymethane, 2-methoxyacetaldehyde dimethyl acetal, methoxymethylal, and methyl orthoformate. This colorless liquid with a pungent odor is soluble in ethanol and ether $\left(\left(\mathrm{CH}(\mathrm{OMe})_{3}, 4\right), \mathrm{bp}=100.6{ }^{\circ} \mathrm{C}\right.$, and $\left.d=0.9676 \mathrm{~g} \mathrm{~mL}^{-1}\right)$.

(b) Triethyl orthoformate (TEOF, $\mathrm{CH}(\mathrm{OEt})_{3}, 5$ ), also called diethoxymethoxyethane, triethoxymethane, and ethyl orthoformate a colorless volatile liquid with $\mathrm{bp}=146{ }^{\circ} \mathrm{C}$ and $d=$ $0.891 \mathrm{~g} \mathrm{~mL}^{-1}$, is the orthoester of formic acid.

(c) Triethyl orthoacetate (TEOAc, $\mathrm{CH}_{3} \mathrm{C}(\mathrm{OEt})_{3}, 6$ ) 1,1,1-triethoxyethane, $\left(\mathrm{bp}=142{ }^{\circ} \mathrm{C}, d=0.885 \mathrm{~g} \mathrm{~mL}^{-1}\right)$, is an oily yellow to colorless liquid with a pungent odor.

(d) Triethyl orthopropionate $\left(\mathrm{CH}_{3} \mathrm{CH}_{2} \mathrm{C}(\mathrm{OEt})_{3}, 7\right)$, also called 1,1,1-triethoxypropane and orthopropionic acid triethyl ester, is a clear colorless liquid ( $\mathrm{bp}=155-169{ }^{\circ} \mathrm{C}, d=0.886 \mathrm{~g} \mathrm{~mL}^{-1}$ ) which is soluble in alcohol, chloroform, ethyl acetate, and ether and hydrolyzes slowly in water.

Department of Chemistry, Faculty of Physics \& Chemistry, Alzahra University, P.O. Box 1993891176, Tehran,Iran.E-mail:k.nikoofar@alzahra.ac.ir; kobranikoofar@yahoo. com; Fax: +982188041344; Tel: +982188041344
Orthoesters may be considered to be products of the exhaustive alkylation of unstable orthocarboxylic acids and it is from these that the name "orthoester" is derived. Orthoesters are highly reactive owing to the electron-deficient central carbon atom caused by the -I effect of the electronegative groups OR. ${ }^{1}$ Among the ortheosters introduced above, TEOF involved maximal exploitation in the reactions based on our literature survey (109 reports) followed by TMOF (54 reports), TEOAc (21 cases), TMOAc (4 items), and triethyl orthopropionate ( 2 cases), and other kinds of alkyl orthoesters (1 case) (Fig. 1a). Several orthoesters were applied in various domains as dehydrating agents, ${ }^{5-18}$ alkylating agents, ${ }^{19-24}$ dialkoxymethylation agents, ${ }^{25}$ esterification agents, ${ }^{26}$ methoxy sources, ${ }^{27}$ additives, ${ }^{28-30}$ solvents, ${ }^{31-33}$ and protecting groups. ${ }^{34-36}$ This functional group is also necessary for some conversions such as the Johnson-Claisen rearrangement. ${ }^{37}$ Fig. $1 \mathrm{~b}$ demonstrates the assorted applications mentioned vs. the type of orthoester. As specified, TMOF and TEOF are the most commonly used in different processes, except for the case of rearrangements where TMOAc is the most abundant.

Different kind of orthoesters also have many applications in several branches of science, such as polymers, ${ }^{38-43}$ liquidcrystalline compounds, ${ }^{44}$ biochemistry, ${ }^{45-49}$ medicine $^{50-56}$ and medicinal organic chemistry, ${ }^{57-60}$ inorganic chemistry, ${ }^{61,62}$ organometallic chemistry, ${ }^{63}$ dynamic covalent chemistry, ${ }^{64}$ supramolecular chemistry, ${ }^{65-68}$ and crystal structure analysis. ${ }^{69}$ Orthoesters have also been used in the synthesis of natural products, e.g. loganin is a monoterpene glucoside occupying a central position in the generation of secoiridoids and alkaloids, obtained from orthoesters biosynthetically. Because of this, in 1973, Buechi and co-workers described the total 


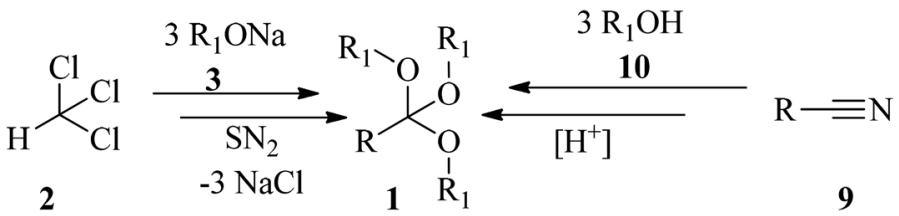

Scheme 1 The Pinner reaction for orthoester synthesis.

a

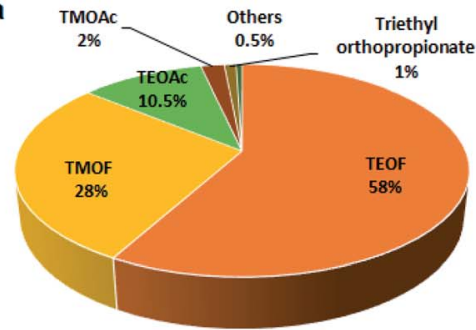

- Polymer

- Liquid crystals

- Biochemistry

- Medicine

- Medicinal organic chemsitry

- Inorganic chemistry

- Organometallic chemsitry

- Dynamic covalent chemistry

- Supramolecular chemistry

- Crystal structure analysis

Natural products

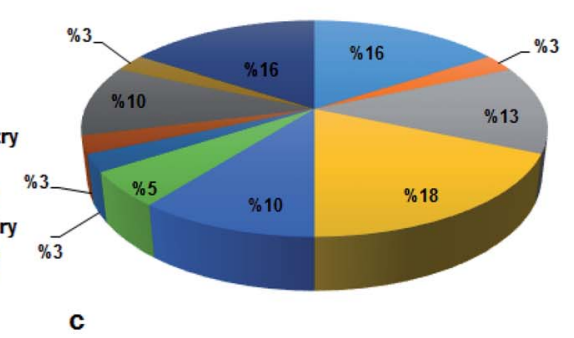

$=$ TMOAC

TEOAC

$=$ TEOF

$\because$ TMOF

- Total Number of reprots

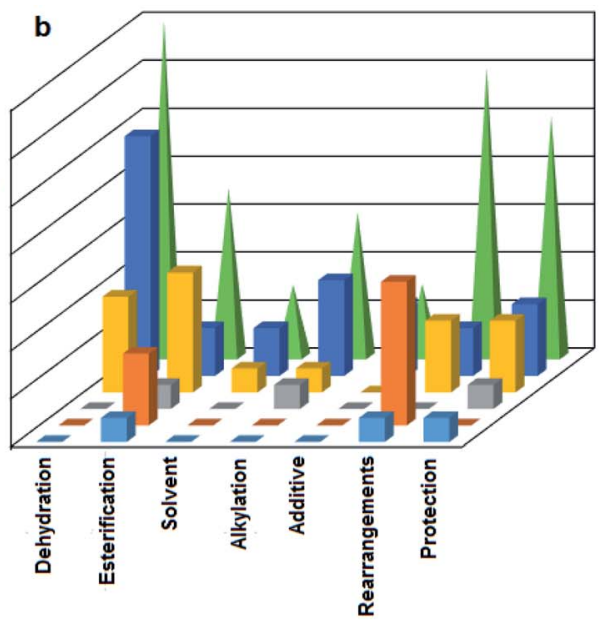

Fig. 1 The abundances of different orthoesters as substrates in organic transformations (a), assorted applications of different kinds of orthoesters in some processes (b), and the classification of their utilization in various domains of science and technology (c).

synthesis of loganin. It should be noted that trimethyl orthoformate was employed in some of the steps in the preparation of $\operatorname{loganin},{ }^{70}$ and the total synthesis of $(-)$-monomorine, ${ }^{71}$ and $( \pm)$-vernolepin..$^{72}$ It has been reported that TEOF is exploited in the total synthesis of palytoxin, as a marine natural product. ${ }^{73} \mathrm{In}$
1976, Greenlee and Woodward reported the total synthesis of marasmic acid, one of the many fungal metabolites obtained from the Basidiomycetes, in which trialkyl orthoformates were applied in some of the syntheses. ${ }^{74}$ Chan and Koide utilized orthoesters for the first total synthesis of the stresgenin B

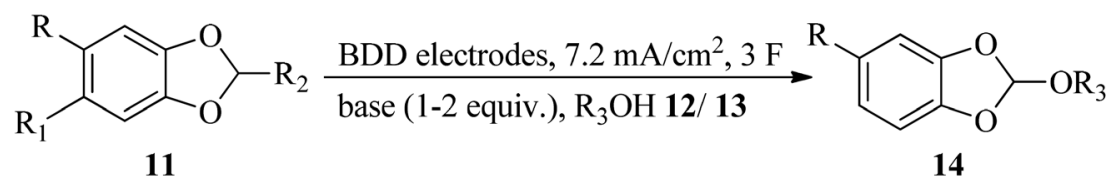

$\mathrm{R}=\mathrm{H}, \mathrm{Me}, \mathrm{t}$ - $\mathrm{Bu}, \mathrm{OMe}, \mathrm{CH}_{2} \mathrm{OMe}, \mathrm{Cl}, \mathrm{CN}, \mathrm{CH}_{2} \mathrm{CO}_{2} \mathrm{Me}, \mathrm{OCH}_{2} \mathrm{CO}_{2} \mathrm{Me}, \mathrm{CH}_{2} \mathrm{CHCH}_{2}$

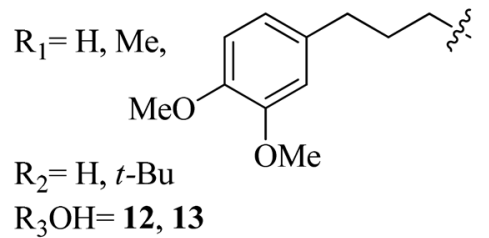<smiles>[R][I-][R]</smiles>

Scheme 2 The electrochemical synthesis of highly fluorinated orthoesters. 


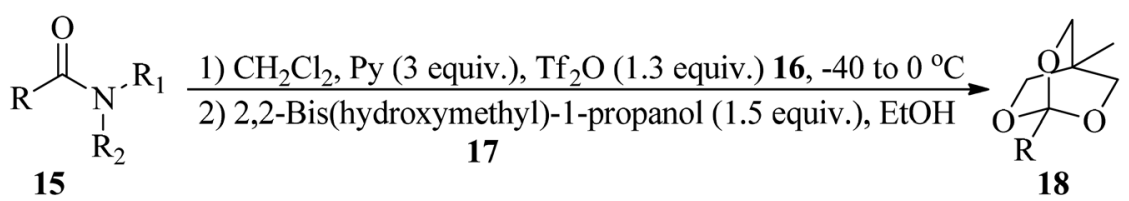

15<smiles>[R]#[R]c1ccccc1</smiles><smiles>CC(C)(C)Cc1ccccc1</smiles>

$\mathrm{R}_{1}=\mathrm{CH}_{3}, \mathrm{CH}_{3} \mathrm{CH}_{2}, \mathrm{PhCH}_{2}$

$\mathrm{R}_{2}=\mathrm{H}, \mathrm{CH}_{3}, \mathrm{CH}_{3} \mathrm{CH}_{2}$<smiles></smiles>

scaffold as a heat shock protein expression inhibitor. ${ }^{75}$ The application of orthoesters in the synthesis of condensed carboncage organics was investigated in the preparation of twistane as a cycloalkane and also the simplest diamondoid. In 1967,
Gauthier and Deslongchamps obtained twistane via a multistep process started by TEOF as one of the substrates. ${ }^{76}$ The diagram in Fig. 1c illustrates the vast range of applications of different kinds of orthoesters in various sciences. The results

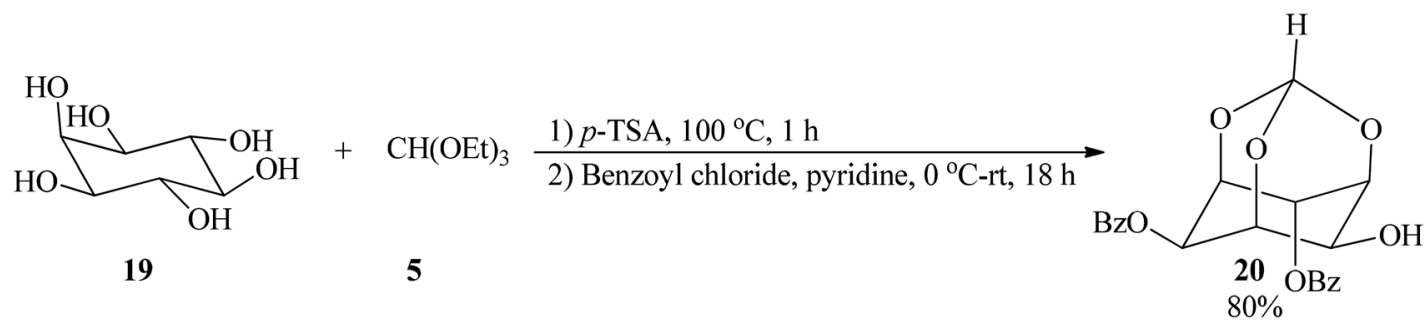

Scheme 4 The preparation of 2,4-di-O-benzoyl-myo-inositol 1,3,5-orthoformate.<smiles>[R]C1COC2(CCC2)O1</smiles>

$n=2-4$<smiles>[R]CCl</smiles><smiles>Cc1ccc2ccccc2c1</smiles>

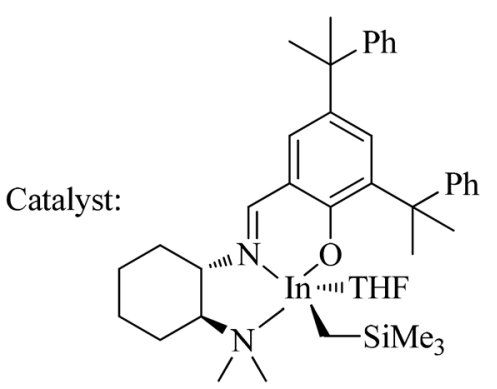

Scheme 5 The synthesis of spiro orthoesters. 

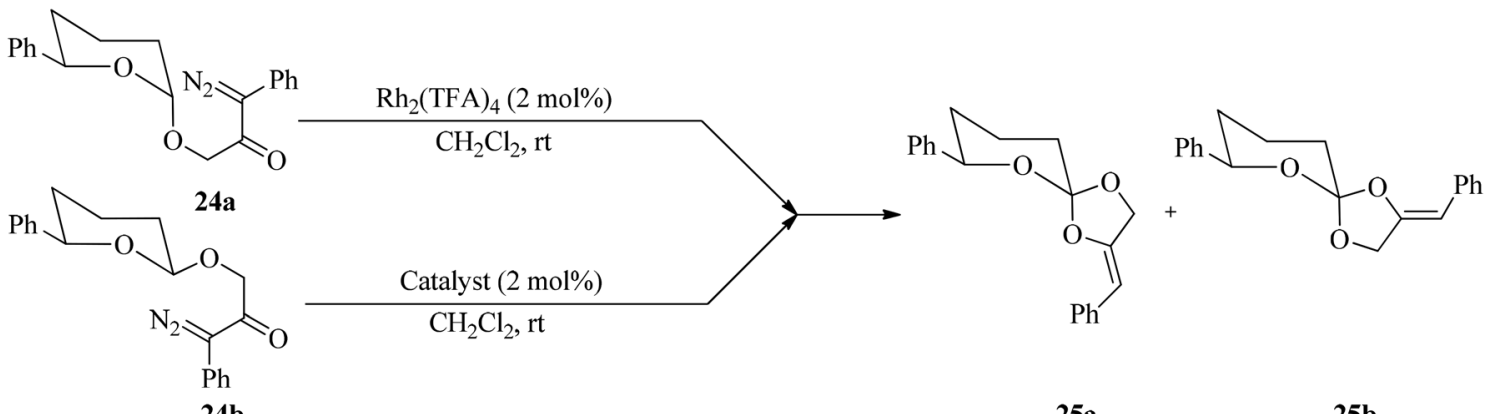

$24 \mathrm{~b}$

Catalyst: $\mathrm{Rh}_{2}(\text { cap })_{4}, 14 \%, 80: 20$

25b

$\mathrm{Rh}_{2}\left(\mathrm{O}_{2} \mathrm{CCPh}_{3}\right)_{4}, 14 \%, 80: 20$

$\mathrm{Rh}_{2}$ (oct) $)_{4}, 37 \%, 70: 30$

$\mathrm{Rh}_{2}(\mathrm{OAc})_{4}, 40 \%, 70: 30$

$\mathrm{Rh}_{2}(\mathrm{TFA})_{4}, 47 \%, 70: 30$

Scheme 6 The Rh(II)-catalyzed synthesis of spirocyclic orthoesters.

indicate the comprehensive use of orthoesters in many domains of science and technology.

In addition to the Williamson and Kay method, there are various procedures for the preparation of orthoesters. The Pinner reaction of nitriles (9) with alcohols (10) in the presence of strong acids generated orthoesters (Scheme 1). ${ }^{77}$ Electrochemical approaches ${ }^{78-81}$ are also employed for the synthesis of these compounds, e.g., new highly fluorinated orthoesters (14) were synthesized through the functionalization of 1,3-benzodioxoles (11) in the 2 position with diverse fluorinated alcohols (such as 1,1,1,3,3,3-hexafluoropropan-2-ol (HFIP, 12) or 2,2,2trifluoroethanol (TFE, 13)) in an undivided cell and in the presence of $N, N$-diisopropylethylamine or 1,8-diazabicyclo[5.4.0]undec-7-ene (DIPEA/DBU) as basic electrolytes by borondoped diamond (BDD) electrodes under a constant current density of $7.2 \mathrm{~mA} \mathrm{~cm}{ }^{-2}$ until a catalytic quantity of $3.0 \mathrm{~F} \mathrm{~mol}^{-1}$ of electricity has passed (Scheme 2). ${ }^{82}$

Secondary and tertiary amides (15) were reacted with triflic anhydride (16) by pyridine in $\mathrm{CH}_{2} \mathrm{Cl}_{2}$ at low temperatures to form imino and iminium triflates within $4 \mathrm{~h}$, which on treatment with 2,2-bishydroxymethyl-1-propanol (17) utilizing pyridine buffered solution attained 2,6,7-trioxabicyclo[2.2.2]octane orthoesters (18) (Scheme 3). ${ }^{83}$

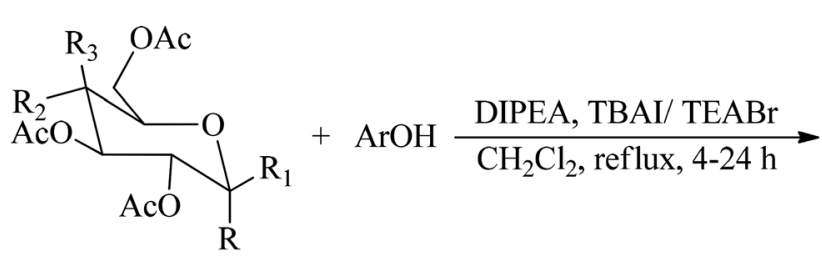

26 $\alpha: \mathrm{R}=\mathrm{I}, \mathrm{R}_{1}, \mathrm{R}_{2}=\mathrm{OAc}, \mathrm{R}_{3}=\mathrm{H}$

27 $\alpha$ : $\mathrm{R}=\mathrm{I}, \mathrm{R}_{1}, \mathrm{R}_{2}=\mathrm{H}, \mathrm{R}_{3}=\mathrm{OAc}$

28 $\alpha$ : $\mathrm{R}=\mathrm{Br}, \mathrm{R}_{1}=\mathrm{H}, \mathrm{R}_{2}=\mathrm{OAc}, \mathrm{R}_{3}=\mathrm{H}$

28 $\beta$ : $\mathrm{R}=\mathrm{H}, \mathrm{R}_{1}=\mathrm{Br}, \mathrm{R}_{2}=\mathrm{OAc}, \mathrm{R}_{3}=\mathrm{H}$

$29 \alpha: \mathrm{R}=\mathrm{Cl}, \mathrm{R}_{1}=\mathrm{H}, \mathrm{R}_{2}=\mathrm{OAc}, \mathrm{R}_{3}=\mathrm{H}$

29ß: $\mathrm{R}=\mathrm{H}, \mathrm{R}_{1}=\mathrm{Cl}, \mathrm{R}_{2}=\mathrm{OAc}, \mathrm{R}_{3}=\mathrm{H}$

ArOH:<smiles>[R]C1(C)CCc2c(C)c(O)c(C)c(C)c2O1</smiles>

30: $\mathrm{R}=\mathrm{C}_{16} \mathrm{H}_{33}$

31: $\mathrm{R}=\mathrm{CH}_{3}$

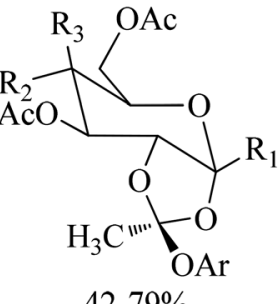

$42-79 \%$

33: $\mathrm{Ar}=1, \mathrm{R}=\mathrm{OAc}, \mathrm{R}_{1}=\mathrm{H}$

34: $\mathrm{Ar}=1, \mathrm{R}=\mathrm{H}, \mathrm{R}_{2}=\mathrm{H}, \mathrm{R}_{1}=\mathrm{OAc}$

35: $\mathrm{Ar}=2, \mathrm{R}=\mathrm{OAc}, \mathrm{R}_{2}=\mathrm{OAc}, \mathrm{R}_{1}=\mathrm{H}$

36: $\mathrm{Ar}=3, \mathrm{R}=\mathrm{OAc}, \mathrm{R}_{2}=\mathrm{OAc}, \mathrm{R}_{1}=\mathrm{H}$

Scheme 7 Synthetic procedure for peracetylated orthoester. 


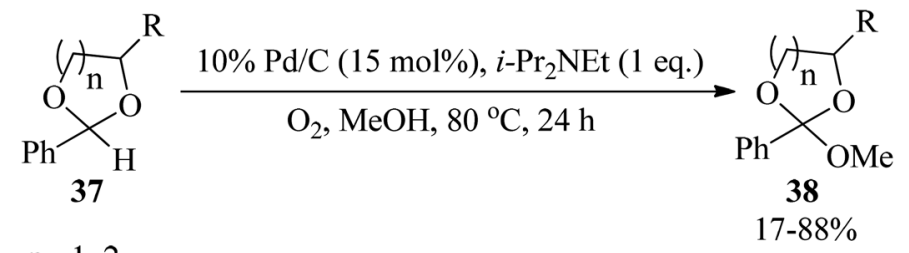

$\mathrm{n}=1,2$

$\mathrm{R}=\mathrm{H}, \mathrm{CH}_{3}$

Scheme 8 The synthesis of orthoesters via the methoxylation of cyclic acetals.

2,4-Di-O-benzoyl-myo-inositol 1,3,5-orthoformate (20), a cyclic alkyl orthoester, was obtained from successive treatment of myo-inositol (19) with TEOF (5) and benzoyl chloride by Shashidhar and Praveen in 2001 (Scheme 4). ${ }^{84}$

The reaction of epoxides (21) and lactones (22) in the presence of a cationic indium catalyst under heating with benzene resulted in spiro orthoesters (23) (Scheme 5). ${ }^{85}$
Tetrahydropyranyl acetals containing a phenyl diazoketone substituent (24) underwent $\mathrm{Rh}$ (II)-catalyzed $\mathrm{C}-\mathrm{H}$ insertion through an unusual $\mathrm{C}-\mathrm{O}$ bond generation to give spirocyclic orthoesters (25) (Scheme 6). ${ }^{86}$

3,4,6-Tri- $O$-acetyl-1,2-O-(1-tocopheroxyethylidene)- $\alpha$-D-glucopyranose (vitamin E sugar 1,2-orthoester) (33-36) with exo-type stereoselectivity were synthesized through the reaction of sugar halides (26-29) with various phenols, such as $\alpha$-tocopherol (30), chroman-6-ol (31), and 2,6-dimethylphenol (32) by $N, N$-diisopropylethylamine (DIPEA) and tetrabutylammonium iodide (TBAI) or tetraethylammonium bromide (TEABr) in refluxing $\mathrm{CH}_{2} \mathrm{Cl}_{2}$ for 4-24 h. The obtained peracetylated orthoesters (3336) were deprotected by utilizing aminolysis $\left(\mathrm{NH}_{3} / \mathrm{MeOH}\right)$ or by reduction in the presence of DIBAL-H (Scheme 7). ${ }^{87}$

Palladium on carbon $(\mathrm{Pd} / \mathrm{C})$ catalyzed the straightforward methoxylation of the benzylic positions of cyclic acetals (37) by i$\mathrm{Pr}_{2} \mathrm{NEt}$ in refluxing methanol under atmospheric oxygen as a green oxidant to obtain orthoesters (38) (Scheme 8). ${ }^{88}$

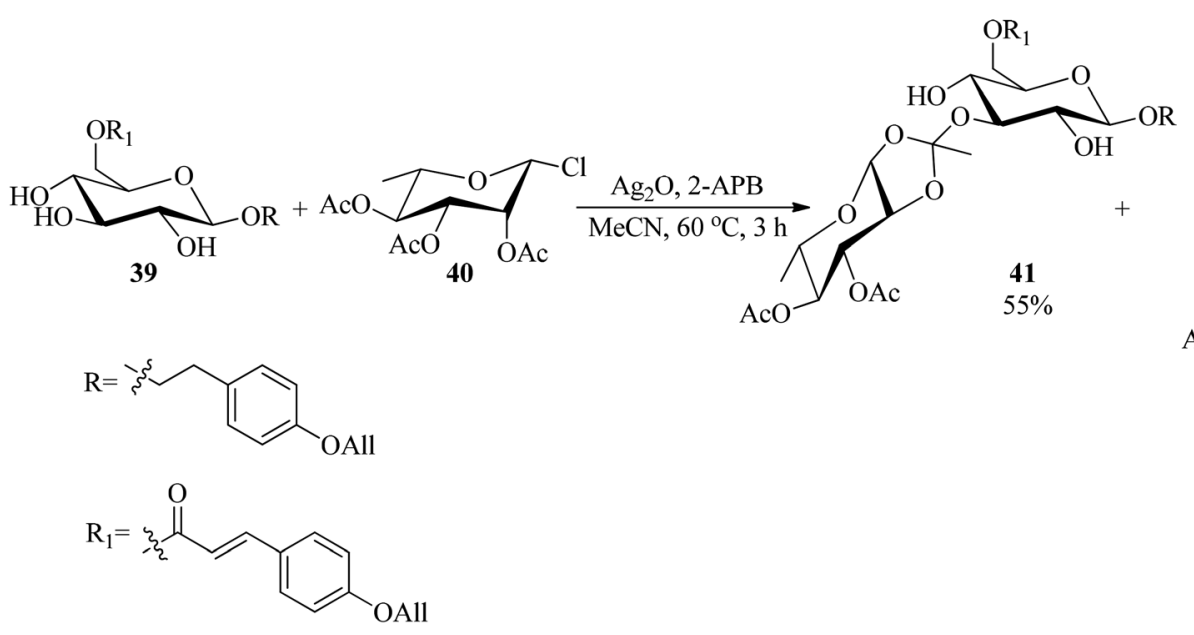

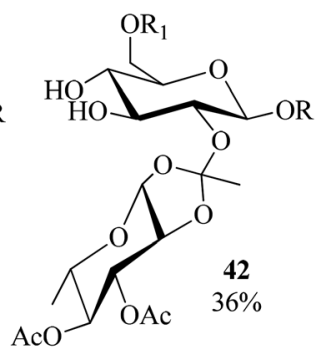

Scheme 9 The preparation of orthoesters via the Koenigs-Knorr glycosylation reaction.

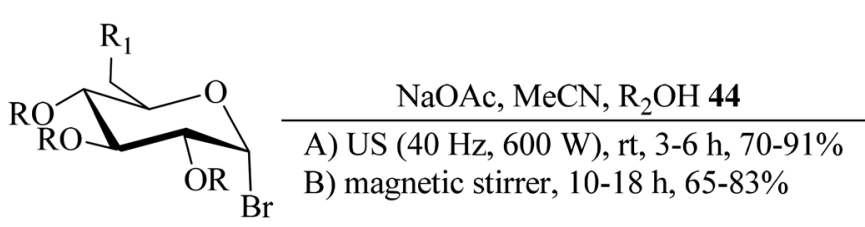

43

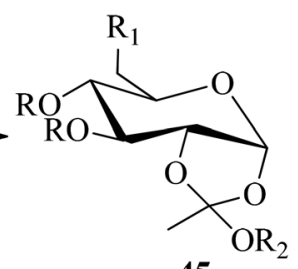

45

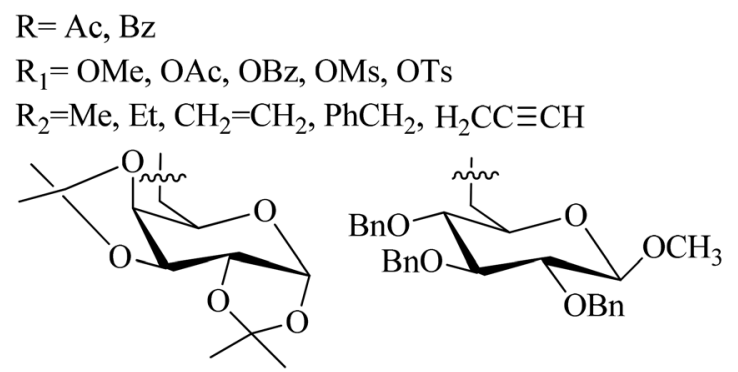

Scheme 10 The synthetic route to sugar 1,2-orthoesters. 


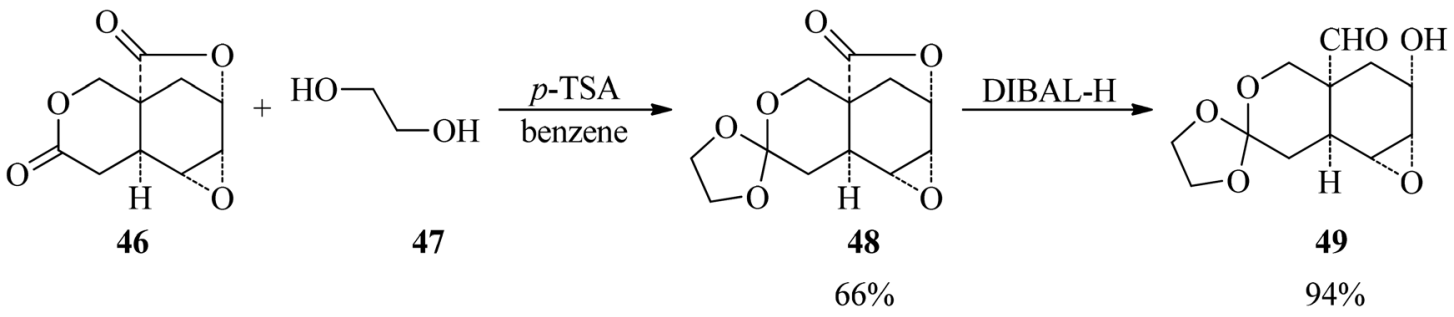

Scheme 11 The preparation of a crystalline ethylene orthoester possessing an aldehydic moiety.

The Koenigs-Knorr glycosylation reaction of glucopyranoside (39) with rhamnosyl chloride (40) as a glycosyl donor was accomplished using a catalytic amount of 2-aminoethyl diphenylborinate (2-APB, $5 \mathrm{~mol} \%)^{89}$ and silver $(\mathrm{I})$ oxide $\left(\mathrm{Ag}_{2} \mathrm{O}\right)$ in acetonitrile at $60{ }^{\circ} \mathrm{C}$ to obtain the mixture of 3 - and 2 -orthoesters (41) and (42) in 55\% and 36\% yields, respectively within $3 \mathrm{~h}$ (Scheme 9). ${ }^{90}$

Zhao et al. prepared sugar 1,2-orthoesters (45) via the reaction of peracetylated mannopyranosyl bromides (43) with alcohol derivatives (44) and anhydrous sodium acetate (NaOAc) as a base in acetonitrile at room temperature under ultrasound irradiation $(40 \mathrm{KHz}$ and $600 \mathrm{~W})($ method $\mathrm{A})$, and the traditional reaction under high-speed magnetic stirring (method $\mathrm{B}$ ). The results confirmed that an ultrasound-assisted reaction proceeded much better than the traditional method (70-91\% yields, 3-6 h) (Scheme 10). ${ }^{91}$

The reaction of dilactone (46) with ethylene glycol (47) by $p$ toluenesulfonic acid ( $p$-TSA) in the presence of magnesium sulfate in refluxing benzene obtained the crystalline ethylene orthoester (48) in $66 \%$ yield within $4.5 \mathrm{~h}$, which underwent a reduction reaction with diisobutylaluminum hydride as a reducing agent in combined dimethoxyethane/toluene $(1: 2)$ media at $-76{ }^{\circ} \mathrm{C}$ to room temperature to afford the hydroxy aldehyde (49) in $94 \%$ yield (Scheme 11)..$^{22}$
Hexachlorobuta-1,3-diene (50) was refluxed with sodium methoxide in methanol for $12 \mathrm{~h}$ to obtain a mixture of 4,4dimethoxy-2-oxobut-3-enoic acid (51) and (Z)-2,4,4-trichloro1,1,1,3-tetramethoxybut-2-ene (52) in $39 \%$ and $54 \%$ yields, respectively in which for easy identification, compound (51) was reacted with diazomethane $\left(\mathrm{CH}_{2} \mathrm{~N}_{2}\right)$ in methanol at room temperature to produce methyl $(Z)-4,4$-dimethoxy-2-oxobut-3enoate (53) in moderate yield (56\%), while orthoester $Z-52$ was converted into methyl (Z)-2,4,4-trichloro-3-methoxybut-2-enoate $(Z-54)$ in good yield (70\%) via acid hydrolysis in THF at $50{ }^{\circ} \mathrm{C}$ for $2 \mathrm{~h}$ (Scheme 12). ${ }^{93}$

In 2018, a review entitled "Synthesis and biological activity of oxazolopyrimidines" was published. In some parts of it, orthoesters were used to prepare oxazolo[ $[4,5-d]$ pyrimidines and 7-aminooxazolo[5,4- $d]$ pyrimidines. ${ }^{94}$

Perillo et al. presented a review article entitled "Synthesis and properties of seven- to nine-membered ring nitrogen heterocycles. Cyclic amidines and cyclic amidinium salts" which pointed to the application of orthoesters in synthetic methods..$^{95}$ In 2011, Lavigne's research group published a review article about the route yield from N-heterocyclic carbene precursors. They introduced trialkylorthoesters as the precarbenic unit. ${ }^{96}$ In 2013, A. Elassar and co-workers published a review article about diaminomaleonitrile (DAMN) in which

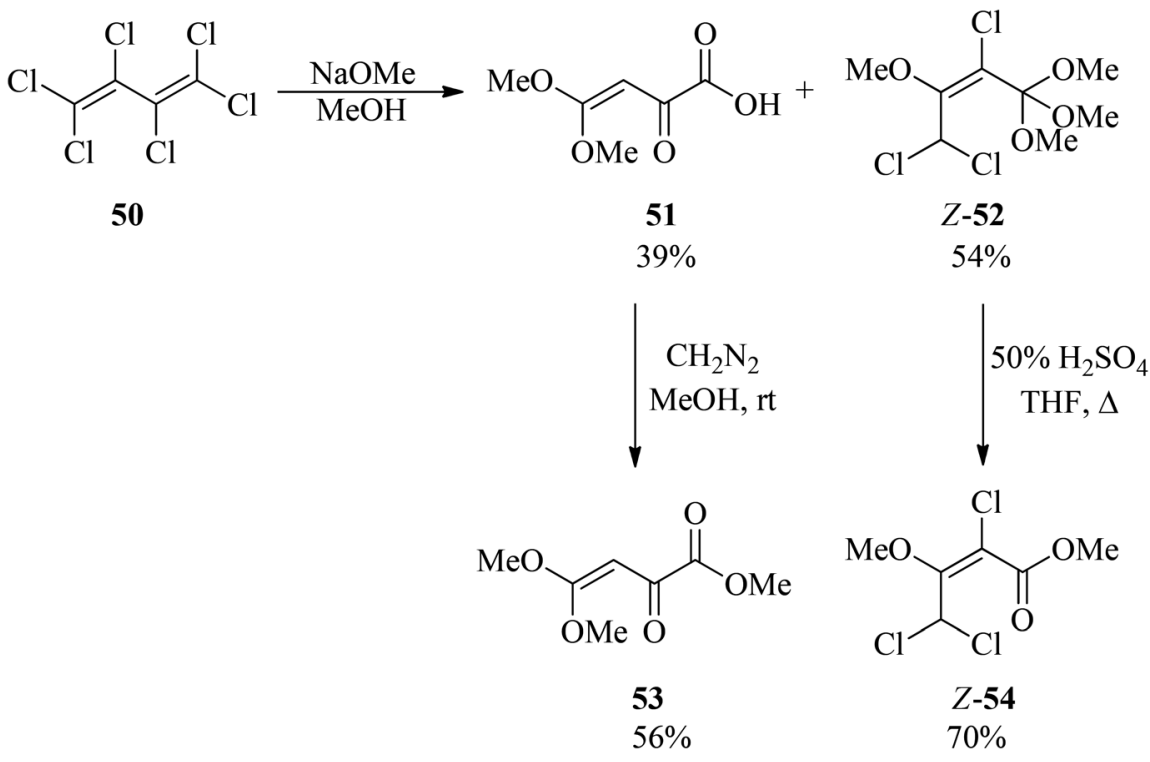

Scheme 12 The synthesis of some Z-orthoester structures. 


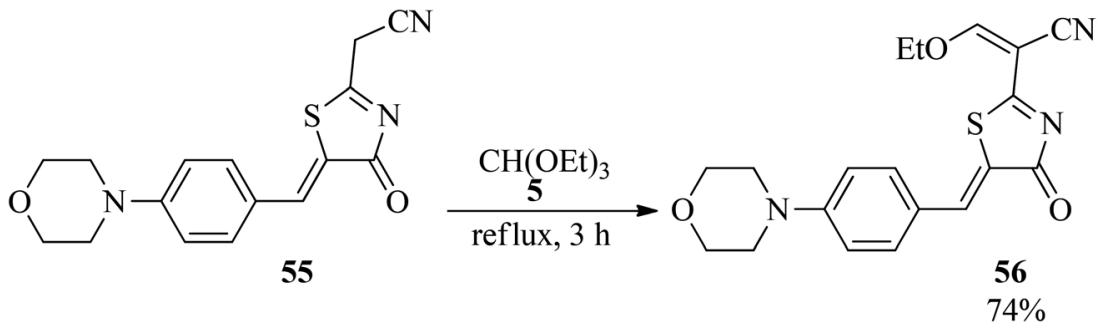

Scheme 13 The synthesis of 3-ethoxy-2-[5-(4-(morpholin-4-yl)benzylidenyl)-4-oxo-4,5-dihydro-thiaol-2-yl]acrylonitrile by TEOF.

the mentioned synthon reacted with various orthoesters to prepare different kinds of biologically active heterocycles. ${ }^{97}$

Numerous review papers have reported on different applications of orthoesters; ${ }^{\mathbf{9 8}, 99}$ for example, a 1986 review article entitled "Alkyl orthoesters and their applications in organic synthesis", by Pavlova and co-workers, focused on a systematic account of data describing the chemical properties of alkyl esters of orthocarboxylic acids. The proposed reaction mechanisms were discussed and the scope of utility of the orthoesters in the solution of diverse problems in organic synthesis was shown. ${ }^{100}$ Moreover, a 1988 article entitled "Carbon-carbon bond formation and annulation reactions using trimethyl and triethyl orthoformates", by Ghosh and Ghatak, focused on the annulation reactions by orthoformates and also the introduction of a formylation-cyclization method for the production of functionalized polycyclic bridged-bicyclo[3.3.1]nonanes, cyclopentenones, and other isolated products to develop the synthetic potential of carbon-carbon bond formation reaction via orthoformates. ${ }^{98}$ In 2007 , a review of "Recent studies on reaction pathways and applications of sugar orthoesters in synthesis of oligosaccharides", was published by Kong. ${ }^{101}$ In 2009, Liao and co-workers presented a focused literature survey on plant orthoesters. ${ }^{102}$ In 2014, a review article with the title "The orthoester Johnson-Claisen rearrangement in the synthesis of bioactive molecules, natural products, and synthetic intermediates-recent advances", was published with 211 ref. 103. In 2016, another review was also published with the title "Recent development in the orthoester Johnson-Claisen rearrangement and application", by the Alam group. ${ }^{99}$ In 2009, a spotlight titled "Alkyl orthoformate: a versatile reagent in organic synthesis", was compiled by Frizzo. ${ }^{104}$ It should be noted that, during the preparation of this review article, a paper was published entitled "Orthoesters: multiple role players in organic synthesis", by Nazarian and Dabiri. ${ }^{\mathbf{1 0 5}}$

Due to the central role of orthoesters and their comprehensive applications, the authors considered the literature reports of usage of orthoesters according to several classes of organic transformations. The initial classification is based on the reaction media: solvent-free conditions, aqueous medium and organic solvents. Each part is also subdivided according to the structures of the achieved products. This dual classification demonstrates the importance of the reaction media in progressing the preparation of each class of organics, because the nature of the solvent and its interaction with the reaction components and reagents (orthoesters and other participants) affect the route of the process and may change it seriously. The authors hope the review will highlight the significant role of orthoesters in organic and pharmaceutical chemistry as well as in biosciences and be a proper guide to designing new procedures and approaches to obtain new organics to reach a better life.

\section{Orthoester reactions under solvent-free conditions}

Performing organic reactions under solvent-free conditions has been notable recently for chemists due to its individual ecoenvironmental and economical features. In fact, in the absence of solvents the substrates are closer, allowing the right effectual contacts to let the reaction happen. This process, that elevates the reactivity of the substrates, diminishes the reaction time and energy usage, and performs the procedures more selectively in a safe and clean manner. In addition, the absence of hazardous solvents is in line with the rules of green chemistry, turning the transformation into an eco-friendly process. So, because of the importance of the reaction being accomplished under solvent-free conditions, below we focus on reports of utilizing orthoesters in various classes of organic synthesis. The presence of about 150 references in this area confirmed the significance of this method.

\subsection{Synthesis of ethoxymethylenes}

In 2004, Lamphon et al. synthesized 3-ethoxy-2-[5-(4-(morpholin4-yl)benzylidenyl)-4-oxo-4,5-dihydro-thiaol-2-yl]acrylonitrile<smiles>CCOC=Nc1nc2c(cc1C(=O)OCC)c(C)c(C#N)c(=O)n2C</smiles>

Scheme 14 The synthesis of ethoxymethyleneamino derivatives. 
containing an ethoxymethylene moiety (56) in $74 \%$ yield via the condensation of TEOF (5) with 2-cyanomethyl-5-[4-(morpholin-4yl)benzylidenyl]-4,5-dihydro-4-thiazolinones (55) under reflux conditions within $3 \mathrm{~h}$ (Scheme 13). ${ }^{106}$

\subsection{Synthesis of ethoxymethylene amino derivatives}

In 2001, Mekheimer presented a novel technique for the synthesis of ethoxymethyleneamino derivative (58) ${ }^{\mathbf{1 0 7 - 1 1 0}}$ in high yield $(73 \%)$ via the condensation of a 1,8-naphthyridin-2-one ring system (57) with TEOF under reflux conditions within 8 h. ${ }^{109}$ Condensation of TEOF $^{111}$ with 3-amino-5-bromo-4,6dimethylthieno[2,3- $b]$ pyridine-2-carbonitrile ${ }^{\mathbf{1 1 2}}$ also generated a Schiff base (Scheme 14). ${ }^{113}$

\subsection{Synthesis of acetamides}

In 2015, Grandi et al. presented an efficacious, fast and highyielding method for the conversion of amine hydrochloride salts (61) to acetamides (63). Initially, the reaction between equimolar amounts of the primary and secondary amines (59) with ammonium chloride (60) under heating in ethanol obtained amine hydrochloride salts (61) in a $2 \mathrm{~h}$ period with excellent yields $(>90 \%)^{\mathbf{1 1 4}}$ which were transformed into their corresponding acetamides (63) via the acetylation reaction with trimethyl orthoacetate $(\mathbf{6 2})^{\mathbf{1 1 5 , 1 1 6}}$ by two different pathways: (a) using microwave irradiation (Biotage Initiator ${ }^{\mathrm{TM}}$ Sixty EXP) at $135{ }^{\circ} \mathrm{C}$ in methanol, and (b) under conventional heating conditions through refluxing. The results demonstrated that MW-assisted reaction promotion with shorter reaction times (15 min) than conventional heating (1-4 h) (Scheme 15). ${ }^{\mathbf{1 1 6}}$

In 2010, Khan et al. presented a simple methodology for the synthesis of unsymmetrical $N, N^{\prime}$-disubstituted acetamidines $(67) .{ }^{117,118}$ In this paper, ethyl( $\left.1 E\right)$ - $N$-(4-oxo-2-phenylquinazolin$3(4 H)$-yl)ethanimidoate (65) was first prepared via the condensation reaction of 3-amino-2-phenyl-4(3H)-quinazolinone (64) with TEOAc (6) using acetic acid under reflux conditions. After completion of the reaction, the mixture was poured into ice-cold water. The resultant precipitation was filtered, washed with water and recrystallized from ethanol to produce (65) as a white crystalline solid in $83 \%$ yield within $5 \mathrm{~h} .{ }^{119}$ In the next step, $\mathrm{N}$-(4oxo-2-phenyl-3(4H)-quinazolinoyl)- $N$-(aryl)acetamidines were obtained through the condensation reaction of (65) with substituted aromatic amines (66) by glacial acetic acid at reflux condition in moderate to excellent yields (46-95\%) for 4-5 h (Scheme 16). It was found that electron-donating aromatic amines gave the corresponding acetamidines in good yields while the reaction failed with electron-withdrawing aromatic amines. The reaction proceeded selectively with just primary aromatic amines, including electron-donating substituents. ${ }^{\mathbf{1 1 8}}$ On the other hand, symmetrical $N, N^{\prime}$-disubstituted acetamidines were produced by a microwave-assisted $(850 \mathrm{~W})$ condensation reaction of triethyl orthoacetate with the anilines in acetic acid within very short reaction times (5-7 min). High

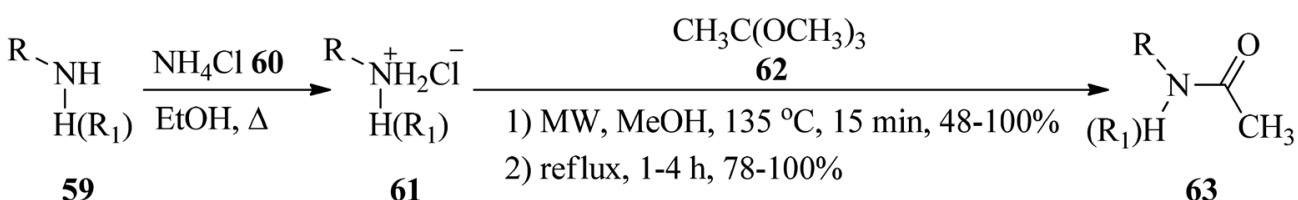

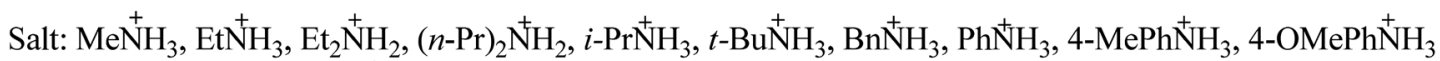<smiles>CC([NH3+])c1ccccc1CCC[NH3+]</smiles><smiles>CC(C)C[NH2+]CC(C)C</smiles>

Scheme 15 The synthesis of acetamides from amine hydrochloride salts and trimethyl orthoacetate.

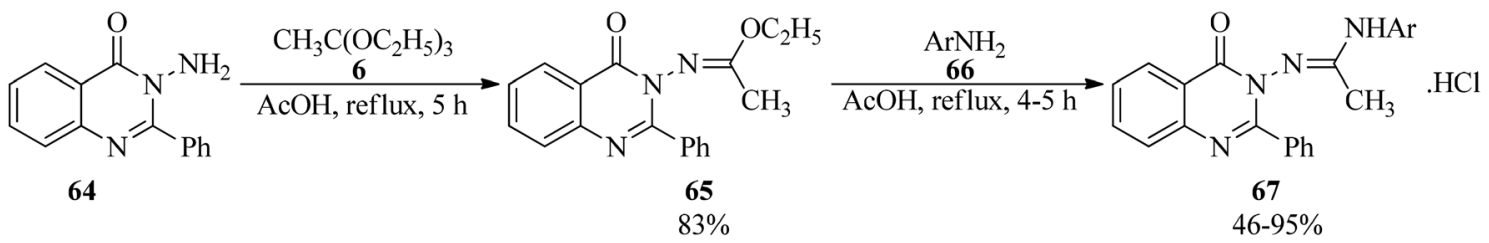

$\mathrm{Ar}=\mathrm{Ph}, 4-\mathrm{OHPh}, 4-\mathrm{MePh}, 2,4,6,-\mathrm{Me}_{3} \mathrm{Ph} 4-\mathrm{OMePh}, 3-\mathrm{BrPh}, 4-\mathrm{BrPh}, 4-\mathrm{ClPh}$, 4-IPh, 2-naphthyl

Scheme 16 The preparation of $N$-(4-oxo-2-phenyl-3(4H)-quinazolinoyl)- $N$-(aryl)acetamidines begins by forming amino quinazolinone and TEOAC. 


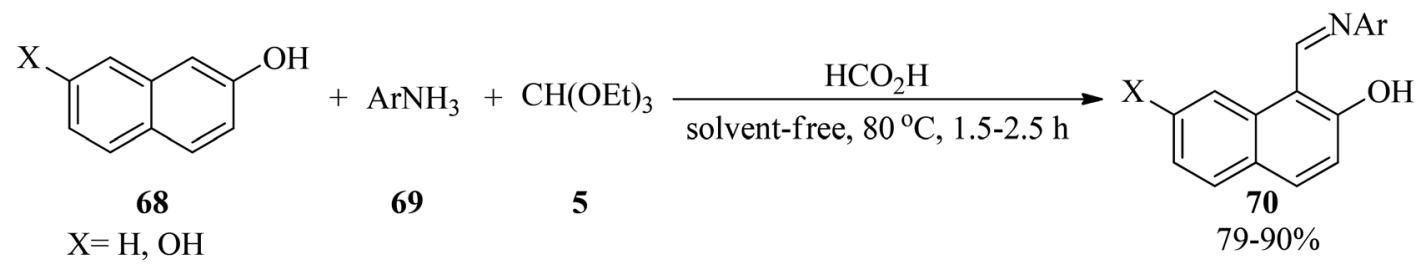<smiles>Cc1cc(C)nc(NC(=O)c2cccnc2)n1</smiles>

Scheme 17 Anil-like product formation utilizing TEOF.

yields and high purity of the product were obtained by the removal of ethanol as a by-product, via placing a receiver between the round-bottom flask and the condenser under heating by microwave irradiation at $850 \mathrm{~W}$ for $2-3 \mathrm{~min} .{ }^{120}$

\subsection{Synthesis of imines}

In 2012, Olyaei et al. synthesized novel anil-like products (70) $)^{\mathbf{1 2 1 , 1 2 2}}$ via the one-pot three-component condensation reaction of naphthols (68), TEOF (5), and heteroaryl amines (69) by formic acid as catalyst under solvent-free conditions at $80{ }^{\circ} \mathrm{C}$ in high yields (79-90\%) within 1.5-2.5 h (Scheme 17). Investigation of ${ }^{1} \mathrm{H}$ NMR and FT-IR exhibited that the products are in tautomeric equilibrium between the enol-imine and ketoenamine forms. Moreover, intramolecular hydrogen bonds were observed in the synthesized Schiff bases. In this research, 14-(2-hydroxynaphthyl)-14H-dibenzo[ $a, j]$ xanthene was also prepared through the treatment of 2-naphthol with TEOF in the absence of heteroaryl amines under solvent-free conditions at $80{ }^{\circ} \mathrm{C} .{ }^{122}$

\subsection{Synthesis of imidates}

In 2018, Verrier et al. reported metal and solvent-free microwave-assistance for the convenient preparation of $\mathrm{N}$ - sulfonyl and $N$-sulfinyl imidate derivatives by a leaky septum filled up with $4 \AA$ A MS which was placed $3 \mathrm{~cm}$ above the top of the microwave-tube. The treatment of trimethylorthoesters (71) with 4-methylbenzenesulfonamide (72) under solvent-free conditions at $180{ }^{\circ} \mathrm{C}$ afforded $N$-sulfonylimidates (73) within 10-30 min. Replacing (72) with tert-butanesulfinamide (74) in the presence of pyridinium $p$-toluenesulfonate (PPTS) (10 mol\%) at $80{ }^{\circ} \mathrm{C}$ yielded $N$-sulfinyl imidates (75) within $30-$ $60 \mathrm{~min}$ (Scheme 18). The design of an efficient apparatus with the ability to use molecular sieves to trap methanol, short reaction times, easy purification and isolation of the compounds, and excellent conversion and yields are some advantages of this strategy. ${ }^{123}$

\subsection{Synthesis of enamines}

Majee et al. developed an improved method of the Miyashita protocol $^{\mathbf{1 2 4}}$ for the synthesis of enamine derivatives $(\mathbf{7 8})^{\mathbf{1 2 5 , 1 2 6}}$ by the three-component condensation reaction of 1,3-dicarbonyls (76), $N$-methylurea (77) and TMOF (4) using zinc triflate $\left[\mathrm{Zn}(\mathrm{OTf})_{2},(5 \mathrm{~mol} \%)\right]$ under solvent-free conditions at room temperature within 7-9 $\mathrm{h}$ in good yields (56-85\%) (Scheme 19). ${ }^{126}$

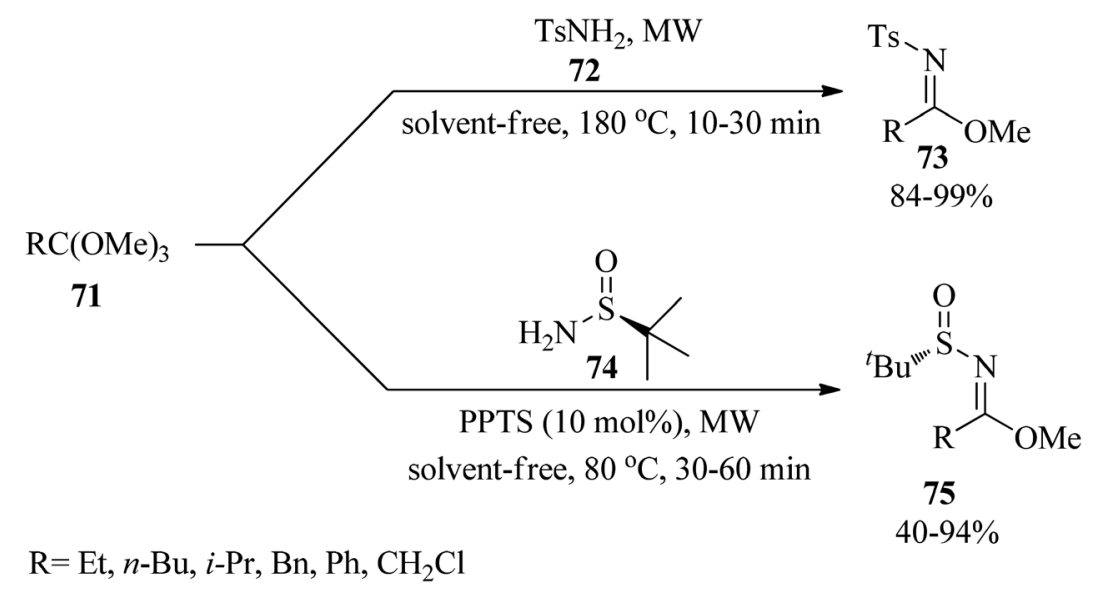

Scheme 18 Imidate synthetic procedure to form trimethyl orthoesters. 
<smiles>[R]C(=O)CC([R])=O</smiles>

$\mathrm{R}=\mathrm{Me}, \mathrm{Et}$ $\mathrm{R}_{1}=\mathrm{Me}, \mathrm{OMe}, \mathrm{OEt}, \mathrm{O} t$-Bu, OAllyl $\mathrm{R}, \mathrm{R}_{1}=-\mathrm{CH}_{2} \mathrm{C}(\mathrm{Me})_{2} \mathrm{CH}_{2}-$

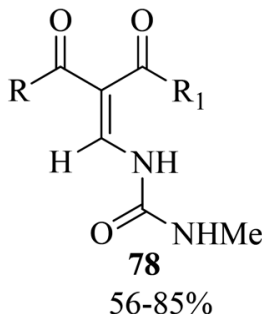

Scheme 19 Enamine synthesis by TMOF.

\subsection{Synthesis of formamidines}

Mazloumi et al. originated and characterized $\mathrm{TiO}_{2}-[\mathrm{bip}]-\mathrm{NH}_{2}{ }^{+-}$ $\mathrm{HSO}_{4}{ }^{-}$as an effective and eco-friendly catalyst through the modification of nanoporous $\mathrm{TiO}_{2}$ with bis-3(trimethoxysilylpropyl)-ammonium hydrogen sulfate and then its catalytic activity was investigated for the generation of $N, N^{\prime}$ diarylformamidines $(\mathbf{8 0})^{127,128}$ via the $N$-formylation reaction of anilines (79) with TEOF (5) under solvent-free conditions at $60{ }^{\circ} \mathrm{C}$ in very short reaction times (3-40 min) in high to excellent yields (83-100\%) (Scheme 20). In this research, the formation of the unsymmetrical diarylformamidines or aliphatic formamidines was unsuccessful. ${ }^{128}$

\subsection{Synthesis of lactones}

The condensation reaction of trans-2-alkene-1,4-diols (81) with triethyl orthoesters $(6,7)$ in $1: 2$ molar ratio was accomplished by utilizing catalytic amounts of hydroquinone or phenol under solvent-free conditions at $140-150{ }^{\circ} \mathrm{C}$ to give $\gamma$-lactones containing a vinylic substituent on the $\beta$-position (82) in 5291\% yields within $24 \mathrm{~h}$ (Scheme 21). ${ }^{129}$

\subsection{Synthesis of aminomethylene bisphosphonates}

In 2011, Reddy et al. designed an easy, efficient, and green procedure for the synthesis of amino methylene bisphosphonates $(\mathbf{8 5})^{\mathbf{1 3 0 - 1 3 5}}$ via the one-pot three-component condensation reaction of amines (83), TEOF (5), and dimethyl phosphite (84) using an alumina solid support $\left(\mathrm{Al}_{2} \mathrm{O}_{3}\right)$ by microwave irradiation $(490 \mathrm{~W})$ in excellent yield $(82-90 \%)$ for $12 \mathrm{~min}$ in two intervals. In addition to the microwave irradiation manner, the reaction was also performed under conventional thermal heating (90 $\left.{ }^{\circ} \mathrm{C}, 3-4 \mathrm{~h}, 30-58 \%\right)$ (Scheme 22). The results revealed shorter reaction times and higher yields using microwaveassistance. ${ }^{\mathbf{1 3 5}} \mathrm{A}$ similar transformation occurred via the treatment of primary amines, diethyl phosphite, and TEOF using amberlyst-15 under solvent-free conditions at room temperature within $90 \mathrm{~min}$ in good to excellent yields (70-95\%). All compounds were screened for in vitro antioxidant (by nitric<smiles>[R][R]1ccc(N)cc1</smiles>

Scheme 20 The generation of $N, N^{\prime}$-diarylformamidines with TEOF.

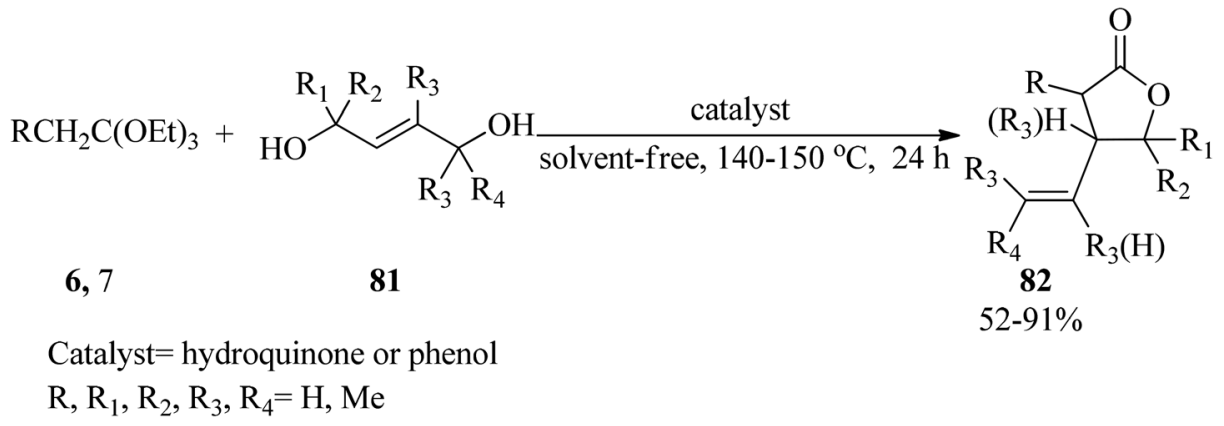

Scheme 21 The preparation of some classes of $\gamma$-lactones. 


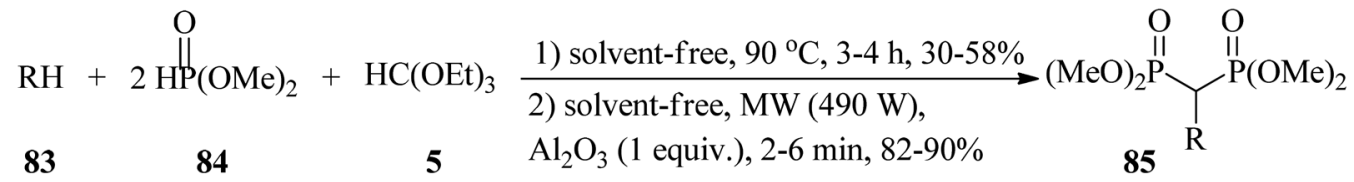

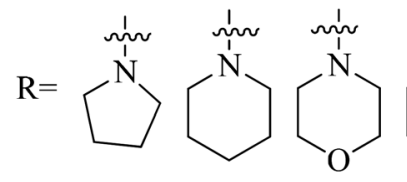<smiles>CN1CCN(C(=O)N2CCN(C#N)CCN2C)CC1</smiles>

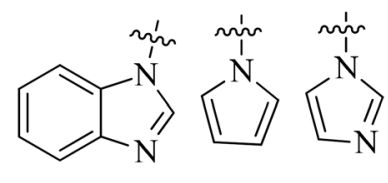

Scheme 22 A three-component route to obtain amino methylene bisphosphonates

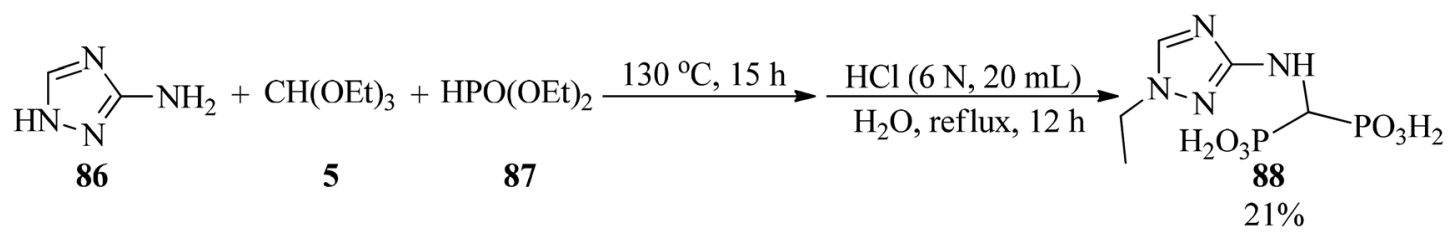

Scheme 23 The synthesis procedure for biologically active aminomethylenebisphosphonic acid.

oxide, DPPH radical scavenging, $\mathrm{H}_{2} \mathrm{O}_{2}$ methods), ${ }^{136-139}$ and antimicrobial activities. ${ }^{140}$

\subsection{Synthesis of aminomethylenebisphosphonic acids}

In 2017, some aminomethylenebisphosphonic acids (88) were prepared by Miszczyk et al. through the reaction of 3-amino1,2,4-triazole (86) with diethyl phosphite (87) and TEOF (5), in a 1:2:4 molar ratio (Scheme 23). The products are powerful inhibitors of the activity of J774E cells. So they can be used in antiosteolytic therapy, and are equipotent to the popular drug zoledronate and exhibit higher activity than the drug incadronate. ${ }^{\mathbf{1 4 1 , 1 4 2}}$

\subsection{Synthesis of indole derivatives}

Zirconium(Iv) chloride $\left(\mathrm{ZrCl}_{4}, 5 \mathrm{~mol} \%\right)$ catalyzed the electrophilic substitution reaction of indole (89) with TEOF (5) in a $3: 1$ molar ratio under solvent-free conditions at $50{ }^{\circ} \mathrm{C}$ to obtain tris(indolyl)methane $(\mathbf{9 0})^{\mathbf{1 4 3}}$ in a short reaction time (22 min) in excellent yield (95\%) (Scheme 24). ${ }^{\mathbf{1 4 4}}$

The regioselective reaction of carbazole (91) with TEOF (5) using $p$-TSA under solvent-free conditions at $80{ }^{\circ} \mathrm{C}$ gave 9(diethoxymethyl)carbazole (92) in 65\% yield in $48 \mathrm{~h}$. On the other hand, 4-methoxycarbazole (93) was regioselectively functionalized at the $\mathrm{C}_{1}$ position via reaction with (5) in the presence of trichloroacetic acid in dichloromethane at room temperature to furnish various carbazole derivatives, such as 4methoxycarbazole-1-carboxaldehyde (94), bis[4-methoxycarbazol1-yl]methylium trichloroacetate (95), tricarbazolylrnethane (96) according to the reaction conditions (Scheme 25). ${ }^{\mathbf{1 4 5}}$

\subsection{Synthesis of triaroyl methanes}

Boron trifluoride etherate liquid $\left(\mathrm{BF}_{3} \cdot \mathrm{OEt}_{2}, 0.05 \mathrm{~mol}\right)$ catalyzed the condensation reaction of aryl ketones (97) with TEOF (5) under microwave irradiation to obtain triaroyl methanes (98) in 55-85\% yields for 8-10 min. It was found that a substrate containing a bulky group such as (99) afforded a fused cyclopentenone ring product (100) in $79 \%$ yield within $8 \mathrm{~min}$ (Scheme 26). ${ }^{146}$

\subsection{Synthesis of 5,15 -diphenyl-10,20-dimethyl porphyrins}

In 2003, the reaction of 5-phenyldipyrromethanes (101) with orthoesters (102) was presented for the generation of 5,15diphenyl-10,20-dimethyl porphyrins (DPPs) (103) by trichloroacetic acid (TCA) (Scheme 27). Notably, trimethyl

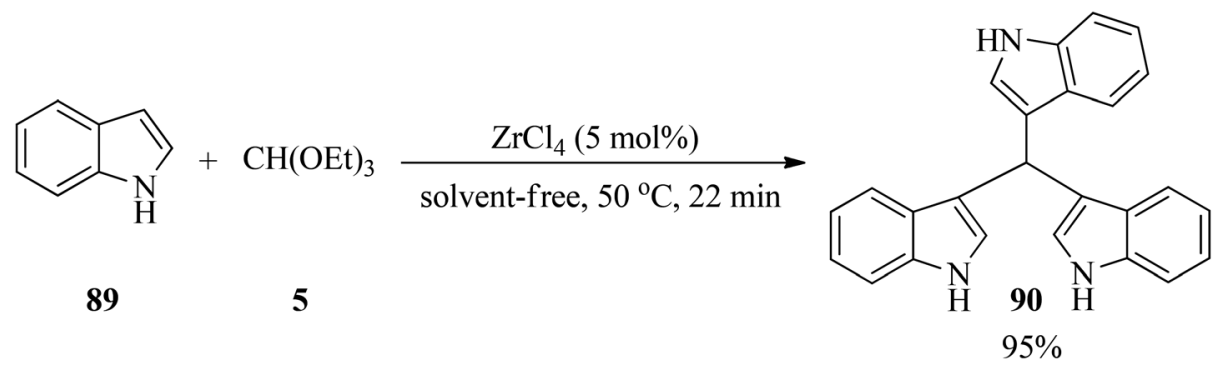

Scheme 24 Tris(indolyl)methane synthesis. 


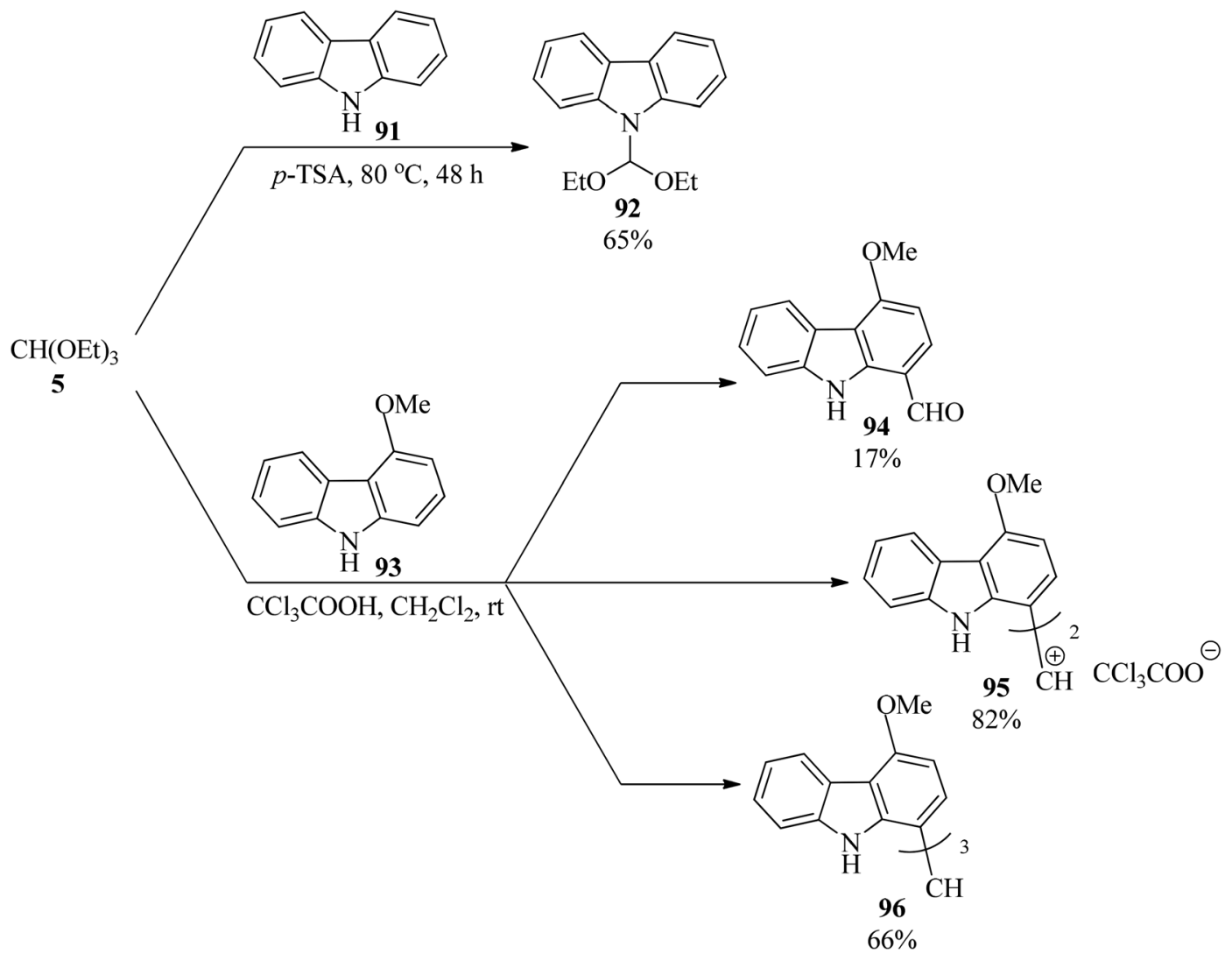

Scheme 25 The preparation of various heterocycles containing an indole moiety using TEOF.

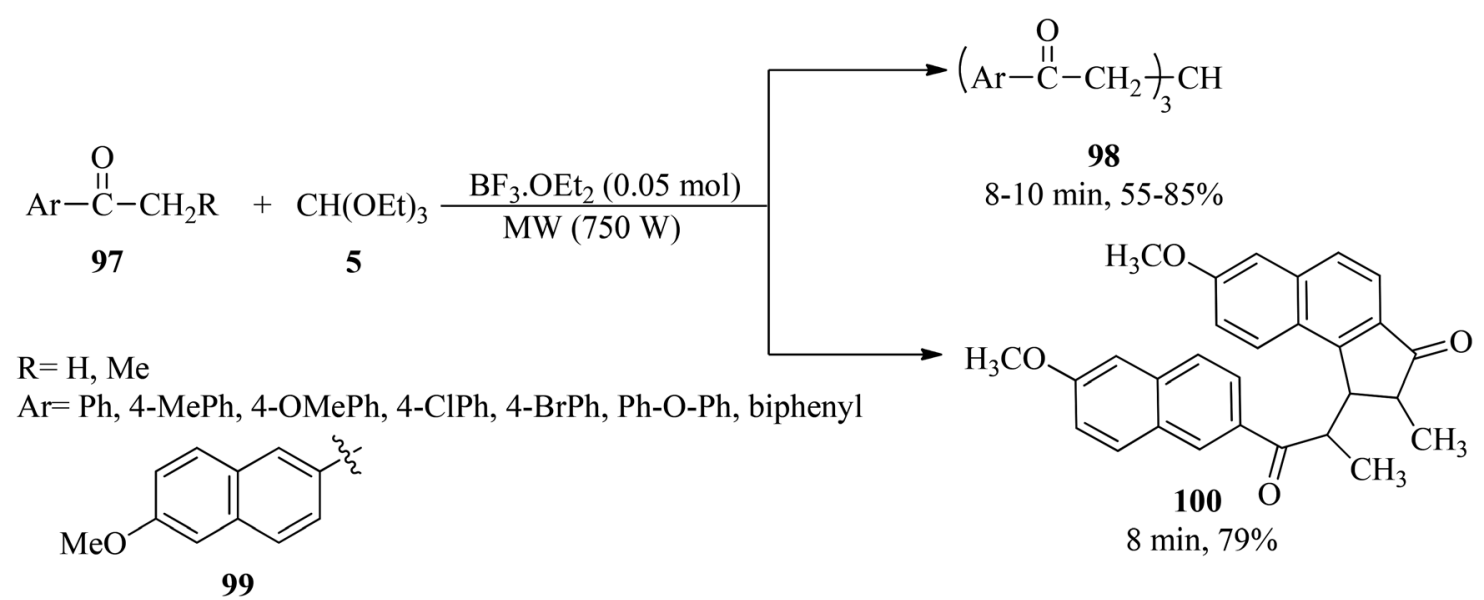

Scheme 26 The triaroyl methane synthetic procedure.

orthobenzoates as the bulky orthoesters produced scrambled products. Also, the 5-phenyldipyrromethane, including strong electron-withdrawing substituents on the phenyl ring, improved the scrambled products. ${ }^{147}$

\subsection{Synthesis of allyl alcohol}

In 2019, Wormann and Maier presented an integrated procedure for the conversion of glycerol (104) to the cyclic orthoester (105) in high yield through the reaction with TMOF
(4) by a catalytic amount of PPTS at room temperature for $2 \mathrm{~h}$, which was converted into allyl alcohol (107) under pyrolysis conditions at $270{ }^{\circ} \mathrm{C}$ using PPTS under solvent-free conditions. This reaction progressed via the disintegration of the orthoester (105) into carbene (106) and recoverable methanol, which was followed by decarboxylation to produce the mentioned product (107) in high yield (76\%) within $1.5 \mathrm{~h}$ (Scheme 28). ${ }^{148}$ 
<smiles>[R][R]([R])c1cc[nH]c1C(c1ccc[nH]1)c1ccc[nH]1</smiles>

Scheme 27 Obtaining 5,15-diphenyl-10,20-dimethyl porphyrins (DPPs).

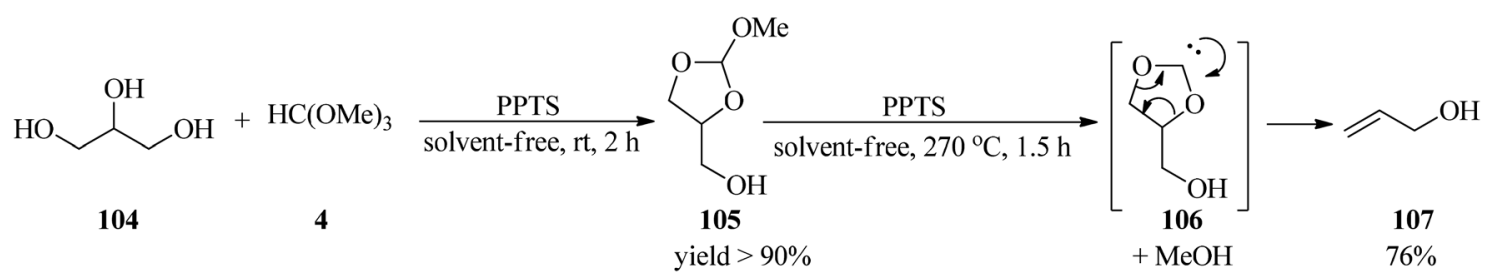

Scheme 28 Allyl alcohol preparation from glycerol and TMOF.

\subsection{Orthoester exchange reaction}

Calmanti et al. investigated the reactivity of glycerol (104) with TMOF (4) with the purpose of developing a credible synthetic strategy for glycerol valorization. It was found that the treatment of glycerol with TMOF under various conditions provided a mixture of compounds (105), (108), (109). Hence, in order to synthesize 4-(dimethoxymethoxy)methyl)-2-methoxy-1,3dioxolane (109), different parameters, such as different molar ratios of TMOF, temperature, and the absence or presence of various catalysts, were examined. Significantly among different amounts of glycerol and TMOF, the best result was obtained in a molar ratio of $1: 10$ at $90{ }^{\circ} \mathrm{C}$. Moreover, product (109) was selectively synthesized in the presence of a catalyst as well as in catalyst-free conditions, taking advantage of the thermodynamically controlled equilibrium between intermediates. To probe the effect of a catalyst, various catalysts, such as basic catalysts $\left(\mathrm{K}_{2} \mathrm{CO}_{3},\left(\left[\mathrm{P}_{1888}\right] \mathrm{CH}_{3} \mathrm{OCO}_{2}{ }^{-}\right)\right.$or Brønsted and Lewis acid catalysts were employed in which both Brønsted and Lewis acid catalysts progressed this reaction, and specifically Brønsted acidic ionic liquids (BSMImHSO ${ }_{4}$ and BSMImBr) were the most efficient catalysts (Scheme 29). ${ }^{\mathbf{1 4 9}}$

In 2012, the one-pot fusion reaction of bis(enaminone) derivative (110) with TEOF (5) under solvent-free conditions was reported to obtain 1,1'-(3-methyl-4-phenylthieno[2,3- $b$ ] thiophene-2,5-diyl)bis(4,4,4-triethoxybut-2-en-1-one) (111) as pale red crystals in relatively high yield (57\%) (Scheme 30$).{ }^{\mathbf{1 5 0}}$

\subsection{Synthesis of 1,2-dimethyltetramethoxydisilane}

The reaction of methyldichlorosilane with TMOF at room temperature afforded dimethoxymethylsilane overnight ${ }^{151,152}$ in $61 \%$ yield. Then, photolysis of dimethoxymethylsilane in the presence of a drop of mercury in the gas phase resulted in 1,2dimethyltetramethoxydisilane in $81 \%$ yield within 8 h. ${ }^{153}$<smiles>COC(OC)OC[C@H]1CO[C@@H](OC)O1</smiles>

Catalyst: $\mathrm{BSMImHSO}_{4}$ or BSMImBr

Scheme 29 The synthesis of 4-(dimethoxymethoxy)methyl-2-methoxy-1,3-dioxolane. 
<smiles>CNC=CC(=O)c1sc2sc(C(=O)C=CNC)c(-c3ccccc3)c2c1C</smiles><smiles>CCOC(/C=C/C(=O)c1sc2sc(C(=O)/C=C/C(OCC)(OCC)OCC)c(-c3ccccc3)c2c1C)(OCC)OCC</smiles>

Scheme 30 Preparing 1,1'-(3-methyl-4-phenylthieno[2,3-b]thiophene-2,5-diyl)bis(4,4,4-triethoxybut-2-en-1-one).

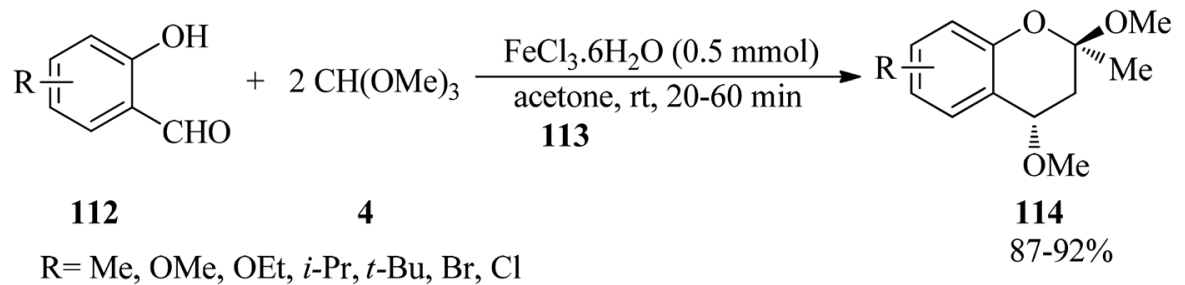

Scheme 31 The synthesis of 2,4-dimethoxy-2-methyl-2H-1-benzopyrans.

\subsection{Synthesis of chromanes, chromenes, and thiochromene}

In 2002, Yadav et al. interpreted the highly diastereoselective synthesis of 2,4-dimethoxy-2-methyl-2H-1-benzopyrans (114) via the three-component reaction of $o$-hydroxybenzaldehydes (112), acetone (113), and trimethyl orthoformate (4) utilizing a catalytic amount of ferric chloride hexahydrate $\left(\mathrm{FeCl}_{3} \cdot 6 \mathrm{H}_{2} \mathrm{O}, 0.5\right.$ $\mathrm{mmol}$ ) at room temperature in excellent yields (87-92\%) for 20$60 \mathrm{~min}$. The only diastereomer bore a trans-relationship between two methoxy groups at the 2- and 4-positions (Scheme 31). Mild reaction conditions, experimental simplicity, easily available substrates, short reaction times, and excellent yields are some of the advantages of this process. ${ }^{\mathbf{1 5 4}}$

In 2012, Ahmad and Silva Jr investigated the oxidation of different oxygen-containing benzo-fused cycloalkenes with various trialkyl orthoformates $(\mathbf{4}, \mathbf{5})$ in the presence of hypervalent iodine reagent [[hydroxy(tosyloxy)iodo]benzene, HTIB] under solvent-free conditions. It was found that $2 \mathrm{H}$-chromenes (115) generated alkoxy-substituted $4 H$-chromenes (116) as the main product, along with the trans-addition product (117). On the other hand, $2 H$-thiochromene (118) and 4-methyl- $2 H$-chromene (120) obtained $4 H$-thiochromene (119) and cis-3,4-

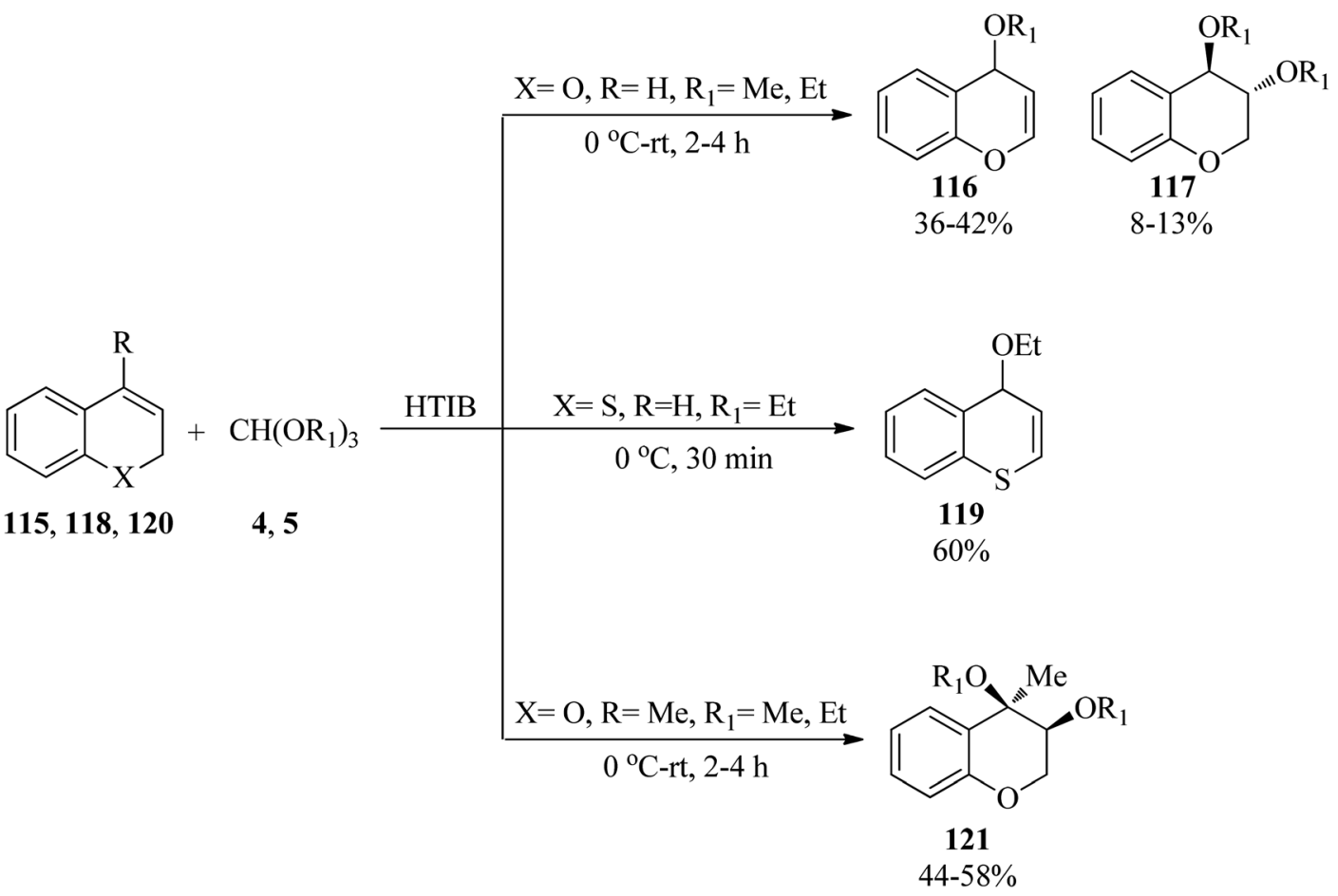

Scheme 32 The synthesis of different chromenes using trialkyl orthoformates. 


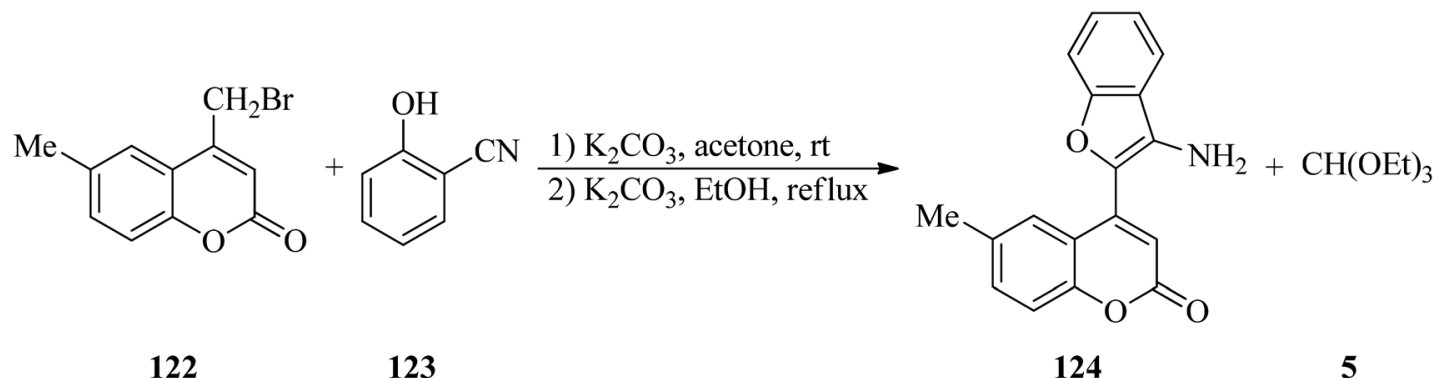

122<smiles>Cc1ccc2oc(=O)c3cnc4c5ccccc5oc4c3c2c1</smiles>

Scheme 33 The synthesis of fused polycyclic heterocycles utilizing TEOF.

dialkoxy-4-methyl-3,4-dihydro-2H chromenes (121), respectively (Scheme 32). ${ }^{155}$

\subsection{Synthesis of coumarin derivatives}

Kulkarni and Sun's research group investigated a three-step sequence, as an array to obtain angularly fused polycyclic heterocycles with coumarin, benzofuran and pyridine rings (125). They started from 4-bromomethylcoumarins (122) and salicylonitrile (123) followed by the addition of TEOF (5) (Scheme 33). Several of these exhibited promising inflammation-inhibiting and anti-microbial properties. ${ }^{156}$

\subsection{Etherification and esterification reaction, and Johnson-Claisen rearrangement}

In 1997, Liu and co-workers described a simple and efficient process for the preparation of alkyl squarates (131) through the reaction of squaric acid (126), orthoformates (4, 5, 127-129), and appropriate alcohols (130) under reflux conditions in 7797\% yields (Scheme 34 ). ${ }^{157}$
Furfuryl ethers (135) as bio-renewable fuel could be synthesized via two pathways: (a) a sequential reaction method was used in which the appropriate orthoester $(5,128,133)$ was synthesized upon treatment with TMOF (4) and an alcohol (132) in the presence of ZSM-5 zeolite $(\mathrm{Si} / \mathrm{Al}$ ratio $=30: 1$, ZSM-5-(30)) catalyst $(40 \mathrm{mg})$ at $60-40{ }^{\circ} \mathrm{C}$, followed by the addition of furfuryl alcohol (134) to obtain furfuryl ether (135) bio-fuels. (b) The mentioned products were synthesized through a tandem etherification condensation reaction of (4), an excess amount of alcohol (132), and furfuryl alcohol (134) at $40{ }^{\circ} \mathrm{C}$ by ZSM-5-(30) $(40 \mathrm{mg}$ ) in good yield and good to high selectivity (Scheme 35). It must be mentioned that the low temperature applied improved selectivity by decreasing the production of hydrolysis products, and the competing polymerization reactions resulting in humin by-products. ${ }^{158}$

In 2015, Zhang et al. utilized $\mathrm{ZrO}_{2}$ supported $\mathrm{Pd}(\mathrm{OH})_{2}$ $\left(\mathrm{Pd}(\mathrm{OH})_{2} / \mathrm{ZrO}_{2}\right)$ as a new catalytic system for the synthesis of aryl ethers (137) via the reaction of substituted cyclohexanones (136) with orthoesters $(\mathbf{4}, \mathbf{5}, \mathbf{1 2 7})$ as both dehydrating and nucleophilic reagents under an atmospheric pressure of oxygen $(0.5$<smiles>[R20]Oc1c([R20])c(=O)c1=O</smiles>

130: $\mathrm{R}=\mathrm{Me}, \mathrm{Et}, i-\mathrm{Pr}, \mathrm{Bu}, t-\mathrm{Bu}$

Scheme 34 Preparation method of alkyl squarates. 


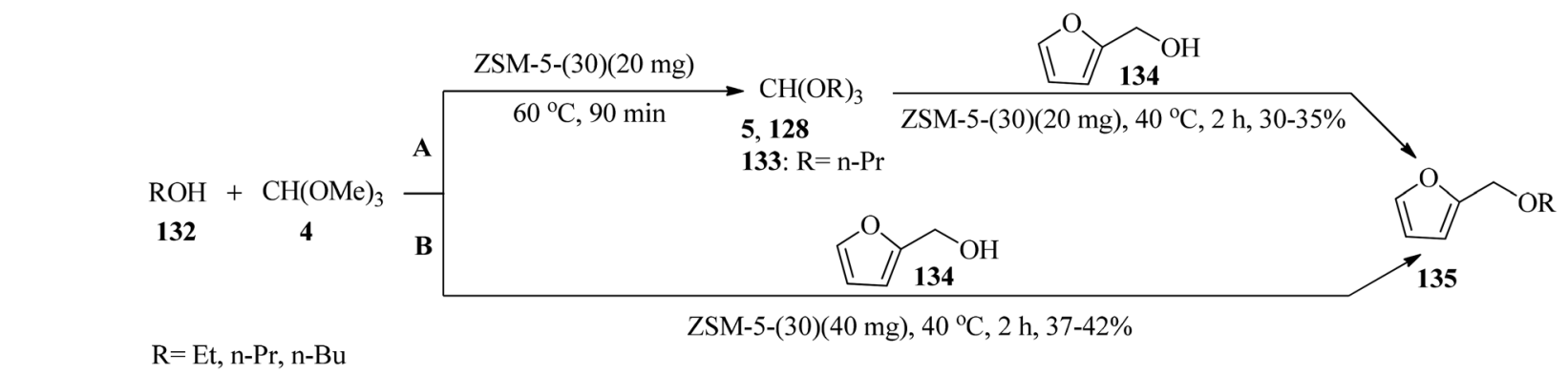

Scheme 35 The synthesis of furfuryl alcohols.

MPa) at $140{ }^{\circ} \mathrm{C}$ for $6 \mathrm{~h}$ (Scheme 36). It was found that in the presence of TMOF (4) reagent, the corresponding aryl ethers were obtained in moderate to good yields. Additionally, replacing other orthoester reagents, such as TEOF (5) and triisopropyl orthoformate (127) with (4) furnished the relevant products in low yields. Comparatively, the weak yields of the products compared to their high conversion were because of the generation of phenols as by-products. Due to the lower reactivity of TIPOF (127) to attain the related product than TMOF (4) or TEOF (5), this orthoester was employed as a dehydrating reagent in the reaction of cyclohexanones with alcohols to provide aryl ethers without forming isopropoxybenzene. ${ }^{159}$

In 1998, Varma and Kumar developed an applicable oxidative method for the synthesis of 4-alkoxy-2-arylquinolines (139) through the reaction of readily available 2-aryl-1,2,3,4tetrahydro-4-quinolones $(\mathbf{1 3 8})$ with orthoformates $(\mathbf{4}, \mathbf{5})$ using the hypervalent iodine oxidative reagent, HTIB, in the presence of a few drops of perchloric acid under solvent-free conditions at reflux to room temperature within $1.5 \mathrm{~h}$ in good yields (75$88 \%$ ) (Scheme 37). ${ }^{160}$

Unsymmetrical ethers (141) were obtained via the reaction of allylic and benzylic alcohols $(\mathbf{1 4 0})$ with orthoesters $(5,6,62,133)$ using acidic catalysts such as montmorillonite KSF and K10, $\mathrm{BF}_{3} \cdot \mathrm{Et}_{2} \mathrm{O}, \mathrm{SiO}_{2}$, amberlyst- 15 at room temperature under an $\mathrm{N}_{2}$ atmosphere. It is noteworthy that the change in the catalyst was accompanied by an important change in the yields and the type of products obtained, such as dimerized ethers (142) and $O$ acetylated (143) via competitive reactions (Scheme 38). This reaction was general due to the presence of varied orthoesters, but selective with regard to different allylic and benzylic alcohols. On the other hand, Johnson-Claisen orthoester rearrangement ${ }^{161-164}$ of allylic alcohols (144) with TEOAc (6) by

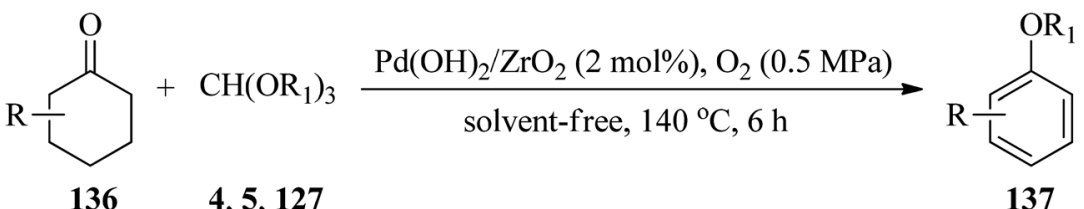

Conversion: $79-100 \%$

$\mathrm{R}=\mathrm{H}, \mathrm{Me}, \mathrm{Ph}, 1$-tetralone

Yield: $11-78 \%$

$\mathrm{R}_{1}=\mathrm{Me}, \mathrm{Et}, i-\mathrm{Pr}$

Scheme 36 The synthesis of aryl ethers.<smiles>[R]c1ccc(C2CC(=O)c3ccccc3N2)cc1[R]</smiles>

138

$\mathrm{R}=\mathrm{H}, \mathrm{Me}, \mathrm{OMe}, \mathrm{Cl}$

$\mathrm{R}_{1}=\mathrm{H},-\mathrm{OCH}_{2} \mathrm{O}-$

$\mathrm{R}_{2}=\mathrm{Me}, \mathrm{Et}$

\section{$+\mathrm{CH}\left(\mathrm{OR}_{2}\right)_{3}$ \\ $\underset{\text { solvent-free, reflux to rt, } 1.5 \mathrm{~h}}{\mathrm{HTIB}(1.2 \mathrm{mmol}) \mathrm{HClO}_{4}}$}

4,5<smiles>[R]c1ccc(-c2cc([R20])c3ccccc3n2)cc1[R]</smiles>

139

$75-88 \%$

Scheme 37 The synthesis of 4-alkoxy-2-arylquinolines. 


$$
\begin{aligned}
& \mathrm{R} \widehat{\mathrm{OH}}+\mathrm{R}_{1} \mathrm{C}\left(\mathrm{OR}_{2}\right)_{3} \underset{\text { solvent-free, } \mathrm{rt}, 5 \mathrm{~min}-12 \mathrm{~h}}{\mathrm{catalyst}} \mathrm{R} \curvearrowright \mathrm{OR}_{2}+\overbrace{\mathrm{O}} \overbrace{\mathrm{R}}+\overbrace{\mathrm{O}} \\
& 1405,6,62,133
\end{aligned}
$$

Scheme 38 The reaction of allylic and benzylic alcohols with orthoesters.

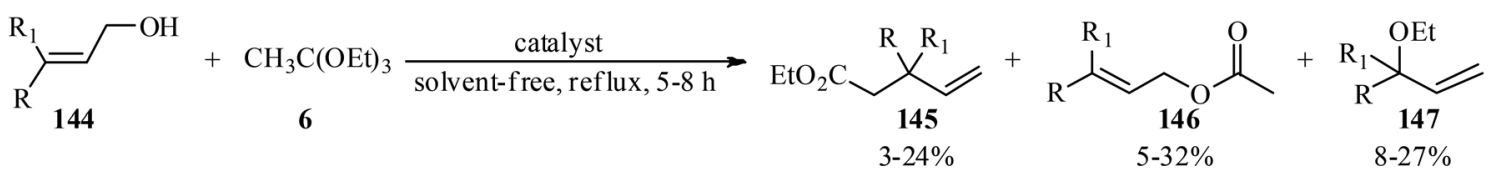

$\mathrm{R}, \mathrm{R}_{1}=\mathrm{H}, \mathrm{Me}, \mathrm{Ph}$

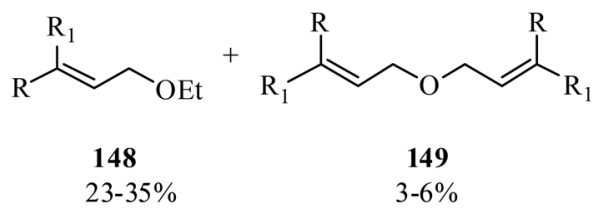

Scheme 39 The Johnson-Claisen orthoester rearrangement of allylic alcohols.

MMKSF, MMK10, and $\mathrm{SiO}_{2}$ under reflux conditions and $\mathrm{N}_{2}$ atmosphere produced a mixture of Claisen ester (145), acetylated product (146), ethyl ether (147), unsymmetrical terminal ether (148), and dimeric ether (149) in which $O$-acetylation and $O$-alkylations were significant side reactions (Scheme 39). ${ }^{\mathbf{1 6 4}}$

Tamura and co-workers prepared 2-arylalkanoates $(\mathbf{1 5 1}, \mathbf{1 5 2})$ via oxidative 1,2-aryl migration of alkyl aryl ketones (150) with diacetoxyphenyliodine, as oxidizing reagent, in TMOF (4) under acidic conditions at room temperature or $60{ }^{\circ} \mathrm{C}$ in high yields (74-88\%) (Scheme 40). ${ }^{165}$

In 2004, Yoshino and Togo introduced a green, easy, inexpensive, and highly efficient system for the esterification of carboxylic acids (153) with TEOAc (6) by a typical room- temperature ionic liquid, 1-butyl-3-methylimidazolium hexafluorophosphate $\left([\mathrm{bmim}] \mathrm{PF}_{6}\right)$, at $80-100{ }^{\circ} \mathrm{C}$ under neutral and solvent-free conditions in good yields (Scheme 41). The proposed method greatly facilitated the formation of the desired ethyl esters (154), especially for less acidic carboxylic acids, and it could also be used for sterically hindered carboxylic acids, like 2,4,6-triisopropylbenzoic acid or 2,2,2-triphenylacetic acid, and for amino acid without any racemization. Notably, replacement of trimethyl orthoacetate with TEOAc exhibited similar reactivity. On the other hand, the utilization of [bmim $] \mathrm{BF}_{4}$ instead of $[\mathrm{bmim}] \mathrm{PF}_{6}$, as an ionic liquid, revealed the same results. ${ }^{166}$

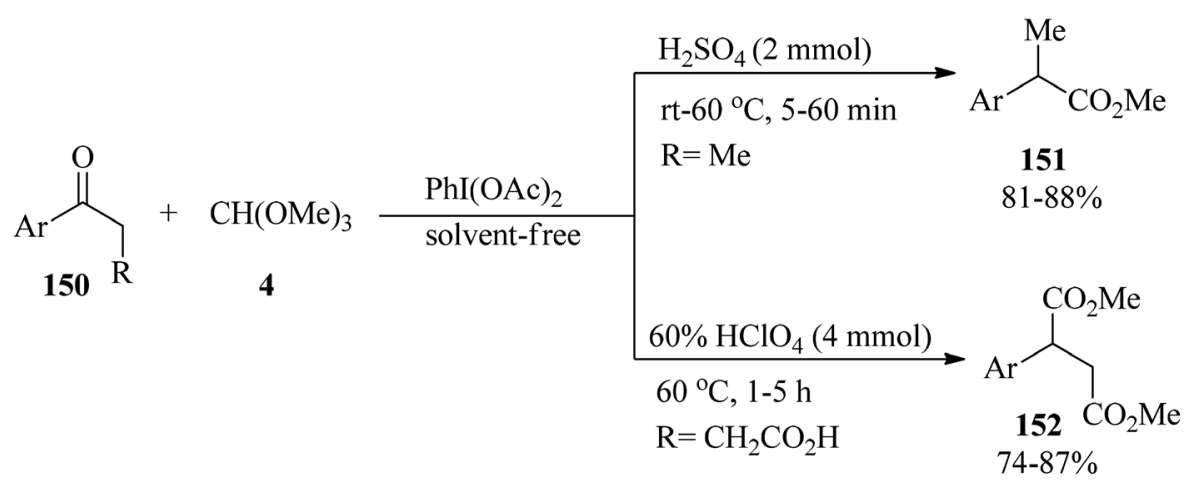

$\mathrm{Ar}=\mathrm{Ph}, 4-\mathrm{MePh}, 4-\mathrm{OMePh}, 4-i-\mathrm{BuPh}, 4-\mathrm{FPh}, 4-\mathrm{BrPh}$, 4-cyclohexylphenyl, 2-naphthyl, 9,10-dihydrophenanthrene 


$$
\begin{array}{cccc}
\mathrm{RCO}_{2} \mathrm{H} \\
\mathbf{1 5 3}
\end{array}
$$

$\mathrm{R}=3,5-\left(\mathrm{NO}_{2}\right)_{2} \mathrm{Ph}, 2,6-(\mathrm{OMe})_{2} \mathrm{Ph}$, 1-naphthyl, cyclohexyl, 2,4,6-(i-pr $)_{3} \mathrm{Ph}, \mathrm{CPh}_{3}$, pentadecyl,<smiles>O=C(O)N[C@@H](Cc1c[nH]c2ccccc12)C(=O)O</smiles>

Scheme 41 The esterification of carboxylic acids with TEOAc.

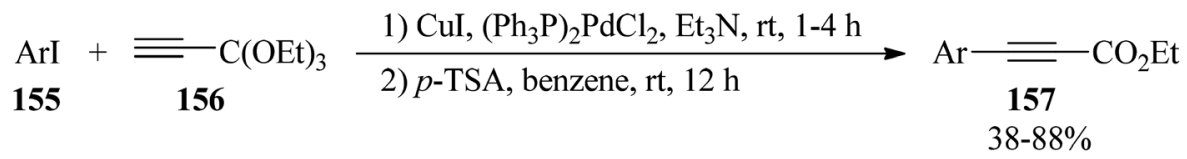

$\mathrm{Ar}=\mathrm{Ph}, 4-\mathrm{MePh}, 4-\mathrm{OMePh}, 4-\mathrm{NO}_{2} \mathrm{Ph}, 4-\mathrm{CNPh}, 4-\mathrm{CO}_{2} \mathrm{MePh}, 2$-pyridinyl, 3-pyridinyl, 2,6- $\mathrm{Me}_{2}-4-$ pyridinyl, 4,6- $\mathrm{Me}_{2}$-2-pyrimidinyl, 6-Me-2-Ph-4-pyrimidinyl

Scheme 42 The synthesis of ethyl arylpropiolate

The cross-coupling reaction of aryl iodides (155) with 3,3,3triethoxy-1-propyne using dichlorobis(triphenylphosphine) palladium $\left[\left(\mathrm{PPh}_{3}\right)_{2} \mathrm{PdCl}_{2}\right]$ and cuprous iodide $(\mathrm{CuI})$ in triethylamine $\left(\mathrm{Et}_{3} \mathrm{~N}\right)$ at room temperature led to the production of 3,3,3-triethoxy-1-aryl-1-propyne within 1-4 h, which after isolation was subsequently reacted with a catalytic amount of $p$-TSA in benzene at room temperature for $12 \mathrm{~h}$ to yield the ethyl arylpropiolates (157) (Scheme 42). ${ }^{167}$
Padmapriya and co-workers reported the alkylation of sulfonic acids $(\mathbf{1 5 8})$ by trialkyl orthoformates $(\mathbf{4}, \mathbf{5})$ to generate the alkyl sulfonates (159) under solvent-free conditions at room temperature for $14 \mathrm{~h}$ or under reflux conditions in a $30 \mathrm{~min}$ period in $43-99 \%$ yields (Scheme 43 ). ${ }^{168}$

In 2009, Borths et al. synthesized $O$-ethyl thioformate (161) via the condensation reaction of TEOF (5) with hydrogen sulfide gas $\left(\mathrm{H}_{2} \mathrm{~S}\right)(\mathbf{1 6 0})$ at 2.1 bar in the presence of sulfuric acid $\left(\mathrm{H}_{2} \mathrm{SO}_{4}\right.$, 98\%, $1 \mathrm{~mol} \%$ ) as a Brønsted acid catalyst under solvent-free

$$
\begin{aligned}
& \begin{array}{cccc}
\mathrm{CH}(\mathrm{OR})_{3} & +\mathrm{R}_{1}-\mathrm{SO}_{2}-\mathrm{OH} & \mathrm{rt,}, 14 \mathrm{~h} & \mathrm{R}_{1}-\mathrm{SO}_{2}-\mathrm{OR} \\
\mathbf{4 , 5} & \mathbf{1 5 8} & \mathbf{1 5 9} & \text { solvent-free, reflux, 30 min } \\
& & 43-99 \%
\end{array} \\
& \mathrm{R}=\mathrm{Me}, \mathrm{Et} \\
& \mathrm{R}_{1}=\mathrm{Me} \text {, Et, 4-MePh, 4-OH-3-OMePhCH} 2 \text {, 4-OH-3-OMePhCHCHCH}
\end{aligned}
$$

Scheme 43 The alkylation of sulfonic acids by trialkyl orthoformates.

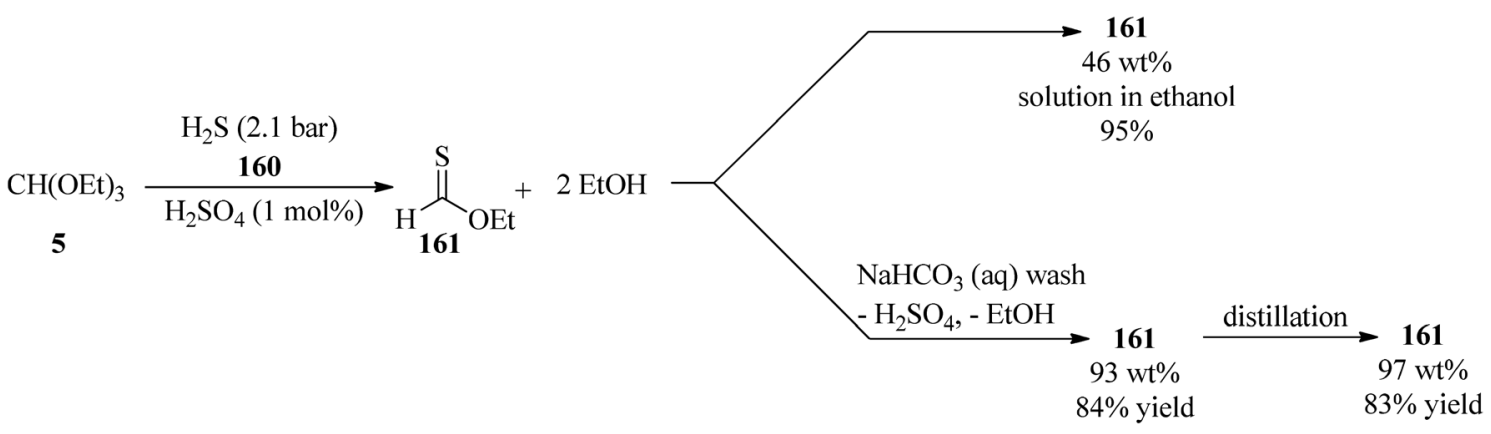

Scheme 44 The condensation of TEOF with $\mathrm{H}_{2} \mathrm{~S}$ to obtain O-ethyl thioformate. 


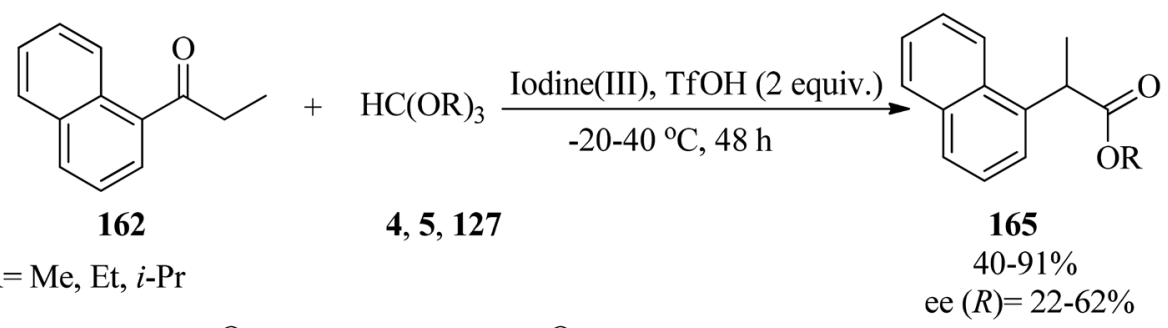

Iodine(III):<smiles></smiles>

163: $\mathrm{R}_{1}=\mathrm{OMe}$

164: $\mathrm{R}_{1}=\mathrm{NHMes}$

Scheme 45 The preparation of alkyl 2-(naphthalen-1-yl)propanoates.

conditions. The $46 \mathrm{wt} \%$ ethanolic $O$-ethyl thioformate solution was obtained in $95 \%$ assay yield and could be purified initially by washing with basic aqueous sodium hydrogen carbonate $\left(\mathrm{NaHCO}_{3}\right)$ to eliminate the sulfuric acid and ethanol and then by distillation at atmospheric pressure to remove the residual ethanol to provide $97 \mathrm{wt} \%$ of $O$-ethyl thioformate as a yellow oil in $83 \%$ yield, which could be utilized as a thioformylating agent for amines (Scheme 44). ${ }^{169}$

In 2016, Malmedy and Wirth developed a stereoselective reaction to access 2-aryl alkanoates (165) in good enantioselectivity via the rearrangement reaction of 1-(naphthalen-1-yl) propan-1-one $(\mathbf{1 6 2})$ with orthoesters $(\mathbf{4}, \mathbf{5}, \mathbf{1 2 7})$ by iodine(III) reagent $(163,164)$ and triflic acid $(\mathrm{TfOH})$ at -20 to $40{ }^{\circ} \mathrm{C}$, yielding the corresponding alkyl 2-(naphthalen-1-yl)propanoate (165) (Scheme 45). In this reaction the effect of different parameters, such as the type of catalyst, catalytic amounts of Lewis acid, the nature of the orthoester, and temperature were investigated. It was found that a reaction with too high a bulkiness of the triisopropyl orthoformate (127) did not result in any rearranged compound. Also, acceptable results were obtained in the presence of 2 equivalents of $\mathrm{TfOH}$. A plausible mechanism for the rearrangement is shown in Scheme $46 .{ }^{170}$ The reaction was promoted through the reaction of the enolic form (167) of ketone (166) with the iodine(III) moiety to produce the

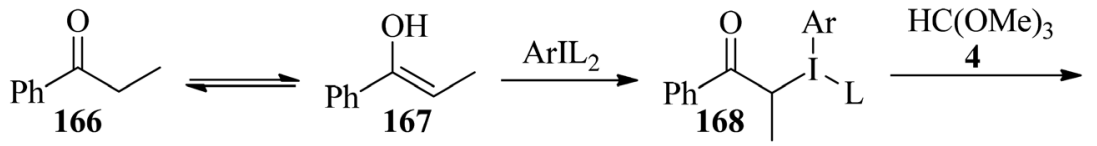<smiles>[R]OC(=[O+]C)C([AlH2])C([AlH2])c1ccccc1</smiles>

$\mathrm{R}=\mathrm{H}, \mathrm{Me}$

Scheme 46 Reaction mechanism for the reaction of ketones with TMOF.

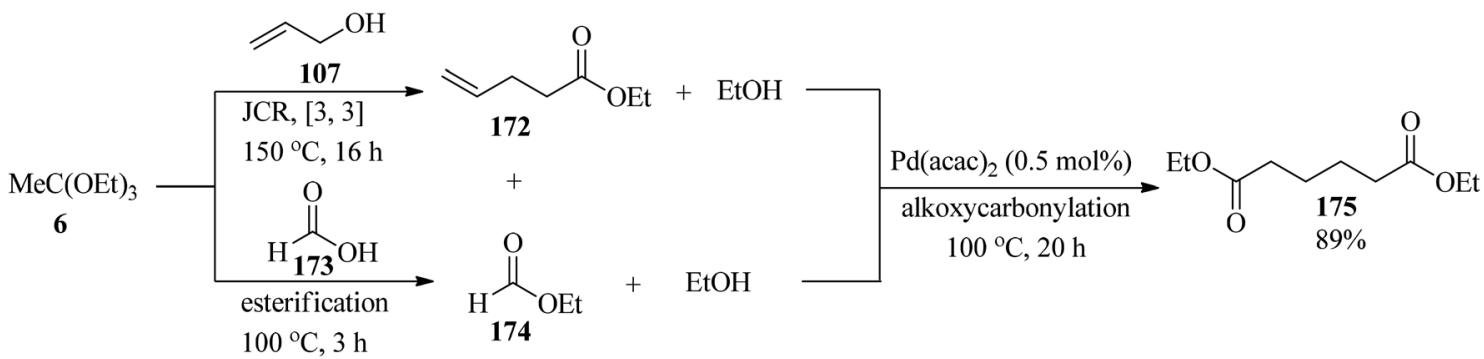

Scheme 47 The synthesis of linear diester diethyl adipate by the Johnson-Claisen rearrangement and alkoxycarbonylation. 


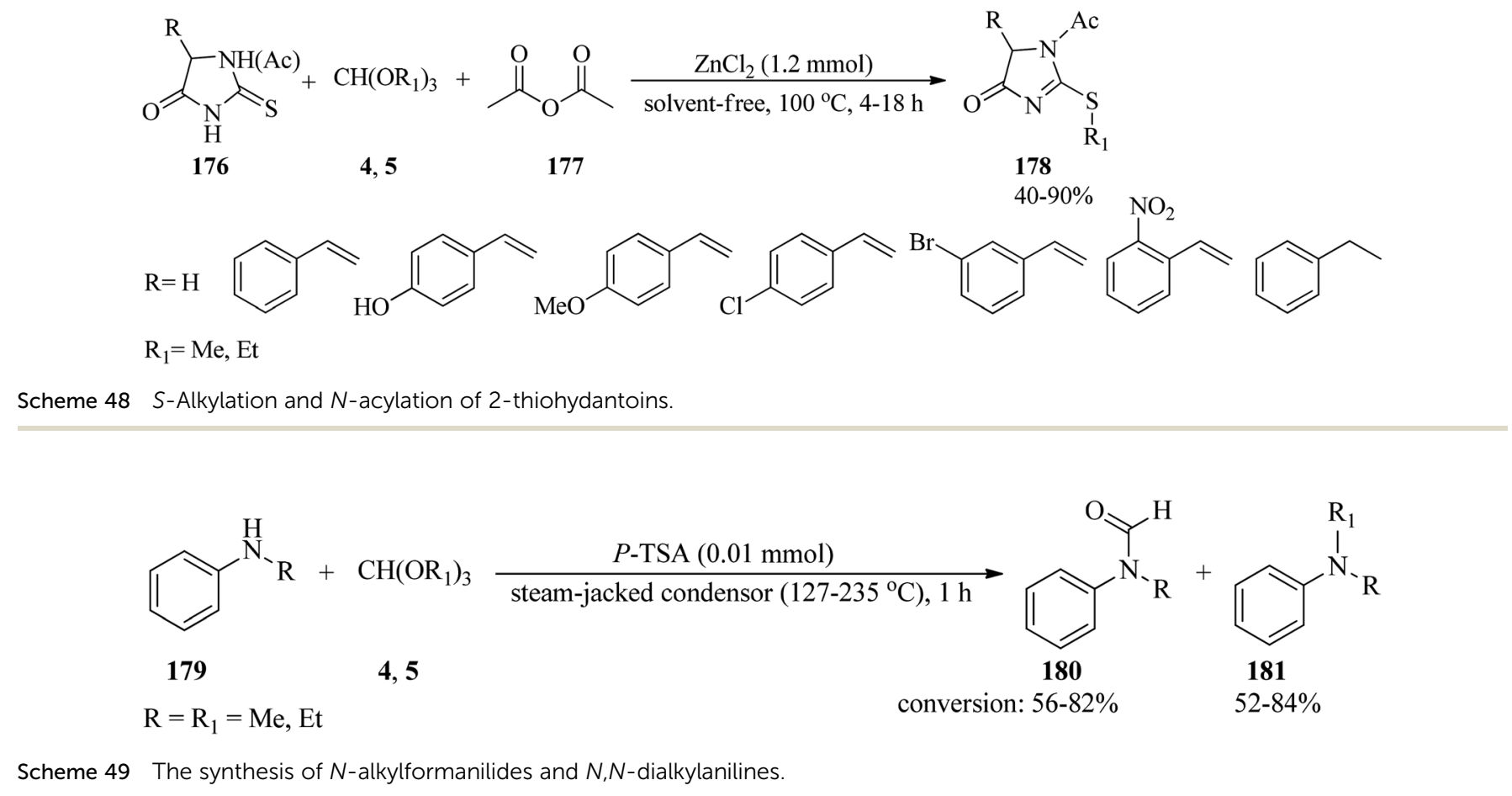

intermediate (168), which provided the ketal (169) by TMOF (4). The elimination of aryliodide was accompanied with 1,2-aryl migration to form the intermediate (170); which was followed by hydrolysis in water to afford the rearranged product (171). ${ }^{171}$

The linear diester diethyl adipate (175) was synthesized by the merger of Johnson-Claisen rearrangement and alkoxycarbonylation via a one-pot procedure. This reaction proceeded through Johnson-Claisen rearrangement (JCR) of allyl alcohol (107) with TEOAc (6, 2 equiv.) to afford ethyl 4-pentenoate (172), which was followed by quenching the excess of (6) by the addition of formic acid (173) to obtain ethyl formate (174). Then, the alkoxycarbonylation of ethyl 4-pentenoate (172) with ethyl formate (174) using the palladium catalytic system such as palladium(II)acetylacetonate $\left(\mathrm{Pd}(\mathrm{acac})_{2}, 0.5 \mathrm{~mol} \%\right)$ and 1,2-bis((di-tert-butylphosphino)methyl)benzene (2 mol\% 1,2 DTBPMB) and methanesulfonic acid (MSA, 8 mol\%) produced the linear diester diethyl adipate (175) in good yield (89\%) (Scheme 47). ${ }^{172}$

\subsection{Alkylation reactions}

In 2008 , the one-pot chemoselective $S$-alkylation and $N$-acylation reaction of 2-thiohydantoins (176) utilizing alkyl orthoformates $(4,5)$ and acetic anhydride $(\mathbf{1 7 7})$ was presented for the synthesis of the products (178) by zinc chloride $\left(\mathrm{ZnCl}_{2}, 1.2\right.$ $\mathrm{mmol}$ ) at $100{ }^{\circ} \mathrm{C}$ within $4-18 \mathrm{~h}$ in $40-90 \%$ yields (Scheme 48 ). ${ }^{173}$

In 1980, Swaringen et al. discovered that the reaction of $\mathrm{N}$ alkylanilines (179) and ortho formats $(\mathbf{4}, 5)$, in a $2: 1$ molar ratio, gave high yields of $N$-alkylformanilides (180) and $N, N$ dialkylanilines (181) in the presence of $p$-TSA (Scheme 49). In addition, aliphatic cyclic amines (such as morpholine or piperidine) and orthoformates gave the corresponding orthoamides. ${ }^{174}$

\subsection{Acetalization reaction}

In 2017, Ugarte and Hudnall presented a highly selective, environmentally friendly, rapid, and solvent-free procedure for the protection of carbonyls to acetals (184) ${ }^{175-182}$ via the reaction of aldehydes (182) with TEOF (5) in equimolar amounts using the tetraarylstibonium salt, 1-diphenylphosphinonaphthyl-8triphenylstibonium triflate ([183][OTf], $0.1 \mathrm{~mol} \%$ ), at room temperature (Scheme 50). Notably, the rate of the reactions increased in the presence of aliphatic aldehydes. This catalyst was recycled and reused for up to 6 runs without losing activity. Furthermore, the tetraarylstibonium salt could catalyze the deprotection of the acetals into their corresponding aldehydes in aqueous media. ${ }^{182}$

In 2009, Kharkongor and Myrboh presented a convenient and efficient one-pot method for the synthesis of $\alpha$-ketoacetals

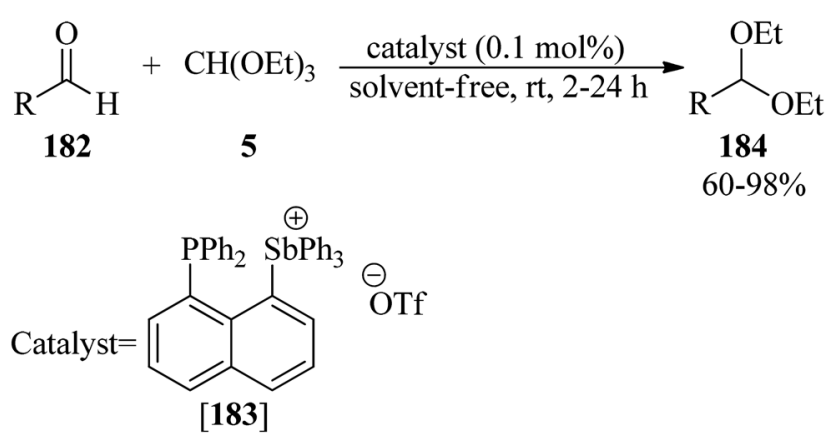

$\mathrm{R}=$ Alkyl, Aryl

Scheme 50 Acetalization with TEOF in the presence of tetraarylstibonium salt. 


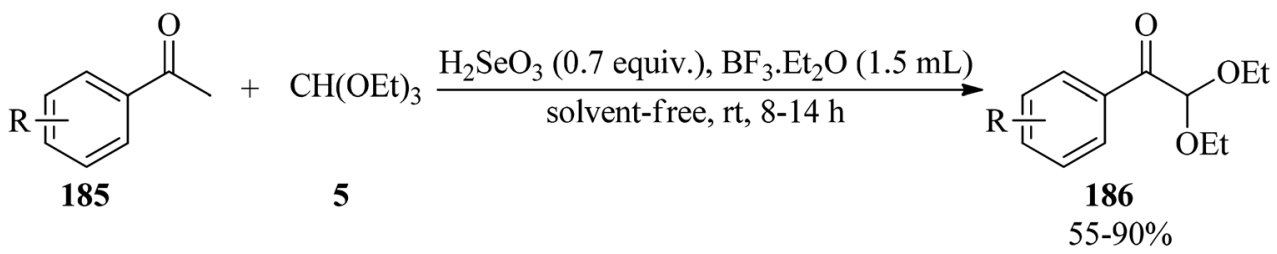

$\mathrm{R}=\mathrm{Ph}$, 4-ClPh, 4- $\mathrm{BrPh}, 4-\mathrm{NO}_{2} \mathrm{Ph}, 3-\mathrm{NO}_{2} \mathrm{Ph}, 3-\mathrm{OH}-\mathrm{Ph}, 4-\mathrm{OHPh}$, 4-MePh, 4-OMePh, 3-NHCOMePh, 4-NHCOMePh, 2-furanyl, 5-Me-2-furanyl, 2-thiophenyl, 2-naphthyl

Scheme 51 Acetalization with TEOF in the presence of selenous acid.

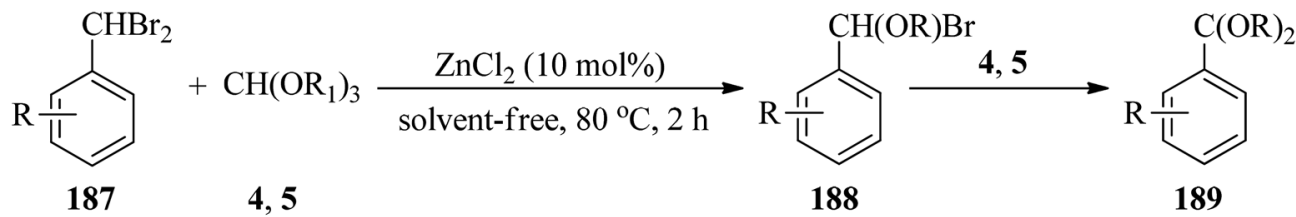

$$
\begin{aligned}
& \mathrm{R}=4-\mathrm{CH}(\mathrm{OMe})_{2}, 4-\mathrm{CH}(\mathrm{OEt})_{2}, 4-\mathrm{CO}_{2} \mathrm{Me}, 4-\mathrm{CO}_{2} \mathrm{Et}, 3-\mathrm{OAc}, 4-\mathrm{CHBr}_{2}, 4-\mathrm{CHO} \\
& \mathrm{R}_{1}=\mathrm{Me}, \mathrm{Et}
\end{aligned}
$$

Scheme 52 Acetalization via the double debromoalkoxylation of dibromomethylarenes.

(186) from substituted acetophenones (185) and TEOF (5) by selenous acid $\left(\mathrm{H}_{2} \mathrm{SeO}_{3}, 0.7\right.$ equiv.) and $\mathrm{BF}_{3} \cdot \mathrm{Et}_{2} \mathrm{O}(1.5 \mathrm{~mL})$ as a catalyst under solvent-free conditions at room temperature in moderate to excellent yields (55-90\%) within 8-14 h (Scheme 51). ${ }^{183}$ Acetals could be also synthesized via the reaction of various acidic methines such as cyanoesters and 3,4,5-trimethoxybenzylmalononitrile with orthoformates under heating and solvent-free conditions. The reaction has been shown to be useful for the production of protected aldehydes and 2,4-diamino-5-benzylpyrimidines. ${ }^{184}$<smiles>[R]c1ccc(C(=O)CI)cc1</smiles>

$\mathrm{R}=\mathrm{H}, \mathrm{OH}, \mathrm{Me}, \mathrm{F}, \mathrm{OTBS}, \mathrm{OAc}, \mathrm{OBn}$

193:<smiles>Cc1ccc2c(c1)C(=O)CCC2C</smiles>

Scheme 53 The synthesis of iodo ketones and iodo dimethyl ketals. 


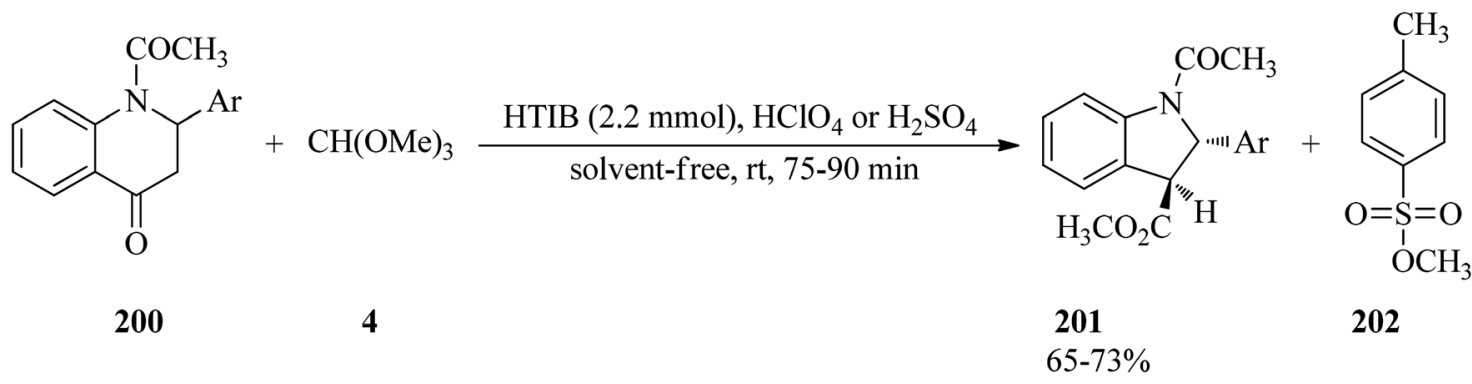

$\mathrm{Ar}=\mathrm{Ph}, 4-\mathrm{OMePh}, 4-\mathrm{ClPh}, 4-\mathrm{BrPh}, 4-\mathrm{NO}_{2} \mathrm{Ph}$

Scheme 54 The ring contraction of $\mathrm{N}$-acetyl-2-aryl-1,2,3,4-tetrahydro-4-quinolones with TMOF.

Aromatic aldehyde acetals (189) ${ }^{\mathbf{1 8 5}, 186}$ were synthesized via double debromoalkoxylation of dibromomethylarenes (187) with trialkyl orthoformate $(4,5)$ using $\mathrm{ZnCl}_{2}(10 \mathrm{~mol} \%)$ under solvent-free conditions at $80^{\circ} \mathrm{C}$ (Scheme 52). This reaction was promoted by the reaction of dibromomethylarenes (187) with an excess of $(\mathbf{4}, \mathbf{5})$ to form $\alpha$-brominated ether intermediates $(\mathbf{1 8 8})$ which underwent a second debromoalkoxylation in the presence of an excess of $(4,5)$ to provide acetal $(\mathbf{1 8 9})$ and the removal of 2 moles of alkyl bromide and 3 moles of formate ester. ${ }^{186}$

In 2006, Gazizov et al. investigated the reaction of TEOF with 1,1,2,2-tetrabromoethane with different molar ratios at $180{ }^{\circ} \mathrm{C}$ under solvent-free conditions within $10 \mathrm{~h}$. It was found that dehydrobromination reaction took place via the reaction of triethyl orthoformate with 1,1,2,2-tetrabromoethane in $1: 2$ molar ratios to obtain tribromoethylene, ethyl formate, ethyl bromide, and ethanol as the main products along with low amounts of ethyl acetate and dibromoethylene. On the other hand, the debromination reaction was accomplished via the reaction of substrates in a $2: 1$ molar ratio to give ethyl formate, ethyl bromide, dibromoethylene, ethyl hypobromite, and acetal. $^{187}$

\subsection{Synthesis of $\alpha$-iodo ketones and $\alpha$-iodo dimethyl ketals}

In 2008, Yadav et al. presented a new, effective, and simple protocol for the synthesis of $\alpha$-iodo ketones (191) and $\alpha$-iodo dimethyl ketals (192) via the reaction of substituted acetophenones (190), TMOF (4) and iodine at room temperature under solvent-free conditions (Scheme 53). It must be mentioned that the selectivity of the obtained products from acetophenones was attributed to the workup procedures. It was found that, after completion of the reaction, if the reaction mixture was quenched in the presence of aqueous saturated $\mathrm{Na}_{2} \mathrm{~S}_{2} \mathrm{O}_{3}$ and then extracted by dichloromethane, the $\alpha$-iodinated dimethoxy ketal was obtained as the main product, but when the reaction mixture was stirred in the presence of water before washing with aqueous saturated $\mathrm{Na}_{2} \mathrm{~S}_{2} \mathrm{O}_{3}$, the $\alpha$-iodo ketones were afforded as the main products. In this conversion, the ringdirected iodination or $\alpha, \alpha$-diiodination products were never

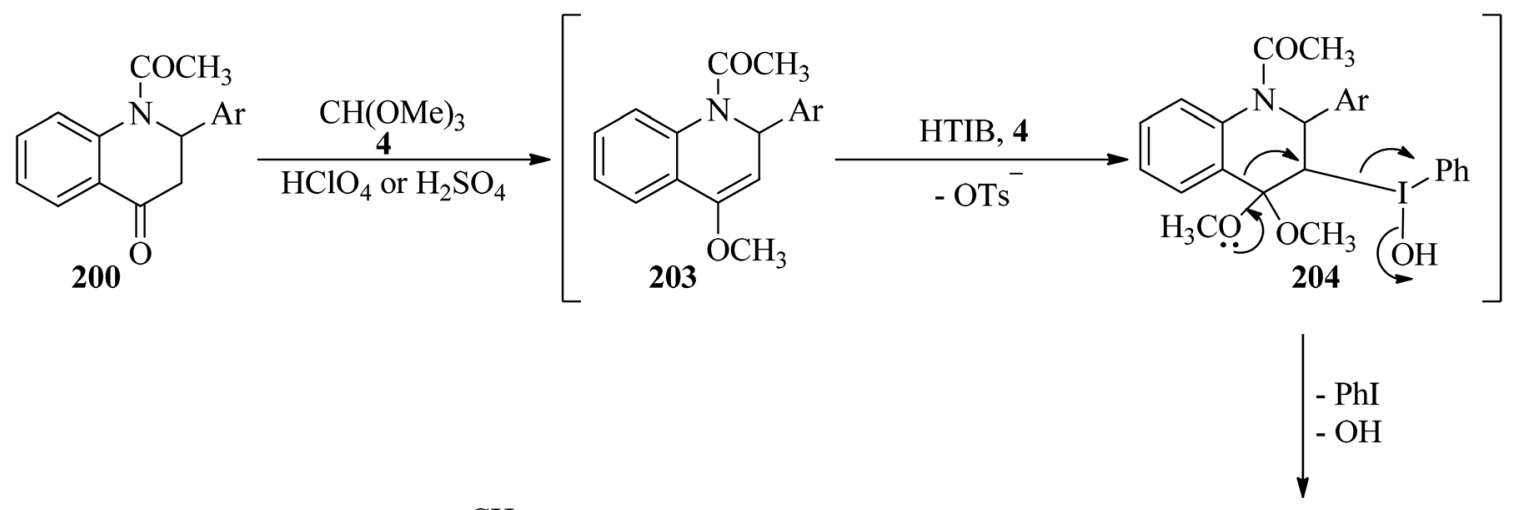<smiles>COS(=O)(=O)c1ccc(C)cc1</smiles><smiles>CC(=O)[C@H]1c2ccccc2N(C(C)=O)[C@@H]1[Al]</smiles>

201<smiles>COC(=O)C1c2ccccc2N(C(C)=O)C1[Al]</smiles>

205

Scheme 55 A mechanistic approach for the ring contraction of $\mathrm{N}$-acetyl-2-aryl-1,2,3,4-tetrahydro-4-quinolones with TMOF. 


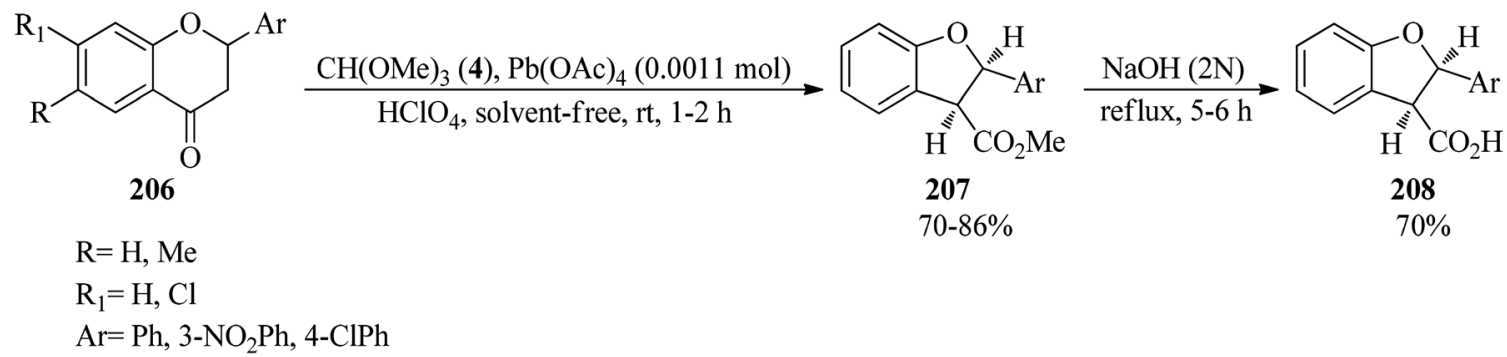

Scheme 56 The oxidative reaction of flavanones with TMOF using $\mathrm{Pb}(\mathrm{OAc})_{4}$.<smiles>[R]c1cc2c(c([R])c1[R])CCC=C2</smiles>

$\mathrm{R}_{1}=\mathrm{H}, \mathrm{OMe}$

$\mathrm{R}_{2}=\mathrm{Me}, \mathrm{OMe}$

Scheme 57 The reaction of 1,2-dihydronaphthalenes with TMOF.

obtained. It is significant that this transformation in the presence of cyclohexanones (193) as a starting material resulted in the $\alpha$-iodo ketos (194) as the only product, but 1,3-cyclohexadione (195) and substituted 1,3-cyclohexadione such as dimedone $(197)$ yielded the $\alpha$-iodinated products $(196,198)$ and the aromatized compound $(199)^{188}$ in good yields. ${ }^{189}$

\subsection{Ring-contraction reactions}

In 2007, Kumar et al. described a stereoselective method for the synthesis of trans-methyl $\mathrm{N}$-acetyl-2-aryl-2,3-dihydroindol-3carboxylates (201) via the ring contraction of $\mathrm{N}$-acetyl-2-aryl1,2,3,4-tetrahydro-4-quinolones (200) with TMOF (4) by HTIB as oxidizing agent in the presence of a few drops of either $\mathrm{HClO}_{4}$ or $\mathrm{H}_{2} \mathrm{SO}_{4}$ at room temperature in high yields (65-73\%) for appropriate times (75-90 $\mathrm{min}$ ) (Scheme 54). This reaction was accompanied by the formation of methyl $p$-toluenesulfonate (202) as a by-product in small quantity. The proposed mechanism, shown in Scheme 55, was begun through the ketalisation of (200) with (4) using either $\mathrm{HClO}_{4}$ or $\mathrm{H}_{2} \mathrm{SO}_{4}$ to form intermediate enol ether (203). Then the electrophilic attack of HTIB on the double bond of enol ether (203) led to the iodine(III) complex (204), from which the elimination of iodobenzene from (204) with concurrent migration of aryl residue from the $\mathrm{C}_{4}$ to the $\mathrm{C}_{3}$ position gave intermediate carbocation (205), which on hydrolysis obtained the ring-contracted product (201) together with (202). To accomplish greater stability of the resultant carbocation, the migration of aryl residue was preferred over the $\mathrm{C}_{2}$ position aryl ring. Eventually, (201) was afforded by ring contraction of compound (200), and meanwhile by-product

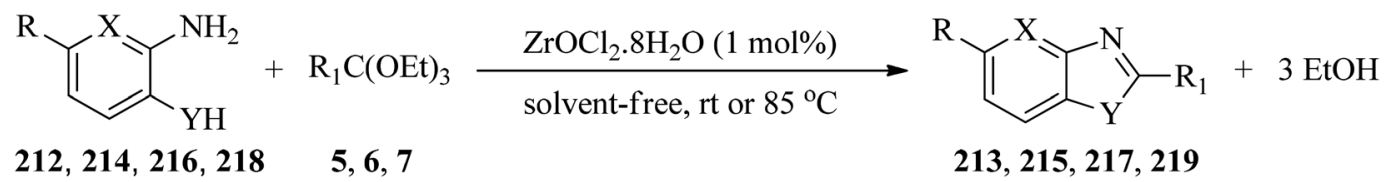

212, 213: $\mathrm{X}=\mathrm{C}, \mathrm{Y}=\mathrm{NH}, 85^{\circ} \mathrm{C}, 4-10 \mathrm{~min}, 83-97 \%$

214, 215: $\mathrm{X}=\mathrm{C}, \mathrm{Y}=\mathrm{O}$, rt or $85{ }^{\circ} \mathrm{C}, 4-10 \mathrm{~min}, 85-95 \%$

216, 217: $X=C, Y=S, r t, 4-6 \min , 93-97 \%$

218, 219: $X=N, Y=O, 85^{\circ} \mathrm{C}, 12 \min , 88-89 \%$

$\mathrm{R}=\mathrm{H}, \mathrm{Me}, \mathrm{Cl}$

$\mathrm{R}_{1}=\mathrm{H}, \mathrm{Me}, \mathrm{Et}$

Scheme 58 The synthesis of benzimidazoles through the condensation of trialkyl orthoformates with diamines. 


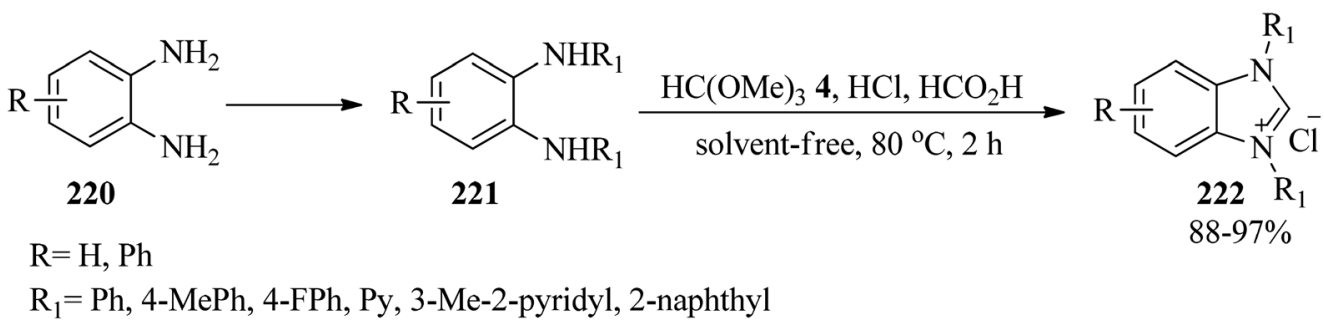

Scheme 59 The synthesis of benzimidazole-based N-heterocyclic carbenes.

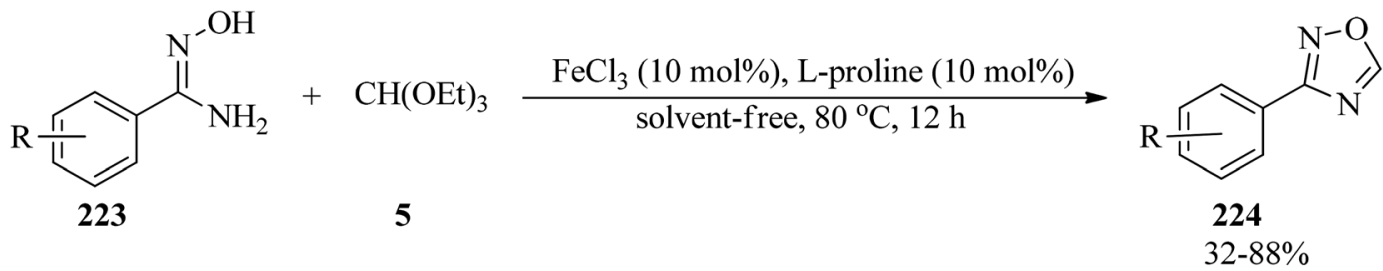

$\mathrm{R}=\mathrm{H}, 4-\mathrm{Cl}, 3-\mathrm{Cl}, 4-\mathrm{NO}_{2}, 4-\mathrm{Br}, 2,4-\mathrm{Cl}_{2}, 4-\mathrm{OMe}, 3-\mathrm{OMe}$

Scheme 60 The preparation of 3-substituted 1,2,4-oxadiazoles.

(202) was produced, probably through the in situ condensation of methanol with $p$-TSA. ${ }^{190}$

Flavanones (206), ${ }^{191-193}$ through the oxidative reaction with TMOF (4) using lead tetraacetate $\left(\mathrm{Pb}(\mathrm{OAc})_{4}, 0.0011 \mathrm{~mol}\right)$ and $70 \%$ perchloric acid under solvent-free conditions at room temperature, were converted into cis-methyl-2,3-dihydro-2arylbenzofuran-3-carboxylates (207) in high yields (70-86\%) within 1-2 h. Subsequent alkaline hydrolysis of the product (207) by aqueous $\mathrm{NaOH}$ solution under reflux conditions obtained the corresponding acids (208) within 5-6 h in 70\% yields (Scheme 56). ${ }^{193}$

Thallium(III) trinitrate $\left[\mathrm{Tl}\left(\mathrm{NO}_{3}\right)_{3} \cdot 3 \mathrm{H}_{2} \mathrm{O}\right]$ catalyzed the oxidation of various olefins ${ }^{194}$ such as 1,2-dihydronaphthalenes (209) with TMOF (4) at $0{ }^{\circ} \mathrm{C}$ to obtain indans (210) in good yields (82$92 \%$ ) within a very short $1 \mathrm{~min}$ period (Scheme 57). ${ }^{195}$ It was found that 1,2-dihydronaphthalenes (209) without an alkyl substituent at the double bond produced mainly the ringcontraction products (210) in high yields, ${ }^{\mathbf{1 9 4 - 2 0 4}}$ while the substrates containing an alkyl group because of their lower reactivity gave the addition products (211) in the presence of methanol, ${ }^{197,198,205}$ although there are some exceptions. ${ }^{\mathbf{2 0 0 , 2 0 6}}$

\subsection{Synthesis of benzimidazoles, benzoxazoles, benzothiazoles, and oxazolo $[4,5-b]$ pyridines}

In 2007, the Mohammadpoor-Baltork group presented a green and efficient protocol for the preparation of a new library of benzimidazoles (213), benzoxazoles (215), ${ }^{207,208}$ benzothiazoles (217), ${ }^{128,209}$ and oxazolo[4,5-b]pyridines $(219)^{210-212}$ via the condensation reactions of orthoesters $(5,6,7)$ with $o^{-}$ substituted aminoaromatics such as $o$-phenylenediamine (212), $o$-aminophenol (214), $o$-aminothiophenol (216), and 2-amino-3hydroxypyridine (218), respectively, by catalytic amounts of $\mathrm{ZrOCl}_{2} \cdot 8 \mathrm{H}_{2} \mathrm{O}$ under solvent-free conditions at room temperature or $85{ }^{\circ} \mathrm{C}$ for short reaction times (4-12 $\mathrm{min}$ ) and moderate to excellent yields (83-97\%) (Scheme 58)..$^{\mathbf{2 1 2}}$

In $2018, \mathrm{ZrOCl}_{2} \cdot 8 \mathrm{H}_{2} \mathrm{O}$ @nano $\mathrm{SiO}_{2}$ as a new catalyst was originated and characterized and subsequently its catalytic

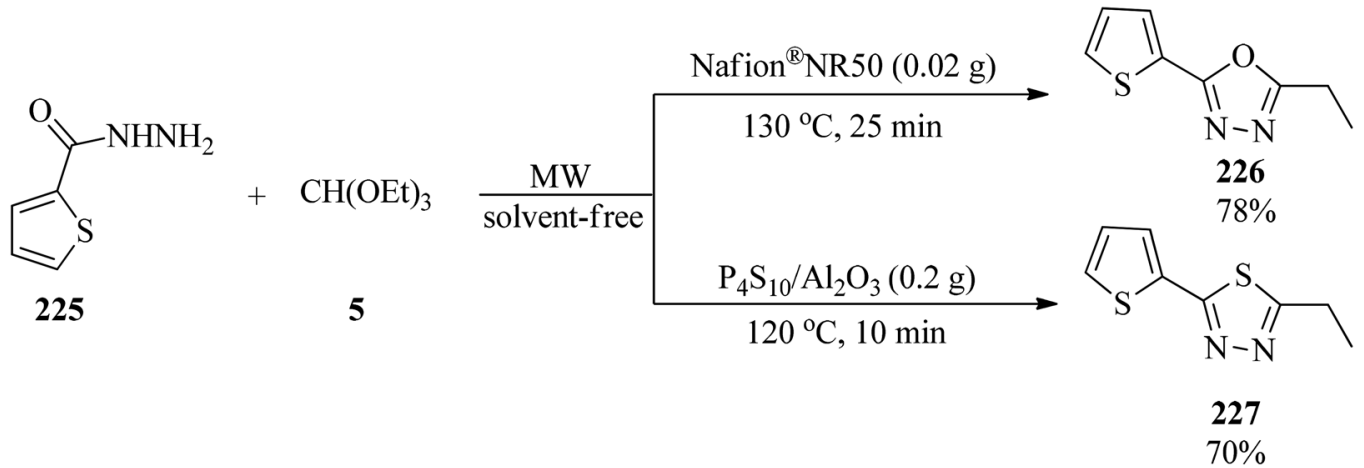

Scheme 61 The microwave-assisted synthesis of 1,3,4-oxadiazoles and 1,3,4-thiadiazoles. 


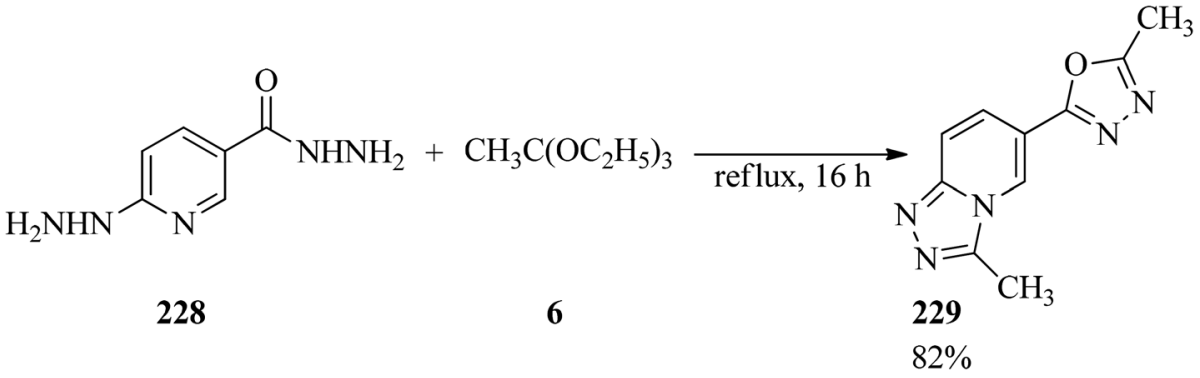

Scheme 62 Double [4 + 1] cyclocondensation of 6-hydrazinonicotinic acid hydrazide hydrate with TEOAc.

activity $(0.01 \mathrm{~g})$ has been investigated for the preparation of benzimidazoles ${ }^{\mathbf{2 1 3}, 214}$ via the condensation reaction of trialkyl orthoformates with diamines under solvent-free condition at $60{ }^{\circ} \mathrm{C}$ within reaction times of $1.5-5.5 \mathrm{~h}$ and $70-90 \%$ yields. High yields (70-90\%), recyclability, and reusability of the synthesized catalyst are some of the main advantages of this method. ${ }^{214}$ Nano-Ni(II)/Y zeolite, as a non-toxic heterogeneous catalyst, at $60{ }^{\circ} \mathrm{C}$ under solvent-free conditions also accelerated this transformation within 46-122 $\mathrm{min}$ in good to excellent 79$99 \%$ yields. ${ }^{215}$

In 2013, Wang and co-workers developed a simple and efficacious process for the synthesis of benzimidazole-based Nheterocyclic carbenes (222) via the cyclization of $N, N^{\prime}$-diarylaryldiamines (221), arising from aryldiamines (220), with TMOF (4) using concentrated $\mathrm{HCl}$ and formic acid at $80{ }^{\circ} \mathrm{C}$ for $2 \mathrm{~h}$ in $88-97 \%$ yields (Scheme 59). Notably, the reaction was unsuccessful with diamines containing strong electronwithdrawing substitutions. ${ }^{216}$

\subsection{Synthesis of oxadiazoles and thiadiazoles}

In 2016, Kaboudin et al. investigated iron(III) chloride/L-proline as an efficient catalytic system for the synthesis of 3-substituted 1,2,4-oxadiazoles (224) from amidoximes (223) and TEOF (5) (Scheme 60). ${ }^{217}$

Polshettiwar and Varma performed the solvent-free synthesis of 1,3,4-oxadiazoles (226) $)^{218-223}$ and 1,3,4-thiadiazoles (227) by the condensation of acid hydrazide (225) and triethyl orthoalkanates (5) under microwave irradiation (40-140 W). According to Scheme 61, the condensation of hydrazide and TEOF were successfully undertaken in two catalytic systems which were solid supported Nafion ${ }^{\circledR} \mathrm{NR} 50$ and $\mathrm{P}_{4} \mathrm{~S}_{10} / \mathrm{Al}_{2} \mathrm{O}_{3} .{ }^{223}$

The double $[4+1]$ cyclocondensation reaction of 6-hydrazinonicotinic acid hydrazide hydrate (228) containing two dinucleophilic centers ${ }^{224}$ with TEOAc (6) obtained oxadiazolyltriazolopyridine (229) in $82 \%$ yield within $16 \mathrm{~h}$ under reflux conditions (Scheme 62). In this transformation, the hydrazine and the hydrazide moieties exhibited similar reactivity, whereas in the presence of aldehyde as one other carbon<smiles>[R][R]([H])[R]#[R3]c1c([NH3+])cc([R])c([R])c1[R4]</smiles><smiles>[R]c1cc(NC=C2C(=O)OC(C)(C)OC2=O)c([R3])c([R])c1[R]</smiles><smiles>[R]c1c([R])c([R])c2c(=O)cc[nH]c2c1[Y19]([H])([H])C(=O)OCC(=O)O</smiles>

[bmim] $\mathrm{BF}_{4}: 66-85 \%$

[bmim]OTf: $73-90 \%$ 


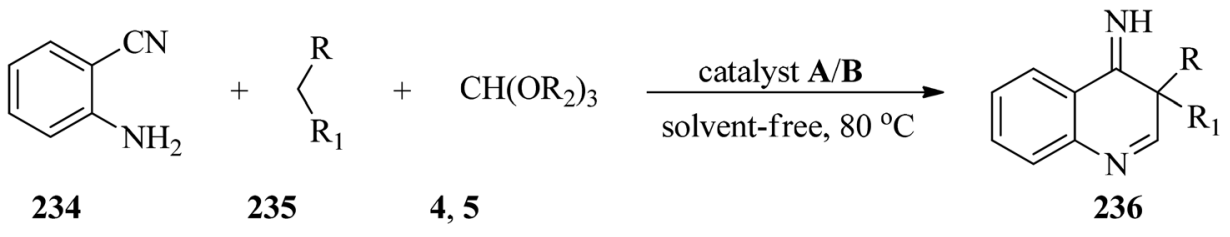

A: $\mathrm{Fe}_{3} \mathrm{O}_{4} @$ @APTES-MAH NPs (0.03 g), 38-162 min, 70-92\%

B: VSA NRs (10 mol\%), 34-160 min, 72-94\%

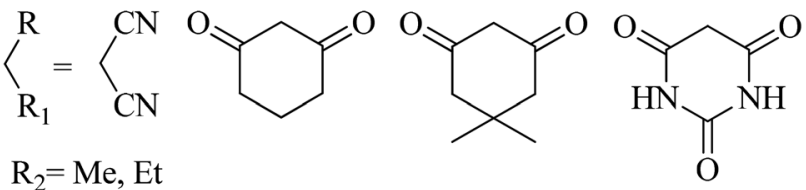<smiles>CCOC(=O)CC(C)=O</smiles>

Scheme 64 The synthesis of new 4-iminoquinolines.

donor moiety the hydrazine and the hydrazide groups were treated chemoselectively and regioselectivly. ${ }^{225}$

\subsection{Synthesis of quinolones}

In 2012, Yadav et al. developed a simple and green method for the synthesis of $4(1 \mathrm{H})$-quinolones via a two-step reaction. At first, the one-pot three-component condensation reaction of arylamines (230), Meldrum's acid (231), and TMOF (4) by 1butyl-3-methylimidazolium bromide [bmim] $\mathrm{Br}$ as ionic liquid catalyst at $40 \pm 2{ }^{\circ} \mathrm{C}$ obtained arylaminomethylene-1,3-dioxane4,6-dione (232) in $68-94 \%$ yield in $2 \mathrm{~h}$. After purifying, the resulting products underwent a cyclization reaction along with the elimination of acetone and $\mathrm{CO}_{2}$ using $[\mathrm{bmim}] \mathrm{BF}_{4}$ or $[\mathrm{bmim}]$ OTf at $80 \pm 2{ }^{\circ} \mathrm{C}$ in a $2 \mathrm{~h}$ period to afford $4(1 \mathrm{H})$-quinolones $(233)$ (Scheme 63). The results revealed the better utility of [bmim]OTf in comparison with $[\mathrm{bmim}] \mathrm{BF}_{4}{ }^{226}$

In 2018, Kanaani and Nasr-Esfahani prepared and characterized maleic anhydride coated magnetite nanoparticles $\left(\mathrm{Fe}_{3}-\right.$ $\mathrm{O}_{4} @$ @APTES-MAH NPs) and nanorod vanadatesulfuric acid (VSA NRs) as Brønsted acid nanocatalysts. Subsequently, their catalytic activity was examined for the synthesis of new 4-iminoquinolines (236) via the one-pot three-component reaction of equimolar amounts of 2-aminobenzonitrile (234), orthoesters $(\mathbf{4}, \mathbf{5})$, and active methylenes (235) under solvent-free conditions at $80^{\circ} \mathrm{C}$. In this reaction the influence of different parameters, such as the type of catalyst and orthoesters, was examined. It was found that both VSA NRs and $\mathrm{Fe}_{3} \mathrm{O}_{4}$ @APTES-MAH NPs catalysts yielded the corresponding 4-iminoquinolines (236) in good to excellent yields. VSA NRs in comparison with $\mathrm{Fe}_{3} \mathrm{O}_{4}$ @APTES-MAH NPs slightly improved the reaction times and yields (Scheme 64). They discovered that, among different orthoesters, TEOF was more effective. Short reaction times, high yields, simple purification of the products, the inexpensiveness, stability, recyclability and reusability of the catalysts are some of the advantages of this method. ${ }^{227}$

\subsection{Synthesis of isoquinoline derivatives}

1,2,3,4-Tetrahydro-10-oxopyrimido[ $\left[4^{\prime}, 5^{\prime}: 4,5\right]$ thieno[2,3-c $][1,2,4]$ triazolo[3,4-a]isoquinoline $(239,68 \%)$ and 5-(3,5-dimethylpyrazol-1-yl)-1,2,3,4-tetrahydropyrimido $\left[4^{\prime}, 5^{\prime}: 4,5\right]$ thieno[2,3-c] isoquinolin-8(9H)-one $(\mathbf{2 4 1}, \mathbf{7 2} \%)$ were synthesized via the ring closure of triazolo and pyrazolothienotetrahydroisoquinoline $(\mathbf{2 3 8}, \mathbf{2 4 0})$, derived from key precursors beginning from 4-cyano1-morpholin-4-yl-5,6,7,8-tetrahydroisoquinoline-3(2H)thione<smiles>CC#CC#CCC1CCc2c(-n3nc(C)cc3C)nc3sc(C(N)=O)c(N)c3c2C1</smiles><smiles>Cc1cc(C)n(-c2nc3sc4c(=O)[nH]cnc4c3c3c2CCCC3)n1</smiles>

Scheme 65 The synthesis of isoquinolines with the aid of TEOF. 


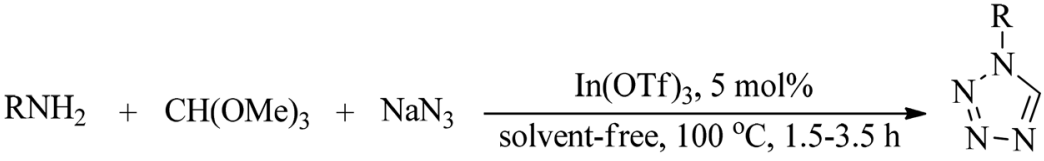

$$
\begin{aligned}
& 242 \quad 243 \quad 244 \\
& 70-92 \%
\end{aligned}
$$

$\mathrm{R}=\mathrm{Bn}, n-\mathrm{Bu}, t-\mathrm{Bu}$, cyclohexyl, $\mathrm{Ph}, 4-\mathrm{MePh}, 2-\mathrm{OMePh}, 2,3-\mathrm{Me}_{2} \mathrm{Ph}, 4-\mathrm{FPh}, 2-\mathrm{ClPh}, 2-\mathrm{Cl}-3-\mathrm{FPh}$, 3- $\mathrm{NO}_{2} \mathrm{Ph}, 4-\mathrm{CO}_{2} \mathrm{EtPh}$, 4-vinylaniline, 2-pyridyl, furfurylamine, $(S)$-1-phenylethylamine

Scheme 66 The preparation of substituted-1H-1,2,3,4-tetrazoles.

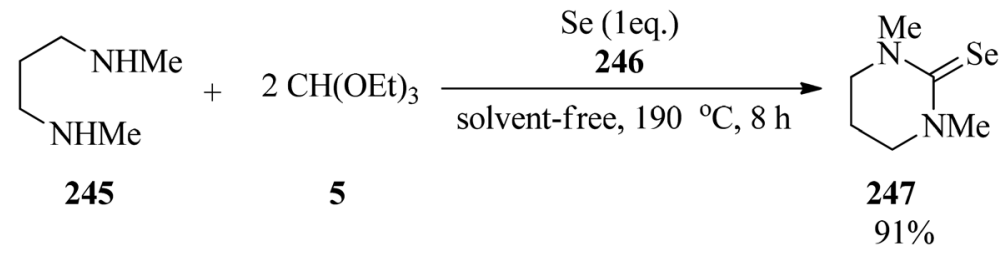

Scheme 67 Selenourea synthesis by the condensation of amines, TEOF, and Se.

(237), with TEOF (5) using a few drops of glacial acetic acid under reflux conditions for 1-2 $\mathrm{h}$ (Scheme 65). The synthesized products were examined and evaluated as antimicrobial agents. ${ }^{228}$

\subsection{Synthesis of 1-substituted-1H-1,2,3,4-tetrazoles}

Indium triflate $\left[\operatorname{In}(\mathrm{OTf})_{3}, 5 \mathrm{~mol} \%\right]$ as a highly efficient Lewis acid catalyst, catalyzed the one-pot three-component condensation reaction of amines (242), TMOF (4), and sodium azide (243) under solvent-free conditions at $100{ }^{\circ} \mathrm{C}$ to furnish 1-

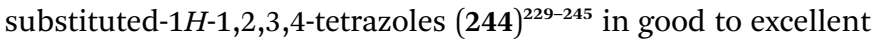
yields (70-92\%) within 1.5-3.5 h. Both electron-donating and electron-withdrawing anilines yielded the products in high yields. The catalytic system also proceeded well with heterocyclic amine and aliphatic amines (Scheme 66). ${ }^{245}$ On the other hand, the reaction of substituted anilines, TEOF, and trimethylsilyl azide ${ }^{209,246}$ also afforded 244 using $\mathrm{FeCl}_{3}(20 \mathrm{mmol} \%)$ under solvent-free conditions at $70{ }^{\circ} \mathrm{C}$ within $5-7 \mathrm{~h}$ in $87-95 \%$ yields. $^{246}$

\subsection{Synthesis of selenoureas}

Selenoureas (247) were obtained by a novel three-component condensation reaction from primary or secondary amines (245), TEOF (5) and metallic selenium (246) (Scheme 67). ${ }^{247}$

\subsection{Synthesis of piperazinyl pyridines}

In 2000, Rao et al. described a new simple method for the synthesis of 2-amino-3-cyano-5- $N$-substitued piperazinyl pyridines (250) via the condensation reaction of TEOAc (6), malononitrile (248), and $N$-substituted piperazine (249) in a $2: 1: 1$ molar ratio in the presence of excess of ammonium acetate $(5$ moles) under reflux conditions at $90-92^{\circ} \mathrm{C}$ for $2 \mathrm{~h}$ in moderate yields (50-68\%) (Scheme 68). The products were obtained by a simple filtration and recrystallization from ethylacetate $/ n$ hexane. Elemental and spectral data (FT-IR, PMR) confirmed the structures of the isolated compounds. ${ }^{248}$

\subsection{Synthesis of pyrimidine derivatives}

In 2010, Nagarajan and Reddy prepared substituted pyrimidine derivatives (253) via the one-pot three-component condensation reaction of acetylenedicarboxylates (251), amines (252), and orthoformates $(4,5)$ with a molar ratio of $1: 2: 1$ in the presence of $\mathrm{ZnCl}_{2}(0.5 \mathrm{~mol} \%)$ under solvent-free conditions at room temperature in $27-80 \%$ yields within $1-3 \mathrm{~h}$ (Scheme 69). ${ }^{249}$

In 2006, Toche et al. presented a two-step procedure for the synthesis of 4-amino-5-(4-bromobenzoyl)-3-ethyl-2 $(1 H)$-pyrimidone (257). First, the domino three-component condensation reaction of 4-bromobenzoylacetonitrile (254), mono-

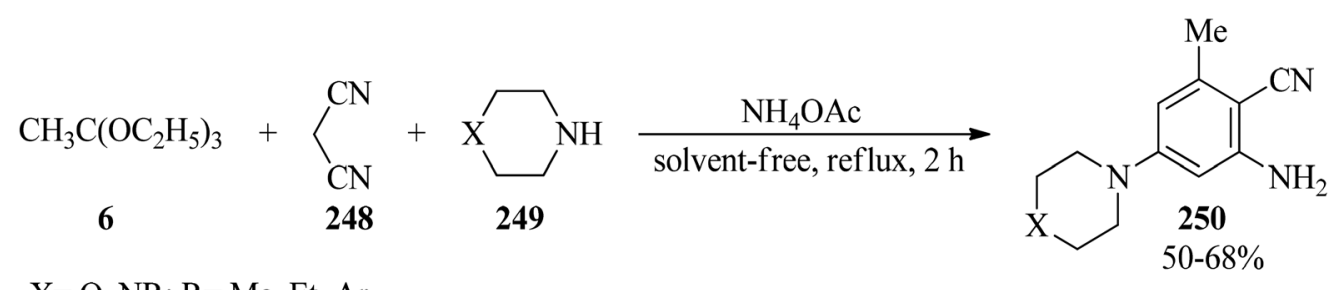

Scheme 68 Synthetic route to substituted piperazinyl pyridines. 


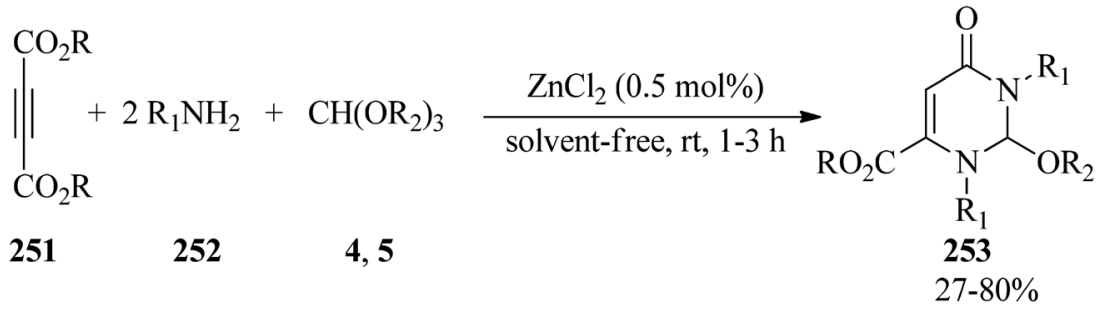

$\mathrm{R}, \mathrm{R}_{2}=\mathrm{Me}, \mathrm{Et}$

$\mathrm{R}_{1}=\mathrm{Et}, n-\mathrm{Pr}, 4-\mathrm{OMePh}, 4-\mathrm{NO}_{2} \mathrm{Ph}, 2-\mathrm{OMe}-5-\mathrm{MePh}, 2,5-\mathrm{Et}_{2} \mathrm{Ph}, 3,4-\mathrm{F}_{2} \mathrm{Ph}, 2-\mathrm{Cl}-4-\mathrm{BrPh}$,

2-Br-4-FPh, 2-Cl-4-BrPh, 2,4,6- $\mathrm{Me}_{3} \mathrm{Ph}, 2,4,6-\mathrm{Br}_{3} \mathrm{Ph}, 2,6-\mathrm{Br}_{2}-4-\mathrm{MePh}, 2,6-\mathrm{Br}_{2}-4-\mathrm{MePh}$

Scheme 69 The synthesis of substituted pyrimidine derivatives.

alkylated ureas $(77,255)$, and TEOF (5) at $65-70{ }^{\circ} \mathrm{C}$ yielded enamine intermediates (256). Subsequently, the resultant precipitate (which dissolved in $\mathrm{EtOH} / \mathrm{NaOEt}$ under reflux conditions) underwent an intramolecular cyclization reaction and dissolved in refluxing ethanol to produce 257 in 56-64\% yield (Scheme 70). The compounds were evaluated for their insect repellent activity against Sitophilus oryzae (Coleoptera, Curculeonidae). ${ }^{250}$

1,2-Oxazolo[5,4- $d]$ pyrimidin-4(5H)-ones (259) were obtained in $46-74 \%$ yields via the ring-closure reaction of 1,2oxazole-4-carbohydrazides $(\mathbf{2 5 8})$ with boiling orthoesters $(\mathbf{5}, \mathbf{6})$ under solvent-free conditions within 1-5 h (Scheme 71). The in vitro mycobacterial and cytotoxicity activities of the products were screened against Mycobacterium fortuitum in an MABA test, and lung (A549) and fibroblasts (L929) cell lines, respectively. ${ }^{251}$

Ethyl-substituted 2-(4-bromo-phenyl)amino-3-aminopyrazolo $[3,4-d]$ pyrimidin-4-one (260) was refluxed in the presence of TEOF (5) and $p$-TSA, as catalyst, in order to obtain 2ethyl-8-(4-bromophenyl)-pyrazolo[3,4- $d][1,2,4] 8 H$-triazolo[2,3- $a]$ $4 H$-pyrimidin-4-one (261) in 95\% yield (Scheme 72). ${ }^{\mathbf{2 5 2}}$ The

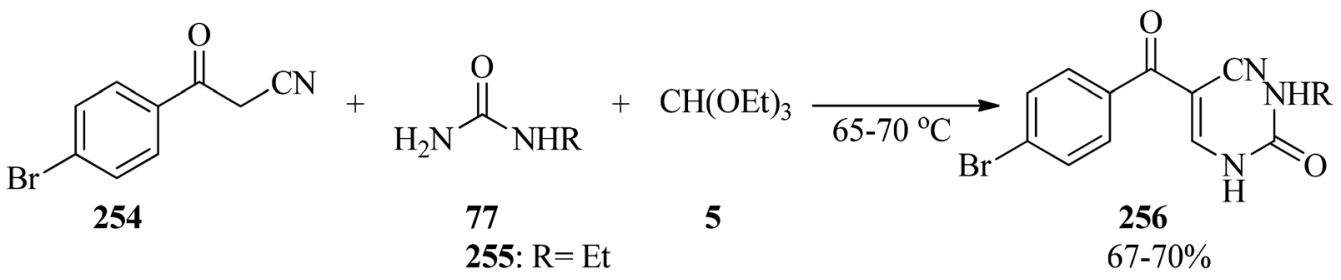

255: $\mathrm{R}=\mathrm{Et}$<smiles></smiles>

Scheme 70 The domino synthesis of 4-amino-5-(4-bromobenzoyl)-3-ethyl-2(1H)-pyrimidones.<smiles>[3H]/C=N/NC(=O)c1c(C)noc1N</smiles><smiles></smiles>

$\mathrm{Ar}=\mathrm{Ph}, 4-\mathrm{OHPh}$, 4-OMePh, 4- $\mathrm{MePh}, 4-\mathrm{CF}_{3} \mathrm{Ph}, 4-\mathrm{ClPh}, 2,4-\mathrm{Cl}_{2} \mathrm{Ph}, 3,4-\mathrm{Cl}_{2} \mathrm{Ph}, 4-\mathrm{NO}_{2} \mathrm{Ph}$

$\mathrm{R}=\mathrm{H}, \mathrm{Me}$

Scheme 71 Ring closure of 1,2-oxazole-4-carbohydrazides with orthoesters. 
products have previously been reported as potential antiinflammatory-analgesic agents. ${ }^{253}$

Due to the key role of fluorine-containing heterocyclic products in biological and pharmacological activities, ${ }^{254-256}$ and also the development of new functional groups, ${ }^{257-263}$ in 2008, 5(trifluoromethyl)-pyrazolo[1,5-a]pyrimidines (264), 6-thienoyl-7(trifluoromethyl)-[1,2,4]triazolo[4,3-a]pyrimidine (266) and 6thienoyl-7-(trifluoromethyl)benzimidazo[1,2-a]pyrimidine (268) were synthesized via the condensation reaction of 4,4,4trifluoro-1-(thien-2-yl)butane-1,3-dione (262), TEOF (5) and the appropriate heterocyclic amines, such as aminopyrazoles (263), 3-amino-1,2,4-triazole (265), and 2-aminobenzimidazole (267), respectively, by pressurized microwave irradiation $(300 \mathrm{~W}, 17.2$ bar) at $100{ }^{\circ} \mathrm{C}$ under solvent-free conditions for $5 \mathrm{~min}$ (Scheme 73). ${ }^{264}$

In 2000, 2-amino-4,5-di-(2-furyl)furan-3-carbonitrile (269) ${ }^{265}$ was utilized as a key starting material for the synthesis of furo $[3,2-e][1,2,4]$ triazolo[1,5-c]pyrimidines (273). At first, the condensation of (269) with TEOAc (6) under reflux conditions for $5 \mathrm{~h}$ obtained the corresponding 2-ethoxyimine (270) in good yield $(65 \%)$ which upon treatment with hydrazine hydrate (271) was converted into (272). Eventually, the cyclocondensation of (272) with TEOF (5) under reflux conditions for $8 \mathrm{~h}$ achieved (273) in 73\% yield (Scheme 74). The products were purified by simple filtration and crystallization and were finally characterized by their correct analyses and spectroscopic data (IR and ${ }^{1} \mathrm{H}$ NMR). ${ }^{266}$

In 2000, Dave and Shah synthesized $7 H-1,2,4$-triazolo[1,5-c] pyrrolo[3,2-e]pyrimidines (277) via the domino multicomponent reaction of 1,4-disubstituted 2-amino-3-cyanopyrroles (274), ${ }^{267}$ TEOF (5), and hydrazine hydrate (271) under reflux conditions. This reaction proceeded through the condensation of 274 with 5 under reflux conditions to generate 1,4-disubstituted $\mathrm{N}$-ethoxymethylene-2-amino-3-cyanopyrroles (275) in 3$4 \mathrm{~h}$ in good yields (70-88\%) which led to 5,7-disubstituted 3amino-4-imino-7 $H$-pyrrolo[2,3- $d]$ pyrimidines $(276)(60-88 \%)$ on hydrazinolysis with 271 within $3.5-4$ h. Finally, the cyclocondensation reaction of $\mathbf{2 7 6}$ with one carbon donor moiety, such as 5, afforded product (277) ${ }^{268,269}$ in 6-7 h in weak to high yields $(42-70 \%)$ (method A). On the other hand, the similar reaction of 4-hydrazino-7H-pyrrolo[2,3- $d]$ pyrimidines $(278)^{270}$ with 5 and 271 (method B) obtained the [4,3-c] isomers (279),<smiles>CCn1cc2c(=O)n(N)c(Nc3ccc(Br)cc3)nc2n1</smiles>

Scheme 72 The synthesis of 2-ethyl-8-(4-bromophenyl)-pyrazolo[3,4-d][1,2,4]8H-triazolo[2,3-a]4H-pyrimidin-4-ones.

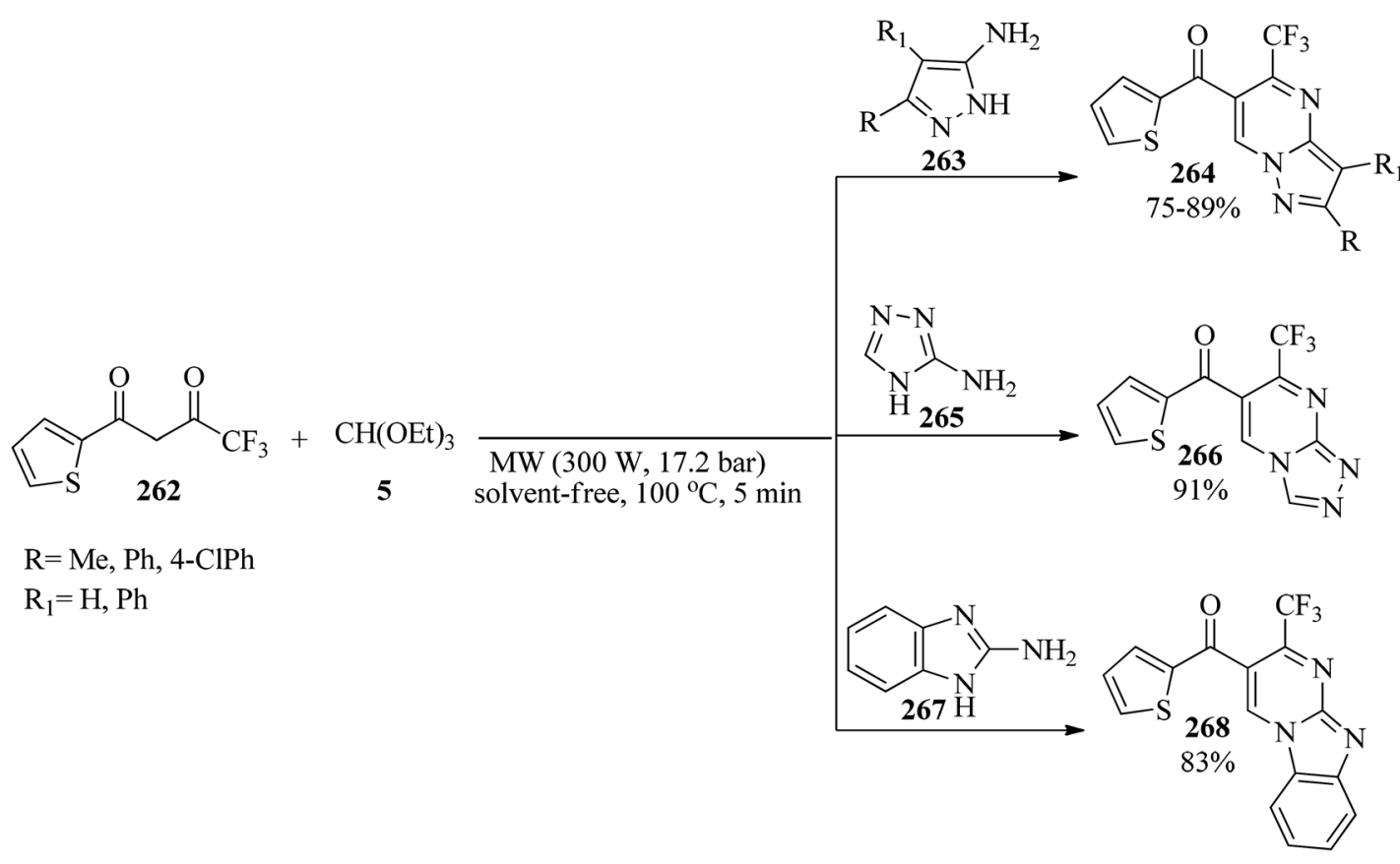

Scheme 73 The preparation of some fluorinated pyrimidines. 
<smiles>CCOC(C)=Nc1oc(CC)c(CC)c1C#N</smiles>

Fu: 2-furyl

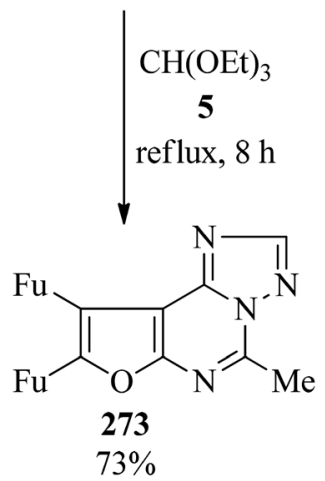

Scheme 74 Preparation procedure of furo[3,2-e][1,2,4]triazolo[1,5-c]pyrimidines.

which using formic acid were isomerized to the thermodynamically more stable $[1,5-c]$ isomers (277) through Dimroth rearrangement (Scheme 75). Notably, the latter procedure was faster and more efficient. ${ }^{269}$

In 2005, Rashad et al. prepared several derivatives containing thieno[2,3- $d]$ pyrimidine systems with potent anti-inflammatory properties: e.g. 11-hydrazino-5,6-dihydronaphtho[ $\left[1^{\prime}, 2^{\prime}: 4,5\right]$ thieno[2,3- $d]$ pyrimidines were refluxed with triethyl orthoesters for $10 \mathrm{~h}$ to obtain 8,9-dihydronaphtho[ $\left[1^{\prime}, 2^{\prime}: 4,5\right]$ thieno[3,2-e] $[1,2,4]$ triazolo[ $[4,3-c]$ pyrimidines ${ }^{271,272}$ in $72-86 \%$ yields; which were isomerized to the thermodynamically more stable triazolo $[1,5-c]$ pyrimidines under heating in either acid or basic media. ${ }^{272}$ Thieno[2,3-b]-pyridine-2-carbohydrazide (280) was refluxed with TEOF (5) for $4 \mathrm{~h}$ to form 3-aminopyrido $\left[3^{\prime}, 2^{\prime}: 4,5\right]$ thieno[3,2-d]pyrimidines (281) in $73 \%$ yield (Scheme 76). ${ }^{273}$

2,4-Dimethyl-7-benzyledineamino-8-oxopyrimido $\left[4^{\prime}, 5^{\prime}: 4,5\right]$ seleno[2,3-b]pyridine (283) was synthesized upon cyclocondensation of benzylidene carbohydrazone (282) with TEOF (5) by a few drops of acetic acid under reflux conditions for $1 \mathrm{~h}$ in $51 \%$ yield (Scheme 77 ). ${ }^{274}$

In 2004, three pathways were presented for the synthesis of pyrido[2,3- $d$ ] pyrimidines (286) through the one-pot threecomponent condensation reaction of equimolar amounts of 6aminouracils (284), alkyl nitriles (285), and TEOF (5) in (a)<smiles>[R]c1cn([Y16]([H])([H])[H])c(N)c1C#N</smiles>

$\mathrm{R}=\mathrm{Ph}, 4-\mathrm{OMePh}$, 4-ClPh, 4-OCIPh

$\mathrm{R}_{1}=4-\mathrm{OMePh}, 4-\mathrm{OClPh}, 4-\mathrm{BrPh}, 4-\mathrm{IPh}$

Scheme 75 The synthesis of 7H-1,2,4-triazolo[1,5-c]pyrrolo[3,2-e]pyrimidines. 
<smiles>CC(=O)c1c(C)nc2sc(C(=O)NN)c(N)c2c1-c1ccc(N(C)C)cc1</smiles>

Scheme 76 Formation of 3-aminopyrido[3',2':4,5]thieno[3,2-d]pyrimidines.

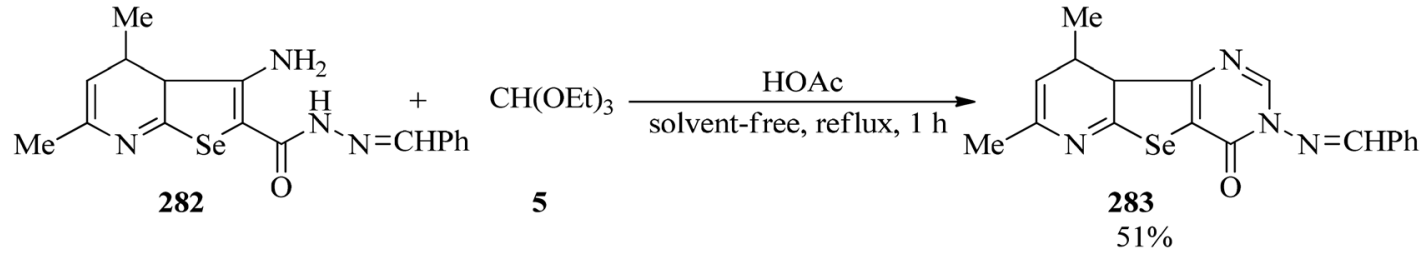

Scheme 77 Synthetic approach for 2,4-dimethyl-7-benzyledineamino-8-oxopyrimido[4' $\left.5^{\prime}: 4,5\right]$-seleno[2,3-b]pyridine.

solvent-free conditions, (b) using ethanol as a solvent under heating thermal conditions, and (c) under microwave irradiation with $360 \mathrm{~W}$ power at $75{ }^{\circ} \mathrm{C}$ utilizing acetic anhydride (Scheme 78), for which the third method had a great effect on decreasing the time and increasing the yield. ${ }^{275}$ Some compounds have different pharmacological activities, such as antibacterial, ${ }^{276}$ antitumor, ${ }^{277}$ cardiotonic, hepatoprotective, and antihypertensive, ${ }^{278}$ and antibronchitic effects. ${ }^{279}$

2,3,5,7-Substituted-pyrido[2,3- $d$ ]pyrimidin-4(3H)-ones (288) were synthesized in good to excellent yields (75-96\%) from the cyclocondensation reaction of 2-amino- $N, 6$-substituted phenyl4-substituted nicotinamides $(287)$ with orthoesters $(6,7)$ by

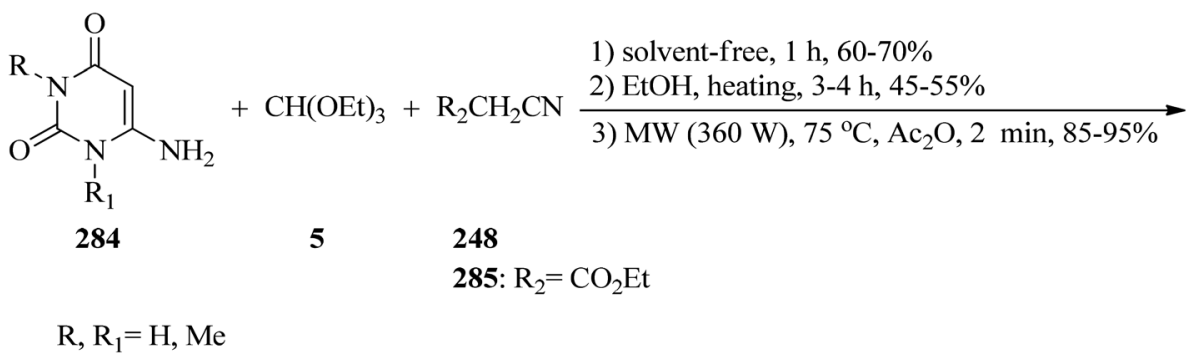<smiles>[R2]c1cc2c(=O)n([R])c(=O)n([Y])c2nc1N</smiles>

286

$\mathrm{R}, \mathrm{R}_{1}=\mathrm{H}, \mathrm{Me}$

Scheme 78

Pyrido[2,3-d]pyrimidine synthetic routes under three sets of conditions.

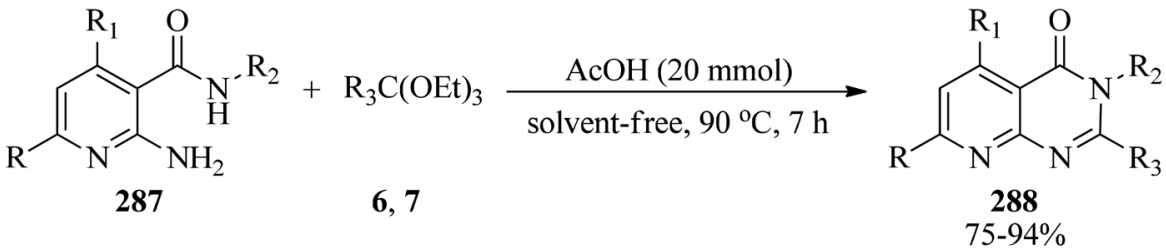

$\mathrm{R}=\mathrm{Ph}, 4-\mathrm{ClPh}$

$\mathrm{R}_{1}=\mathrm{Me}, \mathrm{CF}_{3}$

$\mathrm{R}_{2}=4-\mathrm{FPh}$, 4-ClPh, 4-IPh, 4-MePh, 2-MePh, 4-OMePh, 2-OMePh, 3,5- $\mathrm{Me}_{2} \mathrm{Ph}, 3,4-(\mathrm{OMe})_{2} \mathrm{Ph}, 4-\mathrm{SMePh}$, 4-CF 3 Ph

$\mathrm{R}_{3}=\mathrm{Me}, \mathrm{Et}$

Scheme 79 The formation of substituted-pyrido[2,3-d]pyrimidin-4(3H)-ones. 
<smiles>[R]Oc1cc(N([R2])c2cc(=O)[nH]c(=O)[nH]2)ccc1[R]</smiles><smiles>CCCCCCCCCCCCCC</smiles>

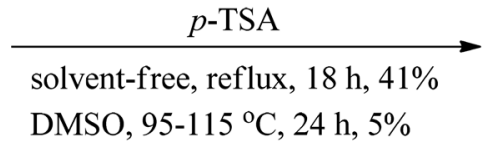

$\mathrm{R}=\mathrm{H}, \mathrm{Me}$

$\mathrm{R}_{1}=\mathrm{H}, \mathrm{Ac}$

$\mathrm{R}_{2}=\mathrm{H}_{2} \mathrm{C}$<smiles></smiles>

$\mathrm{CH}_{2}(\mathrm{CHOAc})_{3} \mathrm{CH}_{2} \mathrm{OAc}$

$\mathrm{R}_{3}=\mathrm{Me}, \mathrm{Et}$

Scheme 80 Cyclization by TEOF to obtain N-containing heterocycles.

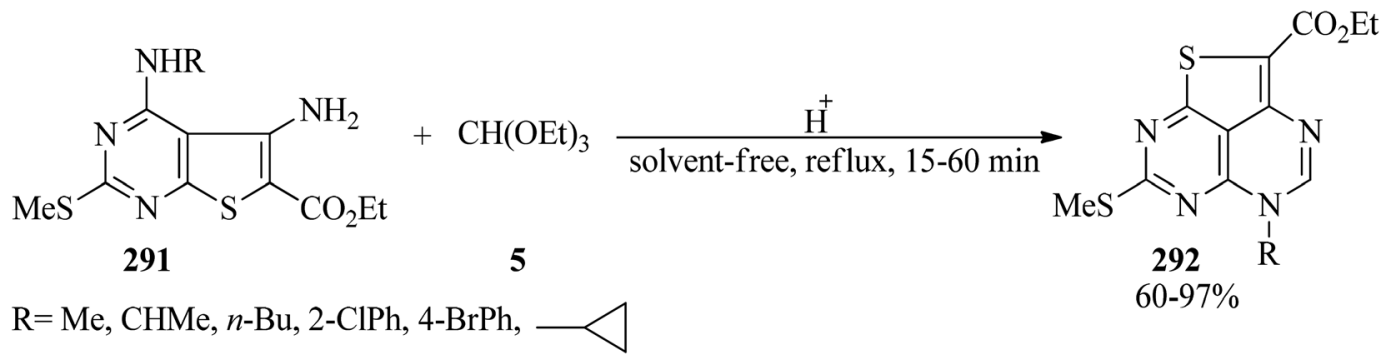

Scheme 81 The preparation of 7-(methylthio)-5H-1-thia-3,5,6,8-azaacenaphthylene-2-carboxylates.

catalytic amounts of glacial acetic acid at $90{ }^{\circ} \mathrm{C}$ for $7 \mathrm{~h}$ (Scheme 79). All the resultant compounds (288) were examined for antibacterial activity against Gram +ve and Gram -ve bacteria. ${ }^{280}$

The cyclization of compounds (289) with excess amounts of trialkyl orthoformates $(\mathbf{4}, 5)$ resulted in products $(290)$ using catalytic amounts of $p$-TSA under reflux conditions or in DMSO as solvent at $95-115{ }^{\circ} \mathrm{C}$ in $5-41 \%$ yields within $18-24 \mathrm{~h}$ (Scheme 80). ${ }^{281}$

Acid-mediated cyclocondensation of ethyl 5-amino-4(substituted amino)-2-(methylthio)thieno[2,3- $d]$ pyrimidine-6carboxylates (291) with TEOF (5) resulted in ethyl 5-substituted 7-
(methylthio)-5H-1-thia-3,5,6,8-azaacenaphthylene-2-carboxylates (292) in 60-97\% yields within 15-60 min (Scheme 81). ${ }^{282}$

In 2016, Castillo and co-workers developed pyrazolo[5,1- $b]$ purines $(\mathbf{2 9 4})$ by a microwave-assisted $(300 \mathrm{~W})$ cyclocondensation of pyrazolo[1,5- $a$ ]pyrimidine-6,7-diamines (293) with orthoesters $(\mathbf{4}, \mathbf{6}, 7)$ at $110-120{ }^{\circ} \mathrm{C}$ under solvent-free conditions in good to excellent yields (81-96\%) within 510 min (Scheme 82). ${ }^{283}$

\subsection{Synthesis of triazin derivatives}

In 2012, Sachdeva and co-workers synthesized 2-amino-4methylpyrimido[1,2-a][1,3,5]triazin-6-ones (297) and 4-amino-2-

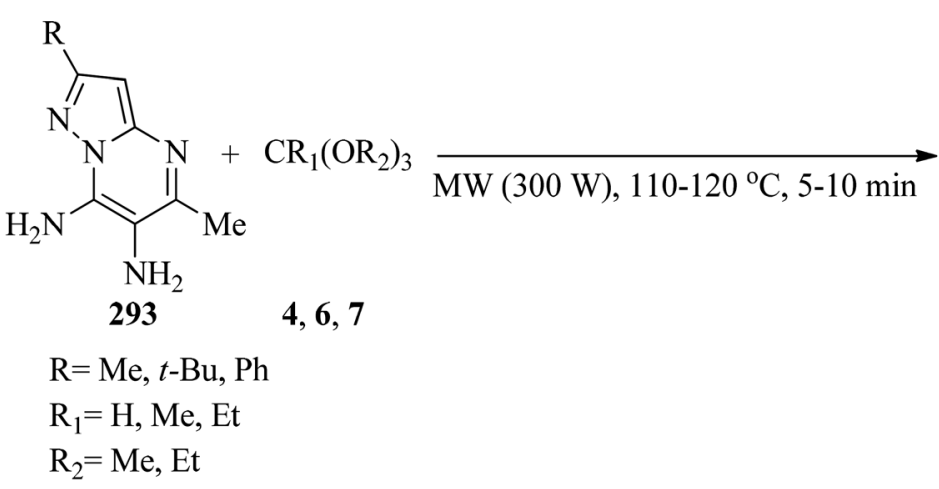<smiles>[R]c1cc2nc(C)c3nc([R16][4H])[nH]c3n2n1</smiles>

Scheme 82 The microwave-assisted synthesis of pyrazolo[5,1-b]purines. 
<smiles>[R2]NC(=N)Nc1nc([R])cc(=O)[nH]1</smiles><smiles>[R2]C(CC)=[NH+]/C([R20])=N\c1nc([R])cc(=O)[nH]1</smiles>

296

$\mathrm{R}=\mathrm{Me}, \mathrm{CF}_{3}, \mathrm{Ph}$

$\mathrm{R}_{1}=\mathrm{H}, \mathrm{Me}$

$\mathrm{R}_{2}=\mathrm{H}, \mathrm{Me}, \mathrm{Ph}, 4-\mathrm{OMePh}$, 3-ClPh, 3-BrPh, 4-OMePhCH $2,4-\mathrm{ClPhCH}_{2}$, 1-indolinyl

$\mathrm{R}_{1}, \mathrm{R}_{2}=-\mathrm{CH}_{2} \mathrm{CH}_{2} \mathrm{OCH}_{2} \mathrm{CH}_{2}-$

Scheme 83 The synthesis of 4-amino-2-methylpyrimido[1,2-a][1,3,5]triazin-6-ones.

methylpyrimido[1,2-a][1,3,5]triazin-6-ones (299) utilizing 1-(6- triethylorthoacetate (6) in glacial acetic acid under reflux oxo-1,6-dihydropyrimidin-2-yl)guanidines (295) as starting conditions to form an iminium ion intermediate (296). Subsematerials. Firstly, the guanidines (295) were condensed with quent intramolecular cyclization along with the elimination of<smiles>CCOC(Oc1ccccc1C1CC(C)=NN1C(=N)N)Oc1ccccc1C1CC(C)=NN1C(=N)N</smiles><smiles>CC1=NNC(c2ccccc2O)C1</smiles><smiles>CC1=NN2/C(=N/C(=N)N)N=COc3ccccc3C2C1</smiles>

303

Scheme 84 The synthesis of dihydro-pyrazolo benzoxadiazocin-5-ylidene guanidines. 
<smiles>CC1=NN(C(=N)/N=C\NC(=N)N2N=C(C)CC2N2N=C(C)CC2c2ccc(C)cc2)C(c2ccc(C)cc2)C1</smiles><smiles>CC1=NN(c2ncnc(N)n2)C(c2ccc(C)cc2)C1</smiles>

Scheme 85 Formation procedure for 2-amino-4-[4,5-dihydro-3-methyl-5-(4-methylphenyl)-1H-pyrazol-1-yl]-1,3,5-triazine.

ethanol yielded product (297); which was followed by thermal rearrangement for unsubstituted $\left(\mathrm{NH}_{2}\right)$, alkyl-substituted $\left(\mathrm{NHCH}_{3}\right)$, and aralkyl guanidines $\left(\mathrm{NHCH}_{2} \mathrm{Ph}(\mathrm{R})\right)$ via ring opening of pyrimidine at the amide moiety to produce the ringopen triazine carbenone (298). Finally, intramolecular nucleophilic attack of the N-1 nitrogen of 1,3,5-triazine on the carbonyl functional group and annulation, respectively, achieved product (299) (Scheme 83). It is noteworthy that the guanidines (295) containing a tertiary amino group such as $-\mathrm{N}\left(\mathrm{CH}_{3}\right)_{2}$, $-\mathrm{N}\left(\mathrm{CH}_{2} \mathrm{CH}_{2}\right)_{2} \mathrm{O}$, indolino and or aryl secondary amino substituent groups, e.g. - $\mathrm{NHPh}, \mathrm{NHPh}(3-\mathrm{Br}), \mathrm{NHPh}(3-\mathrm{Cl}), \mathrm{NHPh}(4-$ $\mathrm{OMe}$ ) produced mainly the corresponding product $297 .{ }^{284}$

In 2002, Světlík and Liptaj synthesized new heterocyclic ring systems including a pyrazole moiety, such as $N-[(5 E)-1,12-b$ dihydro-substituted-5H-pyrazolo[1,5-e][1,3,5]-benzoxadiazocin5-ylidene]guanidine (303) or 2-amino-4-[4,5-dihydro-3-methyl-5(4-methylphenyl)-1H-pyrazol-1-yl]-1,3,5-triazine (308). The products (303) were obtained via the re-esterification of TEOF
(5) with phenolic hydroxys of two equivalents of 4,5-dihydro-3methyl-5-(2-hydroxyphenyl)-1H-pyrazole-1-carboximidamide (300) to produce orthoester (301) which underwent a cyclization reaction with the vicinal amidine moiety to form an oxadiazocine system (302). Then, the nucleophilic attack of the adjoining exocyclic imine nitrogen on the carbon atom of the other amidine group enabled C1-transfer, which was followed by loss of the disubstituted pyrazoline component to obtain (303) (Scheme 84). On the other hand, the condensation reaction of 4,5-dihydro-3-methyl-5-(4-methylphenyl)-1 $H$-pyrazole-1-

carboximidamide acetate (305) with 5 under reflux conditions gave intermediate (306) which was followed by a cyclization reaction to get (307). The reaction was completed by the formation of 2-amino-4-[4,5-dihydro-3-methyl-5-(4-methylphenyl)-1 $H$-pyrazol-1-yl]-1,3,5-triazine (308) for $1 \mathrm{~h}$ in $65 \%$ yield through the elimination of the disubstituted pyrazoline component (Scheme 85). ${ }^{285}$<smiles>[R]n1cnc2c(C=[W])cccc2c1=O</smiles>

$\mathrm{R}=\mathrm{Ph}, 2-\mathrm{MePh}$, 4-MePh, 4-OMePh, 4-BrPh, 4-ClPh, 4- $\mathrm{NO}_{2} \mathrm{Ph}, 3,4-\mathrm{Br}_{2} \mathrm{Ph}, 2,4-\mathrm{Br}_{2} \mathrm{Ph}, \mathrm{Bn}, n-\mathrm{Bu}, t-\mathrm{Bu}$ 


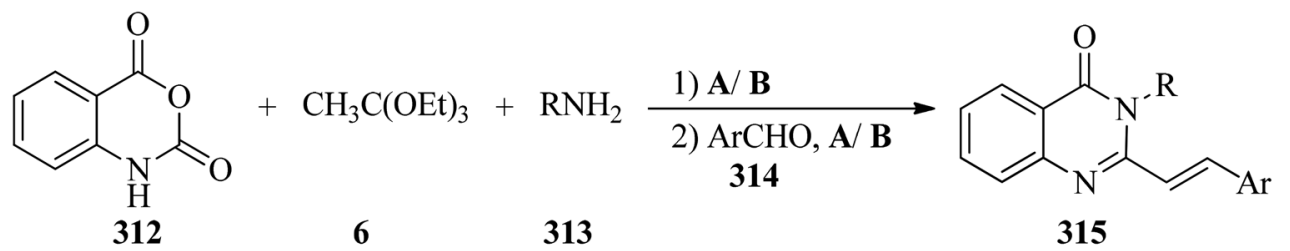

A: solvent-free, $120^{\circ} \mathrm{C}, 5 \mathrm{~h}$

A: $70-79 \%$

B: $72-81 \%$

B: solvent-free, $\mathrm{MW}(150 \mathrm{~W}), 140{ }^{\circ} \mathrm{C}, 20-30 \mathrm{~min}$

$\mathrm{R}=\mathrm{H}, \mathrm{Ph}, \mathrm{Bn}, 4-\mathrm{MePh}, 4-\mathrm{OMePh}, 4-\mathrm{SMePh}$, 4-FPh

$\mathrm{Ar}=\mathrm{Ph}, 4-\mathrm{NMe}_{2} \mathrm{Ph}, 4-\mathrm{OMePh}, 4-\mathrm{MePh}, 4-\mathrm{OBnPh}, 4-\mathrm{ClPh}, 4-\mathrm{BrPh}, 4-\mathrm{CF}_{3}-\mathrm{Ph}$, 2-furanyl, 2-thiofuranyl

Scheme 87 Tandem preparation route for $(E)$-3-substituted-2-styrylquinazolin-4(3H)-ones.

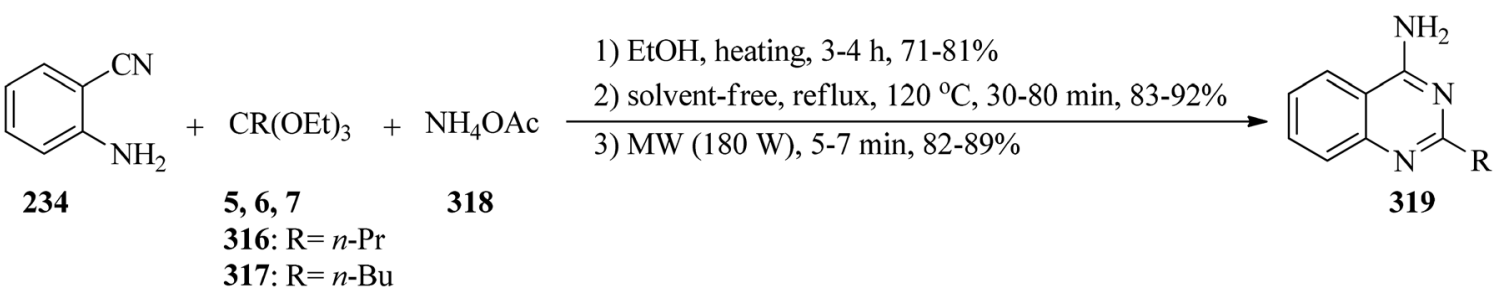

Scheme 88 The synthesis of 2-substituted 4-aminoquinazolines.

\subsection{Synthesis of quinazoline derivatives}

In 2010, Wu et al. prepared 4(3H)-quinazolinones (311) in excellent yields (84-96\%) and very short reaction times (15-20 min) via the one-pot three-component condensation reaction of anthranilic acid (309), ${ }^{286-293}$ TEOF (5) and primary amines (310) under solvent-free conditions at room temperature by silicasupported boron trifluoride $\left(\mathrm{BF}_{3}-\mathrm{SiO}_{2}, 100 \mathrm{mg}\right)$ as a green, recyclable and reusable heterogeneous catalyst (Scheme 86). ${ }^{293}$ Microwaves $(210 \mathrm{~W})$ accelerated the formation of $4(3 H)$-quinazolinones in the absence of solvent via the one-pot threecomponent condensation reaction of anthranilic acid, orthoesters, and ammonium acetate using a catalytic amount of antimony(III) chloride $\left(\mathrm{SbCl}_{3}, 1 \mathrm{~mol} \%\right)$ in excellent yields (8993\%) within $5 \mathrm{~min}$. According to the results, both aliphatic and aromatic substituents on orthoesters indicated no significant effect on the reaction times and the yields, but generally, the presence of a substituent on orthoesters prolonged the reaction times. ${ }^{294}$ Quinazolin-4(3H)-ones could also be obtained from the condensation of anthranilic amide with orthoesters using ionic liquids under ultrasound irradiation in $20-25 \mathrm{~min}$ in $82-91 \%$ yields. ${ }^{209}$

The catalyst/solvent-free one-pot three-component reaction of isatoic anhydrides (312), TEOAc (6), and various amines (313) in equimolar amounts obtained 4(3H)-quinazolinones (311) through two different pathways: (a) utilizing microwave irradiation $(150 \mathrm{~W})$ at $140{ }^{\circ} \mathrm{C}$, and (b) under conventional heating at $120{ }^{\circ} \mathrm{C}$. This method developed through the Knoevenagel condensation reaction of $4(3 \mathrm{H})$-quinazolinones with aromatic aldehydes (314) by a tandem four-component condensation reaction to achieve $(E)$-3-substituted-2-styrylquinazolin-4(3H)ones (315). ${ }^{295,296}$ The results affirmed that MW assisted the reaction progression much better than conventional heating (Scheme 87). ${ }^{296}$

In 2006, three pathways were presented for the synthesis of 2substituted 4-aminoquinazolines (319) via the uncatalyzed onepot three-component condensation reaction of 2-

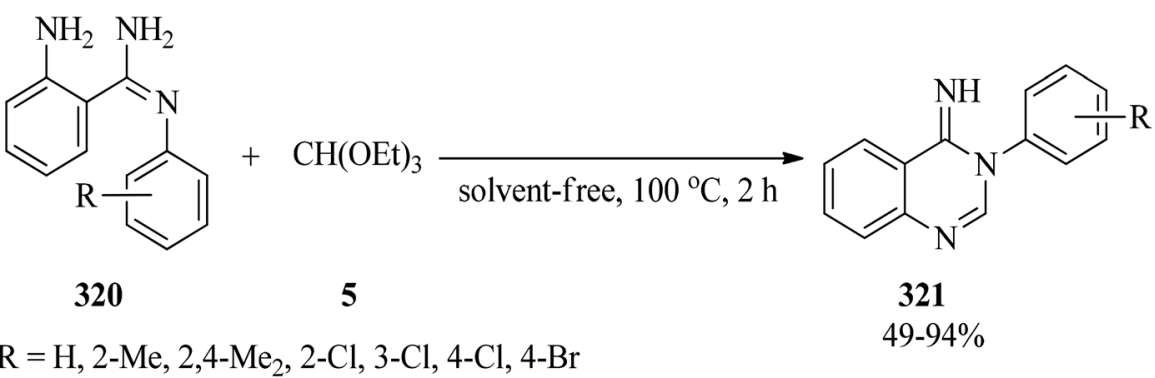

Scheme 89 The synthesis of 3 -arylquinazolin-4(3H)imines. 


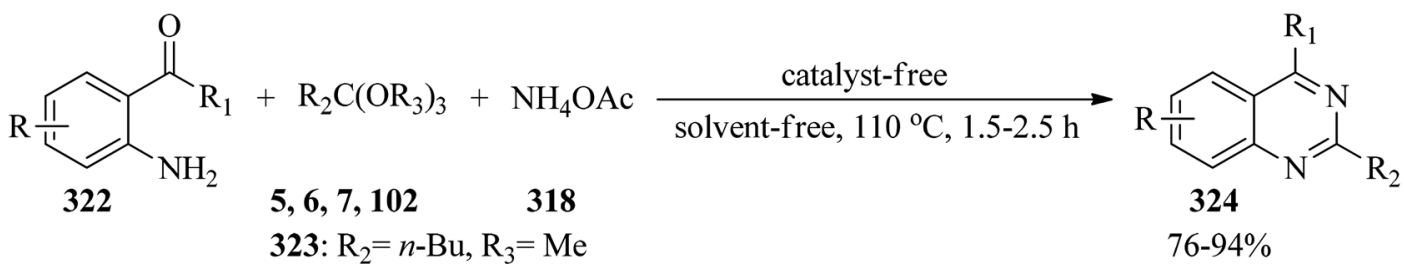

$\mathrm{R}=\mathrm{H}, 4-\mathrm{Cl}, 4-\mathrm{NO}_{2}, 4,5-(\mathrm{OMe})_{2}$

$\mathrm{R}_{1}=\mathrm{Me}, \mathrm{Ph}, 2-\mathrm{FPh}$

Scheme 90 The synthesis of 2,4-disubstituted quinazolines.

aminobenzonitrile (234), orthoesters $(5,6,7,316,317)$, and ammonium acetate (318) in (a) ethanol as solvent under heating conditions, (b) under reflux conditions without a solvent, and (c) microwave irradiation in the absence of a solvent. The results showed that, in comparison with the two premier routes, microwave irradiation has an important influence on decreasing the reaction time (5-7 $\mathrm{min}$ ) (Scheme 88). ${ }^{297}$

In 2015, a catalyst and solvent-free one-step method was reported for the synthesis of 3-arylquinazolin-4(3H)imines (321) by heating 2 -amino- $N$-arylbenzamidines (320) with TEOF (5) (Scheme 89). ${ }^{298}$

In 2015, Bhat and co-workers, presented an efficient and ecofriendly method for the synthesis of 2,4-disubstituted quinazolines (324) in high yields (76-94\%) via the catalyst/solvent-free one-pot three-component reaction of 2-aminoaryl ketones (322), trialkyl orthoesters $(\mathbf{5}, \mathbf{6}, \mathbf{7}, \mathbf{1 0 2}, \mathbf{3 2 3})$, and ammonium acetate (318) in a 1 : 1.5 : 1.5 molar ratio at $110{ }^{\circ} \mathrm{C}$ within $1.5-2.5 \mathrm{~h}$ (Scheme 90). In this study, in order to investigate the scope and limitations of the presented procedure, the reaction was carried out by diverse substituted 2-aminoaryl ketones and trialkyl orthoesters. The reaction was performed by 2-aminobenzophenones and 2 -aminoacetophenones. It was found that the transformation with $2^{\prime}$-aminoacetophenones proceeded faster, which may be ascribed to the steric effect resulting from the aryl substitution, which decreases the reactivity of the carbonyl group. Remarkably, 2-aminobenzophenones containing both electron-withdrawing and electron-donating groups on the aniline ring provided good results. However, 2 '-aminoacetophenones including a strong electron-donating substituent on the aniline ring obtained poor yield. It was also found that the reactivity of aliphatic orthoesters was better than orthobenzoate as an aromatic orthoester, which could probably be attributed to the steric effect of different substituents on the orthoester functional group. It was found that the chain length of the orthoalkylates did not have a significant influence on the reaction results. ${ }^{299}$

In 1970, Potts and Brugel synthesized 3-substituted-triazolo [4,3-c]quinazolines (326) in good yields (70-90\%) via the cyclization reaction of 4-quinazolylhydrazine (325) with orthoesters $(5,6,7)$ using potassium carbonate under reflux conditions for $30 \mathrm{~min}$ (Scheme 91). ${ }^{300}$

\subsection{Synthesis of macrocycles}

The three-component cyclocondensation of $N, N^{\prime}$-dimesitylpropane-1,3-diamine (327), TEOF (5), and ammonium tetrafluoroborate (328) was accomplished to produce the main product macrocycle (329) under solvent-free conditions (Scheme 92) and 1,3-dimesityl-3,4,5,6-tetrahydropyrimidin-1ium tetrafluoroborate in the presence of ethanol as solvent. ${ }^{301}$

\section{Orthoester reactions in aqueous media}

One of the most interesting challenges to chemists is the reaction performance in water media as a cheap, readily available, safe, and non-toxic solvent. This effective and completely green medium causes the ready hydrolysis of some substrates and/or products, such as orthoesters. In fact, reports of the transformation of orthoesters in aqueous media are very rare (8 references) that are discussed below.

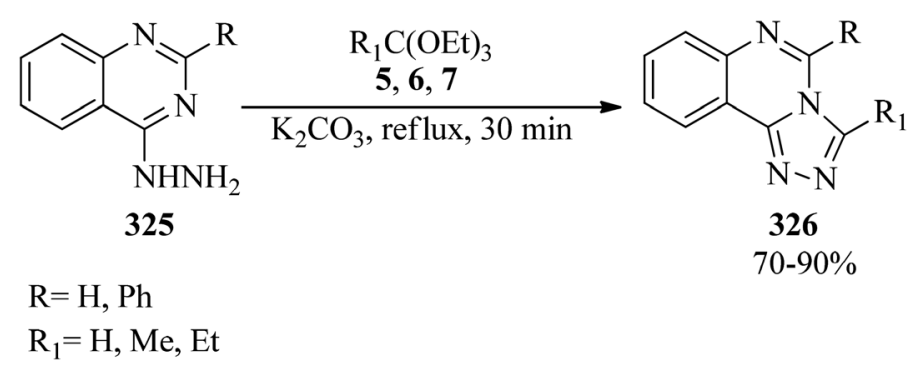

Scheme 91 Formation procedure of 3-substituted-triazolo[4,3-c]quinazolines. 


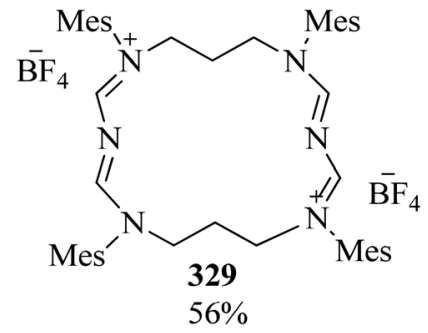

Scheme $92 N$-Bearing macrocycle synthesis.

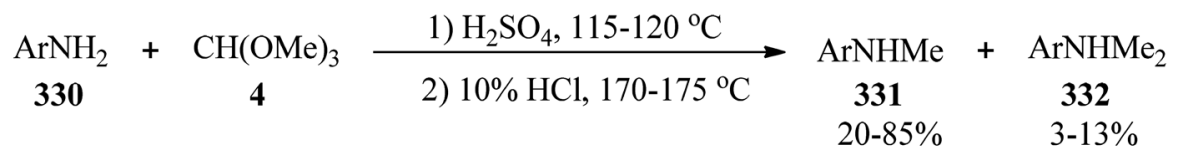

$\mathrm{Ar}=3-\mathrm{IPh}, 4-\mathrm{OMePh}, 3-\mathrm{SMePh}, 3,4,5-(\mathrm{OMe})_{3} \mathrm{Ph}, 4-\mathrm{NO}_{2} \mathrm{Ph}, 2,4-\mathrm{Cl}_{2} \mathrm{Ph}$

Scheme 93 The aqueous alkylation of amines.

\subsection{Synthesis of formamidines}

In 2013, a simple, eco-friendly, and catalyst-free methodology was reported for the $\mathrm{N}$-formylation of amines by TEOF under ultrasound irradiation in water. ${ }^{302}$ Symmetric formamidines could be also prepared via the $\mathrm{N}$-formylation reaction of amines with TMOF using tin(II) chloride-choline chloride $\left(\mathrm{ChCl} / \mathrm{SnCl}_{2}\right.$, $30 \mathrm{~mol} \%$ ), as catalyst and reaction media, in water at $70{ }^{\circ} \mathrm{C}$ for 20-160 min in 30-80\% yields. ${ }^{127}$

\subsection{Alkylation reactions}

The treatment of anilines (330) with TMOF (4) utilizing sulfuric acid at $115-120{ }^{\circ} \mathrm{C}$ resulted in the formation of an $\mathrm{N}$-methylformanilide intermediate; which without isolation was hydrolyzed by aqueous hydrochloric acid (10\%) at $170-175{ }^{\circ} \mathrm{C}$ to obtain $N$-methylated anilines (331) in weak to good yields (20$85 \%)$ and in some cases along with dimethylated derivatives (332) in minor yields (3-13\%) as by-products (Scheme 93)..$^{\mathbf{3 0 3}}$

\subsection{Synthesis of $N$-arylureas}

In 2014, a facile and green procedure was presented for the preparation of $\mathrm{N}$-arylureas (334) through the hydration of various aromatic cyanamides (333) with TEOF (5) in refluxing water in $64-73 \%$ yields within 6-11 h (Scheme 94). It should be noted that the cyanamides including electron-withdrawing groups prolonged reaction times. ${ }^{304}$

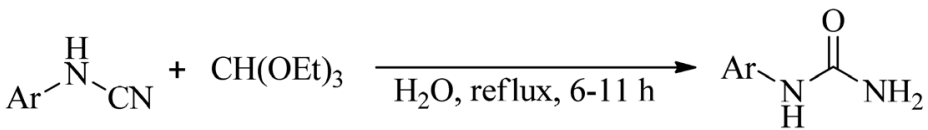

$$
\begin{aligned}
& \begin{array}{lll}
333 & 5 & 334
\end{array} \\
& \text { 64-73\% }
\end{aligned}
$$

$\mathrm{Ar}=\mathrm{Ph}$, 4-MePh, 4-OMePh, 2-MePh, 3-BrPh, 4-ClPh, 4- $\mathrm{NO}_{2} \mathrm{Ph}$, 1-naphthyl

Scheme 94 The water-mediated synthesis of $N$-arylureas.<smiles>[R]c1ccc(C(=O)CCc2ccc([R3])c([R])c2[R])c(O)c1</smiles>

$\mathrm{R}=\mathrm{H}, \mathrm{OH}, \mathrm{OMe}, \mathrm{OBn}$

$\mathrm{R}_{1}, \mathrm{R}_{2}=\mathrm{H}, \mathrm{OMe}$

$\mathrm{R}_{3}=\mathrm{H}, \mathrm{OMe}, \mathrm{Cl}$

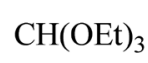<smiles>CC(C)C(C)C(C)C=O</smiles>
$\mathrm{H}_{2} \mathrm{O}$, reflux 5<smiles>[X]c1ccc2c(=O)c(Cc3ccc([R])c([R])c3[R])coc2c1</smiles>

Scheme 95 The preparation of homoisoflavones. 
<smiles>O=C(CS(=O)(=O)c1ccccc1)c1ccccc1</smiles>

337

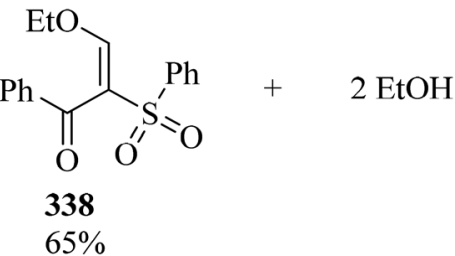

Scheme 96 The synthesis of ethoxymethylenes.

\subsection{Synthesis of homoisoflavones}

In 2008, Rao et al. described a process for the preparation of homoisoflavones $(336)^{305}$ in good yields (78-88\%) via the ring closure of TEOF (5) with 1-(2-hydroxyphenyl)-3-phenylpropane1-ones (335) in the presence of $70 \%$ perchloric acid, which was followed by aqueous hydrolysis of the intermediate perchlorates (Scheme 95). The in vitro antioxidant and antifungal activities of the products were examined using the superoxide (NBT) and agar cup methods, respectively. ${ }^{306}$

\subsection{Synthesis of benzoxazoles}

Maleki et al. synthesized and characterized Ag(1.5\%)@TiO 2 (0.1 $\mathrm{mL}$ ) as a heterogeneous, hazardless, eco-friendly, and reusability nanocatalyst. Then its catalytic activity was examined for the preparation of benzoxazole ${ }^{214,307}$ via the condensation reaction of orthoesters with 2 -amino phenol in water at room temperature within very short reaction times (4-10 $\mathrm{min}$ ) and at excellent yields (82-93\%). ${ }^{307}$

\subsection{Synthesis of 1-substituted-1H-1,2,3,4-tetrazoles}

In 2018, Sharghi et al. synthesized iron-doped acidic multi-walled carbon nanotubes (Fe@acidic-MWCNs). The characterization by inductively coupled plasma (ICP), X-ray diffraction (XRD), scanning electron microscopy (SEM), atomic force microscopy (AFM), Raman, and FT-IR analysis confirmed that the iron nanoparticles were supported on the acidic multi-walled carbon nanotubes (MWCNs). Subsequently their catalytic activity was probed for the preparation of 1-substituted-1 $H$-tetrazoles via the one-pot three-component reaction of substituted anilines, TEOf, and sodium azide in water at $50{ }^{\circ} \mathrm{C}$ within $1-3.5 \mathrm{~h}$ with excellent yields (80-95\%). This reaction was carried out faster in the presence of electron-donating anilines than with electronwithdrawing analogs. ${ }^{308}$ Copper(II) nanoparticles loaded on magnetic core $\left(\mathrm{Fe}_{3} \mathrm{O}_{4} @ \mathrm{SiO}_{2} /\right.$ aza-crown ether-Cu(II)) as a new and highly effective magnetic nanocomposite catalyst in water at $100{ }^{\circ} \mathrm{C}$ also facilitated this transformation within 40-70 min in excellent yields (87-98\%). ${ }^{309}$

\section{Orthoester reactions in organic solvents}

Organic solvents, as carbon-based liquids, are conventional common media to accomplish organic transformations. There are too many organic liquids categorized as solvents. The subdivision of the vast list of solvents could be based on polarity, melting point range, volatility, chemical inertness towards substrates and reagents, or solubility of the existing components<smiles></smiles>

Scheme 97 The synthesis of an anti-Staphylococcus aureus heterocycle.<smiles>[R][CH]C(C)OCCOC</smiles>

Scheme 98 The Ugi reaction to obtain acetamides. 


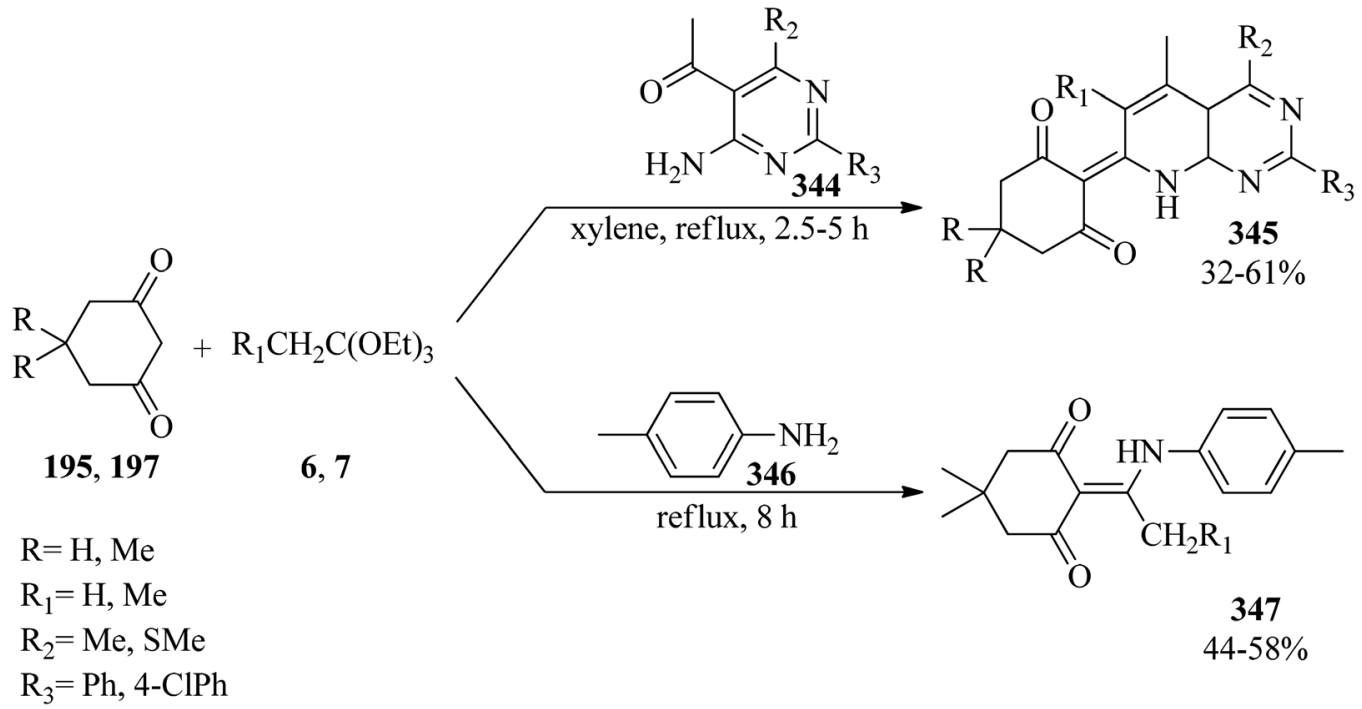

Scheme 99 The synthesis of enamine-bearing heterocycles.

in the reaction. In addition to the solvent characteristics, the chemical and physical nature of each reaction member, and the effective relationship between components and solvents determines the choice of reaction media. According to the detailed data below, most solvents utilized in orthoester-participating transformations are alcohols that dissolve many organic compounds as well as most orthoesters (20 reports). The subsequent grades belong to $\mathrm{CH}_{2} \mathrm{Cl}_{2}$ (16 cases), acetic anhydride (15 items), benzene and its halogen and alkyl substituted analogs (such as chlorobenzene, xylenes, and toluene, 11 cases), acetic acid (10 items), $\mathrm{CH}_{3} \mathrm{CN}$ (8 cases), THF (5 points), ether and DMF (each with 3 cases), and dioxane ( 2 items). The other solvents reported in the literature survey are DMSO, pyridine, $\mathrm{CCl}_{4}$, and ionic liquid that each appeared in just one study.

\subsection{Synthesis of ethoxymethylenes}

In 2000, Elkholy et al. reported the synthesis of 1-benzoyl-1phenylsulfonyl-2-ethoxyethene containing an ethoxymethylene group (338), ${ }^{310-315}$ as yellow crystals, by the reaction of 1-phenyl2-(phenylsulfonyl)ethanone (337) with TEOF (5) in refluxing acetic anhydride. In this reaction 2 moles of ethanol were removed (Scheme 96). ${ }^{315}$

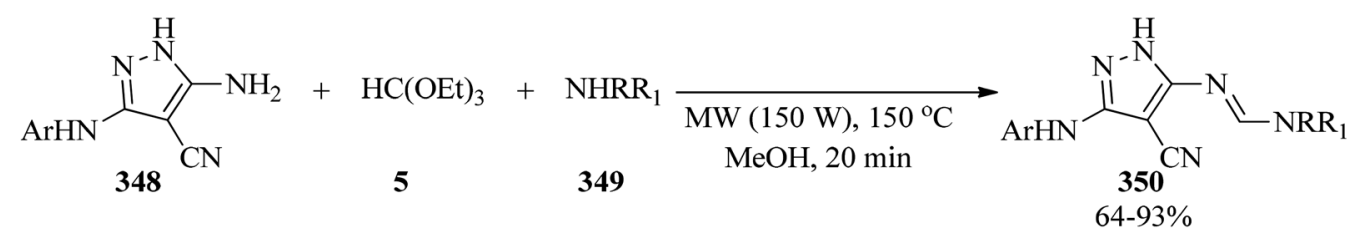

$\mathrm{Ar}=\mathrm{Ph}$, 3-MePh, 4-MePh, 4-EtPh, 2-OMePh, 4-OMePh, 2-OEtPh, 4-OEtPh, 3-CF 3 Ph, 4-FPh, 4-ClPh, 3-BrPh, 4-BrPh

$\mathrm{R}, \mathrm{R}_{1}=-\mathrm{CH}_{2} \mathrm{CH}_{2} \mathrm{OCH}_{2} \mathrm{CH}_{2}-,-\mathrm{CH}_{2}\left(\mathrm{CH}_{2}\right)_{2} \mathrm{CH}_{2},-\mathrm{CH}_{2}\left(\mathrm{CH}_{2}\right)_{3} \mathrm{CH}_{2},-\mathrm{CH}_{2} \mathrm{CH}_{2} \mathrm{NMeCH}_{2} \mathrm{CH}_{2}-$

Scheme 100 Preparing novel $N$-pyrazolylformamidines.

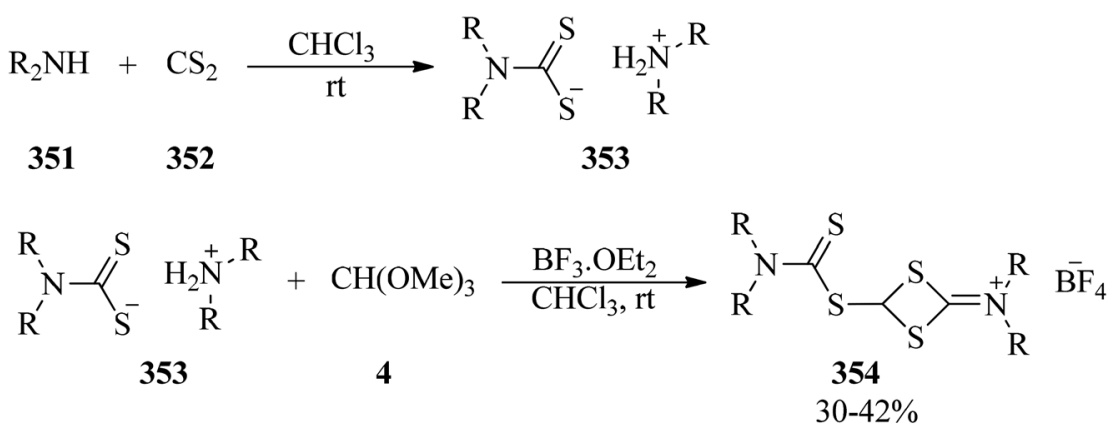

$\mathrm{R}=\mathrm{Et},-\mathrm{CH}_{2}\left(\mathrm{CH}_{2}\right)_{4} \mathrm{CH}_{2}-,-\mathrm{CH}_{2}\left(\mathrm{CH}_{2}\right)_{3} \mathrm{CH}_{2}-$

Scheme 101 Dithiocarbamic acid salt synthetic approach. 


\subsection{Synthesis of ethoxymethylene amino derivatives}

In 2002, 2-(4-fluorophenyl)methylidene-7-(4-fluorophenyl)-2,3dihydro-5-ethoxymethyleneamino-7 $H$-3-oxo-thiazolo[3,2- $a$ pyrimidin-6,8-dicarbonitrile containing an ethoxymethylene amino motif (340 $)^{316-328}$ was synthesized via the condensation of 5-amino-2-(4-fluorophenyl)methylidene-7-aryl-6,8-dicyano-3-oxo2,3-dihydro-7H-thiazolo[3,2-a]pyridine (339) with TEOF (5) in refluxing acetic anhydride $(10 \mathrm{~mL})$ (as catalyst and solvent) (Scheme 97). Pure (340) was obtained from recrystallization from cold water in $78 \%$ yield. Compound (340) exhibited highly antimicrobial activity against Staphylococcus aureus (NCTC-7447). ${ }^{328}$

\subsection{Synthesis of acetamides}

The three-component Ugi reaction of 2-aminophenols (341), cyclohexyl isocyanide (342), and TEOF (5) in equimolar amounts was accomplished using $\mathrm{ZnCl}_{2}(10 \mathrm{~mol} \%)$ in methanol at room temperature to construct $\mathrm{N}$-cyclohexyl-2-(2hydroxyphenylamino)-2-ethoxyacetamides (343) for $12 \mathrm{~h}$ in high yields (80-82\%) (Scheme 98). ${ }^{329}$<smiles>C=C1CCC2[C@@H]3COC(C)(C)O[C@H]3CC[C@]2(C)[C@H]1CC=O</smiles>

355

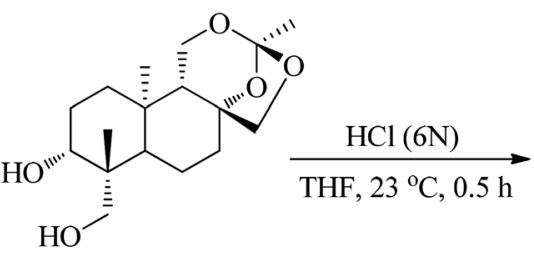

356 $53 \%$<smiles>[R2]C[C@]1(O)CC[C@H]2[C@@](C)(CO)[C@@H](O)CC[C@]2(C)[C@@H]1CO</smiles>

357a: $\mathrm{R}=\mathrm{Ac}, \mathrm{R}_{1}=\mathrm{H}$

357b: $\mathrm{R}=\mathrm{H}, \mathrm{R}_{1}=\mathrm{Ac}$

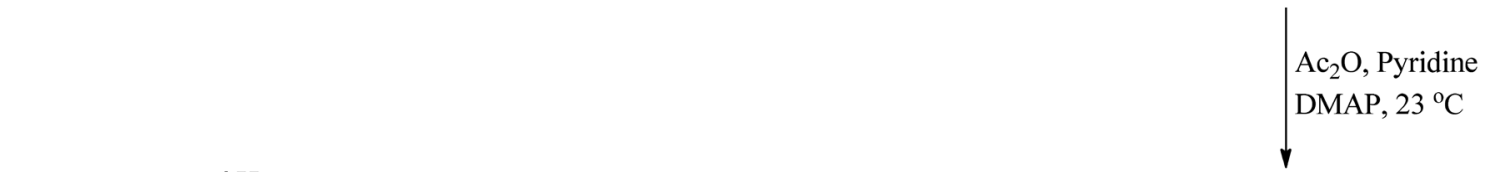<smiles>C[C@]12CC[C@@H](O)[C@@](CO)(C1)[C@@]1(CO)CCC(CO)=C(CO)C1C2</smiles>

1) Burgess reagent (2 equiv.) benzene, $50^{\circ} \mathrm{C}, 1 \mathrm{~h}$

2) $\mathrm{NaOCH}_{3}, \mathrm{CH}_{3} \mathrm{OH}, 23{ }^{\circ} \mathrm{C}, 3 \mathrm{~h}$

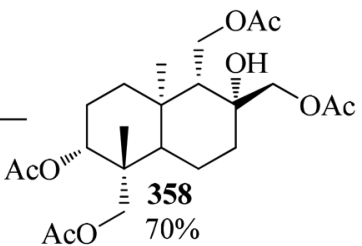
$\mathrm{Ag}_{2} \mathrm{CO}_{3} /$ Celite benzene, reflux, $5 \mathrm{~h}$<smiles>C=C1OC[C@H]2C1=CCC1[C@](C)(C=O)[C@H](O)CC[C@@]12C</smiles><smiles>C[C@@]12C3=C(CCC1[C@]1(C=O)[C@H](O)CC[C@]21C)C(=O)OC3</smiles>

361 362 $86 \%$ $92 \%$ $\mathrm{NaBH}_{4}, \mathrm{CH}_{3} \mathrm{OH}$ $0{ }^{\circ} \mathrm{C}, 10 \mathrm{~min}$<smiles>C[C@]12CC[C@@H](O)[C@@](CO)(C1)C1CC=C3C(=O)OC[C@@H]3[C@]1(C)CC[C@@H]2O</smiles>

Scheme 102 The asymmetric total synthesis of (+)-iresin and (-)-isoiresin. 


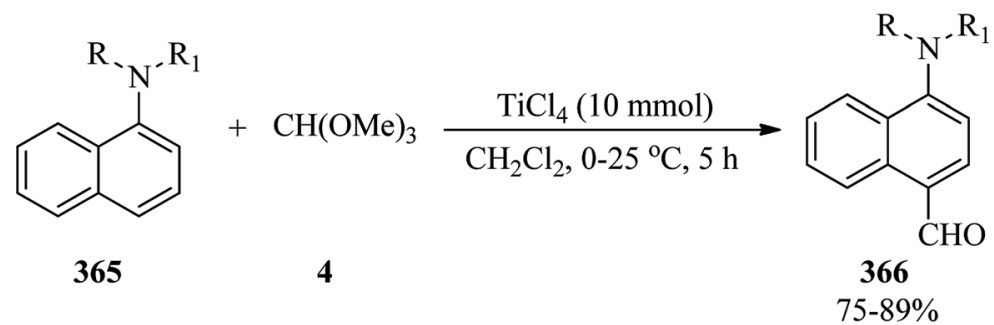

$\mathrm{ArNRR}_{1}: \mathrm{Ar}=\mathrm{Ph}, 1-$ naphthyl, $\mathrm{R}=\mathrm{Me}, \mathrm{Et},-\mathrm{C}_{5} \mathrm{H}_{10^{-}} ; \mathrm{R}_{1}=\mathrm{Me}, \mathrm{Et}, n-\mathrm{Bu},-\mathrm{C}_{5} \mathrm{H}_{10^{-}}$

Scheme 103 The formylation of N,N-dialkylarylamines by TMOF.

\subsection{Synthesis of enamines}

In 2006, Komkov et al. investigated the reaction of cyclohexane1,3-diones $(195,197)$ and orthoesters $(6,7)$ with various amines $(344,346)$. It was found that the one-pot three-component condensation reaction of cyclohexane-1,3-dione (195) and orthoesters with 5-acetyl-4-aminopyrimidines (344) under reflux in $p$-xylene obtained a novel series of 7-(1,3-dioxocyclohex-2ylidene)-7,8-dihydropyrido[2,3- $d]$ pyrimidines (345) in $32-61 \%$ yields in 2.5-5 h, while the condensation of dimedone (197) and orthoesters with $p$-toluidine (346) progressed to generate enamine derivatives $(\mathbf{3 4 7})^{\mathbf{3 3 0 - 3 3 5}}$ under reflux conditions within $8 \mathrm{~h}$ in $44-58 \%$ yields (Scheme 99$){ }^{336}$

\subsection{Synthesis of formamidines}

Lim et al. designed the catalyst-free one-pot three-component condensation reaction of polysubstituted 5-aminopyrazoles (348), TEOF (5), ${ }^{337}$ and cyclic secondary amines (349) ${ }^{338}$ under microwave irradiation $(150 \mathrm{~W})$ at $150{ }^{\circ} \mathrm{C}$ in methanol in order to prepare novel $N$-pyrazolylformamidines (350) in $20 \mathrm{~min}$ in 64$93 \%$ yields (Scheme 100). Some of the synthesized products were found to inhibit interleukin-17 secretion in phenotypic in vitro evaluations. ${ }^{339}$

1,3-Bis-arylcarbamylformamidines were prepared via the reaction of $N$-arylureas with TEOF in boiling acetic anhydride in $85-90 \%$ yields. $^{340}$

\subsection{Synthesis of substituted 2-dialkyliminio-1,3-dithietane tetrafluoroborates}

In 2015, a facile and straightforward methodology was presented for the synthesis of 4 -( $N, N$-dialkyldithiocarbamato)-2dialkyliminio-1,3-dithietane tetrafluoroborates (354) in 30$42 \%$ yields. In this paper, the condensation reaction of secondary aliphatic amines (351) with carbon disulfide (352) in $\mathrm{CHCl}_{3}$ at room temperature first afforded dithiocarbamic acid salt (353) which upon treatment with TMOF (4) using $\mathrm{BF}_{3} \cdot \mathrm{OEt}_{2}$ as catalyst in $\mathrm{CHCl}_{3}$ at room temperature furnished (354) (Scheme 101). This reaction failed with some orthoesters, such as orthovalerate and trimethyl orthobenzoate. $^{341}$

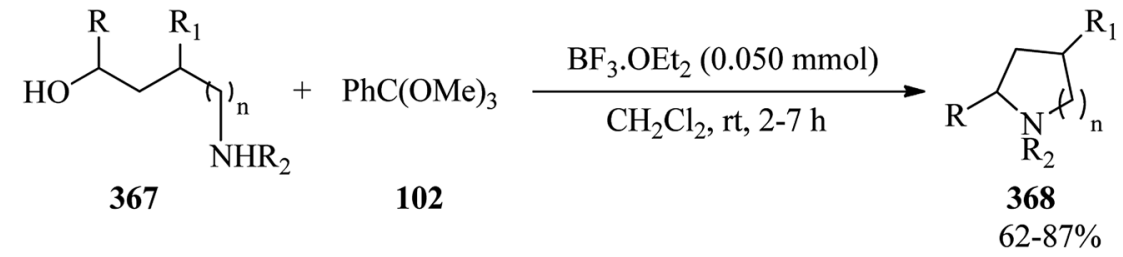

or

or<smiles>[R1]NCCC[C@@H](O)C([R3])O</smiles><smiles>[R16]C([R16])C1CCCN1[R16]</smiles>

370

$\mathrm{n}=1,2$

$\mathrm{R}=\mathrm{CH}_{2} \mathrm{Br}, \mathrm{CH}_{2} \mathrm{OTs},-\mathrm{CH}_{2}\left(\mathrm{CH}_{2}\right)_{3} \mathrm{CH}_{2}-$

$\mathrm{R}_{1}=\mathrm{H}, \mathrm{Ph}$

$\mathrm{R}_{2}=$ Boc, Fmoc, $\mathrm{Cbz}$

$\mathrm{R}_{3}=\mathrm{H}, \mathrm{C}_{5} \mathrm{H}_{11}$

Scheme 104 The synthesis of pyrrolidines and piperidines. 


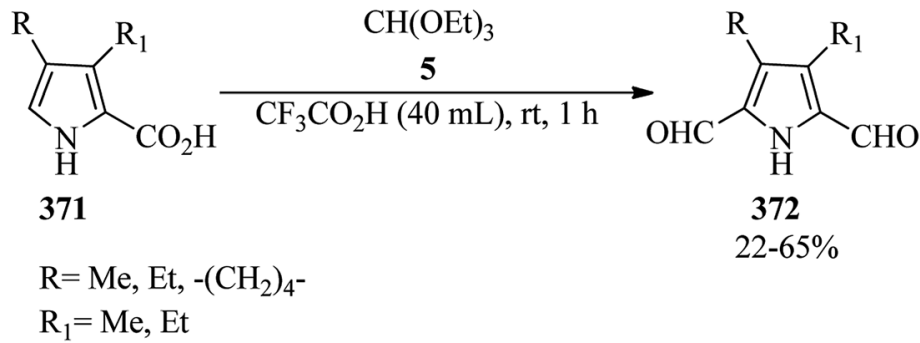

Scheme 105 The preparation of disubstituted pyrrole-2,5-dicarbaldehydes.

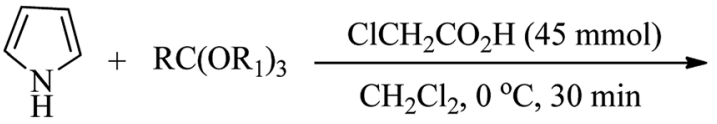

373

$5,7,62,102$

$\mathrm{R}=\mathrm{H}, \mathrm{Me}, \mathrm{Et}, \mathrm{Ph}$

$\mathrm{R}_{1}=\mathrm{Me}, \mathrm{Et}$<smiles>[R]C(c1ccc[nH]1)(c1ccc[nH]1)c1ccc[nH]1</smiles>

374

$34-38 \%$

Scheme 106 Synthetic procedure for tri-(pyrrol-2-yl)alkanes.

\subsection{Synthesis of lactones}

In 2015, Wang and co-workers described the asymmetric total synthesis of (+)-isoiresin (363) and (-)-isoiresin (364) from $(3 S, 5 a R, 7 a S, 8 R, 9 R, 11 a R, 11 b R)$-8-(hydroxymethyl)-3,8,11 $a$-trimethyldecahydro- $1 H$-3,5a-epoxynaphtho[1,2-e][1,3]dioxepin-9-ol (356) derived from readily available aldehyde (355). This transformation occurred via acidic hydrolysis $(\mathrm{HCl}, 6 \mathrm{~N})$ of the orthoester (356) in THF at $23{ }^{\circ} \mathrm{C}$ for $30 \mathrm{~min}$ to form a mixture of monoacetate compounds (357a and 357b) which underwent acetylation to produce the tetrakis-acetate (358). Subsequent regioselective dehydration of (358) by various dehydrating agents and then deacetylation resulted in (359) and (360) in different molar ratios, which upon the regioselective oxidative lactonization reaction using Fétizon reagent obtained (361 and 362). Finally, the reduction of the aldehyde functional group by $\mathrm{NaBH}_{4}$ at $0 \quad{ }^{\circ} \mathrm{C}$ in methanol yielded (363) and (364) (Scheme 102). ${ }^{342}$

\subsection{Synthesis of aminomethylene bisphosphonates}

In 2012, Reddy et al. presented an effective, rapid and green method for the synthesis of aminomethylene bisphosphonates via the one-pot three-component reaction of amines, diethyl phosphite and TEOF in a $1: 2: 1$ molar ratio using $\mathrm{Yb}(\mathrm{PFO})_{3}$ $(10 \mathrm{~mol} \%)$ in the presence of ionic liquid [bmim] [Cl] at $100{ }^{\circ} \mathrm{C}$ for $15-25 \mathrm{~min}$ in good to excellent yields (70-93\%). ${ }^{343}$

\subsection{Synthesis of 4-dialkylarylamino-1- naphthaldehyderivatives}

The reaction of $N, N$-dialkylarylamines (365) with TMOF (4) was accomplished using $\mathrm{TiCl}_{4}(10 \mathrm{mmol})$ in $\mathrm{CH}_{2} \mathrm{Cl}_{2}$ at $0-25{ }^{\circ} \mathrm{C}$ to obtain the corresponding formyl derivatives (366) in $75-89 \%$ yields (Scheme 103). ${ }^{344}$

\subsection{Synthesis of pyrrolidines and piperidines}

Boron trifluoride diethyl etherate $\left(\mathrm{BF}_{3} \cdot \mathrm{OEt}_{2}, 0.050 \mathrm{mmol}\right)$ catalyzed the cyclodehydration of $\mathrm{N}$-carbamate-protected amino<smiles>COc1cccc2[nH]ccc12</smiles>

Catalyst: $\mathrm{CCl}_{3} \mathrm{CO}_{2} \mathrm{H}(0.31 \mathrm{mmol}), \mathrm{HBF}_{4} \cdot \mathrm{OEt}_{2}(0.5 \mathrm{mmol})$

Scheme 107 The synthesis of bis(indolyl)methane salts. 


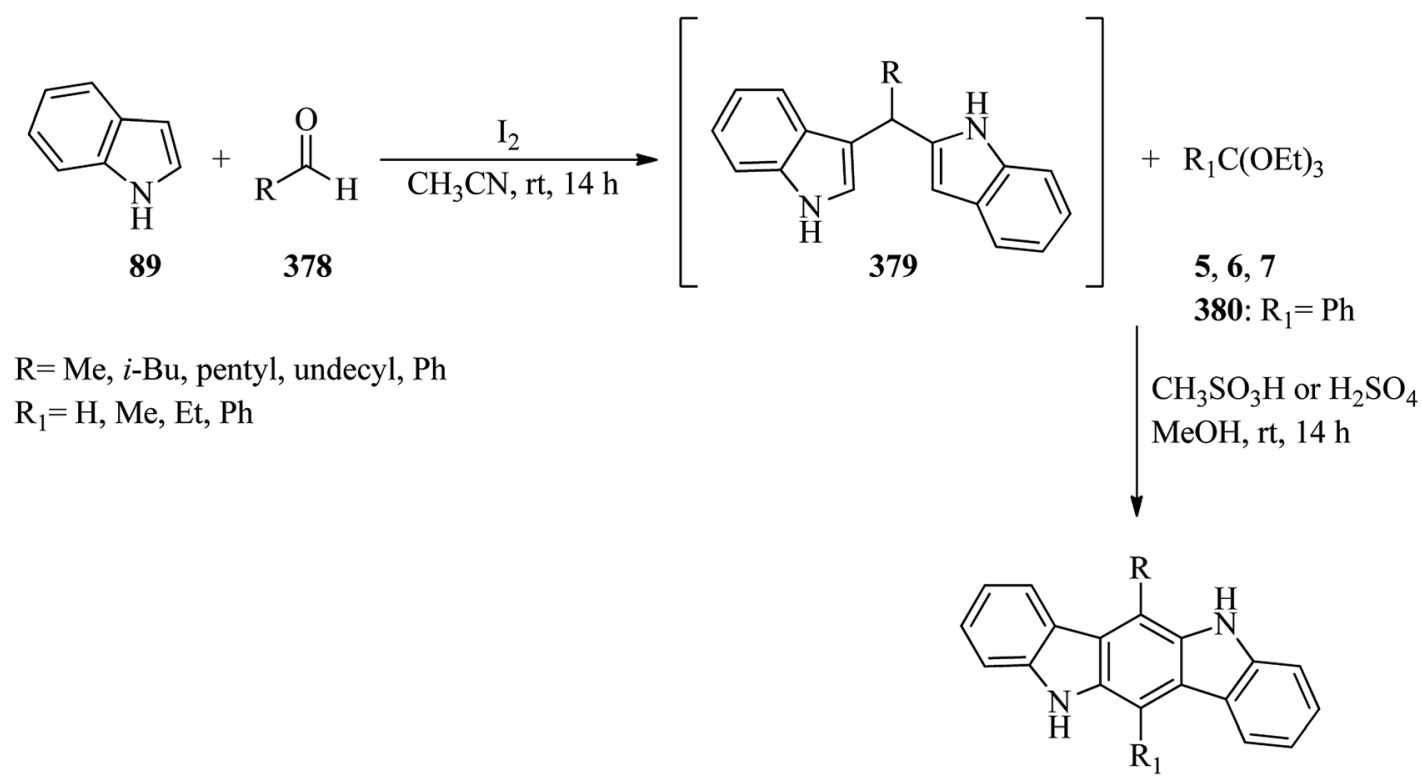

381

Scheme 108 The synthesis of substituted dihydroindolo[3,2-b]carbazoles.

alcohols (367) with trimethyl orthobenzoate (102) in $\mathrm{CH}_{2} \mathrm{Cl}_{2}$ at room temperature to get azaheterocycles such as pyrrolidines and piperidines within 2-7 h, in high yields (62-87\%) (368). Replacing (367) with $N$-carbamate-protected amino vicinal diols (369) in refluxing $\mathrm{CH}_{2} \mathrm{Cl}_{2}$ yielded regio- and stereoselective prolinol derivatives (370) in excellent yields (87-94\%) (Scheme 104). ${ }^{345}$

\subsection{Synthesis of pyrrole derivatives}

In 1998, Tardieux and co-workers presented a simple and mild one-step route for the synthesis of 3,4-disubstituted pyrrole-2,5dicarbaldehydes (372) via the diformylation ${ }^{346,347}$ reaction of $\beta$ substituted pyrrole-2-carboxylic acids (371) with TEOF (5) in trifluoroacetic acid, in a dual role of catalyst and solvent, at room temperature for $1 \mathrm{~h}$ in $22-65 \%$ yields (Scheme 105). ${ }^{347}$

Tri-(pyrrol-2-yl)alkanes (374) could be synthesized via the reaction of pyrrole $(373)$ with orthoesters $(5,7,62,102)$ using chloroacetic acid ( $45 \mathrm{mmol}$ ) in $\mathrm{CH}_{2} \mathrm{Cl}_{2}$ at $0{ }^{\circ} \mathrm{C}$ within $30 \mathrm{~min}$, in $34-38 \%$ yields (Scheme 106). 5-Phenyl-4,6-dipyrrin has also been prepared in comparatively good yield (51\%) through the reaction of pyrrole with trimethyl orthobenzoate by dichloroacetic acid (38 mmol) under similar conditions. ${ }^{348}$

\subsection{Synthesis of indole derivatives}

In 1990, indole-3-carbaldehyde (376) as pale yellow crystals was synthesized upon treatment of 4-methoxyindole (375) with TEOF (5) using trichloroacetic acid in $\mathrm{CH}_{2} \mathrm{Cl}_{2}$ at room temperature within $20 \mathrm{~min}$ in $36 \%$ yield. On the other hand, bis-benzoannellated pentamethine cyanines such as bis(4-methoxyindol3-yl)methyliumtrichloroacetate (377a) and bis(4-methoxyindol3-yl)methyliumtetrafluoroborate $(\mathbf{3 7 7 b})$ were also synthesized in 51 and $76 \%$ yields under similar conditions using trichloroacetic acid and tetrafluoroboric acid diethyl ether $\left(\mathrm{HBF}_{4} \cdot \mathrm{OEt}_{2}\right)$, respectively (Scheme 107). ${ }^{349}$

In 2012, Khaksar and co-workers prepared symmetrical tri$\mathrm{s}$ (indolyl)methanes ${ }^{\mathbf{3 4 9 , 3 5 0}}$ via a catalyst-free reaction of indoles with orthoesters in the presence of hexafluoro-2-propanol

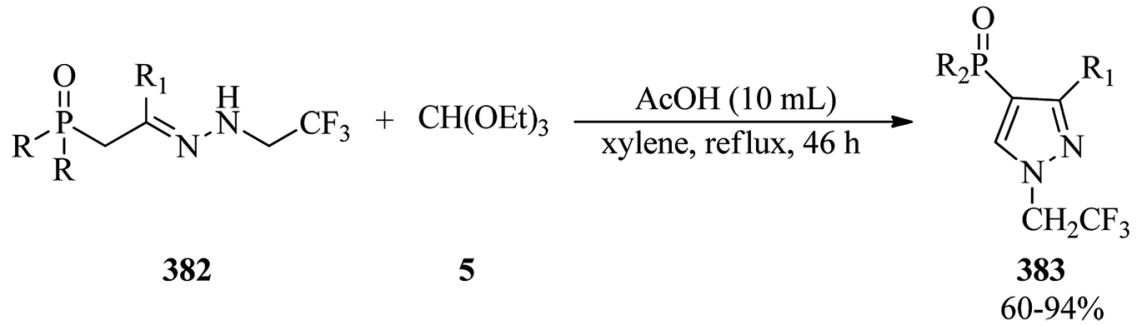

$$
\begin{aligned}
& \mathrm{R}=\mathrm{Ph},-\mathrm{OCH}_{2} \mathrm{C}(\mathrm{Me})_{2} \mathrm{CH}_{2} \mathrm{O}-,-\mathrm{OCH}_{2} \mathrm{C}(\mathrm{Me})(\mathrm{n}-\mathrm{Pr}) \mathrm{CH}_{2} \mathrm{O}- \\
& \mathrm{R}_{1}=\mathrm{Me}, i-\mathrm{Pr}, \mathrm{Ph}
\end{aligned}
$$

Scheme 109 The formation of novel 1-fluorinated-4-phosphopyrazoles. 


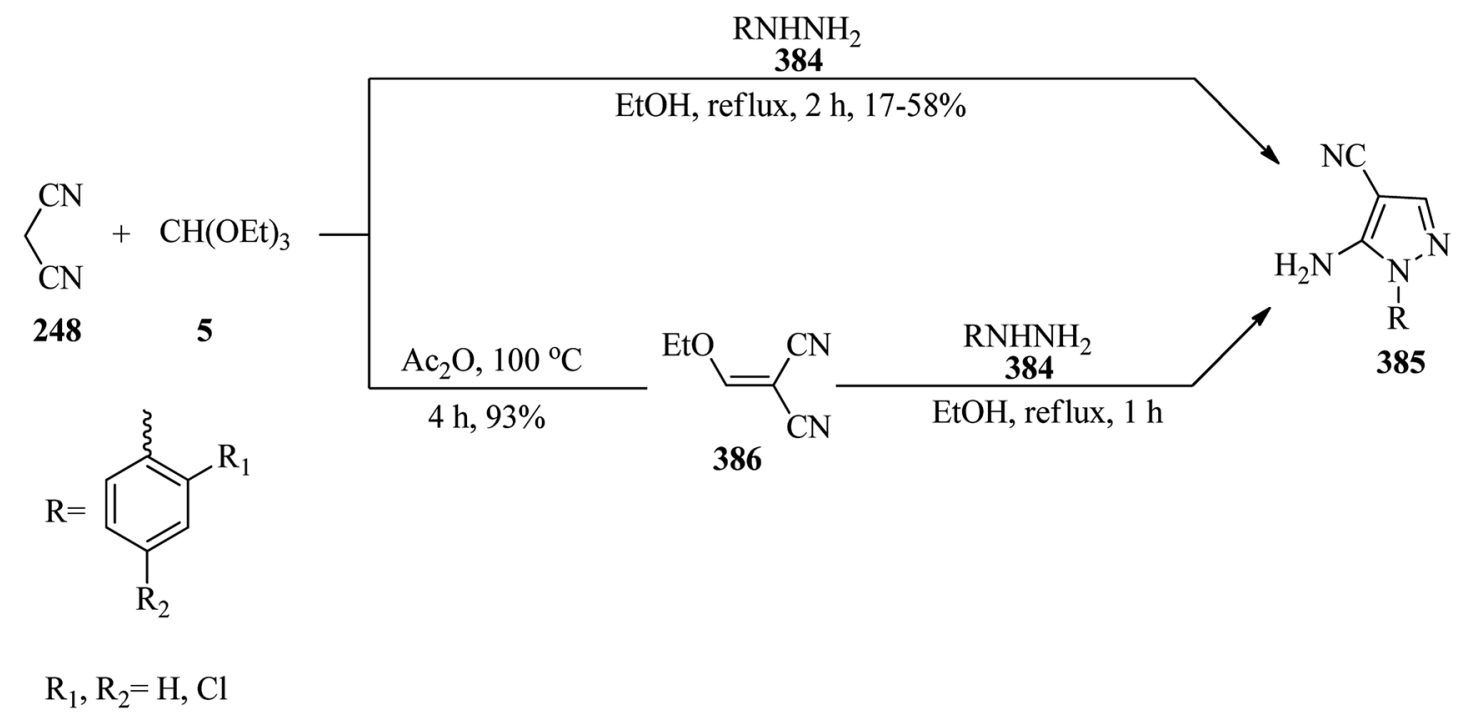

Scheme 110 The formation of substituted 5-aminopyrazole-4-carbonitriles.

(HFIP) at room temperature within 15-60 min in excellent yields $(88-98 \%){ }^{350}$

6-Monosubstituted and 6,12-disubstituted 5,11-dihydroindolo[3,2- $b]$ carbazoles (381) were synthesized in $20-50 \%$ yields via the one-pot three-stage condensation reaction of indole (89) and aldehydes (378) using a catalytic amount of iodine; which underwent an acid-mediated intramolecular ringclosure reaction by orthoesters $(5,6,7,380)$ in methanol at room temperature for $14 \mathrm{~h}$ (Scheme 108). ${ }^{351}$

\subsection{Synthesis of pyrazole derivatives}

In 2003, Hassen et al. described that $N-\left(2^{\prime}, 2^{\prime}, 2^{\prime}\right.$-trifluoroethyl $)$ phosphonyl $\beta$-hydrazones (382) on cyclization with TEOF (5) in the presence of acetic acid in refluxing xylene resulted in novel 1-fluorinated-4-phosphopyrazoles (383) in $46 \mathrm{~h}$, in moderate to excellent yields (60-94\%) (Scheme 109). ${ }^{352}$

1-Substituted 5-aminopyrazole-4-carbonitriles (385) could be prepared via two pathways: (a) The products were produced through the one-pot three-component reaction of 1-substituted hydrazines (384), malononitrile (248), and TEOF (5), in refluxing ethanol within $2 \mathrm{~h}$ in low to moderate yields (17-58\%). (b) The reaction of malononitrile (248) with TEOF (5) in acetic anhydride at $100{ }^{\circ} \mathrm{C}$ which got ethoxymethylenemalononitrile (386) in $93 \%$ yield within $4 \mathrm{~h}$. After completion of the reaction, 1substituted hydrazines (384) were added under similar conditions to afford the desired product (385) in $42-78 \%$ within $1 \mathrm{~h}$ (Scheme 110). ${ }^{353}$

In 2002, an effective, useful, and versatile synthetic approach was introduced for the regiospecific synthesis of 3,4-fusedcycloalkyl-1-arylpyrazoles (395) in 48-64\% yields via two pathways $\mathrm{A}$ and $\mathrm{B}$. In pathway $\mathrm{A}, \mathrm{BF}_{3}$-progressed alkylation of symmetric ketones (387) with TMOF (4) in dichloromethane by Hunig's base formed an $\alpha$-(dimethoxymethyl)ketone intermediate (388), and after isolation, the cyclocondensation of intermediate (388) with arylhydrazine (389) under acidic conditions in refluxing benzene produced product (390) (Scheme 111). In pathway $\mathbf{B}$, the kinetic enolates were first regiospecifically

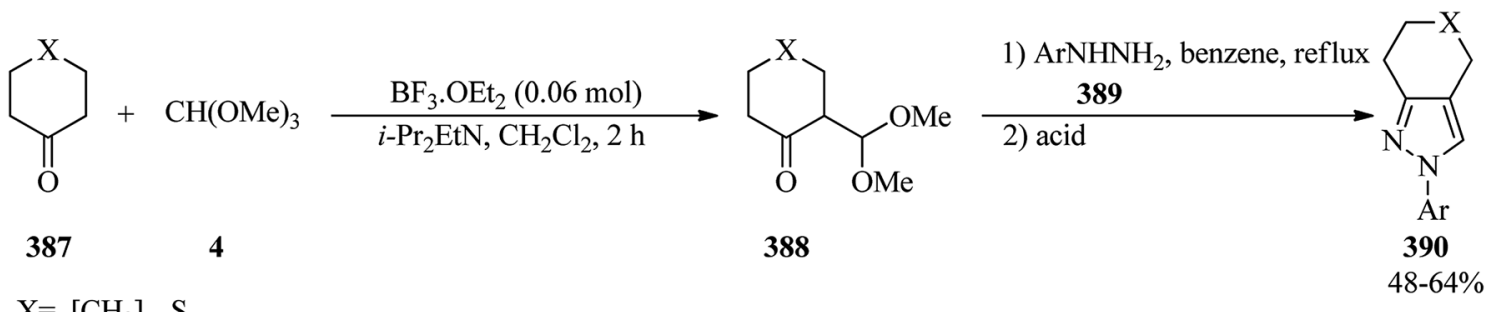

$\mathrm{X}=\left[\mathrm{CH}_{2}\right]_{\mathrm{n}}, \mathrm{S}$

$\mathrm{n}=0-2$<smiles>FC(F)(F)c1cc(Cl)c(N=[W])c(Cl)c1</smiles>

Scheme 111 The regiospecific synthesis of 3,4-fused-cycloalkyl-1-arylpyrazoles (method A). 
<smiles>[X]C1C=CC(=O)CC1[R16]</smiles><smiles>[X]CC(=O)C(C([R])OC)C(OC)OC</smiles>

39

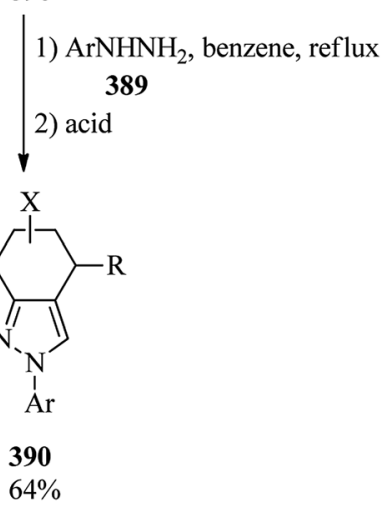

Scheme 112 The regiospecific synthesis of 3,4-fused-cycloalkyl-1-arylpyrazoles (method B).

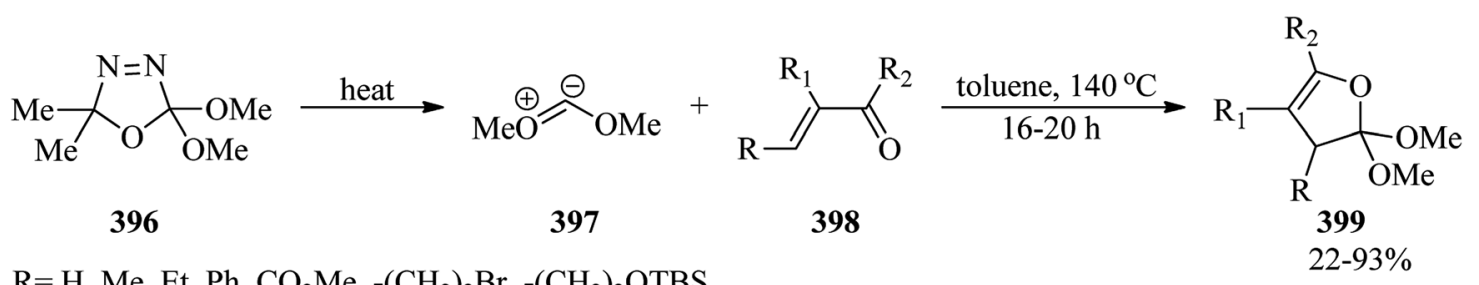

$\mathrm{R}=\mathrm{H}, \mathrm{Me}, \mathrm{Et}, \mathrm{Ph}, \mathrm{CO}_{2} \mathrm{Me},-\left(\mathrm{CH}_{2}\right)_{3} \mathrm{Br},-\left(\mathrm{CH}_{2}\right)_{3} \mathrm{OTBS}$

$\mathrm{R}_{1}=\mathrm{H}, \mathrm{Me}, n-\mathrm{Bu}$

$\mathrm{R}_{2}=\mathrm{H}, \mathrm{Me}, \mathrm{Ph}$

$\mathrm{R}, \mathrm{R}_{1}=-\mathrm{CH}_{2}\left(\mathrm{CH}_{2}\right)_{2} \mathrm{CH}_{2}-$

$\mathrm{R}_{1}, \mathrm{R}_{2}=-\mathrm{CH}_{2}\left(\mathrm{CH}_{2}\right)_{2} \mathrm{CH}_{2}-$

Scheme 113 Synthesizing $\mathrm{O}$-heterocycles containing methoxyfurans, furanones, and furans.

obtained via the condensation of $\alpha, \beta$-unsaturated cycloalkanones (391) with organolithium/Grignard reagents (392) by a copper(I) bromide dimethyl sulfide complex $\left(\mathrm{CuBr} \cdot \mathrm{Me}_{2} \mathrm{~S}\right)$ which was followed by trapping of the above-mentioned enolate utilizing chlorotrimethylsilane (393) as silyl enol-ethers (394). Then, the reaction of the crude enol-ethers (394) with TMOF (4) utilizing catalytic amounts of iodotrimethylsilane (TMSI) in $\mathrm{CH}_{2} \mathrm{Cl}_{2}$ at $-78{ }^{\circ} \mathrm{C}$ for $1 \mathrm{~h}$ achieved intermediate (395) regiospecifically, which on cyclocondensation with arylhydrazine (389) resulted in the product (390) (Scheme 112). ${ }^{354}$

\subsection{Synthesis of methoxyfurans, furanones, and furans}

In 2018, Croisetière and Spino devised a rapid and effective sequence of reactions to synthesize O-heterocycles, containing methoxyfurans, furanones, and furans. Initially, the $[4+1]$ -

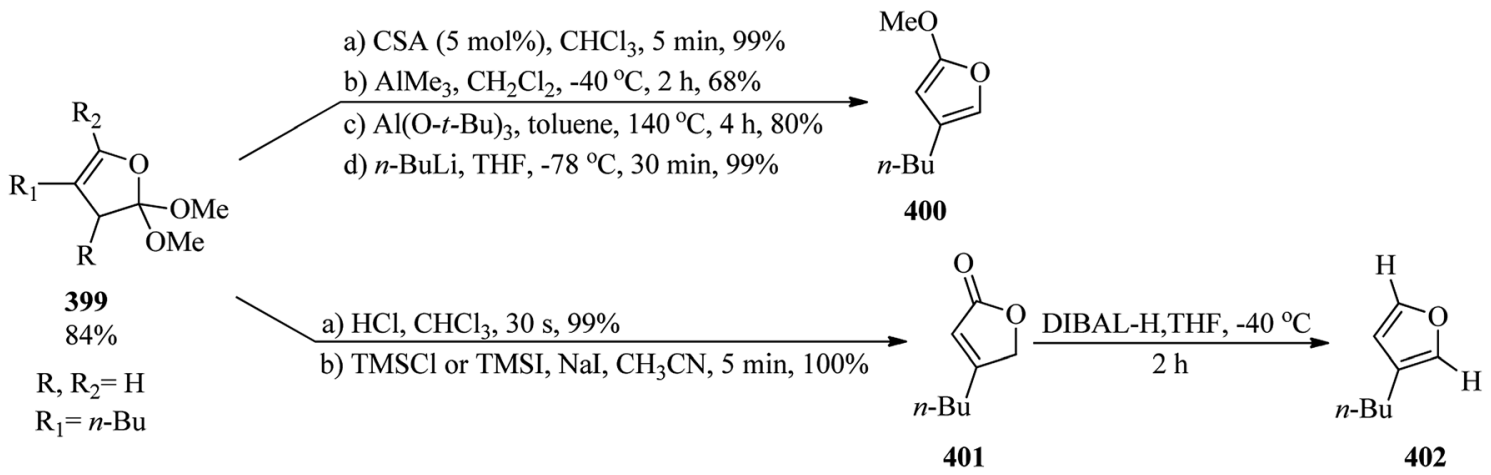

Scheme 114 The synthesis of some novel methoxyfurans and furans. 
<smiles>[R]OC(=O)CC(=O)CC([R])O</smiles>

403<smiles>[R]C(C)=O</smiles>

62,323

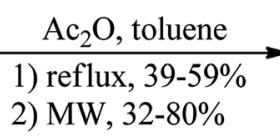

2) $\mathrm{MW}, 32-80 \%$<smiles>[R20]C(=O)C1=C([R2])OC([R])CC1=O</smiles>

$$
\begin{aligned}
& \mathrm{R}=\mathrm{Me}, i-\mathrm{Pr} \\
& \mathrm{R}_{1}=\mathrm{Pr}, i-\mathrm{Pr}, \mathrm{Ph}, \mathrm{CH}_{2} \mathrm{OBn}, \text { cyclohexyl, 2-furyl } \\
& \mathrm{R}_{2}=\mathrm{Me}, \mathrm{Bu}
\end{aligned}
$$

Scheme 115 The synthesis of highly functionalized dihydropyran-4-ones.

annulation reaction of dimethoxycarbene (397), ${ }^{355}$ arising from Warkentin's oxadiazoline (396), with readily available $\alpha, \beta$ unsaturated carbonyls (398) gave cyclic orthoesters (399) (Scheme 113), which were applied as key precursors for the synthesis of methoxyfurans (400), furanones (401), and furans (402). The synthetic methoxyfurans in this report were classified in four parts: first, by a catalytic amount of camphorsulfonic acid in $\mathrm{CHCl}_{3}$; secondly, trimethylaluminum in $\mathrm{CH}_{2} \mathrm{Cl}_{2}$ at $-40{ }^{\circ} \mathrm{C}$; third, using a weaker Lewis acid aluminum tris(tertbutoxide) in toluene at $140{ }^{\circ} \mathrm{C}$; finally, in the presence of $n$-BuLi in THF at $-78{ }^{\circ} \mathrm{C}$. Furanone (401) could be prepared from the acid hydrolysis of orthoester by concentrated $\mathrm{HCl}$ in $\mathrm{CHCl}_{3}$ (method A). Also, utilizing a mild Lewis acid such as TMSCl/ TMSI in the presence of NaI iodide in $\mathrm{CH}_{3} \mathrm{CN}$ furnished furanones (method B). Furan (402) was achieved from the reduction of the resultant furanone by DIBAL-H at $-40{ }^{\circ} \mathrm{C}$ in $\mathrm{THF}^{356}$ (Scheme 114). ${ }^{357}$

\subsection{Synthesis of dihydropyran-4-ones}

In 2015, Clarke et al. utilized a novel modification MaitlandJapp cyclization reaction for the synthesis of highly functionalized dihydropyran-4-ones (404) via the reaction of $\delta$-hydroxy- $\beta$ ketoesters $(403)$ with two easily available orthoesters $(62,323)$ in the presence of acetic anhydride as a dehydrating agent in dry toluene under heating conditions through refluxing and microwave irradiation. It was found that replacing conventional heating with microwave irradiation reduced the large excess amount of orthoesters from 10 equivalents to only 2 equivalents and also the reaction progressed in a few minutes (Scheme 115). ${ }^{358}$

\subsection{Synthesis of pyrano $[2,3-c]$ pyrazoles}

3-Substituted pyrazolin-5-ones (405) were condensed with TEOF (5) in refluxing acetic anhydride to give the intermediate (406) which was then cyclized via Michael addition with hippuric

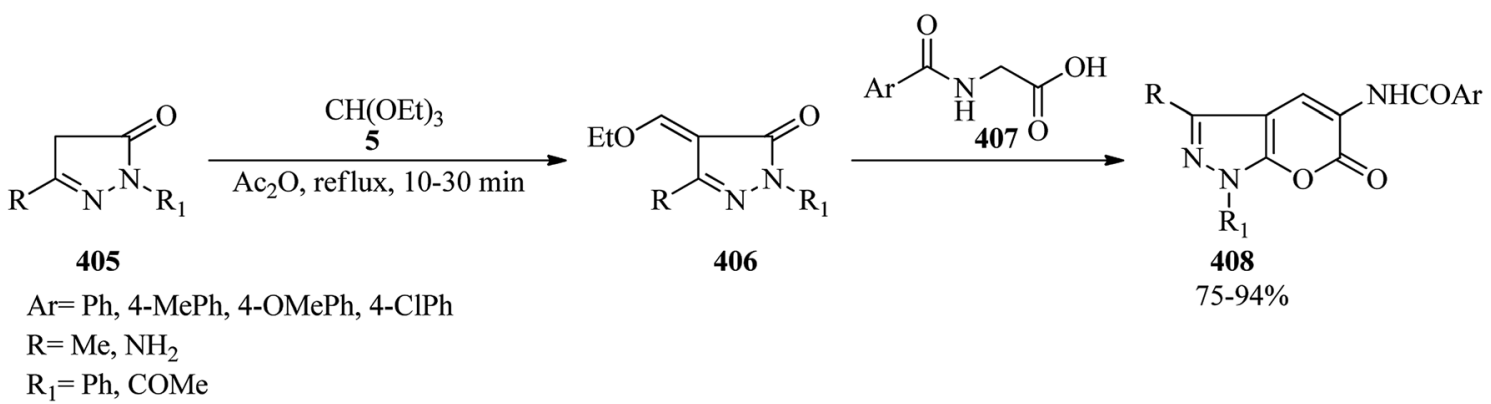

Scheme 116 Pyrano[2,3-c]pyrazoles achievement route.

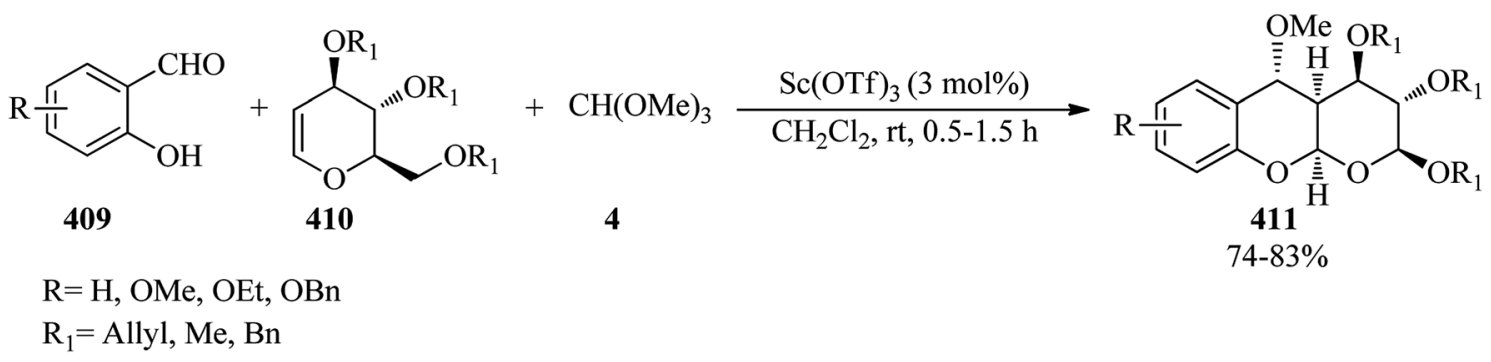

Scheme 117 The formation of cis-fused pyranobenzopyrans. 
<smiles>[R]c1c([R])c([R])c(C=O)c(O)c1[R]</smiles>

$\mathrm{R}, \mathrm{R}_{1}, \mathrm{R}_{3}=\mathrm{H}, \mathrm{OH}, \mathrm{Me}, \mathrm{OMe}$

$\mathrm{R}_{2}=\mathrm{H}, \mathrm{OH}, \mathrm{OMe}, \mathrm{Br}, \mathrm{NO}_{2}$

$\mathrm{R}_{2}, \mathrm{R}_{3}=-\mathrm{CH}=\mathrm{CHCH}=\mathrm{CH}-$

Scheme 118 The stereoselective synthesis of trans-tetrahydropyrano[3,2-c]benzopyrans.

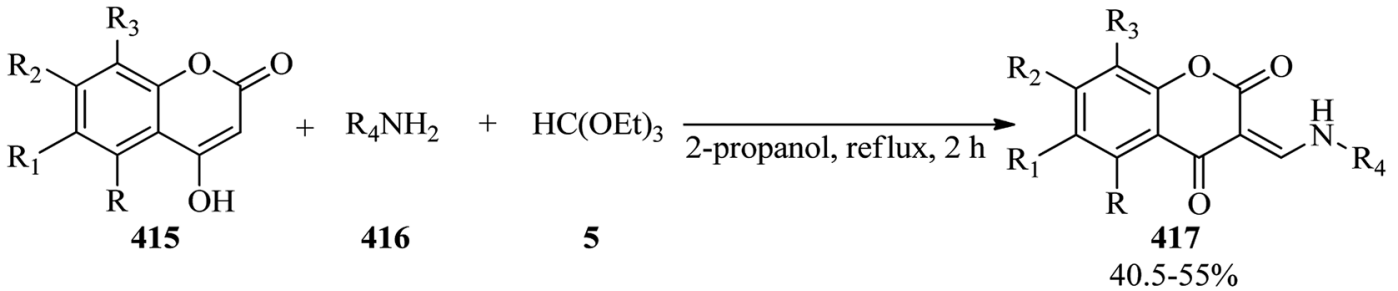

$\mathrm{R}, \mathrm{R}_{1}, \mathrm{R}_{3}=\mathrm{H}, \mathrm{Me}$

$\mathrm{R}_{2}=\mathrm{H}, \mathrm{Me}, \mathrm{OH}$

$\mathrm{R}_{4}=-\mathrm{CH}_{2} \mathrm{CO}_{2} \mathrm{H},-\mathrm{CHMeCO}_{2} \mathrm{H},-\mathrm{CHPhCO}_{2} \mathrm{H}$

Scheme 119 The synthesis of 2-[(substituted-2,4-dioxochromane-3-ylidene)methyl]amino acetic acids.

acids (407) together with ethanol elimination and acetylation of the ring nitrogen to achieve pyrano[2,3-c]pyrazoles (408) for 10$30 \mathrm{~min}$ in good to excellent yields (75-94\%) (Scheme 116). ${ }^{359}$

\subsection{Synthesis of chromane derivatives}

Scandium triflate $\left[\mathrm{Sc}(\mathrm{OTf})_{3}, 3 \mathrm{~mol} \%\right]$ catalyzed the diastereoselective reaction of $o$-hydroxybenzaldehydes (409), glycals (410), and TMOF (4) in dichloromethane at room temperature to furnish $c i s$-fused pyranobenzopyrans (411) within $0.5-1.5 \mathrm{~h}$ in good yields $(74-83 \%)$ with high diastereoselectivity (Scheme 117). ${ }^{360}$ This transformation was also accomplished with various other alkenes, such as indene, styrene and allyltrimethylsilane under similar conditions to give substituted benzopyrans within $2-6 \mathrm{~h}$ in $78-90 \%$ yields with high selectivity. ${ }^{361}$

In 1999, Miyazaki et al. reported a novel, effective, and stereoselective procedure for the synthesis of trans-tetrahydropyrano[3,2-c] benzopyrans (414) in $8-96 \%$ yields in $1-24 \mathrm{~h}$ via the one-pot three-component reaction of $o$-hydroxybenzaldehydes (412), TMOF (4), and unsaturated alcohols (413) utilizing a catalytic amount of $p$-TSA $(0.2 \mathrm{mmol})$ in benzene at room temperature (Scheme 118). ${ }^{362}$

In 2003, the one-pot three-component reaction of 4-hydroxy coumarins (415), ${ }^{363,364}$ carbamates (416), and TEOF (5) was presented for the synthesis of 2-[(substituted 2,4dioxochromane-3-ylidene)methyl]amino acetic acids $(\mathbf{4 1 7})^{365}$ in refluxing 2-propanol within $2 \mathrm{~h}$ in moderate yields (40.5-55\%) (Scheme 119). All the products were screened for their biological activity but only a few molecules were active against $B$. subtilis, $S$. aureus, E. coli and $P$. aeruginosa at minimum inhibitory concentrations (MIC) of $100,300,500 \mu \mathrm{g} \mathrm{mL} \mathrm{m}^{-1}$ compared to streptomycin (CAS 57-92-1) and kanamycin (CAS 59-01-8). ${ }^{366}$

$\operatorname{Pd}(\mathrm{II})$ catalyzed the one-pot cascade three-component coupling reaction of $o$-hydroxybenzaldehydes (418), 4-pentyn-1ols $(419)$, and orthoesters $(4,5)$ in $\mathrm{CH}_{3} \mathrm{CN}$ at $-30{ }^{\circ} \mathrm{C}$ to room temperature achieved a direct diastereoselective synthetic method for chromane spiroacetals $(\mathbf{4 2 0}){ }^{367-369}$ It was found that replacing 4-pentyn-1-ols (419) with the $5 \alpha$ - and $5 \beta$-epimers of 4,5 secocholestan-5-ol (421a, b) yielded the corresponding steroid chroman spiroketals (422a, b and 423a, b) (Scheme 120). ${ }^{368}$

\subsection{Synthesis of chromene derivatives}

Various 2,2-dimethyl-2H-chromenes $\quad(\mathbf{4 2 6})^{370-374}$ could be prepared in $42-67 \%$ yields through a two-step $\mathrm{Yb}(\mathrm{OTf})_{3}$-catalyzed reaction of $o$-hydroxybenzaldehydes (424), TMOF (4), and 2-methylpropene (425) in $\mathrm{CH}_{2} \mathrm{Cl}_{2}$ at room temperature for $60 \mathrm{~h}$, which was followed by refluxing toluene in the presence of a catalytic amount of $p$-TSA $(0.03 \mathrm{~g})$ for $1 \mathrm{~h}$ to eliminate the methanol from the reaction mixture (Scheme 121). Notably, the reaction failed with salicylaldehydes containing methoxy substituents at the 2- and 4-positions. On the other hand, aldehydes including hydroxyl functional groups at the 3- and 5positions could not be fully isolated because other unidentified compounds were formed with similar polarity that prevented a complete purification. ${ }^{374}$

\subsection{Synthesis of coumarin derivatives}

The synthesis of substituted 3-benzoylamino-5-oxo-5,6,7,8tetrahydrocoumarins (427) from 1,3-cyclohexanediones (195, 


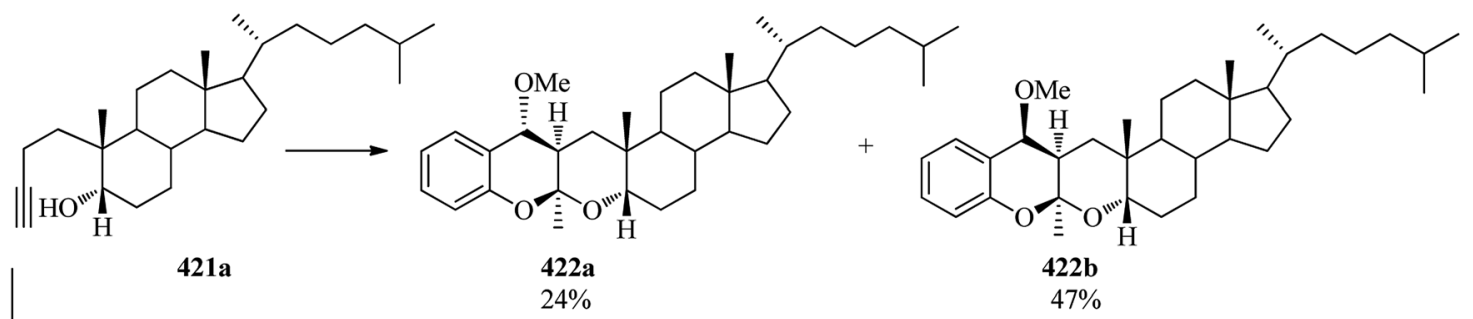

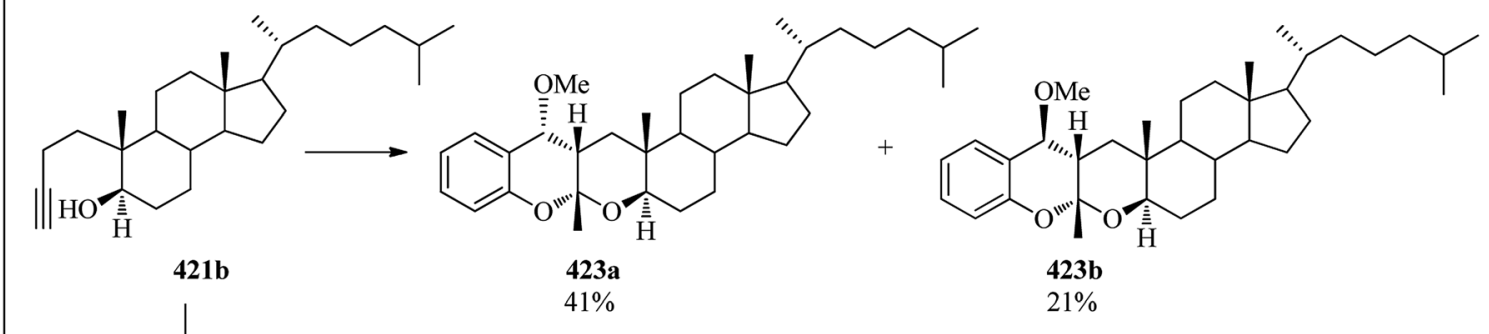<smiles>CC(C)C</smiles>

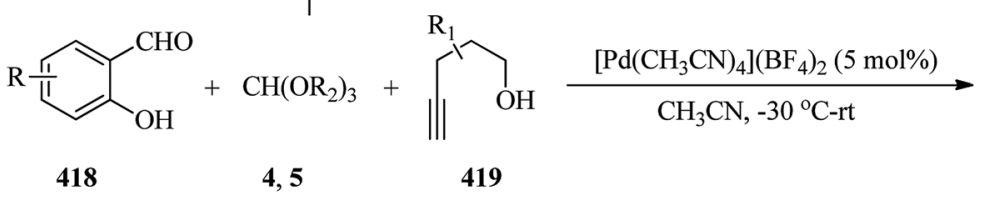

$( \pm)$<smiles>[R20]OC1C[C@@]2(CC([R])CO2)Oc2ccc([R])cc21</smiles>

$\mathrm{R}=\mathrm{H}, \mathrm{OMe}, \mathrm{F}, \mathrm{Br}$

$\mathrm{R}_{1}=\mathrm{Ph}, \mathrm{CH}_{2} \mathrm{Ph}$, cycloalkyl

$\mathrm{R}_{2}=\mathrm{Me}, \mathrm{Et}$

Scheme 120 A synthetic method for chromane spiroacetals.

197), hippuric acid (407), and TEOF (5) (or other one-carbon synthetic equivalents, such as diethoxymethyl acetate or $\mathrm{N}, \mathrm{N}$ dimethylformamide dimethyl acetal) in acetic anhydride has been described (Scheme 122). ${ }^{375}$

In 2003， 8-amino-7-(p-bromophenyl)-10-hydroxypyridino $\left[3^{\prime}, 2^{\prime}-6,5\right] 4 H$-pyrano[3,2-c] $\left.] 1\right]$ benzopyran-6-one (429) was prepared via the cyclocondensation of 2-amino-4-(4'-bromophenyl)-3-cyano-4H,5H-pyrano[3,2-c][1] benzopyran-5-one (428) with TEOF (5) in refluxing acetic anhydride within $2 \mathrm{~h}$ in 55\% yield (Scheme 123). The resultant product exhibited antibacterial and antifungal activities. ${ }^{376}$
In 2000 , the El-Agrody group synthesized 14-methyl-13,14H[1] benzopyrano $\left[3^{\prime}, 4^{\prime}: 5,6\right]-$ pyrano[3,2-e][1,2,4]triazolo[1,5-c]pyrimidine-13-one as colorless crystals in $87 \%$ yield via the ringclosure reaction of 9-amino-8,9-dihydro-8-imino-7-methyl$6 H, 7 H$-[1] benzopyrano[ $\left[3^{\prime}, 4^{\prime}: 5,6\right]$-pyrano[2,3- $\left.d\right]$-pyrimidine-6-one with TEOF in refluxing benzene within $3 \mathrm{~h} .{ }^{377}$ In 2001, they also reported the preparation of antibacterial and antifungal active 11-bromo-14-( $p$-methoxyphenyl)-14H-naphtho[1 $\left.1^{\prime}, 2^{\prime}: 5,6\right]$ pyrano $[3,2-e][1,2,4]$ triazolo[2,3-c] pyrimidine through the cyclocondensation of 10-amino-3 -bromo-12-(p-methoxyphenyl)-11imino-10,11-dihydro-12H-naphtho[ $\left[1^{\prime}, 2^{\prime}: 5,6\right]$-pyrano[2,3-d]

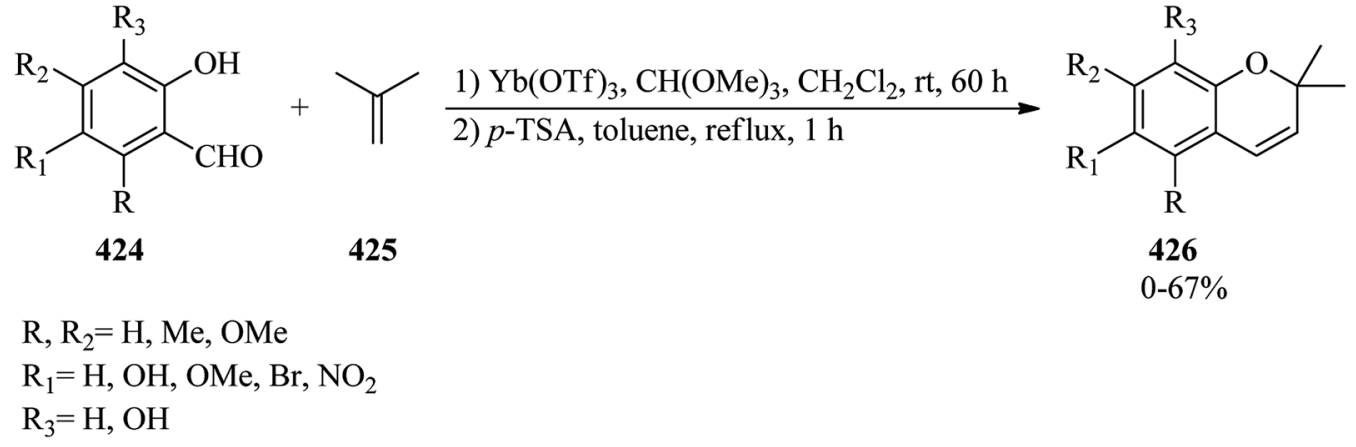

Scheme 121 A synthetic approach to various 2,2-dimethyl-2H-chromenes. 
<smiles>[R]C1([R])CC(=O)CC(=O)C1</smiles>

195,197<smiles>O=C(O)CNC(=O)c1ccccc1</smiles>

407<smiles>[R]C1([R])CC(=O)c2cc(NC(=O)Oc3ccccc3)c(=O)oc2C1</smiles>

5

427

$39-58 \%$

$\mathrm{R}=\mathrm{H}, \mathrm{Me}$

Scheme 122 The synthesis of substituted 3-benzoylamino-5-oxo-5,6,7,8-tetrahydrocoumarins.

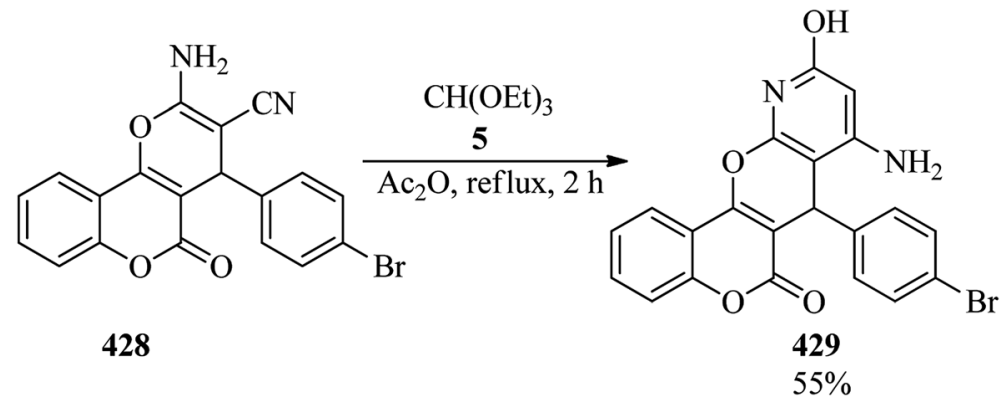

Scheme 123 The formation of amino-7-(p-bromophenyl)-10-hydroxypyridino[3',2'-6,5]4H-pyrano[3,2-c][1]benzopyran-6-ones.

pyrimidine with TEOF under similar condition for $6 \mathrm{~h}$ in $79 \%$ yield. ${ }^{326}$

\subsection{Etherification and esterification reactions}

Bakos et al. reported that a single frustrated Lewis pair catalyst $\mathrm{B}\left(\mathrm{C}_{6} \mathrm{Cl}_{3} \mathrm{H}_{2}\right)\left(\mathrm{C}_{6} \mathrm{~F}_{4} \mathrm{H}\right)_{2}$ could progress the tandem reductive etherification reaction of aldehydes/ketones (430) with trialkyl orthoformate $(\mathbf{4}, \mathbf{5})$, as alkylating agent, to produce ethers $(\mathbf{4 3 1})$ under 20 bar $\mathrm{H}_{2}$ pressure in THF at $55-100{ }^{\circ} \mathrm{C}$, for $16-84 \mathrm{~h}$ with high selectivity (98-99\%) and weak to good yields (35-92\%) (Scheme 124). ${ }^{378}$

In 2016, estrone 3-secondary ethers (435) were made through the eco-friendly etherification/aromatization reaction of readily accessible dienone (432) with trialkyl orthoformates $(\mathbf{1 2 7}, \mathbf{4 3 3}$, 434), as alkylating agent, in a $1: 5$ molar ratio by triflic acid (TfOH, $0.5 \mathrm{mmol}$ ) in the corresponding alcohol $(5 \mathrm{~mL})$ at $100{ }^{\circ} \mathrm{C}$ for $2 \mathrm{~h}$ in $80-87 \%$ yields (Scheme 125). The above-mentioned procedure was applied for the generation of three marketed 3etherified estrogen drugs, quinestrol, quinestradol, and nilestriol, utilizing 19-hydroxyandrost-4-ene-3,17-dione as a commercially available precursor. ${ }^{379}$

Scandium triflate $\left[\mathrm{Sc}(\mathrm{OTf})_{3}, 10 \mathrm{~mol} \%\right]$ catalyzed the one-pot three-component condensation of aldehydes, allylsilane and TMOF in dichloromethane to produce homoallyl ethers ${ }^{380,381}$ at room temperature. Mild reaction conditions, good yields (70$90 \%$ ), high selectivity, recyclability, and reusability of the catalyst are some important advantages of this procedure. ${ }^{381}$ On the other hand, the reaction of equimolar amounts of homoallyl alcohol (436) with TMOF (4) using Lewis acids such as $\operatorname{InCl}_{3}(3$ mmol) in $\mathrm{CH}_{2} \mathrm{Cl}_{2}$ at room temperature obtained homoallyl ethers (437) and homoallyl chlorides (439) in good yields. Notably, homoallyl alcohols with aryl moieties with electron-

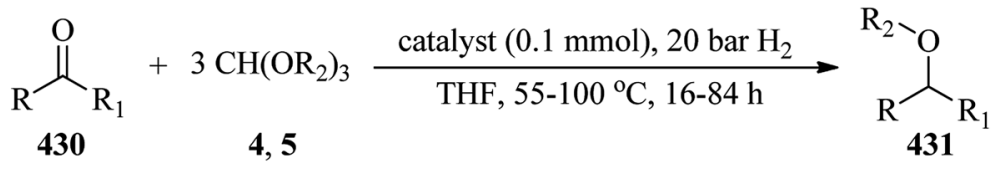

Conversion: $98-99 \%$

Catalyst: $\mathrm{B}\left(\mathrm{C}_{6} \mathrm{Cl}_{3} \mathrm{H}_{2}\right)\left(\mathrm{C}_{6} \mathrm{~F}_{4} \mathrm{H}\right)_{2}$

Yield: $35-92 \%$

$\mathrm{R}=\mathrm{H}$

$\mathrm{R}_{1}=\mathrm{PhCH}_{2}, 4-\mathrm{OMePhCH}_{2}, 4-\mathrm{ClPhCH}_{2}, 4-\mathrm{CO}_{2} \mathrm{MePhCH}_{2}, 4-\mathrm{BrPhCH}_{2}, 2-\mathrm{ClPhCH}_{2}, 3,4-(\mathrm{OMe})_{2} \mathrm{PhCH}_{2}$, 3-OMe-4-OHPhCH 2 , 3-OEt-4-OHPhCH ${ }_{2}, \mathrm{CH}_{2} \mathrm{CH}=\mathrm{CHCH}=\mathrm{CHCH}_{2}, \mathrm{Me}\left(\mathrm{CH}_{2}\right)_{6} \mathrm{CH}=\mathrm{CHCH}_{2}, \mathrm{PhCH}=\mathrm{CHCH}_{2}$ $\mathrm{R}_{2}=\mathrm{Me}$, Et

Scheme 124 Tandem reductive etherification reaction of aldehydes/ketones. 
<smiles>[R20]c1ccc2c(c1)CCC1C2CC[C@]2(C)C(=O)CC[C@H]12</smiles>

Scheme 125 Etherification/aromatization reaction of dienone.

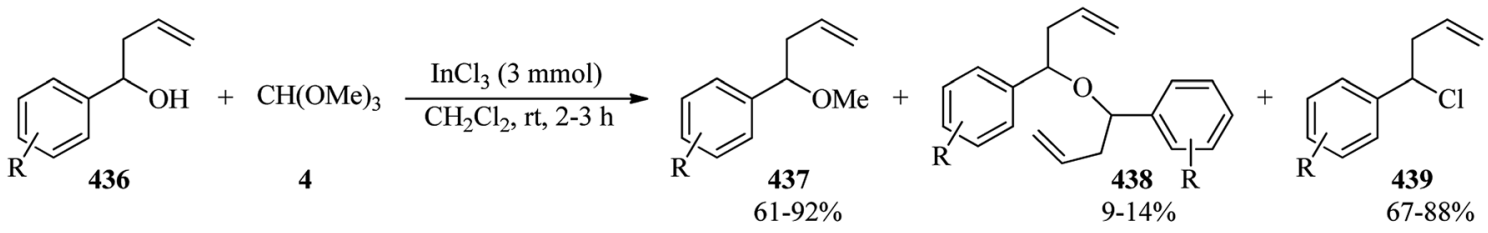

$\mathrm{R}=\mathrm{H}$, 2-Me, 3-Me, 4-Me, 2,5-Me 2 , 4-F, 4-Cl, 4-Br, 4- $\mathrm{CF}_{3}$, 4-CN, 4- $\mathrm{NO}_{2}$, Pentafluoro

Scheme 126 The preparation of some homoallylic compounds.

donating substituents furnished exclusively homoallyl ethers (437) in $84-92 \%$ yields. Homoallyl alcohol including halogen atoms as the substituents resulted in homoallyl ethers $(437,61-$ $72 \%)$ along with bishomoallyl ethers (438) $(9-14 \%)$ as byproducts. The homoallyl alcohols containing several halogen atoms or an electron-withdrawing substituent produced only the homoallyl chlorides (439) in 67-88\% yields (Scheme 126). Similarly, this transformation was accomplished using $\mathrm{BiCl}_{3}$ at room temperature and $\mathrm{BF}_{3} \cdot \mathrm{OEt}_{2}$ at $-78{ }^{\circ} \mathrm{C}$, while treatment utilizing $\mathrm{TiCl}_{4}$ at $-78{ }^{\circ} \mathrm{C}$ afforded exclusively the homoallyl chloride (439) in $92 \%$ yield. Hence, the type of product could be controlled through the selection of the desired Lewis acid. ${ }^{382}$

Maulide and Markó synthesized spirocyclic ethers (442) in $35-63 \%$ yields via the Mukaiyama aldol reaction of the silylated acyloins (440) with functionalized orthoesters (441) by $\mathrm{ZnCl}_{2}$ in dichloromethane at room temperature, which was followed by desilylation of the resultant adducts using TBAF in THF, and finally annulation in the presence of $t$-BuOK (Scheme 127). ${ }^{383}$

In 2013, Lee and Kraus presented a new technique for the synthesis of substituted benzoates (446) in $72-94 \%$ yields via the one-step one-pot inverse electron-demand Diels-Alder reaction of methyl coumalate (443) with orthoesters $(62,444$, 445) as an electron-rich dienophile in toluene at $200^{\circ} \mathrm{C}$ for $16 \mathrm{~h}$ (Scheme 128). ${ }^{384}$

In 1998, Fletcher co-workers reported a facile and inexpensive process for the formation of alkoxy/aryloxycyclopropanes (448) with preference for the generation of the more hindered cis-isomers through the reaction of TMOF (4) with alkenes (447) in the presence of zinc amalgam and $\mathrm{Me}_{3} \mathrm{SiCl}$ in refluxing diethyl ether for $24 \mathrm{~h}$ (Scheme 129). ${ }^{385}$

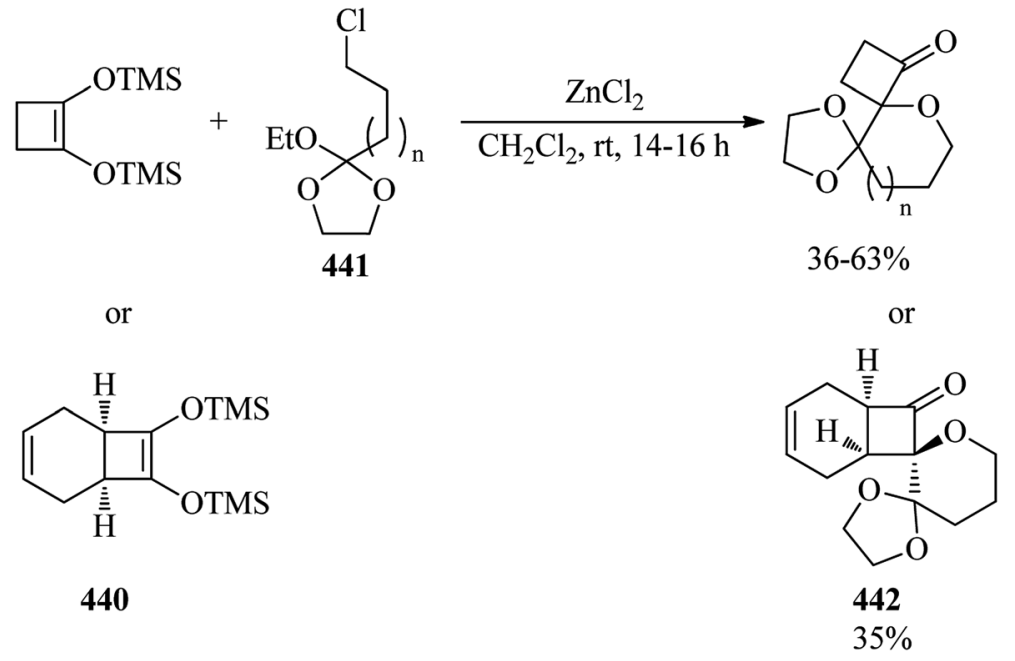

Scheme 127 Mukaiyama aldol reaction of silylated acyloins. 


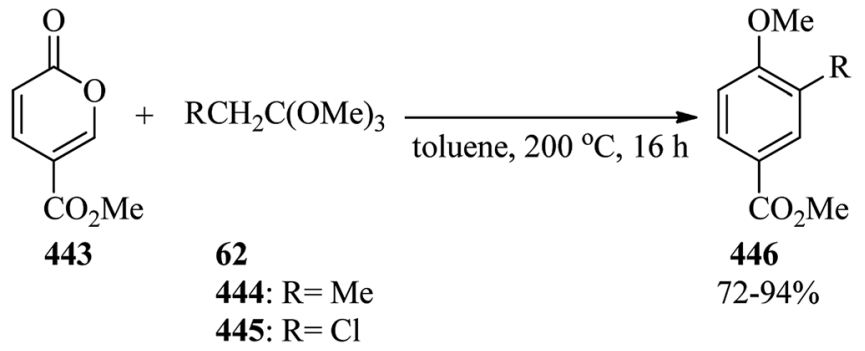

Scheme 128 The synthesis of substituted benzoates.

In 2018, Bunse et al. synthesized ethoxycarbonyl-substituted 1-alkylidenephthalanes (451) from the reaction of orthoester (449) arising from triethyl orthopropanoate (7). This reaction was prompted via halogen-metal exchange of the orthoester (449) with $n$-butyllithium ( $n$-BuLi) in THF at $-78{ }^{\circ} \mathrm{C}$ for $15 \mathrm{~min}$ which was followed by the nucleophilic addition reaction with diverse carbonyl compounds (450) along with regioselective 5exo-dig cyclization of the corresponding intermediate lithium alcoholate and eventually hydrolysis to produce the products (451) as mixtures of $(Z)$ - and $(E)$-configured diastereomers with an approximate range of 90 : 10 to 95 : 5 (Scheme 130). Notably, the aromatic aldehyde benzaldehyde was unsuccessful in getting the phenyl-substituted derivative. ${ }^{386}$

In 2018, Sempere and Carreira prepared $\beta$-substituted $\gamma, \delta$ unsaturated esters (453) via an iridium-catalyzed enantioselective allylic alkylation reaction of trimethyl orthoacetate (62), as an acetate enolate source, with racemic allylic carbonates (452), utilizing $\mathrm{ZnBr}_{2}$ as an additive in 1,4-dioxane at room temperature (Scheme 131). Significantly, halogenated and electron-rich substrates yielded the relative products with high yields and excellent enantioselectivity. Notably, the meroterpenoid (+)-conicol has been synthesized through employment of this new procedure in a formal enantioselective synthesis. $^{387}$

Brodzka and co-workers probed the enzymatic kinetic resolution (EKR) of Novozym 435 as a biocatalyst for the synthesis of enantiomerically pure carboxylic acid esters (456) via the esterification of racemic 3-phenyl-4-pentenoic acid (454) with trialkyl orthoesters $(4,5,6,62,102,323,380,444,455)$ as alkoxy group donors in toluene at $40{ }^{\circ} \mathrm{C}$ (Scheme 132). Based on the resulting data, trialkyl orthoesters including bulky alkyl groups, such as trialkyl orthobenzoate, obtained excellent results for both yield and enantioselectivity ( $50 \%$ yield, $>99 \%$ ee). It was found that the enantioselectivity of EKR is highly dependent on the structure of an alkoxy group donor. ${ }^{388}$

In 2015, Koszelewski et al. described a novel method of kinetic resolution based on irreversible enzymatic esterification of rac-3-hydroxy-3-(aryl)propanoic acids (457) with triethyl orthobenzoate (380) using Novozym 435 tandem metal-enzyme dynamic kinetic resolution (DKR) in toluene at $40{ }^{\circ} \mathrm{C}$ to access enantiomerically active $\beta$-hydroxy ester (458) with low enantioselectivities in low yields $(<1-45 \%)$ for $48 \mathrm{~h}$ (Scheme 133). ${ }^{389}$

In 1993, Trujillo and Gopalan used triethylorthoacetate as an ideal reagent for the transformation of sulfonic acids into their ethyl esters under a catalyst-free mode in dichloromethane $\left(\mathrm{CH}_{2} \mathrm{Cl}_{2}\right)$ at room temperature in high to excellent yields (69$97 \%$ ) for $30 \mathrm{~min}$. The uncatalyzed esterification reaction of carboxylic acids using this reagent was also conveniently performed in refluxing toluene within $24 \mathrm{~h}$ in high yields (81-92\%). Replacing trimethylorthoacetate with triethylorthoacetate resulted in the desired methyl esters. According to the resulting data, the utilization of TEOF instead of triethylorthoacetate was unsuccessful. ${ }^{390}$

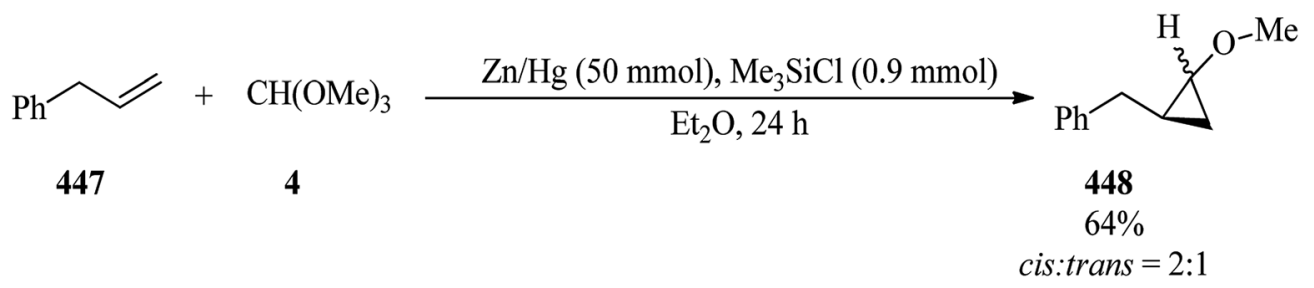

Scheme 129 The formation of alkoxy/aryloxycyclopropanes.

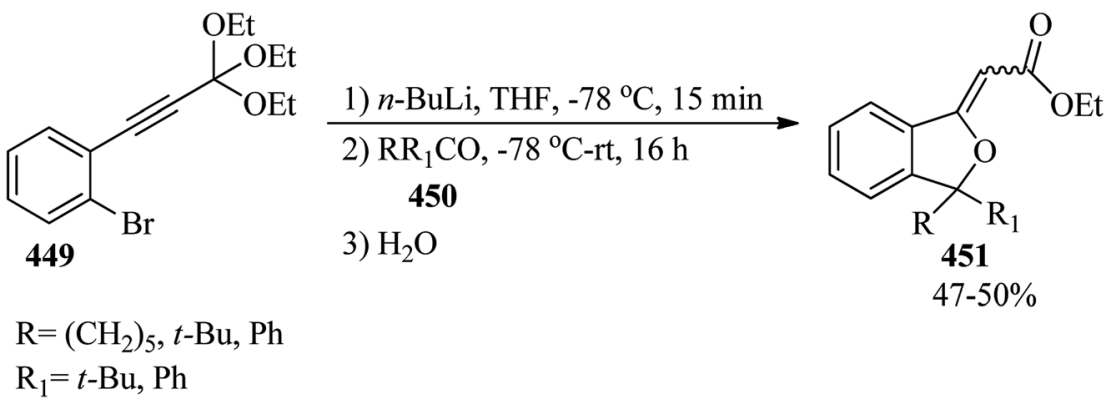

Scheme 130 The preparation of ethoxycarbonyl-substituted 1-alkylidenephthalanes. 


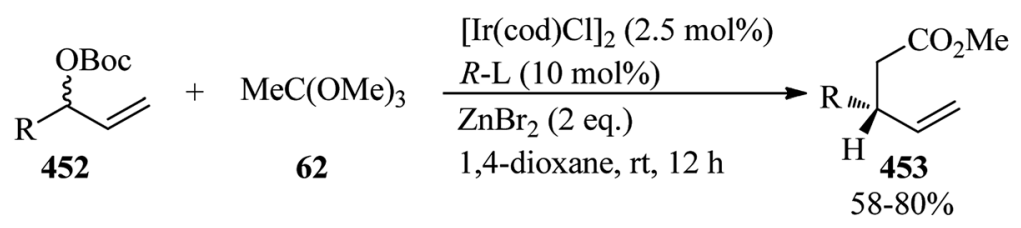

$\mathrm{R}=\mathrm{Ph}, 4-\mathrm{BrPh}$, 4-FPh, 2-OMePh, 3-OMePh, 4- $\mathrm{CO}_{2} \mathrm{MePh}, 3-\mathrm{CF}_{3} \mathrm{Ph}, 4-\mathrm{NO}_{2} \mathrm{Ph}$, 2-naphthyl

$(R)-\mathrm{L}$ :<smiles>COP(Oc1ccc2ccccc2c1-c1cccc2ccccc12)N1c2ccccc2C=Cc2ccccc21</smiles>

Scheme 131 The preparation of $\beta$-substituted $\gamma, \delta$-unsaturated esters.

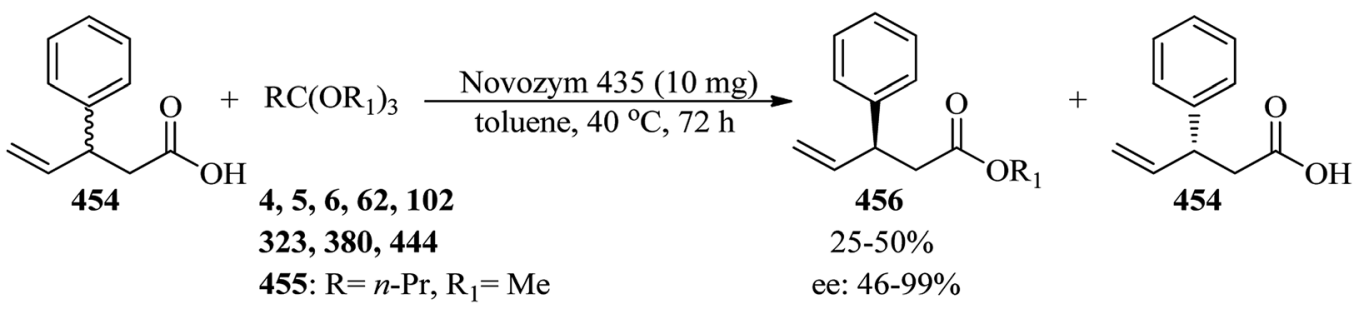

Scheme 132 The synthesis of enantiomerically pure carboxylic acid esters.

In 1996, Schwabacher and Stefanescu designed a useful and convenient method for the generation of methyl phosphinate (460) together with the elimination of methyl formate and methanol via the reaction of phosphinic acid (459) with TMOF (4) in a combined dry THF/toluene $(1: 1)$ medium at $5{ }^{\circ} \mathrm{C}$ to room temperature. This reaction was accompanied by the formation of a by-product (461), which was assumed to form through the attack of the dimethoxymethyl cation on the phosphorus(III) tautomer of (459) or (460) (Scheme 134). ${ }^{391}$

In 1994, King introduced a convenient method for the formation of ester-ethers (463) in 61-95\% yields via the reaction of lactones $(462)$ with orthoformates $(4,5,133)$ using sulfuric acid in the desired alcohol as solvent at $50{ }^{\circ} \mathrm{C}$ within $3-8 \mathrm{~h}$ (Scheme 135). ${ }^{392}$

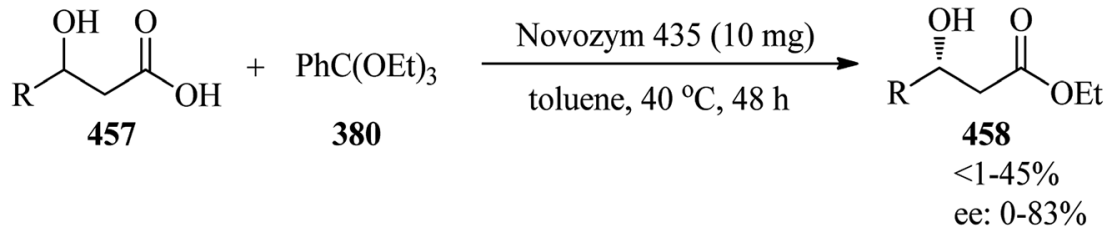

$\mathrm{R}=\mathrm{Ph}, 4-\mathrm{OMePh}, 2-\mathrm{FPh}, 2-\mathrm{BrPh}, 4-\mathrm{CF}_{3}-2-\mathrm{NO}_{2} \mathrm{Ph}, 4-\mathrm{F}-2-\mathrm{NO}_{2} \mathrm{Ph}, 2,4-\left(\mathrm{NO}_{2}\right)_{2} \mathrm{Ph}, 4-\mathrm{CNPh}$

Scheme 133 The synthesis of enantiomerically active $\beta$-hydroxy ester.<smiles>[1H][PH](=O)O</smiles>

459

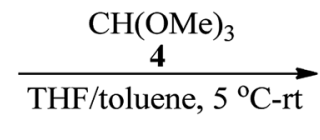

$\mathrm{H}^{-}$
460<smiles>CO[PH](=O)O</smiles>

60<smiles>COC(OC)[PH](=O)OC</smiles>

461

Scheme 134 The generation of methyl phosphinate. 
<smiles>[R2]C1CC([R])([R])OC1=O</smiles>

462

$$
\mathrm{n}=0-2
$$

$\mathrm{R}=\mathrm{H}, \mathrm{Me}$

$\mathrm{R}_{1}=\mathrm{H}, \mathrm{Me}$, pentyl

$\mathrm{R}_{2}=\mathrm{H}, \mathrm{Me}$

$\mathrm{R}_{3}=\mathrm{Me}, \mathrm{Et}, n-\mathrm{Pr}$

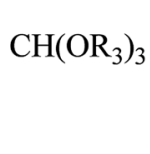

$4,5,133$

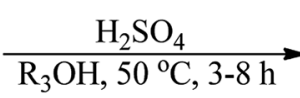<smiles>[R]OC(=O)C([R])CC([R])([R])O[R3]</smiles>

463

$61-95 \%$

Scheme 135 The formation of ester-ethers from lactones and orthoformates.

\subsection{Johnson-Claisen rearrangement}

In 2001, Takao et al. showed that the Claisen rearrangement of the substrate $(\mathbf{4 6 4})^{393,394}$ derived from 1,2:5,6-di-O-isopropylidene- $\alpha$-D-glucofuranose, with triethyl orthopropionate (7) by a catalytic amount of propanoic acid in DMF at $130{ }^{\circ} \mathrm{C}$ for $4 \mathrm{~h}$ obtained an inseparable mixture of the rearrangement products $(465,466$, and 467) as a $1: 2.5: 10$ diastereomeric mixture in a combined yield of $87 \%$ (Scheme 136). Under similar conditions, the reaction of (464) with trimethyl orthobutyrate (455) by powdered molecular sieves $4 \mathrm{~A}$ (MS-4 ̊) afforded an inseparable mixture of the rearrangement products ( 468 and 469) as a $1: 3$ diastereomeric mixture in a combined yield of $46 \%$ (Scheme 137). In both reactions, the $\sigma$-bond formation progressed prevalently from the $\beta$-side. This resultant stereochemical was opposite to the observed rearrangement of (464) with TEOAc. ${ }^{395}$

\subsection{Acetalization reaction}

In 2003, Ma et al. presented an efficient and chemoselective method for the preparation of diethyl acetals in good to excellent yields (63-96\%) via the acetalization ${ }^{\mathbf{1 7 8 , 3 9 6 - 4 0 8}}$ of aldehydes/ ketones with TEOF using $\mathrm{TiO}_{2} / \mathrm{SO}_{4}{ }^{2-}$ in refluxing ethanol for $25 \mathrm{~min}$ to $3 \mathrm{~h}$. It was found that, in competitive reactions, aldehydes and cyclic aliphatic ketones revealed excellent chemoselectivity. ${ }^{408}$ The reaction of enamines (470) with trialkyl orthoformates $(\mathbf{4}, \mathbf{5})$ was also accomplished in the presence of $\mathrm{BF}_{3} \cdot \mathrm{OEt}_{2}$ in $\mathrm{CH}_{2} \mathrm{Cl}_{2}$ to give $\alpha$-dialkoxymethyl carbonyl compounds (471), after hydrolysis, in 61-85\% yields within $1 \mathrm{~h}$ (Scheme 138). ${ }^{409}$

In 1999, Martins et al. reported the regioselective reaction of 2-acylcycloalkanones (472) with TMOF (4) using $p$-TSA (0.78 $\mathrm{mmol}$ ) in methanol at room temperature to afford the corresponding acetals within $24 \mathrm{~h}$ (Scheme 139). It was found that

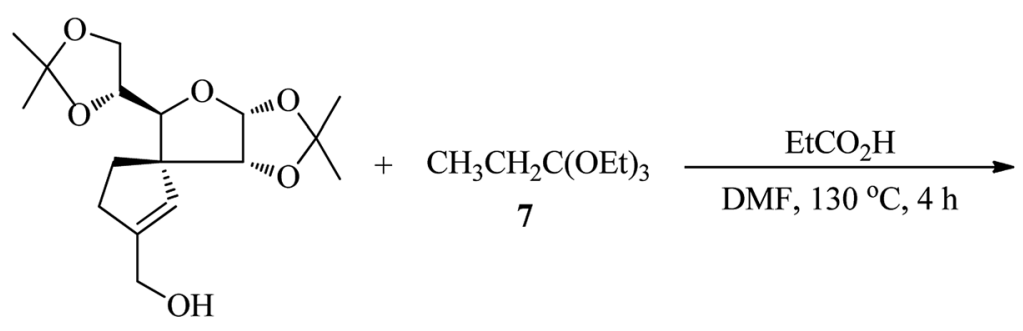

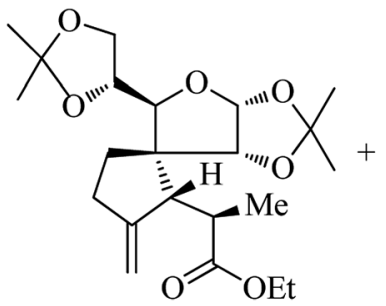<smiles>C=C1CC[C@@]2([C@H]1C(C)C(=O)OCC)[C@@H]([C@@H]1COC(C)(C)O1)O[C@@H]1OC(C)(C)O[C@H]12</smiles>

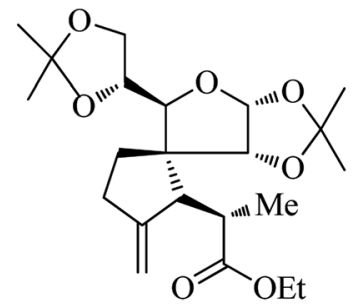

465:466:467 $=1: 2.5: 10$ $87 \%$ 


$$
\underset{455}{464}+\underset{\mathrm{CH}_{3} \mathrm{CH}_{2} \mathrm{CH}_{2} \mathrm{C}(\mathrm{OMe})_{3}}{\stackrel{\mathrm{EtCO}_{2} \mathrm{H}, \mathrm{MS}-4 \mathrm{~A}}{\longrightarrow}}
$$

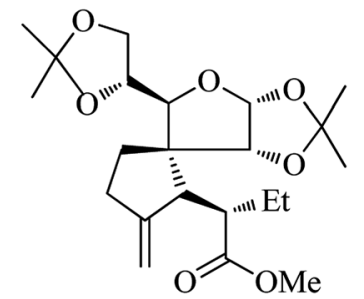

468:469=1:3

$46 \%$

Scheme 137 The Claisen rearrangement of 1,2:5,6-di-O-isopropylidene- $\alpha$-D-glucofuranose with trimethyl orthobutyrate.

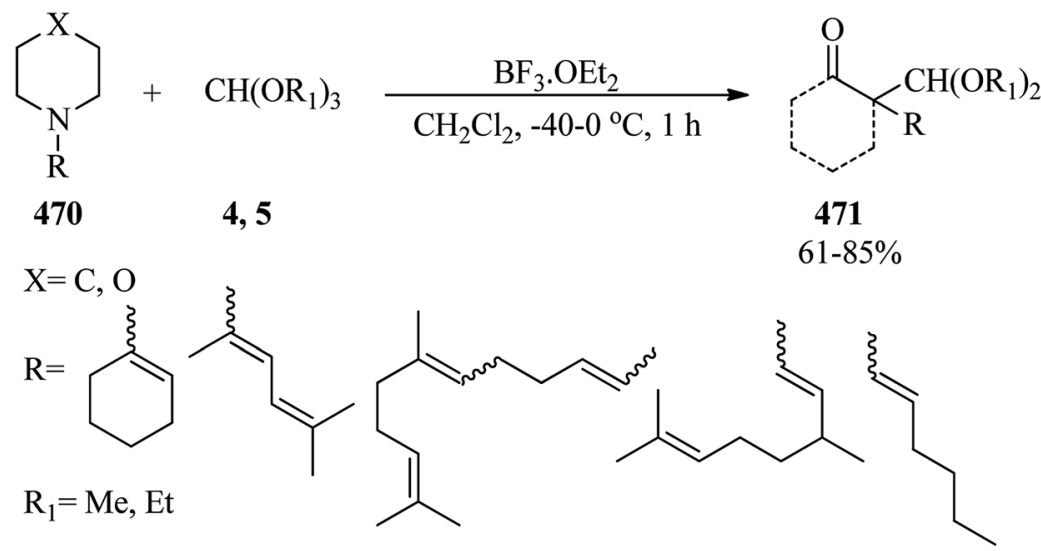

Scheme 138 The chemoselective preparation of diethyl acetals.

the reverse Claisen condensation of electron-donating substituted 2-acylcyclohexanones, where $\mathrm{R}$ was $\mathrm{Me}$, Et or $\mathrm{CH}_{2} \mathrm{Ph}$ with TMOF led to 7,7-dimethoxyalkanoate methyl esters (473) in 80-93\% yields. On the other hand, 2-acyl cyclohexanone dimethyl acetal derivatives (474) in $80-85 \%$ yields were produced when $\mathrm{R}$ was $\mathrm{Ph}, \mathrm{CF}_{3}$ or OMe. Similar to the products (474), 2-acetylcyclooctanone derivative $(\mathrm{R}=\mathrm{Me})$ resulted in acetal $(\mathbf{4 7 5})$ in $86 \%$ yield. Finally, 2-acetylcyclopentanone $(\mathrm{R}=$ $\mathrm{Me})$ and 2-acetyl cycloheptanone $(\mathrm{R}=\mathrm{Me})$ gave rise to acetals (476) and (477) in 75 and $74 \%$ yields, respectively. ${ }^{410}$
In 1991, the highly enantioselective hydroformylation of vinyl aromatics (478) was reported by the Hegedus group in the presence of TEOF (5). They discovered that TEOF plays a special role in stereoselectivity. As can be seen in Scheme 140, the reaction proceeded with $\left(\mathrm{Pt}^{\mathrm{II}} \mathrm{BPPM}\right) / \mathrm{SnCl}_{2}\left(\mathrm{Pt}^{\mathrm{II}} \mathrm{BPPM}\right.$ : 1 - tertbutoxycarbonyl)-(2S,4S)-4-(dibenzophospholyl)-2-

[(dibenzophospholyl)methyl]pyrrolidine) in $o$-dichlorobenzene as solvent. ${ }^{411}$

In 2015, Pospech and co-workers introduced an intermolecular one-step methoxylation/acetalization reaction of donor-

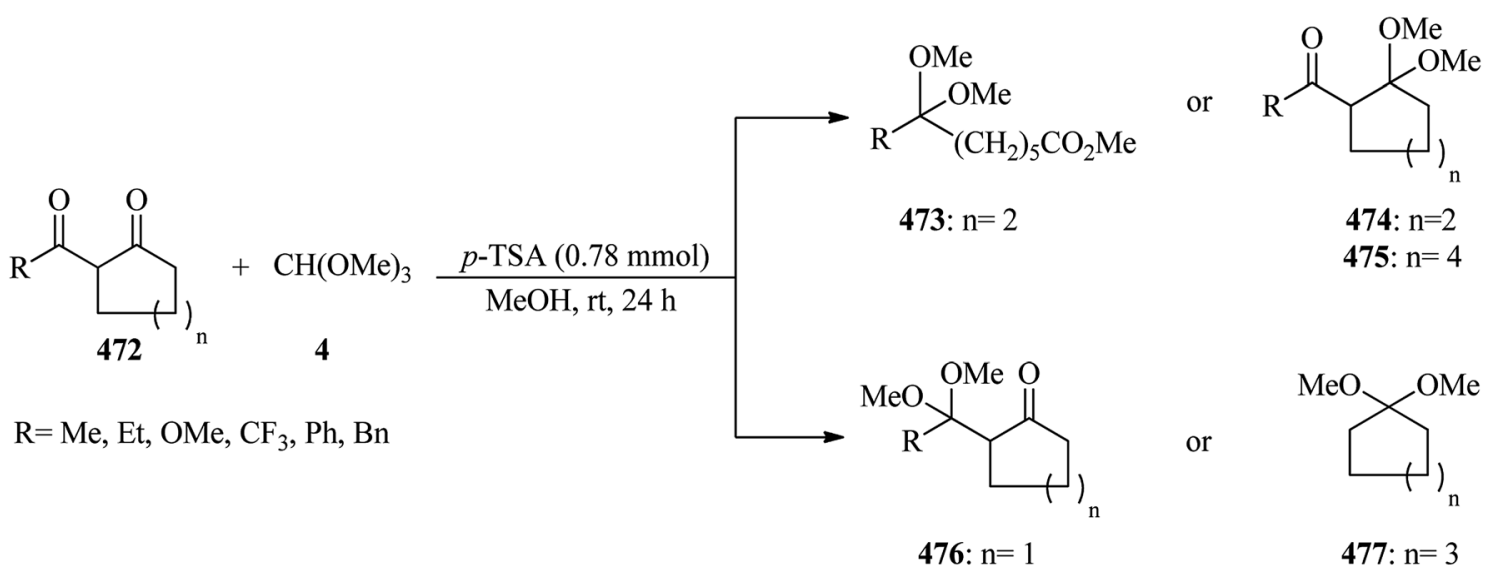

Scheme 139 The regioselective reaction of 2-acylcycloalkanones with TMOF. 


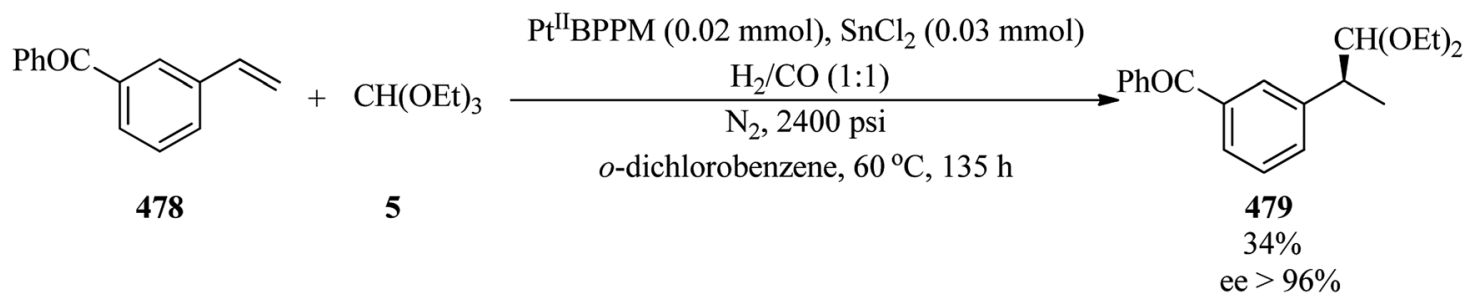

Scheme 140 The enantioselective hydroformylation of vinyl aromatics.

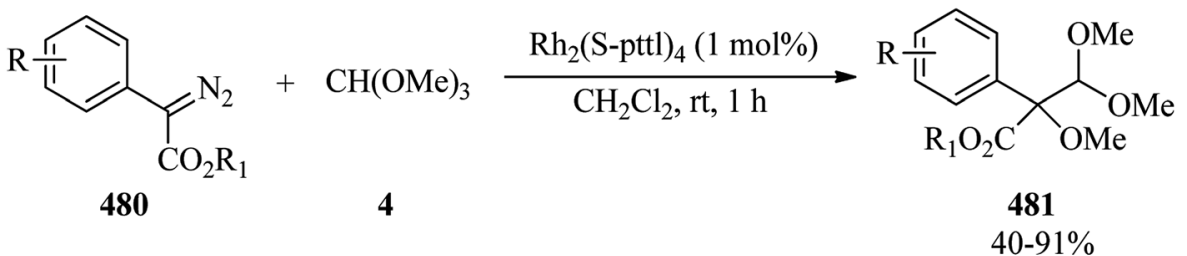

$\mathrm{R}=4-\mathrm{F}, 4-\mathrm{Cl}, 4-\mathrm{Br}, 2,5-\mathrm{F}_{2}, 3,4-\mathrm{Cl}_{2}$, 3-OMe, 3-OEt-4- $\mathrm{CO}_{2} \mathrm{Et}$, 4-OTs, 4-OMs

$\mathrm{R}_{1}=\mathrm{Me}, \mathrm{Et}$

Scheme 141 Methoxylation/acetalization of diazo compounds with TMOF.

acceptor substituted diazo compounds (480) with TMOF (4) utilizing $\mathrm{Rh}_{2}(S \text {-pttl })_{4}(1.0 \mathrm{~mol} \%)$ in $\mathrm{CH}_{2} \mathrm{Cl}_{2}$ at room temperature to synthesize functionalized tertiary $\alpha$-alkoxy- $\beta$-oxo-esters (481) in $1 \mathrm{~h}$ in $40-91 \%$ yields (Scheme 141). The concurrent $\mathrm{C}-\mathrm{O} / \mathrm{C}-\mathrm{C}$ bond generation produces products with exclusive quaternary carbon centers containing substituent groups with various oxidation levels, such as esters, protected aldehydes and alkoxidse. ${ }^{412}$

In 2015 , the cyanation of orthoesters $(5, \mathbf{1 0 2}, \mathbf{3 1 7}, \mathbf{3 8 0}),{ }^{413}$ with sterically congested $\alpha$-cyanoamines, like dicyclohexylcyanoamine (482), as effective cyanating reagents, was described for the formation of cyanoacetals (483) by trichlorosilyl triflate $\left(\mathrm{SiCl}_{3} \mathrm{OTf}\right)$ in $\mathrm{CH}_{2} \mathrm{Cl}_{2}$ at $0{ }^{\circ} \mathrm{C}$ within $0.5 \mathrm{~h}$, in excellent yields (73-97\%) (Scheme 142). ${ }^{414}$

Casiraghi and co-workers prepared 2-hydroxyaryl-1carboxyaldehyde diethylacetals (485) via the reaction of special phenol salts like magnesium halides (484) with TEOF (5) in benzene or diethylether at $20-80{ }^{\circ} \mathrm{C}$ (Scheme 143). This reaction was promoted by a C-regiospecific attack at the ortho positron of the phenoxy moiety. ${ }^{415}$

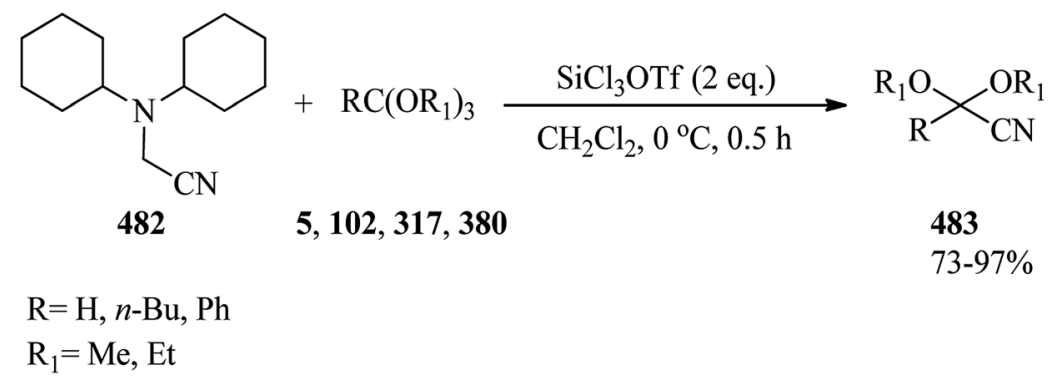

Scheme 142 The cyanation of orthoesters.

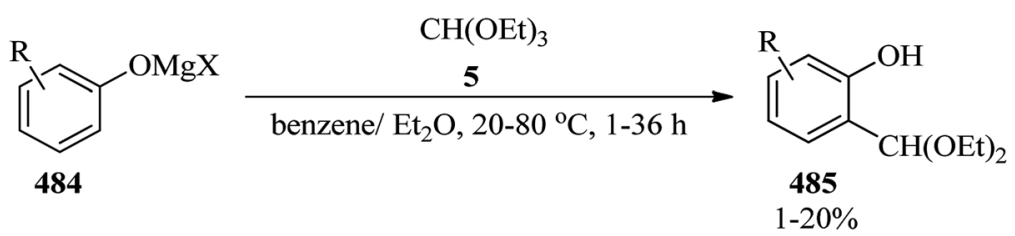

$\mathrm{R}=\mathrm{H}$, 2-Me, 4-Me, 2-i-Pr, 2-t-Bu, 4-i-Pr, 4-t-Bu, 2,4- $\mathrm{Me}_{2}$, 3,4- $\mathrm{Me}_{2}$, 2,5-Me 2 , 2-i-Pr-5-Me, 2-t-Bu-5-Me, 2-naphthyl

Scheme 143 The regioselective preparation of 2-hydroxyaryl-1-carboxyaldehyde diethylacetals. 


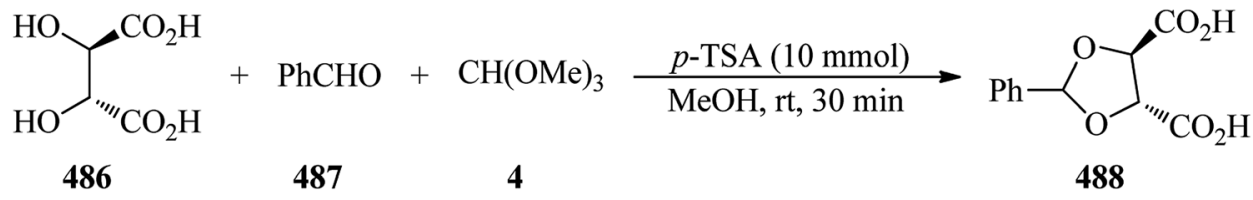

Scheme 144 The formation of (-)-dimethyl 2,3-O-benzylidene-L-tartrate.

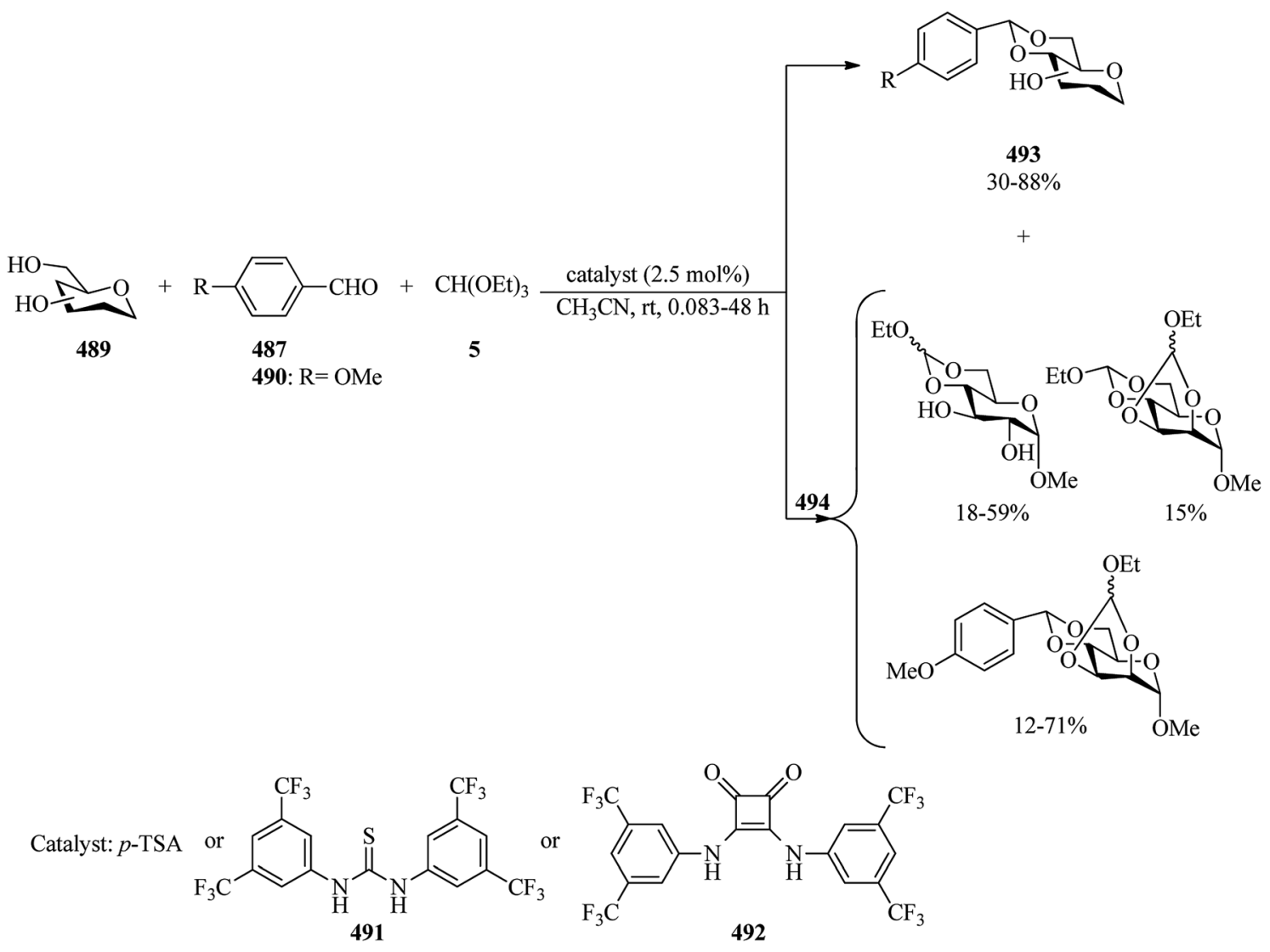

Scheme 145 The regioselective preparation of 4,6-O-arylidenated derivatives of sugars.

In 1993, Byun and Bittman synthesized (-)-dimethyl 2,3-Obenzylidene-L-tartrate and its enantiomer (488) in $83-91 \%$ yields via the reaction of L-tartaric acid (486), benzaldehyde (487), and TMOF (4) by $p$-TSA $(10 \mathrm{mmol})$ in methanol at room temperature (Scheme 144). ${ }^{\mathbf{4 1 6}}$

In 2013, Geng et al. prepared 4,6-O-arylidenated derivatives (493) and orthoesters (494), regioselectively via the protected/ unprotected sugars (489), benzaldehydes $(\mathbf{4 8 7}, 490)$, and TEOF (5) by organocatalysts such as thiourea (491)/squaramide derivatives (492) in anhydrous $\mathrm{CH}_{3} \mathrm{CN}$ at room temperature (Scheme 145). In this procedure the influence of various parameters, such as the amount and type of aldehyde, catalyst and orthoester, was investigated on the time and yield of reaction. It was found that a strong acid-catalyst like $p$-TSA has a great effect in reducing the reaction time. ${ }^{\mathbf{4 1 7}}$

5-Substituted 5,5-dialkoxy-2-penten-4-olides (496) were made through the reaction of 2 -(trimethylsiloxy)furan (495) with orthoesters $(\mathbf{4}, \mathbf{5}, \mathbf{6}, 7, \mathbf{3 8 0})$ in the presence of a few drops of tin(Iv)chloride $\left(\mathrm{SnCl}_{4}\right)$ in $\mathrm{CH}_{2} \mathrm{Cl}_{2}$ at -40 to $10{ }^{\circ} \mathrm{C}$ in $48-91 \%$ yields in a $2 \mathrm{~h}$ period (Scheme 146). ${ }^{418}$

The vicinal diequatorial diols reaction of 2,2,3,3-tetramethoxybutane (497) with TMOF (4) using camphorsulfonic acid in refluxing methanol for 12-18 h yielded butane 2,3-bisacetal (498) in moderate to excellent yields (54-91\%) to protect trans1,2-diols (Scheme 147). ${ }^{419}$

In 1991, Hoffman and Salvador described a one-pot conversion of cyclic ketones to $N$-methyl lactams. The reaction of ketones (499) with TEOF (5) by $p$-TSA in ethanol gave acetal (500) which was treated in situ with $N-(((p$-nitrobenzene)sulfonyl)oxy) methylamine (501) to furnish the $N$-methyl group of the imidate salt (502). Finally, dealkylation of the resulting $O$-ethyl imidate with sodium iodide in refluxing acetonitrile achieved lactams (503) in moderate to high yields (Scheme 148). ${ }^{420}$ 


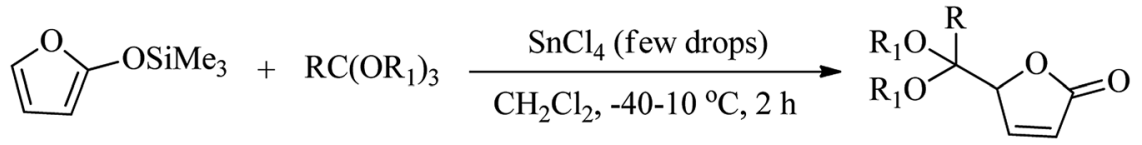

$$
\begin{aligned}
& 495 \quad 4,5,6,7,380 \\
& 496 \\
& \mathrm{R}=\mathrm{H}, \mathrm{Me}, \mathrm{Et}, \mathrm{Ph} \\
& 48-91 \% \\
& \mathrm{R}_{1}=\mathrm{Me} \text {, Et }
\end{aligned}
$$

Scheme 146 The synthesis of 5-substituted 5,5-dialkoxy-2-penten-4-olides.

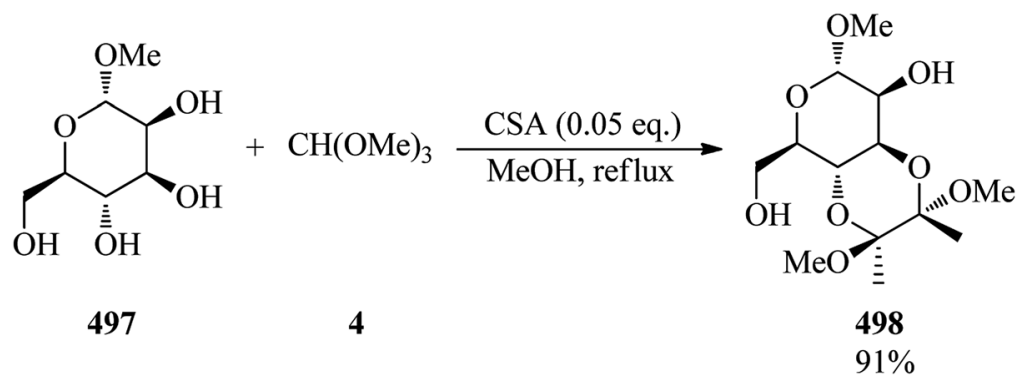

Scheme 147 The reaction of 2,2,3,3-tetramethoxybutane with TMOF

DeMong and Williams suggested an asymmetric synthesis of 2-amino-3,3-dimethoxypropanoic acid (-)-506. The key step is the quenching of a chiral glycine (504) titanium enolate with TMOF (4) in $\mathrm{CH}_{2} \mathrm{Cl}_{2}$ at $-78{ }^{\circ} \mathrm{C}$ to form the appropriate $\alpha$ dimethylacetal $^{421,422}(+)-505$ in $94 \%$ yield. The (-)-506 was obtained in $98 \%$ yield through the hydrogenolysis of the lactone moiety by $20 \mathrm{~mol} \%$ of $\mathrm{Pd}(\mathrm{OH})_{2}$ in a combined THF/MeOH $(3: 1)$ medium; followed by utilizing trituration with ether to eliminate the dibenzyl by-product (Scheme 149). ${ }^{422}$

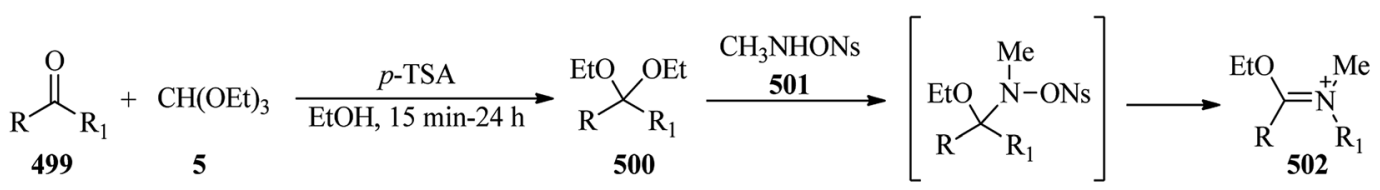

499: cyclohexanone, cyclopentanone, 2-methylcyclohexanone, 2-methylcyclopentanone, cyclooctanone, cyclododecanone, acetophenone

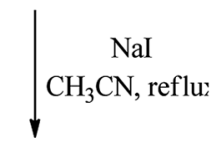<smiles>[R]C(=O)N([R])C</smiles><smiles>CC(C)(C)[N+]1CC(=O)O[C@@H](c2ccccc2)[C@H]1c1ccccc1</smiles>

\section{1) $\mathrm{TiCl}_{4}, \mathrm{Et}_{3} \mathrm{~N}$ \\ 2) $\mathrm{CH}(\mathrm{OMe})_{3}, \mathrm{CH}_{2} \mathrm{Cl}_{2},-78^{\circ} \mathrm{C}$ 4}

$(+)-504$<smiles>COC(OC)[C@H]1C(=O)O[C@@H](c2ccccc2)[C@H](c2ccccc2)[C@H]1C(C)(C)C</smiles>

$(+)-505$

$94 \%$

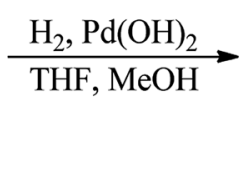

$(-)-506$
$98 \%$

Scheme 149 The asymmetric synthesis of 2-amino-3,3-dimethoxypropanoic acid. 


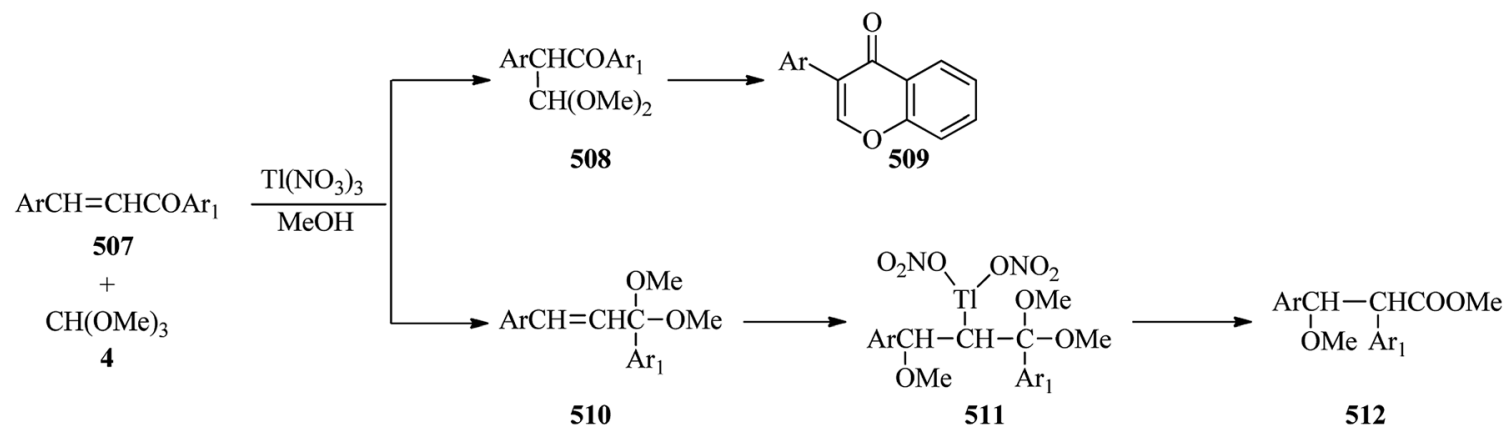

Scheme 150 The reaction of chalcones with TMOF.

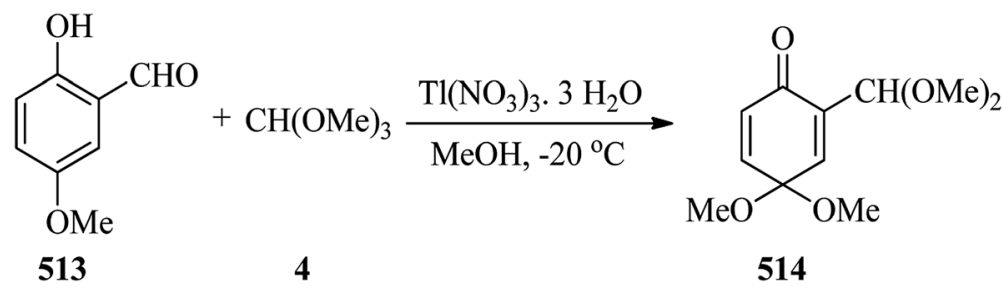

Scheme 151 The oxidation of 2-formyl-4-methoxyphenol with TMOF.

The reaction of chalcones (507) with TMOF (4) was accomplished using thallium(III) trinitrate (TTN) in acidic methanol to afford a $50: 50$ mixture of 3,3-dimethoxy-1,2-diphenylpropan-1one (508, $\mathrm{Ar}=\mathrm{Ar}_{1}=\mathrm{C}_{6} \mathrm{H}_{5}$ ) and methyl 2,3-diphenyl-3methoxypropanoate (512, $\mathrm{Ar}=\mathrm{Ar}_{1}=\mathrm{C}_{6} \mathrm{H}_{5}$ ). The keto acetal (508) ${ }^{423}$ was obtained through normal Ar ring migration, while the ester (512) was obviously achieved by migration of the $\mathrm{Ar}_{1}$ ring. As shown in Scheme 150, owing to the low rate of the treatment of chalcone with TTN and also the faster reaction of aldehydes and ketones with TMOF by TTN to form acetals and ketals, ${ }^{424}$ the ketalization reaction of chalcone apparently competes with oxidative rearrangement. Hence, the oxidative rearrangement resulted in product (508) and the ketalization reaction formed intermediate $(\mathbf{5 1 0})$ which upon treatment with TTN was converted into intermediate (511). Finally, the 1,2migration of the $\mathrm{Ar}_{1}$ group and the respective elimination of TTN furnished product (512) (Scheme 150). ${ }^{425}$

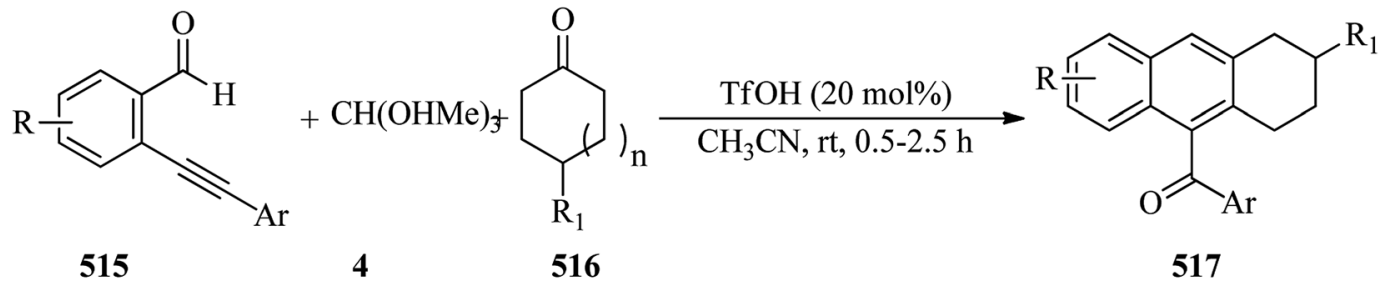

515

\section{6}<smiles>COC1=CCC(Br)C(C)C1</smiles>

$\mathrm{n}=0,1,3$

$\mathrm{R}=$ alkyl, Ar

$\mathrm{R}_{1}=\mathrm{H}, \mathrm{Me}, n-\mathrm{Pr}, \mathrm{C}(\mathrm{Me})_{2} \mathrm{Et}$

$\mathrm{Ar}=\mathrm{Ph}$, 4-OHPh, 4-MePh, 4-ClPh, 2-thiophenyl

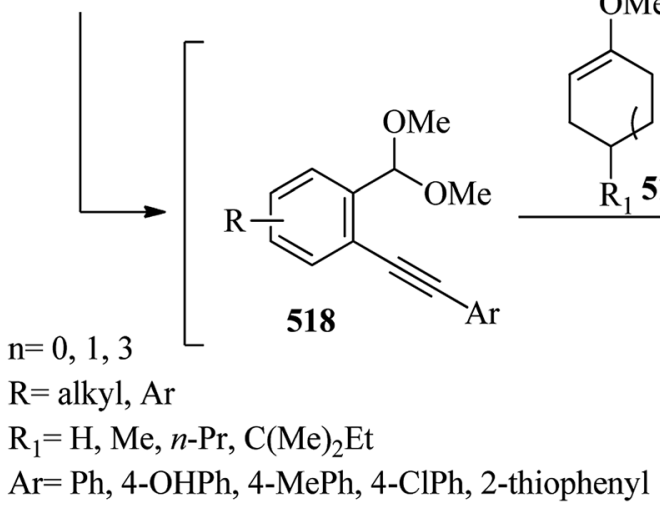

$34-90 \%$

Scheme 152 The synthesis of naphthalenes via domino three-component condensation. 


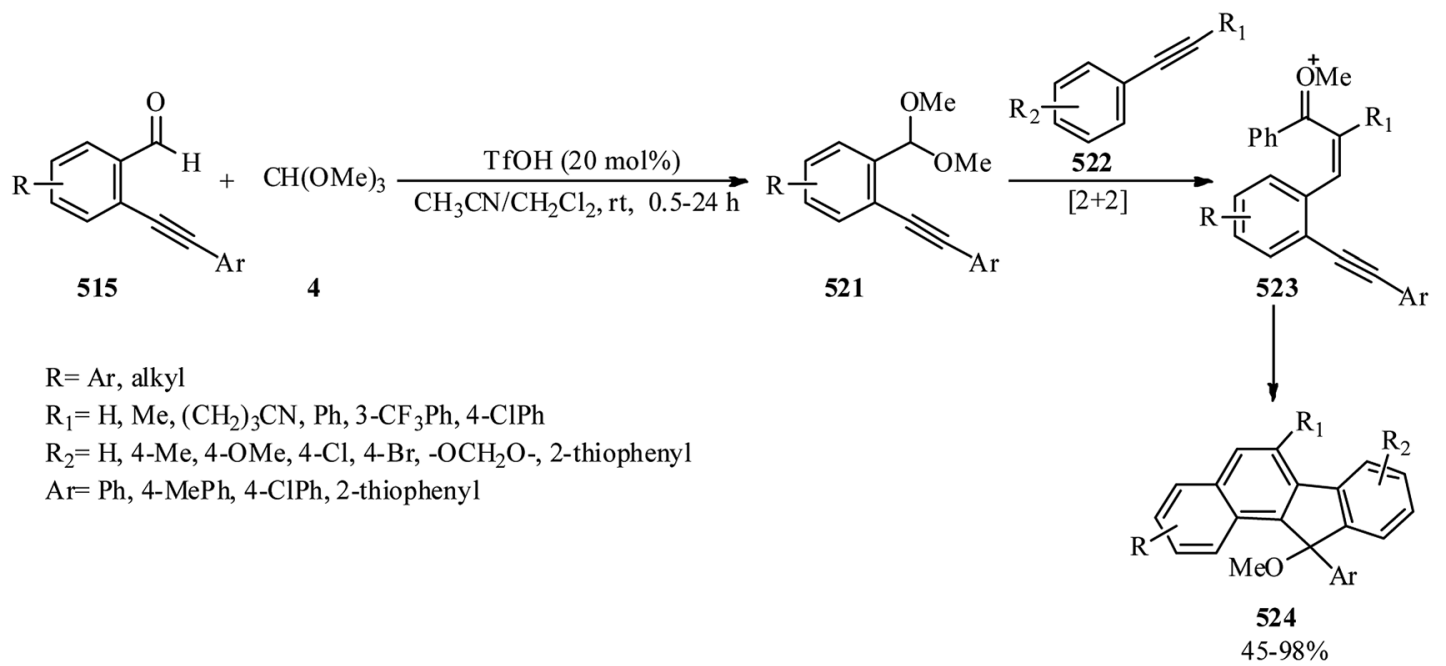

Scheme 153 The regioselective synthesis of substituted benzo[a]fluorenes.

2-Dimethoxymethyl-4,4-dimethoxycyclohexa-2,5-dienone (514) could be prepared via oxidation of 2-formyl-4methoxyphenol (513) with TMOF (4), utilizing thallium trinitrate ${ }^{426,427}$ in methanol at $-20{ }^{\circ} \mathrm{C}$ while the oxidation of 2methoxycarbonyl-4-methoxyphenol furnished methoxycarbonyl-3,4,4-trimethoxycyclohexa-2,5-dienone (Scheme 151). ${ }^{427}$

In 2007, Graham and Smith demonstrated that alcohols could be transformed directly into either acyclic or cyclic acetals in both tandem and sequential oxidation/acetalization processes using manganese dioxide, trialkyl orthoformates and an indium triflate catalyst in dichloromethane at ambient temperature. ${ }^{428}$ In 2015, Manojveer and Balamurugan developed a convenient method for the synthesis of naphthalenes (517) via a domino three-component condensation reaction of $o$-alkynylbenzaldehydes (515), ketones (516), and TMOF (4) in the presence of $\mathrm{TfOH}(20 \mathrm{~mol} \%)$ in acetonitrile at room temperature (Scheme 152). This transformation was initiated via the condensation of $o$-alkynylbenzaldehyde (515) with TMOF (4) by TfOH to obtain the in situ formed acetal (518), which was condensed with enol ether (519), arising from the reaction of ketones with TMOF, to form chalcone (520) which underwent intramolecular cyclization reaction to afford naphthyl ketones $(517){ }^{429}$

Manojveer and Balamurugan presented a facile and efficient process to get substituted benzo[a]fluorenes (524), with regioselectivity via a domino three-component reaction of $o$-alkynylbenzaldehydes, alkynes, and TMOF by TfOH $(20 \mathrm{~mol} \%)$ in $\mathrm{CH}_{3} \mathrm{CN}$ or $\mathrm{CH}_{2} \mathrm{Cl}_{2}$ at room temperature. This reaction proceeded through the reaction of aldehydes (515) with TMOF (4) by TfOH to obtain the in situ formed acetal (521). Subsequent [2 +2 ] cycloaddition between acetal (521) and alkynes (522) generated the cis-isomer (523) which on intramolecular annulation reaction achieved substituted benzo[ $a]$ fluorenes (524) in $45-98 \%$ yields in $0.5-24 \mathrm{~h}$ (Scheme 153). ${ }^{430}$

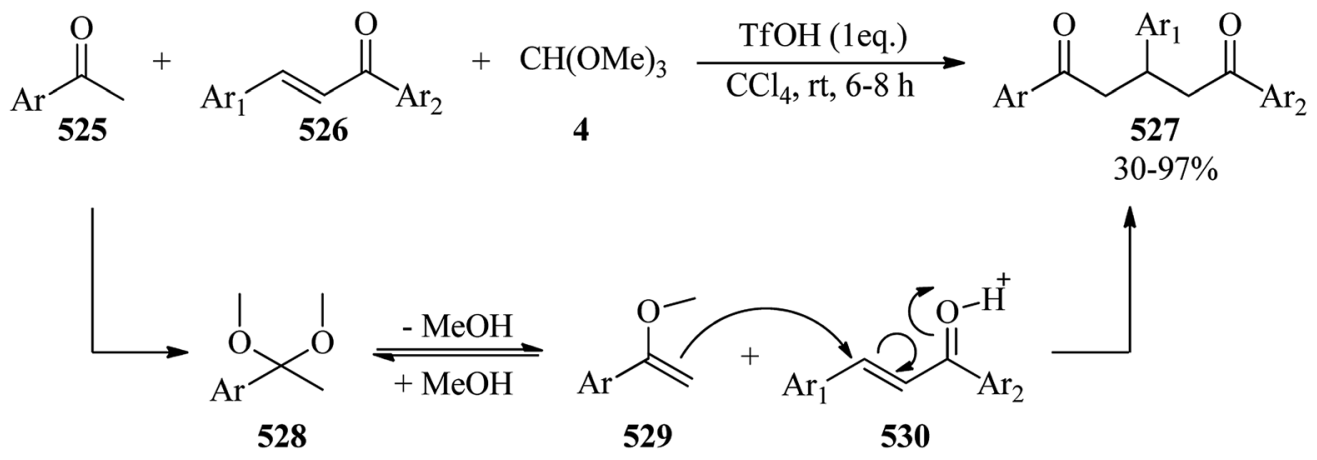

$\mathrm{Ar}=\mathrm{Ph}, 4-\mathrm{MePh}, 4-\mathrm{OMePh}$, 4-ClPh, 4-BrPh, 4-IPh, 2-thiophenyl

$\mathrm{Ar}_{1}=\mathrm{Ph}, 4-\mathrm{OMePh}, 4-\mathrm{ClPh}, 4-\mathrm{NO}_{2} \mathrm{Ph}, 1,3$-benzodioxole

$\mathrm{Ar}_{2}=\mathrm{Ph}, 4-\mathrm{ClPh}$

Scheme 154 The preparation of 1,5-diketones. 
<smiles>[R][R]1ccc(C(=O)NN)cc1</smiles>

$\mathrm{R}=\mathrm{H}, 4-\mathrm{Me}, 4-\mathrm{OMe}, 4-\mathrm{Cl}, 4-\mathrm{NO}_{2}, 3-\mathrm{Br}, 2-\mathrm{Cl}, 2-\mathrm{NO}_{2}$

$\mathrm{R}_{1}=\mathrm{H}, \mathrm{Me}, \mathrm{Et}, \mathrm{Ph}$

Scheme 155 Synthetic approach for substituted 1,3,4-oxadiazoles.

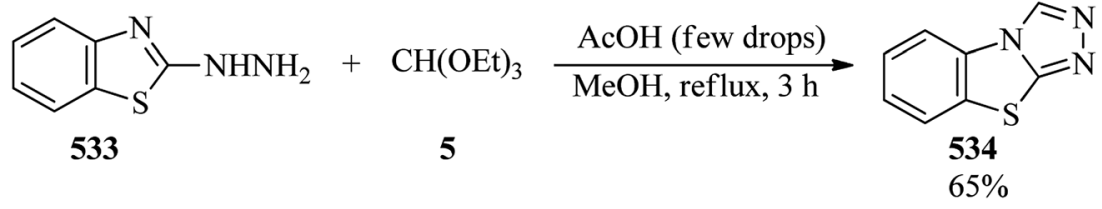

Scheme 156 The formation of 1,2,4-triazolo[3,4-b]benzothiazole.

TfOH catalyzed the one-pot three-component reaction of ketones, such as acetophenones and ethyl phenyl ketones (525), chalcones (526), and TMOF (4) in carbon tetrachloride $\left(\mathrm{CCl}_{4}\right)$ at room temperature to obtain a series of symmetrical and unsymmetrical 1,5-diketones (527) within 6-8 h. This reaction progressed through the in situ formation of acetals (528) from the reaction of ketones with TMOF which set up an equilibrium with the enol ether (529), as an Michael acceptor, which was followed by Michael addition with the activated chalcones by an acidic catalyst (530) to afford 1,5-diketones (527). Replacing acetophenones with ethyl phenyl ketones yielded a mixture of diastereomeric 1,5-diketones (where the syn diastereomers were the major product) in $55-95 \%$ yields (Scheme 154). ${ }^{431}$

\subsection{Synthesis of benzoxazoles, benzothiazoles,} benzimidazoles, oxazoles, oxadiazoles, and imidazoles

In 2009, Lee et al. reported a simple and effective procedure for the generation of benzoxazoles and oxazoles via the one-pot reduction-triggered heterocyclization reaction. Indium/acetic acid promoted the reaction of 2-nitrophenols with trimethyl orthoesters in refluxing benzene to produce benzoxazoles ${ }^{432-434}$ in $50-98 \%$ yields in a $1 \mathrm{~h}$ period. In a similar manner, 1-aryl-2nitroethanones upon treatment with trimethyl orthobenzoate using $\mathrm{In} / \mathrm{AcOH}$ in refluxing acetonitrile afforded oxazoles in $1 \mathrm{~h}$ in $46-72 \%$ yields. ${ }^{434}$ In 2014 , Gnanasekaran and co-workers reported arylhydrazides (531) on reaction with orthoesters $(\mathbf{5}, \mathbf{6}, \mathbf{7}$, 380) by $\mathrm{NH}_{4} \mathrm{Cl}(30 \mathrm{~mol} \%)$ as catalyst in a polar solvent like

$$
\begin{aligned}
& \overbrace{\mathbf{5 3 5}}^{\mathrm{NHCl}}+\underset{\mathbf{5}, \mathbf{6}(\mathrm{OEt})_{3}}{\mathrm{SH}} \frac{\mathrm{Y}(\mathrm{OTf})_{3}(5 \mathrm{~mol} \%)}{\mathrm{DMA}, \text { pyridine }(2 \mathrm{eq} .), 1.5-18 \mathrm{~h}} \\
& \text { 536: } \mathrm{R}=\mathrm{CH}_{2} \mathrm{Cl} \quad 38-68 \% \\
& \text { 537: } \mathrm{R}=\mathrm{C}_{2} \mathrm{Si}(\mathrm{Me})_{3} \\
& \text { 538: } \mathrm{R}=\mathrm{CO}_{2} \mathrm{Et}
\end{aligned}
$$

Scheme 157 The formation of disubstituted benzobisthiazoles.

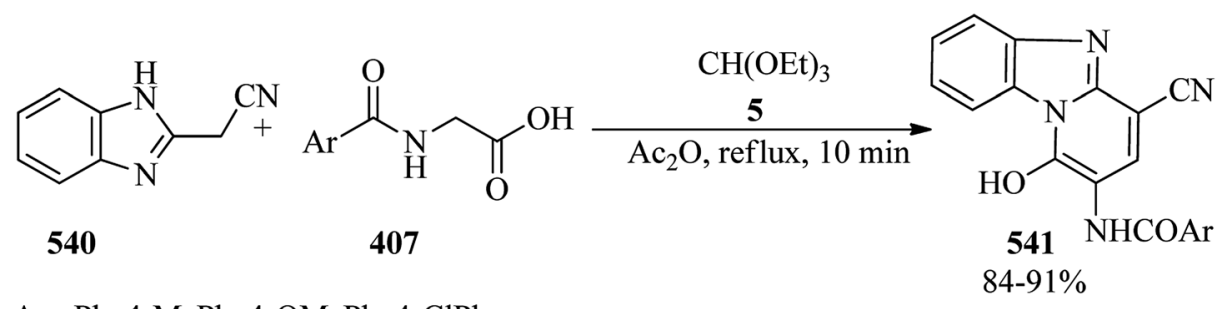

$\mathrm{Ar}=\mathrm{Ph}, 4-\mathrm{MePh}, 4-\mathrm{OMePh}, 4-\mathrm{ClPh}$

Scheme 158 The synthesis of pyrido[1,2-a]benzimidazole derivatives. 


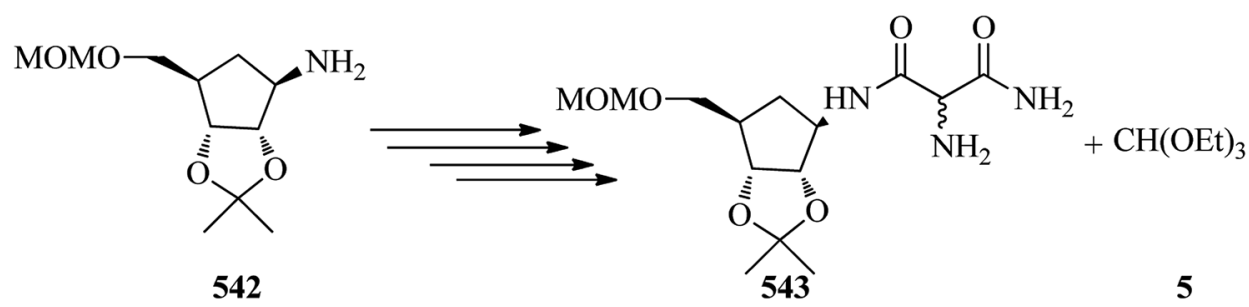

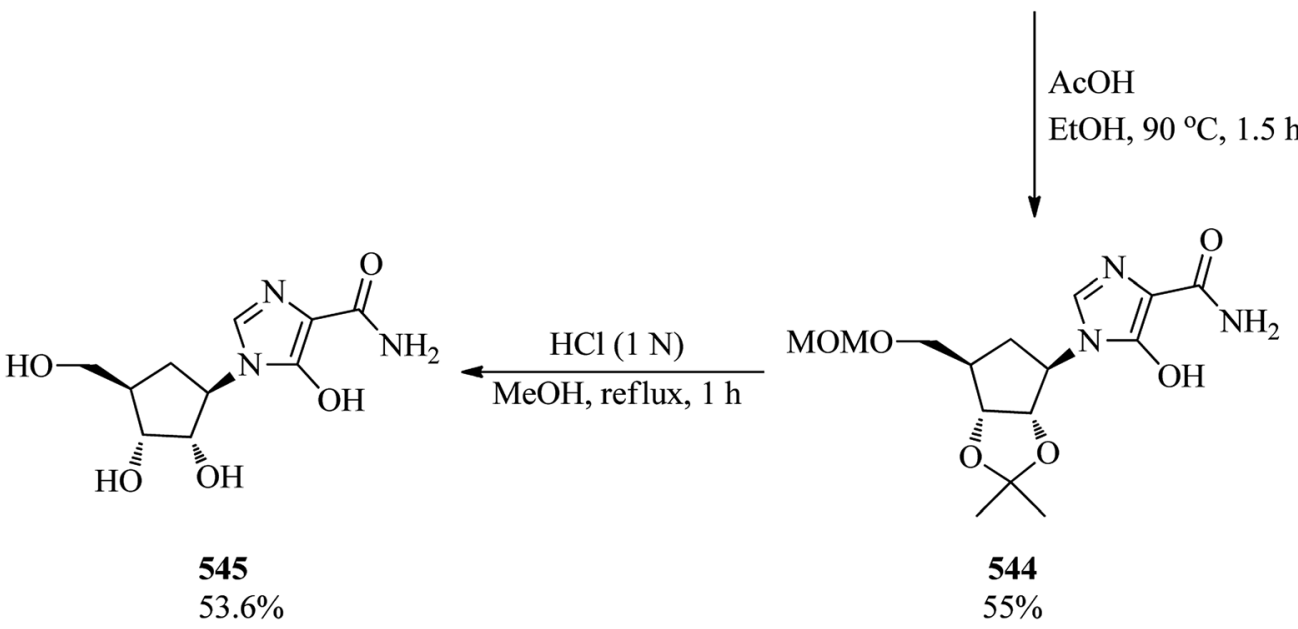

Scheme 159 Synthesizing a carbocyclic analog of bredinin.

ethanol under reflux conditions yielding 2-substituted and 2,5disubstituted 1,3,4-oxadiazoles (532 $)^{435-437}$ within $0.5-10 \mathrm{~h}$, in $22-98 \%$ yields (Scheme 155). The reaction was successful with electron-releasing and electron-withdrawing groups on the arylhydrazide precursor and progressed gently for both nonaromatic and aromatic orthoesters. ${ }^{438}$

In 2014, Al-Majidi obtained 1,2,4-triazolo[3,4-b] benzothiazole (534) as pale yellow crystals on treatment of 2-hydrazinobenzothiazole (533) with TEOF (5) in the presence of a few drops of acetic acid in refluxing methanol for $3 \mathrm{~h}$ in $65 \%$ yield (Scheme 156). The synthesized compound showed moderate antimicrobial activity against Serratia but was inactive against Staphylococcus aureus. ${ }^{439}$

2-Oxo-2H-pyrimido[2,1-b] benzothiazole-3-carbonitriles were prepared through the cyclocondensation of cyanoacetamides with TEOF in nitrobenzene at $190-200{ }^{\circ} \mathrm{C}$ in $77-79 \%$ yields within 3 h. ${ }^{440}$ In 2010 , the Jeffries-EL group prepared some classes of synthetically useful 2,6-disubstituted benzobisthiazoles (539) based on the Lewis acid-catalyzed ring-closing reaction between diamino benzene dithiol (535) and substituted orthoesters $(\mathbf{5}, \mathbf{6}, \mathbf{5 3 6}, \mathbf{5 3 7}, \mathbf{5 3 8})$ in dimethylacetamide (DMA) as organic solvent (Scheme 157). These products

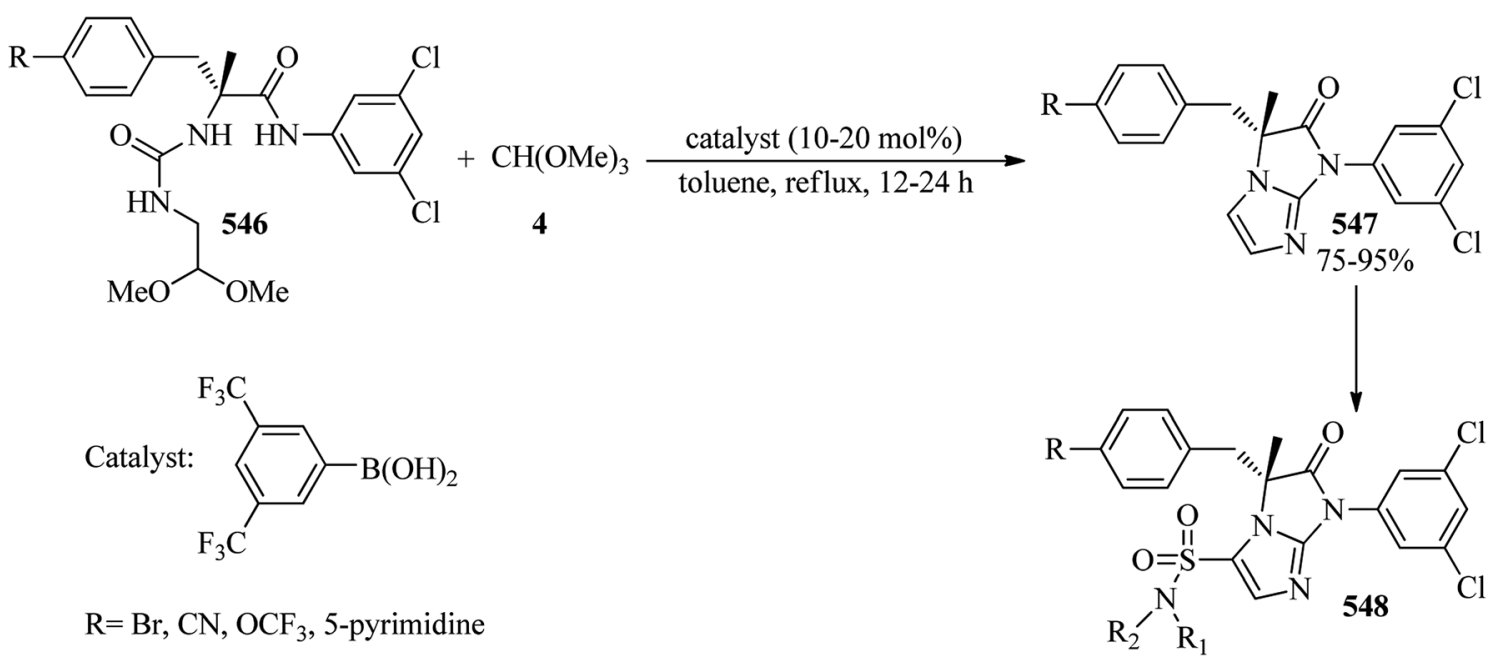

Scheme 160 The cyclodehydration of ureas with TMOF. 


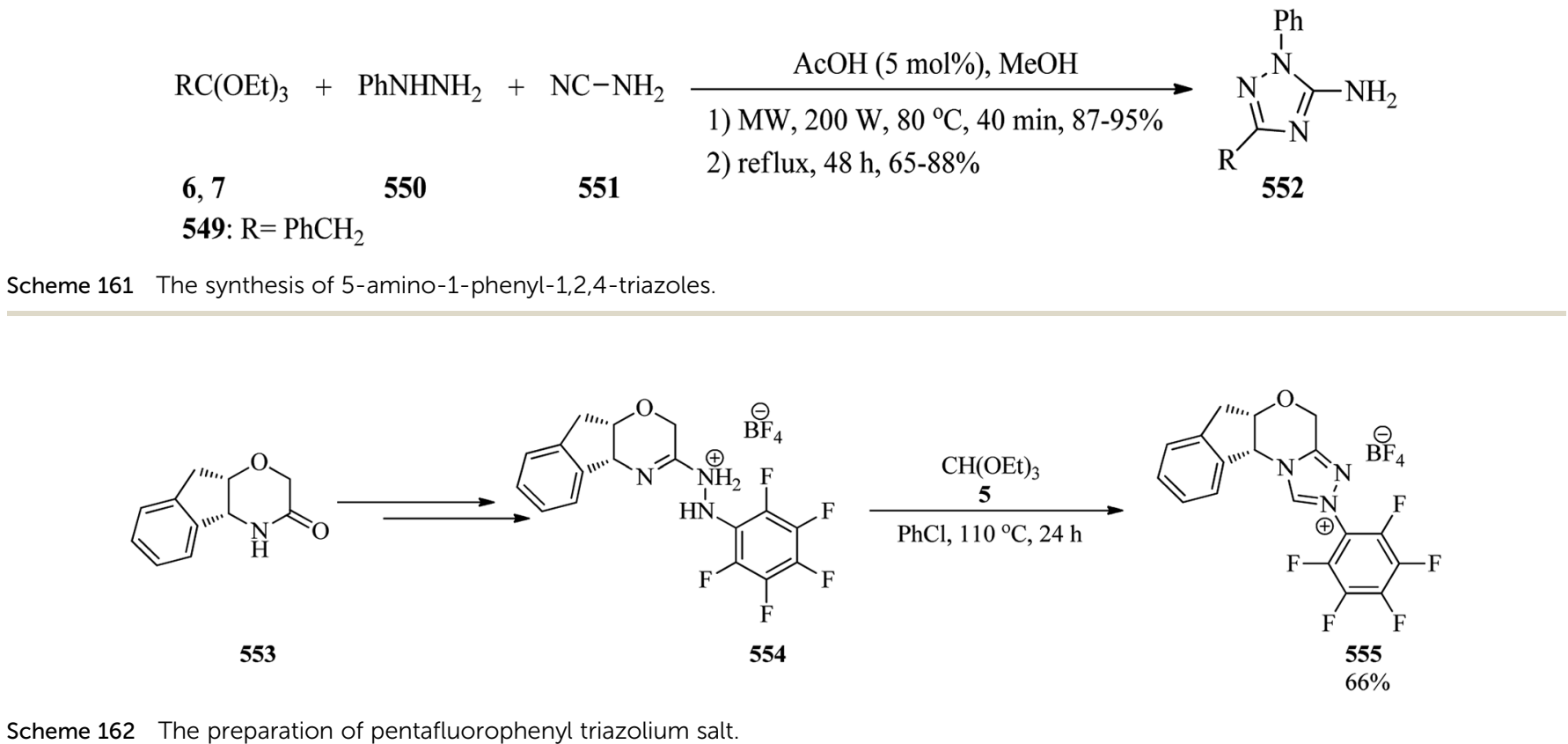

are of interest for the development of new organic semiconductors. $^{\mathbf{4 4 1}}$

Wang et al. developed a mild and facile two-step one-pot method for the synthesis of benzo and heteroaromatic fused imidazoles. ${ }^{\mathbf{4 4 2 - 4 4 5}}$ In first step, ortho-nitroanilines were converted into ortho-diamines by the reduction of the nitro group using iron powder. In the next step, cyclization occurred between ortho-diamines and TEOF by catalytic amounts of ytterbium triflate $(0.005$ equiv. $)$ in acetic acid $(1.0 \mathrm{M})$ at $75{ }^{\circ} \mathrm{C}$ to obtain the corresponding imidazoles within 3 h. ${ }^{\mathbf{4 4 5}}$ Benzimidazoles $^{\mathbf{3 0 8 , 4 4 6 , 4 4 7}}$ were also prepared by Zhang et al. from $o$-phenylenediamines with orthoesters using sulfamic acid (0.05 $\mathrm{mmol}$ ) in methanol at room temperature in $0.5-5 \mathrm{~h}$ in excellent yields (85-98\%). ${ }^{47} \mathrm{ZrCl}_{4}$ in ethanol at room temperature also accelerated this transformation within $0.8-6 \mathrm{~h}$ in excellent yields (81-95\%). ${ }^{448}$ In 2004, the one-pot three-component reaction of 2-cyanobenzimidazole (540), TEOF (5), and hippuric acid (407) was presented for the synthesis of pyrido[1,2- $a]$ benzimidazole derivatives $(\mathbf{5 4 1})^{359,449}$ in refluxing acetic anhydride within $10 \mathrm{~min}$, in excellent yields (84-91\%) (Scheme 158). ${ }^{359}$

Due to the noteworthy biological activities of the natural nucleoside antibiotic, bredinin, such as antiviral and antihepatitis $\mathrm{C}$ effects, and its versatile biological activities, Nair and Zhang synthesized a new carbocyclic analog of bredinin (545) using (3aS,4R,6R,6aR)-6-((methoxymethoxy)methyl)-2,2dimethyltetrahydro-3aH-cyclopenta $[d][1,3]$ dioxol-4-amine (542)

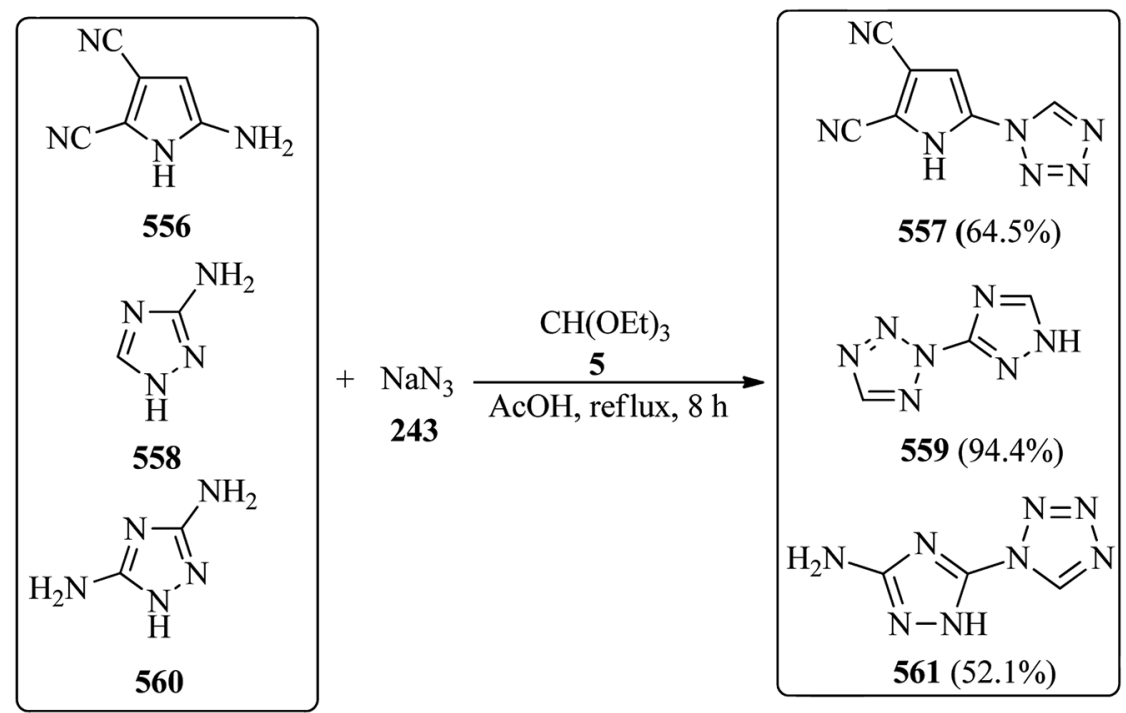

Scheme 163 Synthesizing a library of nitrogen-rich heterocycles. 


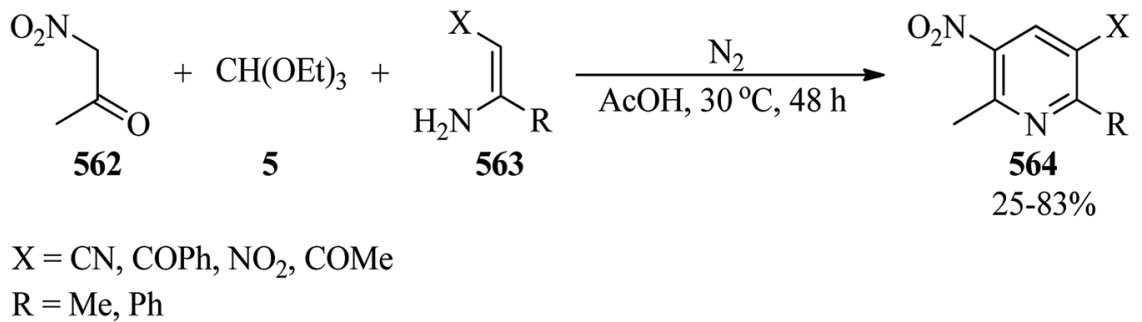

Scheme 164 The cyclocondensation of nitroacetone, TEOF, and enamines.

as a key precursor. In the first step, (542) was converted into the malondiamide intermediate (543) via side-chain functional group conversions. Subsequently, (543) on reaction with TEOF (5) by acetic acid as catalyst under heating in ethanol at $90{ }^{\circ} \mathrm{C}$ underwent cyclization to afford the appropriate 4-carbamoylimidazolium-5-olate ring (544) within $1.5 \mathrm{~h}$ in moderate yield $(55 \%)$. In the final step, the deprotection reaction of the recent compound (544) resulted in (545) (Scheme 159). The resultant product displayed antiviral activity, although it was low, against a number of RNA viruses. More biological properties are under investigation. ${ }^{450}$

The cyclodehydration of urea derivatives (546) with TMOF (4) was accomplished in the presence of boronic acid (10-20 mol\%) under refluxing toluene to attain compounds (547) in $75-95 \%$ yields in $12-24 \mathrm{~h}$ which as key intermediates were converted into a $1 H$-imidazo[1,2-a]imidazol-2-one LFA-1 antagonist (548) (Scheme 160). ${ }^{451}$

\subsection{Synthesis of thiadiazoles, triazoles, and $1 \mathrm{H}$-tetrazoles}

2-Alkylamino-1,3,4-thiadiazoles have been synthesized via the ethanol-mediated reaction of 4-alkylthiosemicarbazide and TEOF, in a $1: 2$ molar ratio, through the accelerated role of concentrated hydrochloric acid by Tomalia and Pmge in $1973 .{ }^{452}$ In 2015, Aouali et al. prepared 5-amino-1-phenyl-1,2,4-triazole derivatives (552) through the one-pot three-component reaction of orthoester $(6,7,549)$, phenylhydrazine $(\mathbf{5 5 0})$ and cyanamide (551) by acetic acid (5 mol\%) in methanol through two different pathways: (a) utilizing microwave irradiation $(200 \mathrm{~W})$ at $80^{\circ} \mathrm{C}$, and (b) under classical heating conditions. The results indicated shorter reaction times and higher yields by the microwave method (87-95\%, $40 \mathrm{~min}$ ) (Scheme 161). ${ }^{453}$

Kerr and co-workers synthesized various chiral and achiral 1,2,4-triazolium salts as key precursors for the generation of $\mathrm{N}$ heterocyclic carbine. In this paper, various 1,2,4-triazolium salts were obtained under different conditions, e.g. pentafluorophenyl triazolium salt (555) as a light tan solid was produced through the reaction of hydrazinium tetrafluoroborate (554), arising from morpholinone derivative (553), with TEOF (5) in chlorobenzene at $110{ }^{\circ} \mathrm{C}$ in $24 \mathrm{~h}$ in $66 \%$ yield (Scheme 162). ${ }^{454}$

Chuprun et al. synthesized tetrazoles via the enantioselective reaction of $\alpha$-amino acids with sodium azide and TEOF in the presence of glacial acetic acid both as catalyst and solvent at $55{ }^{\circ} \mathrm{C}$ within $4 \mathrm{~h}$ in weak to good yields $(23-83 \%)$. The product structure was characterized by ${ }^{1} \mathrm{H}$ and ${ }^{13} \mathrm{C}$ NMR and mass spectra, and their stereoisomeric excess amounts were assigned by chiral HPLC $(20-100 \%) \cdot{ }^{455}$ 1-(6,7,9,10,17,18,20,21-Octahydrodibenzo[ $b, k]-[1,4,7,10,13,16]$ hexaoxacyclooctadecen-2-yl)-

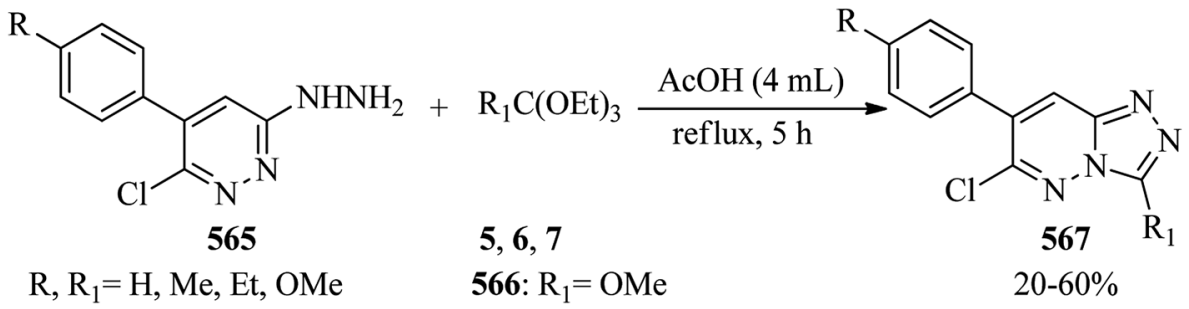

Scheme 165 The synthesis of some new [1,2,4]triazolo[4,3-b]pyridazines.

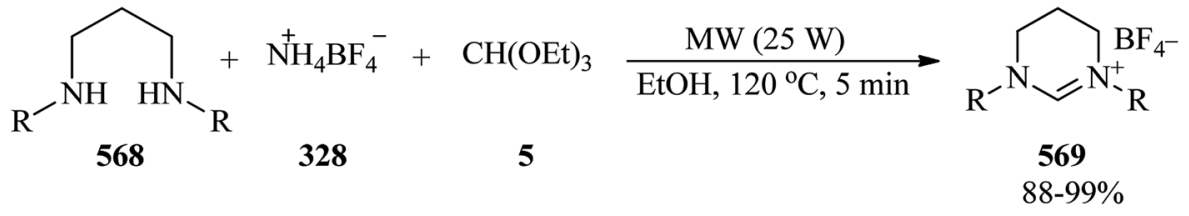

$\mathrm{R}=\mathrm{Me}, \mathrm{Et}, \mathrm{CH}(\mathrm{Me})_{2}, t-\mathrm{Bu}$, cyclohexyl

Scheme 166 The cyclization of $N, N^{\prime}$-dialkyl ethane-1,2-diamines with ammonium salts and TEOF. 
<smiles>CCOC(=O)c1sc(N)c(C(=O)OCC)c1C(=O)O</smiles><smiles>CCOC=Nc1sc(C(=O)OCC)c(C)c1C#N</smiles>

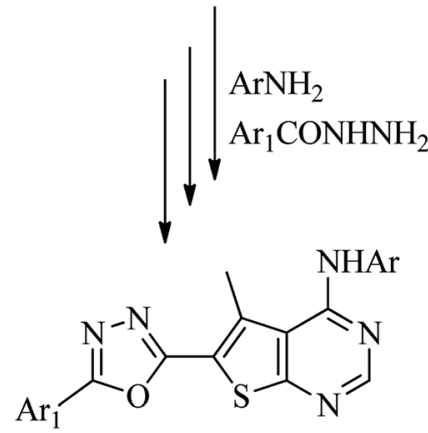

571

Scheme 167 Obtaining 1,3,4-oxadiazole tagged thieno[2,3-d]pyrimidine derivatives.<smiles>NC(=O)c1sc2nc(-c3cccs3)cc([Al])c2c1N</smiles>

$\mathrm{Ar}=4-\mathrm{OMePh}, 4-\mathrm{ClPh}$

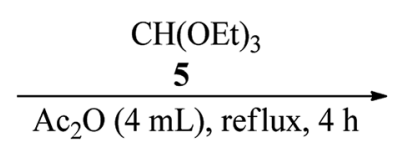<smiles>O=c1[nH]cnc2c1sc1nc(-c3cccs3)cc([Al])c12</smiles>

$80 \%$

Scheme 168 The formation of 9-aryl-7-(2'-thienyl)-pyrido[ $\left[3^{\prime}, 2^{\prime}: 4,5\right]$ thieno[3,2- $\left.d\right]$ pyrimidine-4(3H)-ones.

$1 H$-tetrazole (2) could be synthesized via the domino threecomponent reaction of an arylamino derivative of dibenzo-18crown-6 (1), TEOF, and sodium azide under heating in glacial acetic acid at $105{ }^{\circ} \mathrm{C}$ for $3 \mathrm{~h}$ in $73 \%$ yield. ${ }^{456} \mathrm{Yb}(\mathrm{OTf})_{3}$ also promoted the reaction of amines, TEOF, and sodium azide in 2methoxyethanol at $100{ }^{\circ} \mathrm{C}$ to prepare the 1 -susbstituted $1 H^{-}$ $1,2,3,4$-tetrazoles ${ }^{457-462}$ in $6-9 \mathrm{~h}$ in $71-91 \%$ yields. Some of the products revealed phytocidal activity. ${ }^{462}$ Muralidharan et al. also synthesized a library of nitrogen-rich heterocycles, such as 2-
(1H-tetrazol-1-yl)-1H-imidazole-4,5-dicarbonitrile (557), 1-(1H1,2,4-triazol-3-yl)-1H-tetrazole (559), and 5-(1H-tetrazol-1-yl)- $1 H$ 1,2,4-triazol-3-amine (561) via the critical role of TEOF. As could be seen, the above-mentioned compounds were obtained via the reaction of TEOF and also $\mathrm{NaN}_{3}$ (243) with 2-amino- $1 H^{-}$ imidazole-4,5-dicarbonitrile (556), $1 H$-1,2,4-triazol-3-amine (558), and $1 H-1,2,4$-triazole-3,5-diamine (560), as starting materials, respectively (Scheme 163). ${ }^{463}$<smiles>[R]c1ccc(-c2c(C(C)=O)c(C)nc3sc(C(N)=O)c(N)c23)cc1</smiles>

$\mathrm{R}=\mathrm{OMe}, \mathrm{Cl}$ $\mathrm{Ar}=\mathrm{Ph}, 4-\mathrm{MePh}, 4-\mathrm{ClPh}$<smiles>[R]c1ccc(-c2c(C(C)=O)c(C)nc3sc4c(=O)n([Al])cnc4c23)cc1</smiles>

Scheme 169 The preparation of 8-acetyl-3,9-diaryl-7-methylpyrido[3',2':4,5]thieno[2,3- $d]$ pyrimidine-4(3H)-ones. 


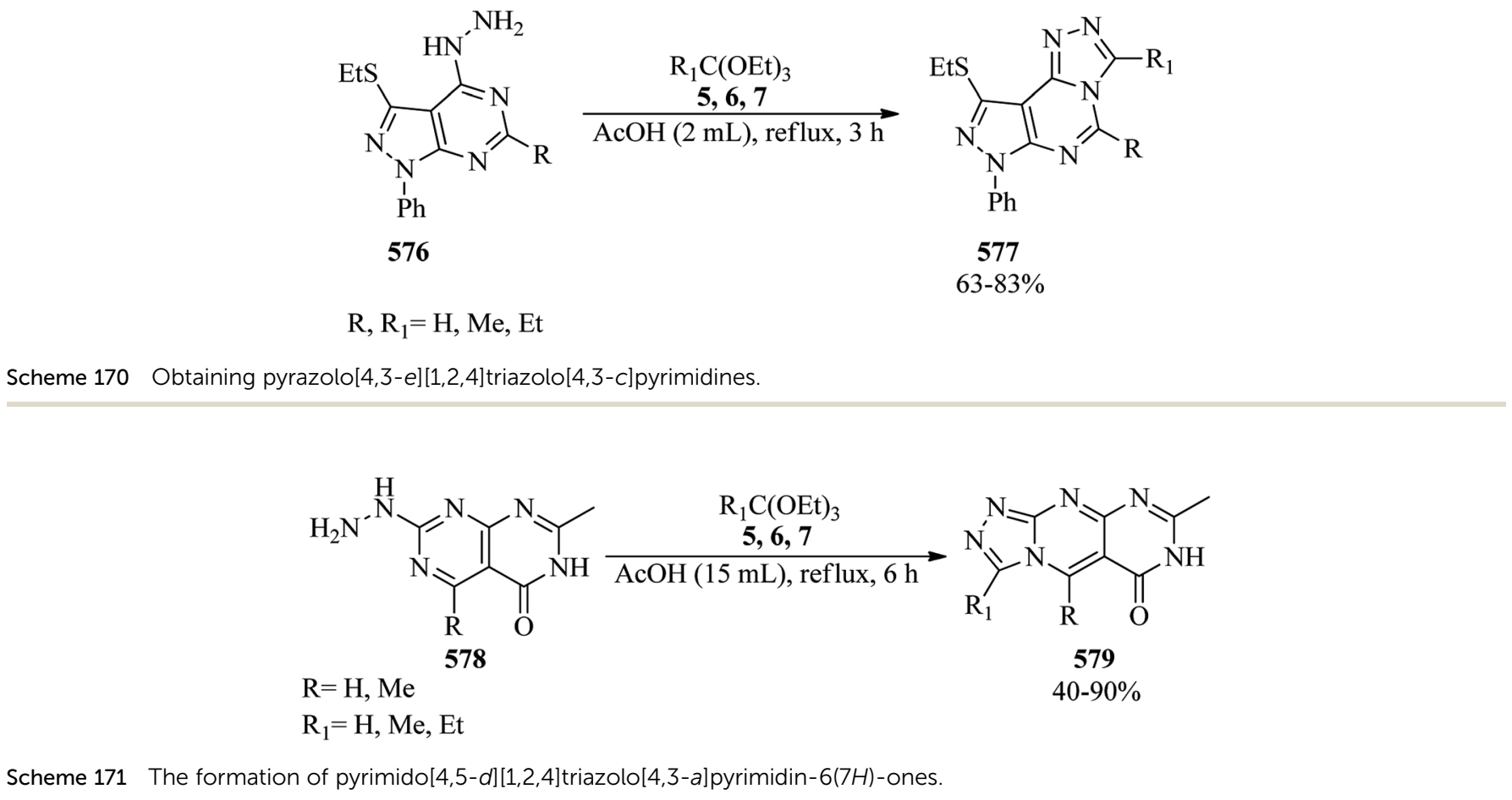

\subsection{Synthesis of pyridines}

5-Nitropyridines (564) were obtained by Sagitullina et al. via the cyclocondensation of nitroacetone (562), TEOF (5) and enamines (563) in acetic acid media (Scheme 164). ${ }^{464}$

\subsection{Synthesis of pyridazine derivatives}

6-Methyl-3,4-diphenylpyrimido $\left[4^{\prime}, 5^{\prime}: 4,5\right]$ selenolo[2,3-c]pyridazine-8 $(7 H)$-one was synthesized via the cyclocondensation reaction of 5-amino-3,4-diphenyl-6-substitutedselenolo[2,3-c] pyridazine with TEOF in acetic anhydride under reflux conditions within $8 \mathrm{~h}$ in $72 \%$ yield. ${ }^{465}$ In 2015 , Arghiani and coworkers reported a simple procedure for the synthesis of new $[1,2,4]$ triazolo[4,3-b]pyridazines $(567)$ on treatment of 6-choloro5-(4-substituted phenyl)-3-pyridazinyl hydrazines (565) with orthoesters $(\mathbf{5}, \mathbf{6}, \mathbf{7}, \mathbf{5 6 6})$ in refluxing acetic acid for $5 \mathrm{~h}$ (Scheme 165). The products were filtered off and crystallized from methanol. ${ }^{466}$

\subsection{Synthesis of tetrahydropyrimidinium salts}

The cyclization of $N, N^{\prime}$-dialkyl or diaryl ethane-1,2-diamines or propane-1,3-diamines (568) with inorganic ammonium salts
(328) and TEOF (5) proceeds under microwave irradiation to afford the corresponding imidazolinium or tetrahydropyrimidinium salts (569). As can be seen in the Scheme 166, the microwave-assisted preparation of some 1,3-diaryl-3,4,5,6tetrahydropyrimidium tetrafluoroborates was performed in ethanolic media. The TEOF is in 2-6 excess to the other substrates. ${ }^{467}$

\subsection{Synthesis of pyrimidine derivatives}

In the synthetic route to obtain 1,3,4-oxadiazole tagged thieno $[2,3-d]$ pyrimidine derivatives (571), the first step was reported via the reaction of 5-amino-4-cyano-3-methylthiophene-2carboxylate (570) with TEOF, in refluxing toluene through the catalytic activity of acetic acid (Scheme 167). ${ }^{468}$

In 2003, Abdel-Rahman and coworkers have reported that pyridine-2-carboxamide derivatives (572) were reacted with TEOF in refluxing acetic anhydride to furnish white crystals of 9aryl-7-(2'-thienyl)-pyrido $\left[3^{\prime}, 2^{\prime}: 4,5\right]$ thieno $[3,2-d]$ pyrimidine$4(3 H)$-ones $(\mathbf{5 7 3})$ (Scheme 168). ${ }^{\mathbf{4 6 9 - 4 7 1}}$

The cyclocondensation of 5-acetyl-3-amino-4-aryl-2-( $N$-aryl $)$ carbamoyl-6-methyl-thieno[2,3-b]pyridines (574) with TEOF was<smiles>[R16]c1nc2c(C)n3c([R])nnc3nc2s1</smiles>

$\mathrm{R}=-\mathrm{CH}_{2}\left(\mathrm{CH}_{2}\right)_{2} \mathrm{CH}_{2}-,-\mathrm{CH}_{2}\left(\mathrm{CH}_{2}\right)_{3} \mathrm{CH}_{2}-,-\mathrm{CH}_{2} \mathrm{CH}_{2} \mathrm{OCH}_{2} \mathrm{CH}_{2}-,-\mathrm{CH}_{2} \mathrm{CH}_{2} \mathrm{NMeCH}_{2} \mathrm{CH}_{2}-$ $\mathrm{R}_{\mathrm{l}}=\mathrm{H}, \mathrm{Me}$ 
<smiles>Nc1nonc1-c1nc2ccccc2[nH]1</smiles>

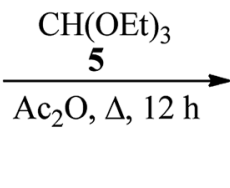
583

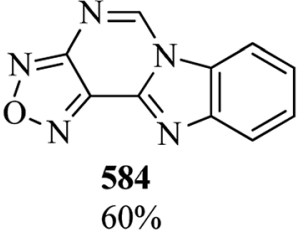

Scheme 173 The synthesis of benzo[4,5]imidazo[1,2-c]-[1,2,5]oxadiazolo[3,4-e]pyrimidine.

accomplished in refluxing acetic anhydride, in a dual role of catalyst and solvent, to achieve 8-acetyl-3,9-diaryl-7-methylpyr$\operatorname{ido}\left[3^{\prime}, 2^{\prime}: 4,5\right]$ thieno[2,3- $\left.d\right]$ pyrimidine-4(3H)-ones $(\mathbf{5 7 5})^{325,472}$ in excellent yields (87-94\%) in $2 \mathrm{~h}$ (Scheme 169). ${ }^{325}$

Pyrazolo[4,3-e][1,2,4] triazolo[4,3-c]pyrimidines (577) were produced via the cyclocondensation reaction of pyrazolo[3,4- $d]$ pyrimidine (576) with triethyl orthoesters $(5,6,7)$ in a $1: 2$ molar ratio in acetic acid, in a dual role of solvent and catalyst, under reflux conditions within $3 \mathrm{~h}$ in $63-83 \%$ yields (Scheme 170). ${ }^{473}$

Pyrimido[4,5- $d][1,2,4]$ triazolo[ $[4,3-a]$ pyrimidin-6(7H)-ones (579) were made through cyclocondensation of 7-hydrazinylsubstituted pyrimido[4,5-d]pyrimidin-4(3H)-ones (578) with triethyl orthoesters $(\mathbf{5}, \mathbf{6}, \mathbf{7})$ in equimolar amounts in refluxing $\mathrm{AcOH}$ in a $6 \mathrm{~h}$ period in $40-90 \%$ yields (Scheme 171). The products showed fluorescent and photophysical properties. ${ }^{474}$

In 2016, 2,4-dichloro-5-amino-6-methylpyrimidine (580) was applied as a starting material for the synthesis of 5-hydrazinyl-7- methyl[1,3]thiazolo[5,4- $d]$ pyrimidines (581) via a multi-step reaction which, on a cyclization reaction with orthoesters $(\mathbf{5}$, 6) in refluxing acetonitrile using catalytic amounts of acetic acid along with the elimination of 3 moles of ethanol, furnished novel thiazolo[5,4- $d][1,2,4]$ triazolo[4,3-a]pyrimidines (582) for $2-4 \mathrm{~h}$ in high yields $(62-89 \%)$ (Scheme 172). ${ }^{475}$

Benzo[4,5]imidazo[1,2-c]-[1,2,5] oxadiazolo[3,4-e]pyrimidine (584) was obtained via the cyclocondensation of 3-amino-4- $\left(1 H^{-}\right.$ benzo[d]imidazol-2-yl)-1,2,5-oxadiazole (583) with TEOF in boiling acetic anhydride for $12 \mathrm{~h}$, in $60 \%$ yield (Scheme 173). ${ }^{476}$

6-\{[(5-Nitrothiophen-2-yl)methylene]amino\}-3-phenyl-2-thioxo-2,3-dihydrothiazolo-[4,5- $d]$-pyrimidin- $7(6 H)$-one $\quad(587)^{477,478}$ as a brown compound was prepared via the cyclocondensation of thiazoline derivative (586), arising from 5-nitro-2thiophenecarboxaldehyde (585), with TEOF in the presence of acetic anhydride under reflux conditions within $3 \mathrm{~h}$ in $61 \%$ yield (Scheme 174). The product (587) revealed good antiinflammatory activity. ${ }^{478}$

Due to the growing biological importance of fused thiazoles, in 2007, Bondock et al. employed 1-chloro-3,4dihydronaphthalene-2-carboxaldehyde (588) as a key precursor for the formation of thiazoline derivative (589) via a multi-step reaction. Subsequent cyclization with TEOF in acetic anhydride under reflux conditions yielded the thiazolo[5,4- $d]$ pyrimidine derivative (590) in 60\% yield in $3 \mathrm{~h}$ (Scheme 175). The compounds were screened and evaluated as antimicrobial agents. ${ }^{479}$

In 1998, Porcari and Townsend developed a fast and efficient method for the preparation of 4-amino-6-bromo-5-cyanopyrrolo

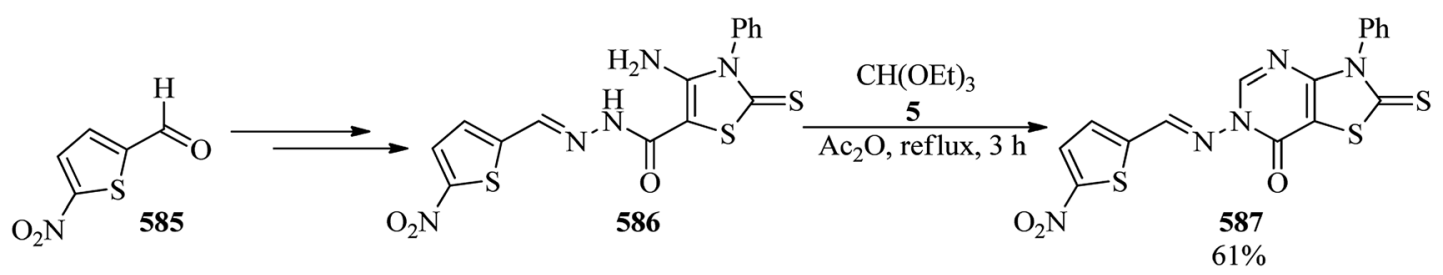

Scheme 174 The synthesis of 6-\{[(5-nitrothiophen-2-yl)methylene]amino\}-3-phenyl-2-thioxo-2,3-dihydrothiazolo-[4,5-d]-pyrimidin-7(6H)one.

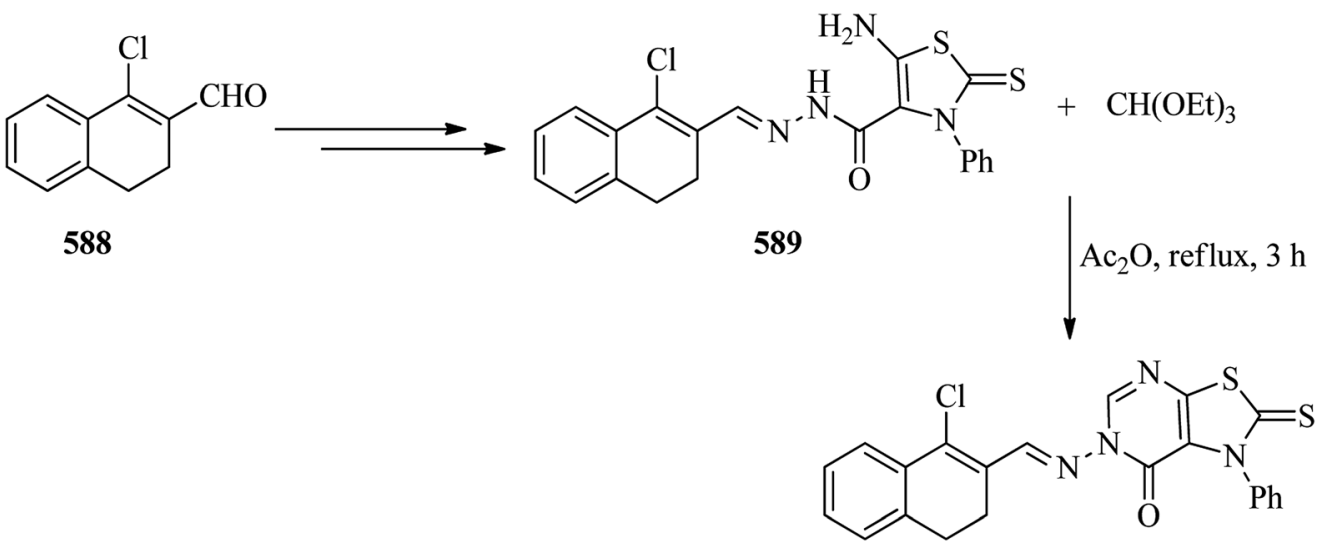




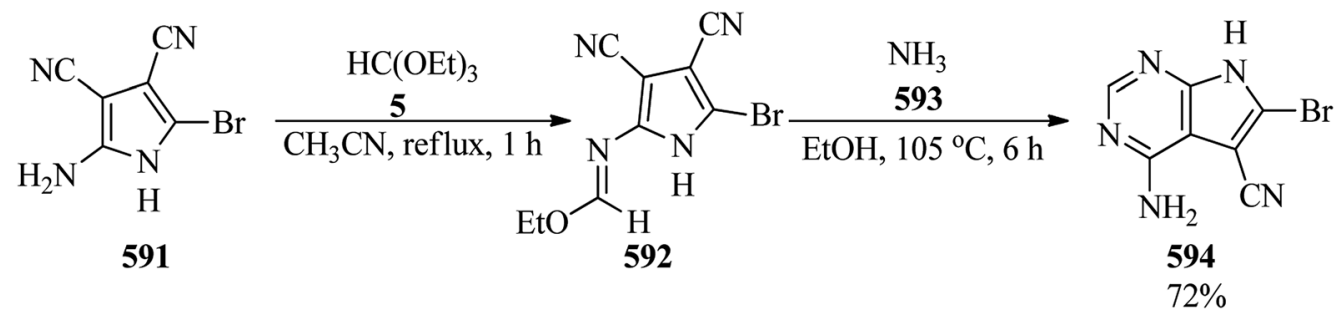

Scheme 176 The preparation of 4-amino-6-bromo-5-cyanopyrrolo[2,3-d]pyrimidine.

[2,3- $d]$ pyrimidine (594) from 2-amino-5-bromo-3,4dicyanopyrrole (591), TEOF (5), and ethanolic ammonia (593). In the first step the reaction of 2-amino-5-bromo-3,4dicyanopyrrole (591) with triethylorthoformate (5) in dry acetonitrile at reflux temperature, for $1 \mathrm{~h}$ formed 2-bromo-5(ethoxymethylene)iminopyrrole-3,4-dicarbonitrile (592) which was used without further purification. Ring annulation to obtain 4-amino-6-bromo-5-cyanopyrrolo[2,3-d]pyrimidine (594) was accomplished by dissolving the unpurified intermediate (592) in saturated ethanolic ammonia and heating this mixture at $105{ }^{\circ} \mathrm{C}$ in a sealed steel reaction vessel for $6 \mathrm{~h}$ (Scheme 176). ${ }^{480}$
In 2015, Abdel Hameed et al. demonstrated a regioselective procedure for the synthesis of pyrazolo[1,5- $a]$ pyrimdines- $7(4 H)$ ones (598) via the reaction of 5-amino pyrazoles (595), Meldrum's acid (231), and TEOF (5) in dioxane at room temperature. This transformation took place via a Knoevenagel condensation of Meldrum's acid (231) with TEOF (5) to produce intermediate (596), as a Michael acceptor, followed by the regioselective Michael addition with the exocyclic amino moiety of 5-amino pyrazoles (595) to obtain the corresponding acyclic adducts (597) in dioxane at room temperature; which after isolation underwent an intramolecular cyclization and then the

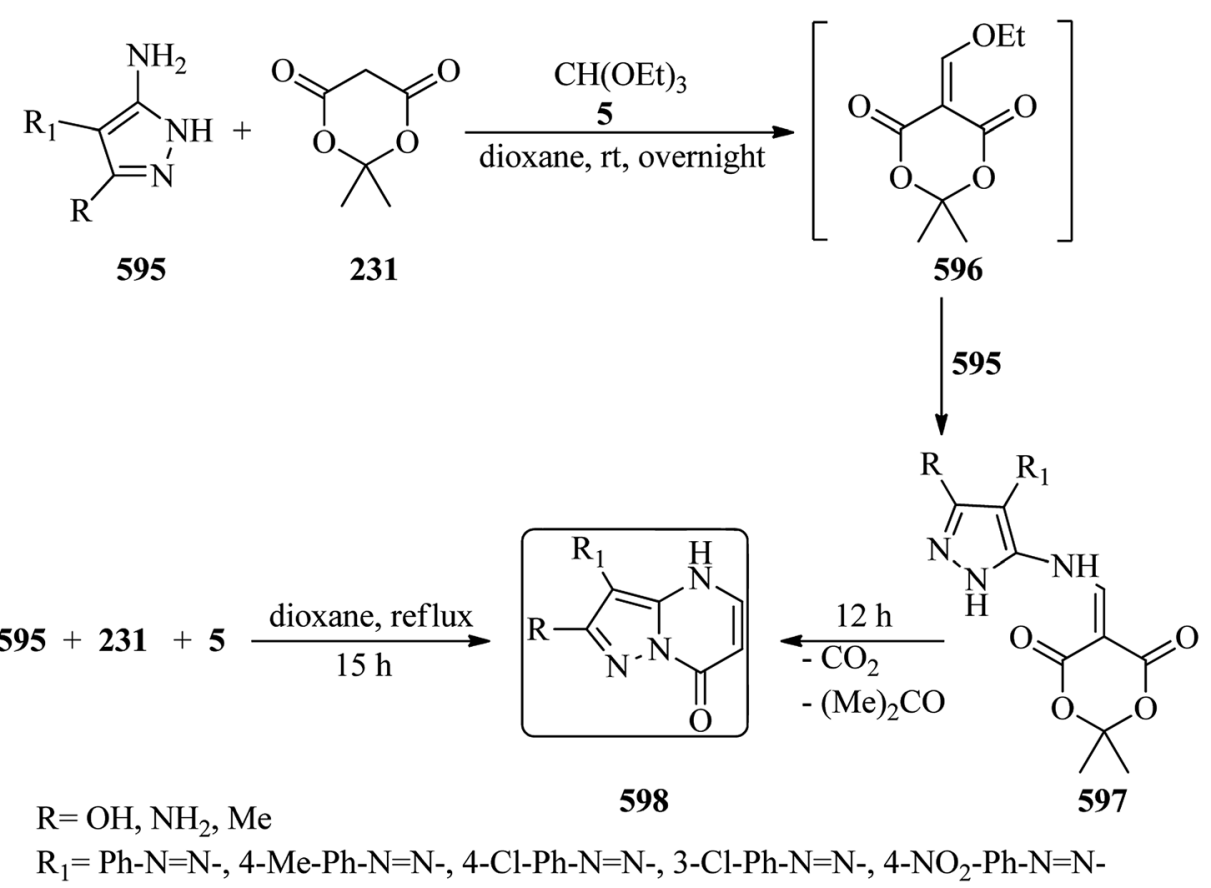

Scheme 177 The regioselective synthesis of pyrazolo[1,5-a]pyrimdines-7(4H)-ones.

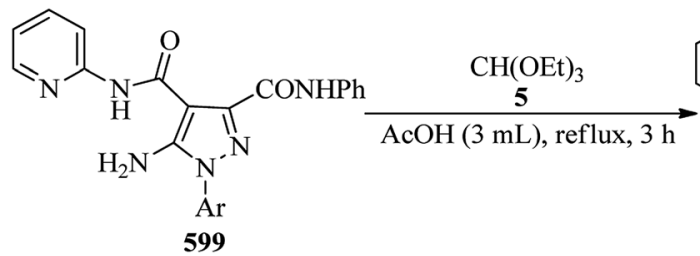<smiles></smiles>

600<smiles>[Y1]n1nc(C(=O)Nc2ccccc2)c2c(=O)n(-c3ccccc3)cnc21</smiles>

601

Scheme 178 The synthesis of pyrazolo[3,4-d]pyrimidin-4-ones. 


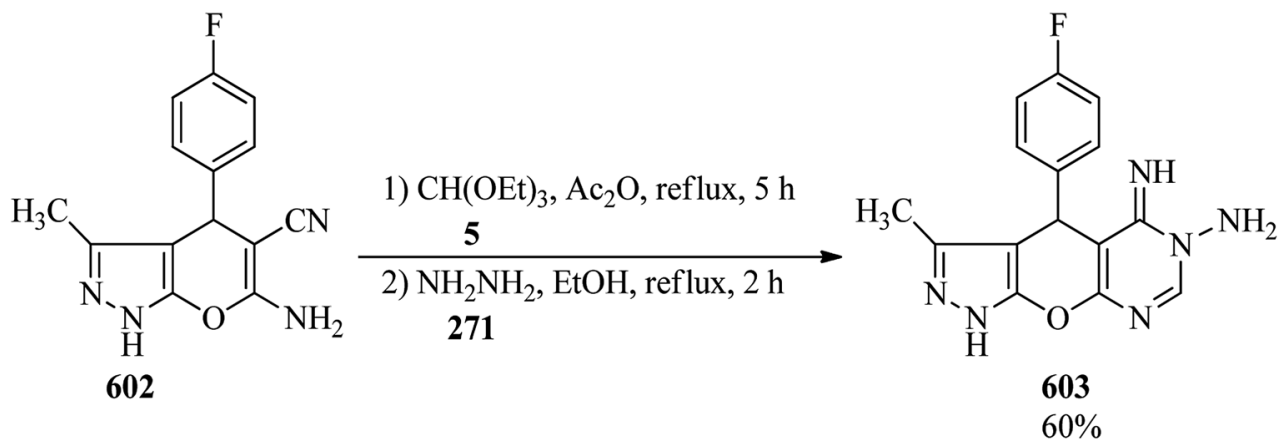

Scheme 179 The preparation of 4-(4-fluorophenyl)-5-imino-3-methyl-1,4-dihydropyrazolo[4', $\left.3^{\prime}: 5,6\right]$ pyrano[2,3-d]pyrimidin-6(5H)-amine.

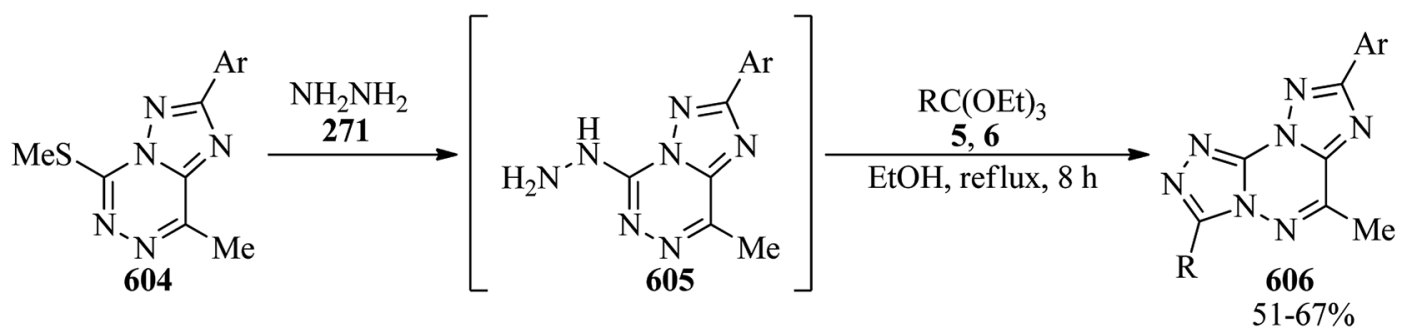

$\mathrm{Ar}=\mathrm{Ph}, 3-\mathrm{MePh}, 4-\mathrm{MePh}$

$\mathrm{R}=\mathrm{H}, \mathrm{Me}$

Scheme 180 The preparation of new bis[1,2,4]triazolo[4,3-b:1', $\left.5^{\prime}-d\right][1,2,4]$ triazines.

elimination of acetone and $\mathrm{CO}_{2}$ to get pyrazolo[1,5- $a$ ]pyrimdines-7(4H)-ones (598) in refluxing dioxane for $12 \mathrm{~h}$. The compound (598) could also be directly obtained at once via the one-step condensation reaction of substrates in refluxing dioxane for $15 \mathrm{~h}$ (Scheme 177). ${ }^{481}$

In 2008, a facile and high-yielding process was developed for the synthesis of pyrazolo[3,4- $d]$ pyrimidin-4-ones (601) in excellent yields (82-92\%). First, aminopyrazoles (599) were condensed with TEOF (5) in glacial acetic acid under reflux conditions for $3 \mathrm{~h}$ to form the intermediate (600) which was then followed by cyclization and removal of an equivalent ethanol to achieve (601) (Scheme 178). ${ }^{482}$

In 2015, 6-amino-3-methyl-4-fluorophenyl-1,4-dihydro-pyrano[2,3-c]pyrazole-5-carbonitrile (602) was employed as

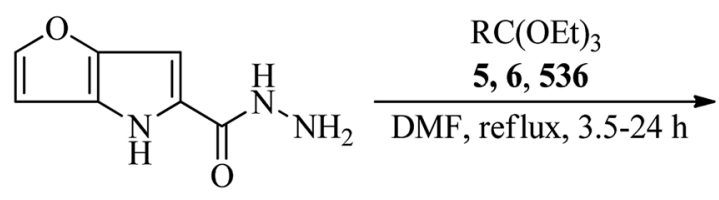

607

$\mathrm{R}=\mathrm{H}, \mathrm{Me}, \mathrm{CH}_{2} \mathrm{Cl}$<smiles>[R]c1[nH]c(=O)c2cc3occc3n2c1[Y9]</smiles>

$69-75 \%$

Scheme 181 The synthesis of furo[2',3':4,5]pyrrolo[1,2-d][1,2,4]triazin-8(7H)-ones.<smiles>[R]c1ccc2[nH]c(C(=O)[O-])c(C)c2c1</smiles>

609

$\mathrm{R}=\mathrm{H}, \mathrm{Me}, \mathrm{OMe}, \mathrm{OEt}, \mathrm{Cl}$<smiles>[R]c1ccc2cn3c4n[nH][nH]c(=O)c4c(C)c3c2c1</smiles>

$70-78 \%$

Scheme 182 The formation of new 8-substituted-10-methyl-l,2-dihydro-1-oxo-l,2,4-triazino[4,5-a]indoles. 


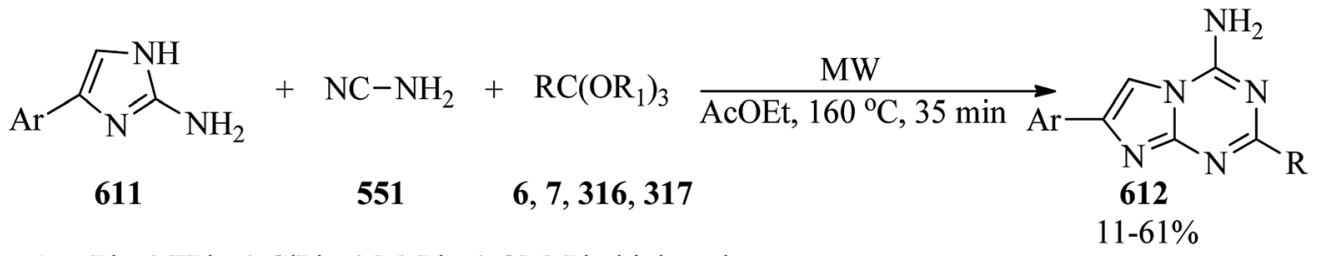

$\mathrm{Ar}=\mathrm{Ph}$, 4-FPh, 4-ClPh, 4-MePh, 4-OMePh, biphenyl

$\mathrm{R}=\mathrm{Et}, \mathrm{Pr}, \mathrm{Bu}$

$\mathrm{R}_{1}=\mathrm{Et}$

Scheme 183 The synthesis of new 2-alkyl substituted 4-aminoimidazo[1,2-a][1,3,5]triazines

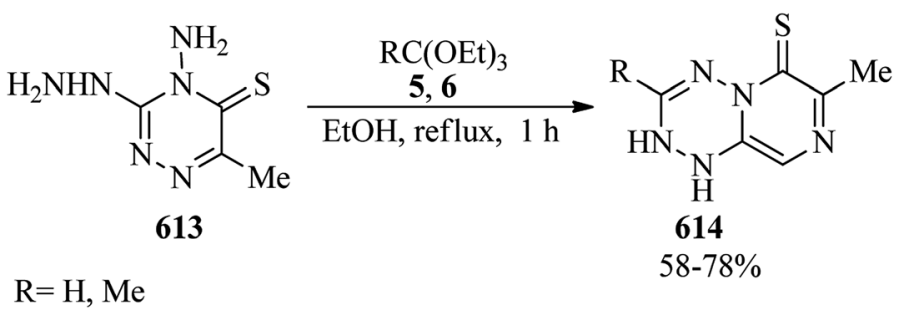

Scheme 184 The preparation of $[1,2,4]$ triazino[3,4-b][1,2,4,5]-tetrazine-6-thiones

a starting material for the preparation of 4-(4-fluorophenyl)-5imino-3-methyl-1,4-dihydropyrazolo $\left[4^{\prime}, 3^{\prime}: 5,6\right]$ pyrano[2,3- $\left.d\right]$ pyrimidin-6(5H)-amine $(\mathbf{6 0 3})^{\mathbf{4 8 3}, \mathbf{4 8 4}}$ as yellow powder. Hence, in the first step, (602) was condensed with TEOF (5) in refluxing acetic anhydride for $5 \mathrm{~h}$; which was followed by the reaction of the isolated solid with hydrazine hydrate (271) in ethanol under reflux conditions for $2 \mathrm{~h}$ to produce (603) in 60\% yield (Scheme 179). The product was screened for antibacterial and antifungal activities compared with norfloxacin and fluconazole as standard drugs. ${ }^{484}$

\subsection{Synthesis of triazine derivatives}

Montazeri et al. established a simple and catalyst-free method for the preparation of new bis[1,2,4]triazolo[4,3-b:1 $\left.1^{\prime}, 5^{\prime}-d\right][1,2,4]$ triazines (606). This reaction progressed through the nucleophilic substitution reaction of 8-methyl-5-methylthio-2-aryl-6 $\mathrm{H}$ -<smiles>Cc1ccc(-c2c3nnc4ccccc4c3nc3sc4c(=N)n(N)cnc4c23)cc1</smiles>

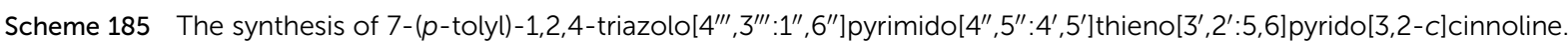

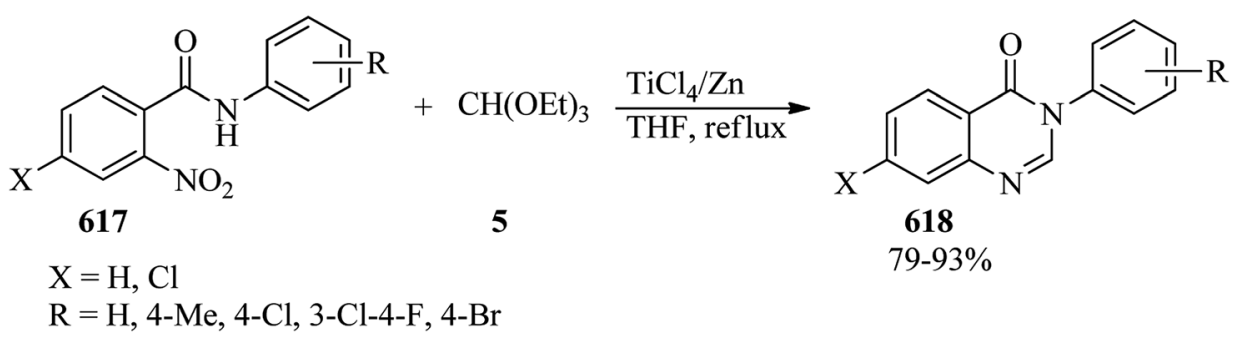

Scheme 186 The synthesis of quinazolin-4(3H)-ones. 
<smiles>[R]c1cc2nc3c4ccccc4[nH]/c(=N\N)n3c2cc1[R]</smiles>

619

$$
\begin{aligned}
& \mathrm{R}=\mathrm{H}, \mathrm{Me} \\
& \mathrm{R}_{1}=\mathrm{H}, \mathrm{Me}, \mathrm{Et}
\end{aligned}
$$<smiles>[R]c1cc2nc3c4ccccc4n4c([R])nnc4n3c2cc1[R]</smiles>

Scheme 187 Obtaining new benzimidazo[1,2-c][1,2,4]triazolo[4,3-a]quinazolines.

$[1,2,4]$ triazolo[1,5- $d][1,2,4]$ triazines (604) with hydrazine hydrate (271) in refluxing ethanol for $3 \mathrm{~h}$ to generate 5-hydrazino compounds (605); which was followed a cyclocondensation by triethyl orthoesters $(5, \mathbf{6})$ under refluxing in ethanol for $8 \mathrm{~h}$ to produce products (606) in 51-67\% yields (Scheme 180). ${ }^{485}$

In 2017, the Zemanová group reported that $4 H$-furo[3,2-b] pyrrole-5-carbohydrazide $(\mathbf{6 0 7})$ on reaction with orthoesters $(\mathbf{5}$, 6, 536) in a polar solvent like DMF under reflux conditions yielded furo $\left[2^{\prime}, 3^{\prime}: 4,5\right]$ pyrrolo[1,2- $\left.d\right][1,2,4]$ triazin-8(7H)-ones (608) within $3.5-24 \mathrm{~h}$, in high yields (69-75\%) (Scheme 181). The products were screened for their antibacterial activity on Gram-negative bacterial species Escherichia coli CCM 7929, Pseudomonas syringae CCM 2114 and Gram-positive bacterial species Micrococcus luteus CCM 732, Bacillus pumilus CCM 2218 and it was found to have good activity. ${ }^{486}$

In 1989, some new 8-substituted-10-methyl-1,2-dihydro-1oxo-1,2,4-triazino[4,5-a]indoles (610) were prepared in $70-78 \%$ yields from the reaction of various 3-methylindole-2- carbohydrazides (609) with TEOF (5) in refluxing dimethylformamide within $8 \mathrm{~h}$ (Scheme 182). These derivatives were evaluated for their antimicrobial activity. Most of the compounds showed good activity against Gram-negative bacteria such as Escherichia coli and Pseudomonas aeruginosa. Chloro-substituted derivatives showed the highest activity against all of the organisms tested. ${ }^{487}$

In 2018, Lim and et al. described a chemo- and regioselective procedure for the synthesis of new 2-alkyl substituted 4-aminoimidazo[1,2-a][1,3,5]triazines (612) in weak to good yields (11-61\%) via the catalyst-free one-pot three-component reaction of 2-aminoimidazoles (611), trialkylorthoesters $(6,7,316,317)$, and cyanamide (551) under microwave irradiation (Discover SP CEM) at $160^{\circ} \mathrm{C}$ in ethyl acetate for $35 \mathrm{~min}$ (Scheme 183). It was found that a growth in length of the alkyl chain group on compound (612) resulted in a reduction in isolated yields. For example, the products originating from TEOAc (6) and triethyl orthopropionate, (7) obtained higher isolated yields than

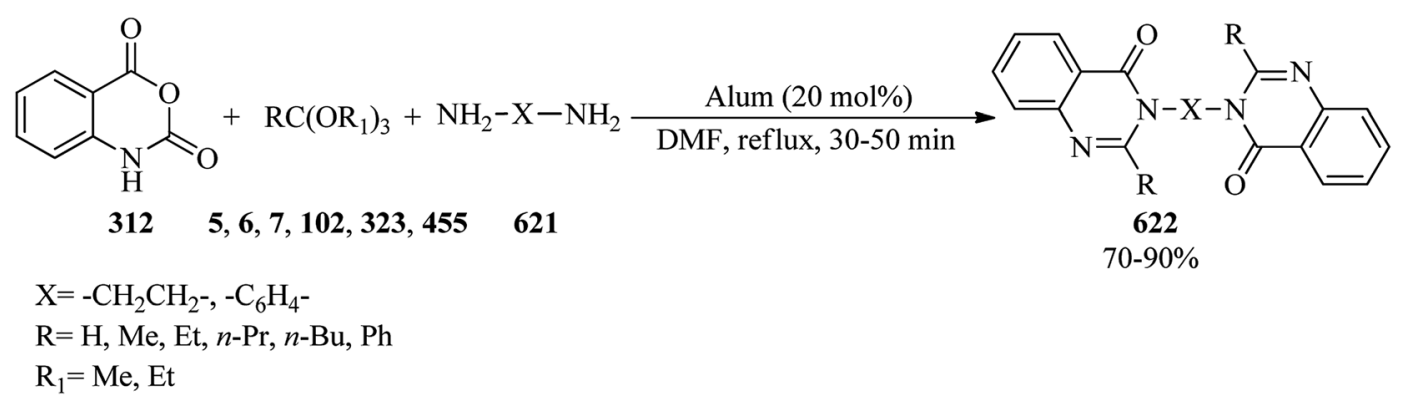

Scheme 188 The formation of bis(quinazolinon-4(1H)-one) derivatives.

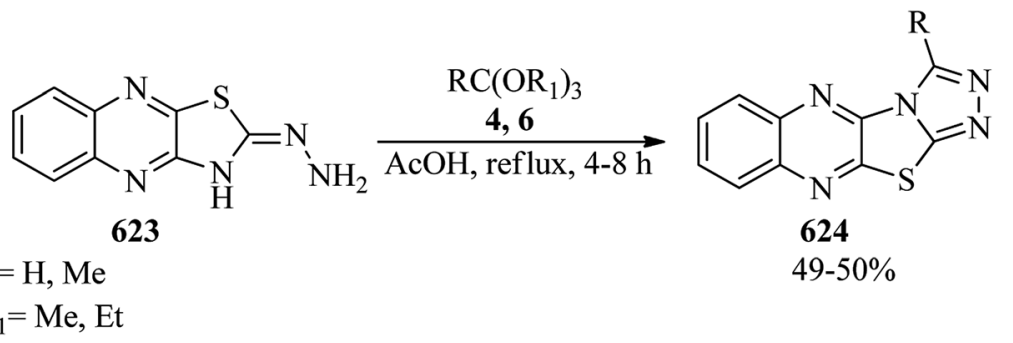

Scheme 189 The synthesis of novel 3 -substitued $[1,2,4]$ triazolo $\left[3^{\prime}, 4^{\prime} ; 2,3\right][1,3]$ triazolo[4,5-b]quinoxalines. 
<smiles>C#CCOC1(c2ccccc2)OC2OC(COc3ccccc3)C1C2(Cc1ccccc1)c1ccccc1</smiles>

625

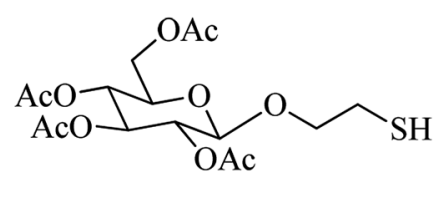

626

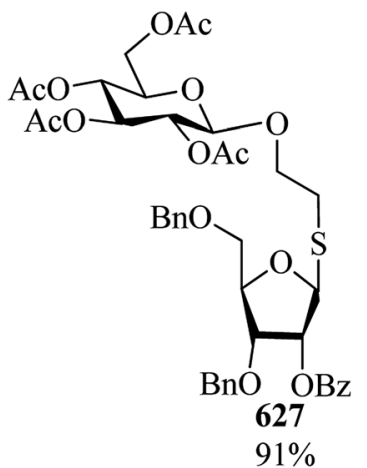

Scheme 190 The synthesis of thiosaccharides and 1-thiotrehaloses

triethyl orthobutyrate (316) or trimethyl orthovalerate (317), which could be ascribed to the proportionately lower reactivity of long-chain orthoesters for the preparation of compounds (612). Molecular and crystal building blocks of resultant molecules were examined using X-ray crystallography. ${ }^{488}$

\subsection{Synthesis of tetrazine derivatives}

Preyssler heteropolyacid $\left(\mathrm{H}_{14}\left[\mathrm{NaP}_{5} \mathrm{~W}_{30} \mathrm{O}_{110}\right], 0.1 \mathrm{mmol}\right)$ catalyzed the green one-pot reaction of 4-amino-3-hydrazino-6methyl-1,2,4-triazin-5(2H)-one with orthoesters in acetic acid under reflux conditions to produce $[1,2,4]$ triazino[ $[4,3-b][1,2,4,5]$ tetrazines within $1-6 \mathrm{~h}$ in excellent yields $(79-95 \%) .{ }^{489}[1,2,4]$ Triazino[4,5-b][1,2,4,5]tetrazines were also prepared from the reaction of 6-methyl-4-amino-5-hydrazino-1,2,4-triazin-3-one with orthoesters. ${ }^{490} \quad[1,2,4]$ Triazino $[3,4-b][1,2,4,5]$-tetrazine-6thiones (614) were synthesized in $58-78 \%$ yields upon treatment of 4-amino-6-methyl-3-hydrazino-4,5-dihydro-1,2,4triazine-5-thione (613) with excess amounts of triethyl orthoesters $(5,6)$ in refluxing ethanol for $1 \mathrm{~h}$ (Scheme 184). ${ }^{491}$

\subsection{Synthesis of cinnoline derivative}

The cyclocondensation of 10-amino-7-( $p$-tolyl)pyrimido $\left[4^{\prime \prime}, 5^{\prime \prime}: 4^{\prime}, 5\right]$ thieno $\left[3^{\prime}, 2^{\prime}: 5,6\right]$ pyrido[3,2-c]cinnoline-11-imine (615) with TEOF (5) was accomplished in refluxing acetic acid for $5 \mathrm{~h}$ to give 7-(p-tolyl)-1,2,4-triazolo[ $\left[4^{\prime \prime \prime}, 3^{\prime \prime \prime}: 1^{\prime \prime}, 6^{\prime \prime}\right]$ pyrimido $\left[4^{\prime \prime}, 5^{\prime \prime}: 4^{\prime}, 5^{\prime}\right]$ thieno $\left[3^{\prime}, 2^{\prime}: 5,6\right]$ pyrido $[3,2-c]$ cinnoline $\quad(\mathbf{6 1 6})$ in $70 \%$ yield (Scheme 185). ${ }^{492}$

\subsection{Synthesis of quinazoline derivatives}

Cobalt(II) chloride $\left(\mathrm{CoCl}_{2}, 10 \mathrm{~mol} \%\right)$ catalyzed the one-pot threecomponent reaction of anthranilic acid, TEOF, and anilines in $\mathrm{CH}_{3} \mathrm{CN}$ at $70{ }^{\circ} \mathrm{C}$ to obtain 3-substituted-quinazolin-4(3H)ones. ${ }^{493-495}$ Both electron-donating and electron-withdrawing anilines provided the products in good yields $(75-95 \%) .{ }^{495}$ Quinazolin-4(3H)-ones (618) could also be obtained in good yields via the novel reductive cyclization of $o$-nitrobenzamides (617) and TEOF (5), promoted by $\mathrm{TiCl}_{4} / \mathrm{Zn}$ in refluxing THF (Scheme 186). ${ }^{496}$

The cyclocondensation of 6-hydrazino-substituted benzimidazo[1,2-c]quinazolines $(\mathbf{6 1 9})$ with orthoesters $(5,6,7)$ was

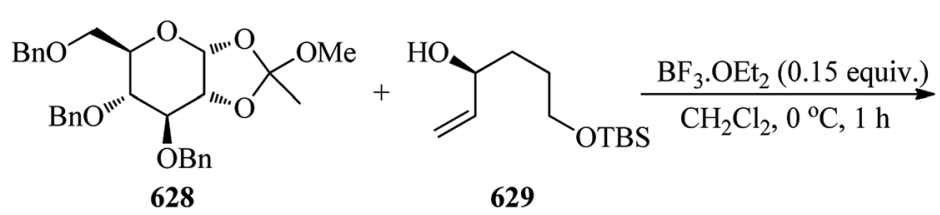<smiles>C=CC(CCCO[Hg])O[C@H]1OC(COCBr)[C@@H](Br)[C@H](O)[C@H]1OCc1ccccc1</smiles><smiles>CC#CC#CCCCCCCCCCCCO</smiles> 

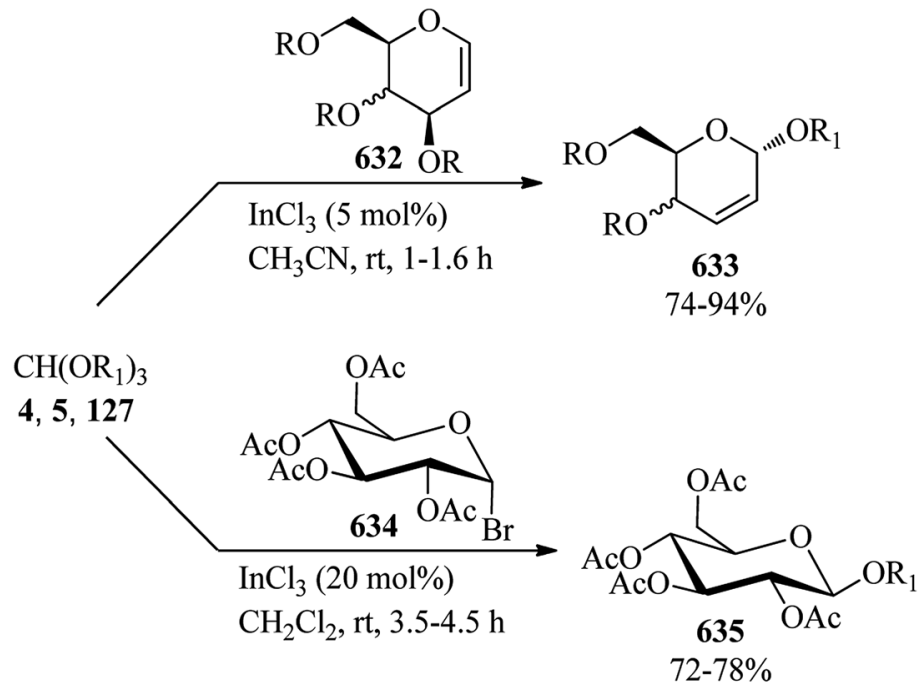

$\mathrm{R}=\mathrm{Ac}, \mathrm{Bn}$

$\mathrm{R}_{1}=\mathrm{Me}, \mathrm{Et}, i$-Pr,

Scheme 192 The formation of O-glycopyranosides.

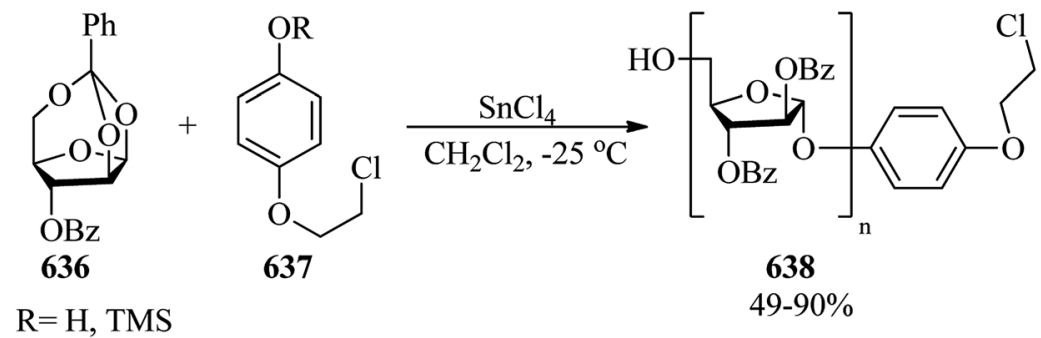

Scheme 193 Glycosyl acceptor synthetic procedure.

accomplished in refluxing ethanol to obtain new benzimidazo $[1,2-c][1,2,4]$ triazolo[4,3-a]quinazolines (620) fin $1 \mathrm{~h}$ in high yields $(70-81 \%)$ (Scheme 187). ${ }^{497}$

Bis(quinazolinon-4(1H)-one) derivatives (622) were also synthesized via the regioselective one-pot pseudo fivecomponent cyclocondensation reaction of isatoic anhydride (312), orthoesters $(5,6,7,102,323,455)$, and diamines (621) using $\mathrm{KAl}\left(\mathrm{SO}_{4}\right)_{2} \cdot 12 \mathrm{H}_{2} \mathrm{O}$ (alum, $20 \mathrm{~mol} \%$ ) as an inexpensive, ecofriendly, readily available, easily separable, and recyclable catalyst in refluxing DMF within 30-50 min in good to excellent yields (79-90\%) (Scheme 188). ${ }^{498}$ 4-Arylaminoquinazolines ${ }^{499}$ were synthesized in excellent yields (84-96\%) within $2 \mathrm{~h}$ via the one-pot three-component condensation reaction of 2-aminobenzamide, anilines, and orthoesters by a catalytic amount of Keggin-type heteropolyacid $\left(\mathrm{H}_{6}\left[\mathrm{PMo}_{9} \mathrm{~V}_{3} \mathrm{O}_{40}\right], 0.03 \mathrm{mmol}\right)$ in refluxing $\mathrm{CH}_{3} \mathrm{CN}$. Significantly, anilines containing electrondonating groups were obtained in slightly better yield. In this reaction, 3-quinazolin-4-one (2) was formed as a by-product in low yield. ${ }^{500}$ Preyssler heteropolyacid $\mathrm{H}_{14}\left[\mathrm{NaP}_{5} \mathrm{~W}_{30} \mathrm{O}_{110}\right]$ also progressed this transformation in refluxing $\mathrm{CH}_{3} \mathrm{CN}$ within 2 h. $^{501}$

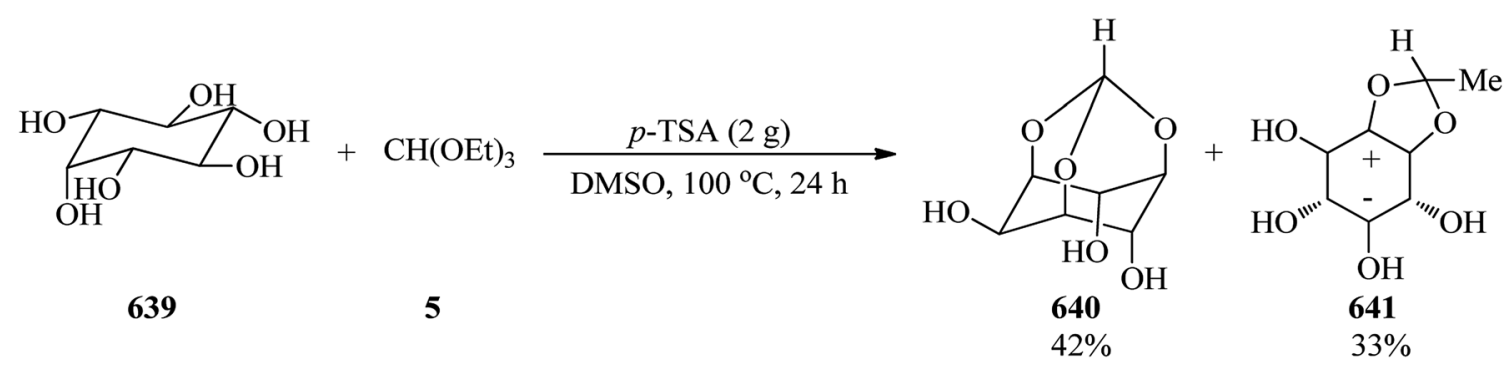

Scheme 194 The synthesis of myo-inositol monoorthoformate and ( \pm )-1,2-O-ethylidene-myo-inositol. 


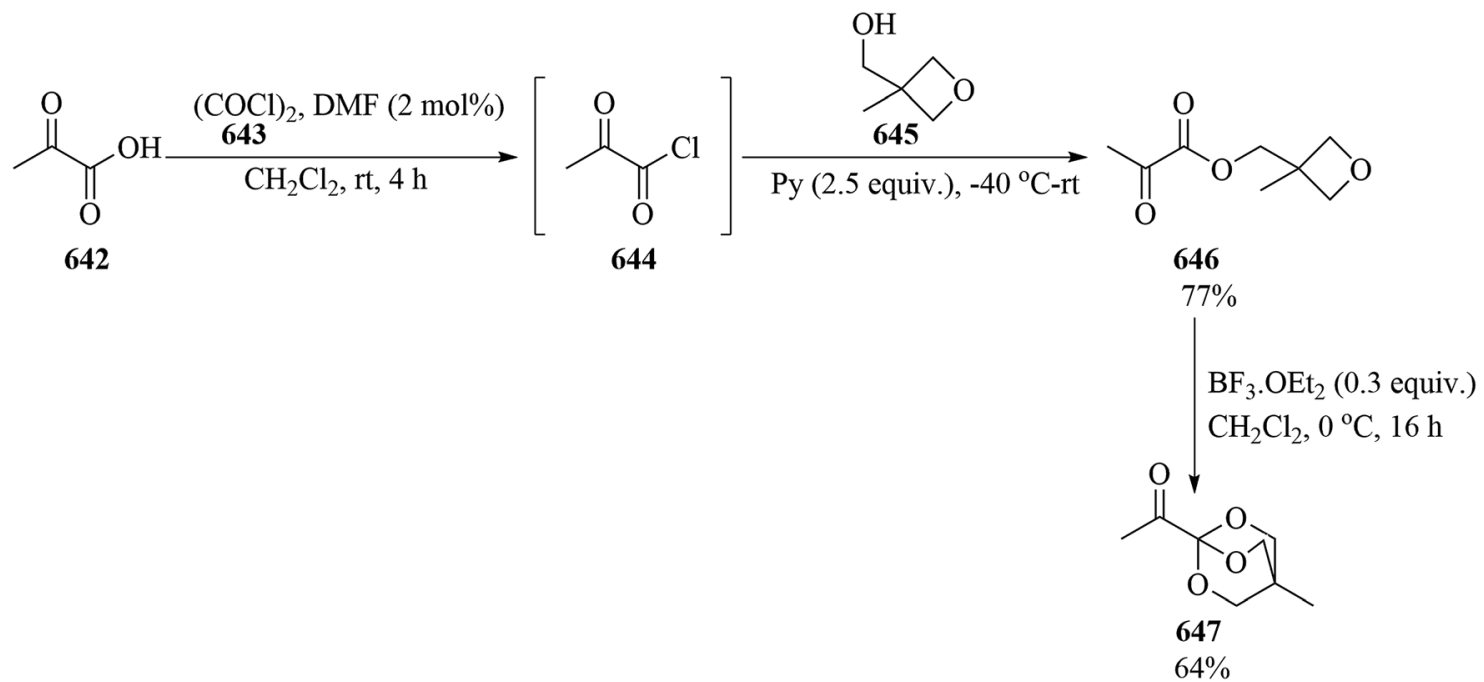

Scheme 195 The preparation of OBO orthoester.

\subsection{Synthesis of quinoxalines}

Novel 3-substitued $\quad[1,2,4]$ triazolo $\left[3^{\prime}, 4^{\prime} ; 2,3\right][1,3]$ triazolo $[4,5-b]$ quinoxaline derivatives $(\mathbf{6 2 4})$ were achieved through the cyclocondensation of $[1,3]$ thiazolo $[4,5-b]$ quinoxaline- $2(3 H)$-one hydrazone $(623)$ with orthoesters $(4,6)$ in acetic acid under reflux conditions within $4-8 \mathrm{~h}$ (Scheme 189). ${ }^{502}$

\subsection{Glycosidation, glycosylation, and oligomerization} reactions

In 2015, Rao et al. employed propargyl 1,2-orthoesters (625) as key synthons and glycosyl donors for the synthesis of thiosaccharides and 1-thiotrehaloses (627) in a 1,2-trans diastereoselective form only via the glycosidation reaction ${ }^{503-509}$ with glycosyl mercaptans (626), as glycosyl acceptor, using gold(III) bromide $\left(\mathrm{AuBr}_{3}, 7 \mathrm{~mol} \%\right)$ as catalyst in $\mathrm{CH}_{2} \mathrm{Cl}_{2}$ at room temperature under argon atmosphere in excellent yields (8394\%) within 6 h (Scheme 190). ${ }^{509}$

In 2015, Vadhadiya and Ramana reported the first total synthesis of sinenside A. In this survey, the glycosidation reaction of orthoester $(628)^{510}$ with allylic alcohol (629), as a glycosyl acceptor, by $\mathrm{BF}_{3} \cdot \mathrm{Et}_{2} \mathrm{O}$ ( 0.15 equiv.) as catalyst in dichloromethane at $0{ }^{\circ} \mathrm{C}$ in the presence of $4 \AA$ molecular sieves obtained $\beta$-glucoside (630) in good yield (76\%) in a $1 \mathrm{~h}$ period, which was employed as a key precursor for the synthesis of sinenside A (631) via a multi-step reaction (Scheme 191). ${ }^{\mathbf{5 1 1}}$

The stereoselective $O$-glycosylation of glycals (632) and glycosylbromides $(\mathbf{6 3 4})$ by orthoformates $(\mathbf{4}, \mathbf{5}, \mathbf{1 2 7})$ in the presence of $\mathrm{InCl}_{3}$ in corresponding solvents $\left(\mathrm{CH}_{3} \mathrm{CN}\right.$ and $\left.\mathrm{CH}_{2} \mathrm{Cl}_{2}\right)$ yielded $O$-glycopyranosides $(633,635)$ at room temperature (Scheme 192). It must be mentioned that both perbenzyl and peracetyl glycals resulted in 2,3-unsaturated-O-glycosides with major $\alpha$ selectivity while glycosylbromides furnished alkoxy glycosides with high $\beta$-selectivity in most cases. ${ }^{\mathbf{5 1 2}}$

$\mathrm{SnCl}_{4}$ catalyzed the oligomerization reaction of 3-O-benzoyl$\beta$-D-arabinofuranose $1,2,5$-orthobenzoate $(636)^{513,514}$ with 4 -(2chloroethoxy) phenol (637a) or (4-(2-chloroethoxy)phenoxy)trimethylsilane (CEP-OTMS, 637b) as a terminating agent in $\mathrm{CH}_{2} \mathrm{Cl}_{2}$ at $-25{ }^{\circ} \mathrm{C}$ to form selectively $\alpha(1 \rightarrow 5)$ linked arabinofuranose oligomers, including 4-(2-chloroethoxy)phenyl (CEP) aglycon with a deprotected 5-OH group at the non-reducing end (638) (Scheme 193). ${ }^{515}$ The resultant glycosyl acceptor (638) could be used in glycosylation reactions. ${ }^{514,516}$

\subsection{Synthesis of $( \pm)$-1,2-O-ethylidene-myo-inositol}

The reaction of myo-inositol (639) with TEOF (5) using $p$-TSA $(2 \mathrm{~g})$ under heating in dimethyl sulfoxide at $100{ }^{\circ} \mathrm{C}$ has been used to obtain myo-inositol monoorthoformate (640) and

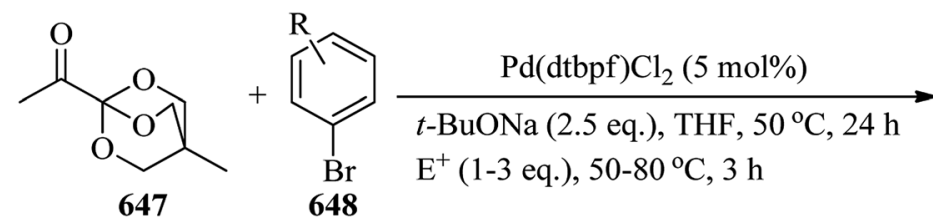<smiles>[R][I-]1=CC=CC(C(F)C(=O)C23OCC(C)(CO2)CO3)=C1</smiles>

649

$66-82 \%$

$\mathrm{R}=4-\mathrm{N}(\mathrm{Me})_{2} \mathrm{Ph}, 4-\mathrm{MePh}, 4-\mathrm{CF}_{3} \mathrm{Ph}$

$\mathrm{E}=\mathrm{CH}_{2}=\mathrm{C}(\mathrm{Br}) \mathrm{CH}_{2} \mathrm{Br}, \mathrm{BrCH}_{2} \mathrm{CO}_{2} \mathrm{Me}, \mathrm{HCCCH}_{2} \mathrm{Br}, \mathrm{BnBr}, \mathrm{BrCH}_{2} \mathrm{C}(\mathrm{O}) \mathrm{Ph}, \mathrm{EtI}, \mathrm{CH}_{2} \mathrm{CHCH}_{2} \mathrm{Br}$

Scheme 196 The mono $\alpha$-arylation of OBO orthoester. 
$( \pm)$-1,2-O-ethylidene-myo-inositol (641) within a $24 \mathrm{~h}$ period in $42 \%$ and $33 \%$ yields, respectively (Scheme 194). It was found that the presence of the chiral carbon of ethylidene in the compound (641) formed a mixtures of the four diastereomers which were not isolated by silica gel column chromatography but were characterized by NMR spectra. ${ }^{517}$

\subsection{6. $\alpha$-Arylation and alkylation of protected pyruvate esters}

In 2017, Esteves et al. interpreted a novel process for the enolate arylation and alkylation of protected pyruvate esters. Hence, in the first step, the orthoester-masked pyruvate equivalent (oxabicyclo[2.2.2] octyl orthoester, OBO $)^{518-521}$ was prepared through the reaction of pyruvic acid (642) with oxalyl chloride (643) to form pyruvoyl chloride (644) which underwent an esterification reaction with 3-methyl-3-oxetanemethanol (645) in the presence of pyridine to afford the ester (646) via a two-step reaction which on reaction with $\mathrm{BF}_{3} \cdot \mathrm{OEt}_{2}$ in $\mathrm{CH}_{2} \mathrm{Cl}_{2}$ at $0{ }^{\circ} \mathrm{C}$ yielded the $\mathrm{OBO}$ orthoester (647) (Scheme 195). Then, the mono $\alpha$-arylation (649) reaction was accomplished via the reaction of (647) with aryl bromide (648) by $\mathrm{Pd}(\mathrm{dtbpf}) \mathrm{Cl}_{2}(5 \mathrm{~mol} \%)$, utilizing at least two equivalents of base in THF at $50{ }^{\circ} \mathrm{C}$ for $24 \mathrm{~h}$. Due to the greater acidity of the product than the starting material, ${ }^{522}$ the resultant aryl ketone was deprotonated in situ by the extra base. Subsequent alkylation by different equivalents of electrophile at 50$80{ }^{\circ} \mathrm{C}$ obtained $\alpha$-arylation and alkylation products (Scheme 196). In the final step, the OBO protective group was conveniently removed using acidic conditions such as $p$-TSA in ethanol at $90{ }^{\circ} \mathrm{C}$ for 3-8 h. The method also enabled mono- and diarylation reactions to happen on a readily available OBOprotected precursor. ${ }^{\mathbf{5 2 1}}$

\section{Conclusions}

In this review, several types of orthoesters have been reported as applicable substrates in classified organic transformations. These treatments have been subdivided according to the reaction medium. This focus is because of the significance of economical and green reactions in organic syntheses. Based on the overall results, the reaction could happen in solvent-free media, in the presence of aqueous conditions, or in organic solvents. Detailed investigations in the form of a literature survey affirmed that the processes containing orthoesters progressed well in the absence of solvents. This important attainment has let researchers design new procedures to achieve compounds with multi-functionalized motifs in the absence of hazardous solvents, utilizing the greater activity potential of substrates and reagents, as they could come into contact effectively within short periods. The aqua-mediated reactions were not extensive, which may be due to the hydrolysis affinity of orthoesters in water. Traditional organic solvents were also mentioned a great deal in reports. The greatest usage involved alcohols, dichloromethane, acetic anhydride, acetonitrile, acetic acid, benzene and its derivatives, and THF. Other common solvents used in lower abundance were DMF, ether, DMSO, dioxane, and $\mathrm{CCl}_{4}$. Some transformations were done under heating conditions and some others required microwave or ultrasound assistance for promotion. Based on the many mentions, TEOF was the most commonly used alkyl orthoester in a vast range of reactions. The authors hope that this article will guide general readers to gain an intense interest in using orthoesters, as versatile and easily-handled synthons, in a great range of reactions with a focus on the environment.

\section{Conflicts of interest}

There are no conflicts to declare.

\section{References}

1 V. V. Mezheritskii, E. P. Olekhnovich and G. N. Dorofeenko, Russ. Chem. Rev., 1973, 42, 392.

2 R. H. Dewolfe, Synthesis, 1974, 1974, 153.

3 A. W. Williamson and G. Kay, Ann. Chem., 1854, 92, 346.

4 R. H. Dewolfe, Carboxylic Ortho Acid Derivatives: Preparation and Synthetic Applications, organic chemistry a series of monographs, Academic Press, New York and London, 1970, ch. 1, pp. 54-122.

5 K. B. Girma, V. Lorenz, S. Blaurock and F. T. Edelmann, Z. Anorg. Allg. Chem., 2008, 634, 267.

6 S. L. Repetto, R. Patel, T. Johnson, J. F. Costello, J. K.-W. Lam and C. J. Chuck, Energy Fuels, 2016, 30, 9080.

7 J. C. Jansen and J. Reedijk, Z. Naturforsch., B: Anorg. Chem., Org. Chem., 1974, 29, 527.

8 T. Wagner, C. G. Hrib, V. Lorenz, F. T. Edelmann, D. S. Amenta, C. J. Burnside and J. W. Gilje, Z. Anorg. Allg. Chem., 2012, 638, 2129.

9 G. C. Look, M. M. Murphy, D. A. Campbell and M. A. Gallop, Tetrahedron Lett., 1995, 36, 2937.

10 Y. F. Song, G. A. van Albada, J. Tang, I. Mutikainen, U. Turpeinen, C. Massera, O. Roubeau, J. S. Costa, P. Gamez and J. Reedijk, Inorg. Chem., 2007, 46, 4944.

11 S. K. Shannon and G. Barany, J. Org. Chem., 2004, 69, 4586.

12 N. Yu, R. Poulain and J.-C. Gesquiere, Synlett, 2000, 2000, 355.

13 M. Schöttner, J. Reiner and F. S. K. Tayman, Phytochemistry, 1997, 46, 1107.

14 D. M. Ketcha, L. J. Wilson and D. E. Portlock, Tetrahedron Lett., 2000, 41, 6253.

15 R. T. Stibrany, D. N. Schulz, S. Kacker, A. O. Patil, L. S. Baugh, S. P. Rucker, S. Zushma, E. Berluche and J. A. Sissano, Macromolecules, 2003, 36, 8584.

16 I. Abrunhosa-Thomas, O. Roy, M. Barra, T. Besset, P. Chalard and Y. Troin, Synlett, 2007, 2007, 1613.

17 F. Zaragoza and S. V. Petersen, Tetrahedron, 1996, 52, 10823. 18 M. O. Frederick and D. P. Kjell, Tetrahedron Lett., 2015, 56, 949.

19 Y. L. Janin, J. Chiki, M. Legraverend, C. Huel and E. Bisagni, Tetrahedron, 1999, 55, 12797.

20 Y. Chen, Chem.-Eur. J., 2019, 25, 3405.

21 Y. C. Mei, B. W. Yang, W. Chen, D. D. Huang, Y. Li, X. Deng, B. M. Liu, J. J. Wang, H. Qian and W. L. Huang, Lett. Org. Chem., 2012, 9, 276-279. 
22 R. S. Hosmane and C. M. Bertha, Synth. Commun., 1990, 20, 2921-2935.

23 N. N. Balaneva, O. P. Shestak and V. L. Novikov, Russ. Chem. Bull., Int. Ed., 2019, 68, 55.

24 M. Nabati and M. Mahkam, Iran. Chem. Commun., 2014, 2, 162-167.

25 M. J. Gallagher and H. Honegger, Tetrahedron Lett., 1977, 18, 2987.

26 J. Gloede, S. Ozegowski, D. Matt and A. De Cian, Tetrahedron Lett., 2001, 42, 9139-9142.

27 W. Noll, Chemistry and Technology of Silicones, Academic Press, New York, 1968, pp. 68-115.

28 Y. Kita, Y. Yoshida, S. Mihara, D.-F. Fang, K. Higuchi, A. Furukawa and H. Fujioka, Tetrahedron Lett., 1997, 38, 8315.

29 G. Dujardin, S. Leconte, A. Bénard and E. Brown, Synlett, 2001, 2001, 147.

30 H. Yanai, T. Oguchi and T. Taguchi, J. Org. Chem., 2009, 74, 3927.

31 M. Cheong, M.-N. Kim and J. Y. Shim, J. Organomet. Chem., 1996, 520, 253.

32 A. D. Morley, Tetrahedron Lett., 2000, 41, 7405.

33 D. A. Wacker and P. Kasireddy, Tetrahedron Lett., 2002, 43, 5189.

34 J. J. Reina, A. D. Maio, J. Ramos-Soriano, R. C. Figueiredo and J. Rojoa, Org. Biomol. Chem., 2016, 14, 2873.

35 A. Gambacorta, D. Tofani and A. Migliorini, Molecules, 2007, 12, 1762.

36 J. L. Giner, Org. Lett., 2005, 7, 499.

37 W. S. Johnson, L. Werthemann, W. R. Bartlett, T. J. Brocksom, T.-T. Li, D. J. Faulkner and M. R. Petersen, J. Am. Chem. Soc., 1970, 92, 741.

38 M. P. Dreyfuss and P. Dreyfuss, J. Polym. Sci., Part A-1: Polym. Chem., 1966, 4, 2179.

39 S. Okamoto, K. Tanaka and A. Sudo, J. Polym. Sci., Part A: Polym. Chem., 2018, 56, 1743.

40 T. Haider, O. Shyshov, O. Suraeva, I. Lieberwirth, M. von Delius and F. R. Wurm, Macromolecules, 2019, 52, 2411.

41 L. Li, K. Knickelbein, L. Zhang, J. Wang, M. Obrinske, G. Z. Ma, L.-M. Zhang, L. Bitterman and W. Du, Chem. Commun., 2015, 51, 13078.

42 S. Maiti, S. Manna, J. Shen, A. P. Esser-Kahn and W. Du, J. Am. Chem. Soc., 2019, 141, 4510.

43 Y. Furusho and T. Endo, Polym. Bull., 2017, 74, 1207.

44 M. Rillich, D. Jehnichen, H. Komber and F. Bohme, Macromol. Chem. Phys., 1995, 196, 1635-1644.

45 C. Adamson, R. J. Pengelly, S. S. K. Abadi, S. Chakladar, J. Draper, R. Britton, T. M. Gloster and A. J. Bennet, Angew. Chem., 2016, 128, 15202.

46 J. L. Darlix, P. Fromageot and E. Reich, Biochemistry, 1973, $12,914$.

47 B. E. Griffin, M. Jarman, C. B. Reese and J. E. Sulston, Tetrahedron, 1967, 23, 2301.

48 B. S. Ross, R. H. Springer, Z. Tortorici and S. Dimock, Nucleos. Nucleot. Nucl., 1997, 16, 1641.
49 L. J. Lawrence, C. J. Palmer, K. W. Gee, T. Wang, H. I. Yamarnura and J. E. Casida, J. Neurochem., 1985, 45, 798.

50 G. Leriche, M. Nothisen, N. Baumlin, C. D. Muller, D. Bagnard, J.-S. Remy, S. A. Jacques and A. Wagner, Bioconjugate Chem., 2015, 26, 1461.

51 B. Li, B. Duan, J. Lia, M. Zhang, Y. Yuan, Y. Ding and A. Hu, Tetrahedron, 2018, 74, 6419-6425.

52 D. Song, S. Sun, Y. Tian, S. Huang, Y. Ding, Y. Yuan and A. Hu, J. Mater. Chem. B, 2015, 3, 3195-3200.

53 R. Cai, L. Zhu, W. Shen and Y. Zhao, Fitoterapia, 2019, 137, 104198.

54 H. J. Schaeffer and C. F. Schwender, J. Med. Chem., 1974, 17, 6-8.

55 X. Huang, F. Du, J. Cheng, Y. Dong, D. Liang, S. Ji, Sh. Lin and Z. Li, Macromolecules, 2009, 42, 783-790.

56 A. H. Shamroukh, M. E. A. Zaki, E. M. H. Morsy, F. M. AbdelMotti and F. M. E. Abdel-Megeid, Arch. Pharm., 2007, 340, 345-351.

57 A. R. Bogdan, S. L. Poe, D. C. Kubis, S. J. Broadwater and D. T. McQuade, Angew. Chem., 2009, 48, 8547.

58 A. Jackson and O. Meth-Cohnt, J. Chem. Soc., Chem. Commun., 1995, 1319.

59 A. Alsughayer, A. A. Elassar, S. Mustafa and F. Al Sagheer, J. Biomater. Nanobiotechnol., 2011, 2, 144-149.

60 L. Shahzadi, M. Yar, A. Jamal, S. A. Siddiqi, A. A. Chaudhry, S. Zahid, M. Tariq, I. Rehman and Sh. MacNeil, J. Biomater. Appl., 2016, 31, 582-593.

61 J.-R. Li, R.-H. Zhang and X.-H. Bu, Eur. J. Inorg. Chem., 2005, 2005, 1913.

62 G. A. van Albada, S. Amani Komaei, H. Kooijman, A. L. Spek and J. Reedijk, Inorg. Chim. Acta, 1999, 287, 226.

63 Y. Sasaki and C. Pittman, J. Org. Chem., 1973, 38, 37233726.

64 R.-C. Brachvogel and M. von Delius, Chem. Sci., 2015, 6, 1399.

65 R.-C. Brachvogel, H. Maid and M. von Delius, Int. J. Mol. Sci., 2015, 16, 20641.

66 R.-C. Brachvogel, F. Hampel and M. von Delius, Nat. Commun., 2015, 6, 7129.

67 M. von Delius, Synlett, 2016, 27, 177.

68 H. Löw, E. Mena-Osteritz and M. von Delius, Chem. Sci., 2018, 9, 4785.

69 N. T. Patil, M. S. Shashidhar, M. I. Tamboli and R. G. Gonnade, Cryst. Growth Des., 2017, 17, 5432.

70 G. Buechi, J. A. Carlson, J. E. Powell and L. F. Tietze, J. Am. Chem. Soc., 1973, 95, 540.

71 S. Zhang, L. Xu, L. Miao, H. Shu and M. L. Trudell, J. Org. Chem., 2007, 72, 3133.

72 G. R. Kieczykowski and R. H. Schlessinger, J. Am. Chem. Soc., 1978, 100, 1938.

73 J. Uenishi, J. M. Beau, R. W. Armstrong and Y. Kishi, J. Am. Chem. Soc., 1987, 109, 4756-4758.

74 W. J. Greenlee and R. B. Woodward, J. Am. Chem. Soc., 1976, 98, 6075.

75 W. C. Chan and K. Koide, Org. Lett., 2018, 20, 7798-7802. 
76 J. Gauthier and P. Deslongchamps, Can. J. Chem., 1967, 45, 297-300.

77 A. Pinner, Chem. Ber., 1883, 16, 1643.

78 A. Fischer and H. Puetter, Eur. Pat., BASF SE, DE10043789A12000, 2000.

79 (a) H. Kolbe, Liebigs Ann. Chem., 1849, 69, 257; (b) F. Lebreux, F. Buzzo and I. E. Markó, J. Electrochem. Soc., 2008, 13, 1.

80 H. G. Thomas and A. Schmitz, Synthesis, 1985, 31.

81 R. Fardel, U. Griesbach, H. Pütter and C. Comninellis, J. Appl. Electrochem., 2006, 36, 249.

82 J. L. Röckl, A. V. Hauck, D. Schollmeyer and S. R. Waldvogel, ChemistryOpen, 2019, 8, 1167.

83 A. B. Charette and P. Chua, Tetrahedron Lett., 1997, 38, 8499.

84 T. Praveen and M. S. Shashidhar, Carbohydr. Res., 2001, 330, 409-411.

85 H.-J. Jung, C. Chang, I. Yu, D. C. Aluthge, T. Ebrahimi and P. Mehrkhodavandi, ChemCatChem, 2018, 10, 3219.

86 F. J. Lombard, R. J. Lepage, B. D. Schwartz, R. C. Johnston, P. C. Healy, E. H. Krenske and M. J. Coster, Org. Biomol. Chem., 2018, 16, 256.

87 P. Wałejko and A. Baj, Monatsh. Chem., 2019, 150, 275.

88 N. Yasukawa, T. Kanie, M. Kuwata, Y. Monguchi, H. Sajiki and Y. Sawama, Chem.-Eur. J., 2017, 23, 10974.

89 C. Gouliaras, D. Lee, L. Chan and M. S. Taylor, J. Am. Chem. Soc., 2011, 133, 13926.

90 D. T. Khong and Z. M. A. Judeh, Org. Biomol. Chem., 2017, 15, 2638.

91 J. Zhao, S. Wei, A. Yue and H. Shao, Chin. J. Chem., 2012, 30, 627.

92 S. Danishefsky, P. F. Schuda, T. Kitahara and S. J. Etheredge, J. Am. Chem. Soc., 1977, 99, 6066.

93 V. A. Egorov, F. A. Gimalova, L. S. Khasanova and M. S. Miftakhov, Russ. Chem. Bull., Int. Ed., 2015, 64, 355358.

94 L. M. De Coen, B. I. Roman, M. Movsisyan, T. S. A. Heugebaert and C. V. Stevens, Eur. J. Org. Chem., 2018, 2018, 2148.

95 I. A. Perillo, M. C. Caterina and A. Salerno, Arkivoc, 2018, i, 288.

96 L. Benhamou, E. Chardon, G. Lavigne, S. BelleminLaponnaz and V. Ceesar, Chem. Rev., 2011, 111, 2705-2733.

97 A. Al-Azmi, A. A. Elassar and B. L. Booth, Tetrahedron, 2003, 59, 2749-2763.

98 S. Ghosh and U. R. Ghatak, Proc. - Indian Acad. Sci., Chem. Sci., 1988, 100, 235.

99 S. Alam, Int. J. Chem. Res., 2016, 8, 173.

100 L. A. Pavlova, Y. A. Davidovich and S. V. Rogozhin, Russ. Chem. Rev., 1986, 55, 1026.

101 F. Kong, Carbohydr. Res., 2007, 342, 345.

102 S.-G. Liao, H.-D. Chen and J.-M. Yue, Chem. Rev., 2009, 109, 1092.

103 R. A. Fernandes, A. K. Chowdhury and P. Kattanguru, Eur. J. Org. Chem., 2014, 2014, 2833.

104 C. P. Frizzo, Synlett, 2009, 2009, 1019.

105 Z. Nazarian and M. Dabiri, ChemistrySelect, 2020, 5, 4394.
106 R. Q. Lamphon, M. S. A. El-Gaby, M. M. Khafagy, G. A. M. ElHag Ali, A. A. El-Maghraby, H. A. Eyada and M. H. M. Helal, Phosphorus, Sulfur Silicon Relat. Elem., 2004, 179, 12791292.

107 E. K. Ahmed, F. F. Abdel-latif and M. A. Ameen, Phosphorus, Sulfur Silicon Relat. Elem., 2005, 180, 95-107.

108 M. A. El-Hashash, M. H. A. Soliman, I. I. Abd El-Gwad, S. S. El-Sakka and M. A. Morsy, Afinidad, 2010, 67, 367-373.

109 R. A. Mekheimer, Synthesis, 2001, 2001, 103-107.

110 M. Khashi, A. Davoodnia and V. S. P. R. Lingam, Res. Chem. Intermed., 2015, 41, 5731-5742.

111 A. S. Oganisyan, A. S. Noravyan and M. Z. Grigoryan, Chem. Heterocycl. Compd., 2004, 40, 75-78.

112 A. Krauze, Z. Bomika, A. M. Shestopalov, L. A. Rodinovskaya, J. Pelcers, G. Duburs, Y. A. Sharanin and V. K. Promonenkov, Khim. Geterotsikl. Soedin., 1981, 3, 377; Chem. Abstr., 1981, 95, 80662.

113 H. M. F. Madkour, A. A. E. Afify, A. A. Abdalha, G. A. Elsayed and M. S. Salem, Phosphorus, Sulfur Silicon Relat. Elem., 2009, 184, 719-732.

114 S. Saba, R. Hernandez, C. Chin Choy, K. Carta, Y. Bennett, S. Bondi, S. Kolaj and C. Bennett, J. Fluorine Chem., 2013, 153, 168-171.

115 S. Saba and J. A. Ciaccio, J. Chem. Educ., 2016, 93, 945-948.

116 M. J. D. Grandi, C. Bennett, K. Cagino, A. Muccini, C. Suraci and S. Saba, Synth. Commun., 2015, 45, 2601-2607.

117 N. L. Reddy, J. B. Fischer, K. J. Burke-Howie, P. Barmettler, M. R Rhodes, E. Weber and J. F. W. Keana, Bioorg. Med. Chem. Lett., 1993, 3, 2113-2116.

118 R. Khan, M. Arfan, J. Mahmood, S. Anjum and M. I. Choudhary, Chin. Chem. Lett., 2010, 21, 905-910.

119 R. N. Laxma, J. B. Fisher and K. J. Burke-Howie, Bioorg. Med. Chem. Lett., 1993, 3, 2113.

120 P. Harding and D. J. Harding, Synth. Commun., 2007, 37, 2655-2661.

121 S. M. Nair and I. Bhattacharya, Asian J. Chem., 2009, 21, 504-510.

122 A. Olyaei, F. Gesmati, M. Sadeghpour, B. Shams and M. Alizadeh, Synth. Commun., 2012, 42, 1650-1660.

123 C. Verrier, S. Carret and J.-F. Poisson, ACS Sustainable Chem. Eng., 2018, 6, 8563-8569.

$124 \mathrm{~W}$. D. Jones Jr, E. W. Huber, J. M. Grisar and R. A. Schnettler, J. Heterocycl. Chem., 1987, 24, 1221-1223.

125 G. I. Graf, D. Hastreiter, L. E. da Silva, R. A. Rebelo, A. G. Montalban and A. McKillop, Tetrahedron, 2002, 58, 9095-9100.

126 A. Majee, S. K. Kundu, S. Santra and A. Hajra, Indian J. Chem., Sect. B: Org. Chem. Incl. Med. Chem., 2014, 53, 124126.

127 N. Azizi, E. Gholibeglo, M. Babapour, H. Ghafuri and S. M. Bolourtchian, C. R. Chim., 2012, 15, 768-773.

128 M. Mazloumi, F. Shirini, O. Goli-Jolodar and M. Seddighi, New J. Chem., 2018, 42, 5742-5752.

129 K. Kondo and F. Mori, Chem. Lett., 1974, 3, 741-742.

130 M. B. Martin, J. S. Grimley, J. C. Lewis, H. T. Heath, B. N. Bailey, H. Kendrick, V. Yardley, A. Caldera, R. Lira, 
J. A. Urbina, S. N. J. Moreno, R. Docampo, S. L. Croft and E. Oldfield, J. Med. Chem., 2001, 44, 909-916.

131 A. Balakrishna, M. V. N. Reddy, P. V. Rao, M. A. Kumar, B. S. Kumar, S. K. Nayak and C. S. Reddy, Eur. J. Med. Chem., 2011, 46, 1798-1802.

132 B. Kaboudin and S. Alipour, Tetrahedron Lett., 2009, 50, 4243-4245.

133 V. I. Krutikov, A. V. Erkin, P. A. Pautov and M. M. Zolotukhina, Russ. J. Gen. Chem., 2003, 73, 205-210.

134 E. Dąbrowska, A. Burzyńska, A. Mucha, E. Matczak-Jon, W. Sawka-Dobrowolska, Ł. Berlicki and P. Kafarski, J. Organomet. Chem., 2009, 694, 3806-3813.

135 G. C. S. Reddy, M. V. N. Reddy, N. B. Reddy and C. S. Reddy, Phosphorus, Sulfur Silicon Relat. Elem., 2011, 186, 74-80.

136 A. Shirwaiker, K. Rajendran and C. Dinesh Kumar, Indian J. Exp. Biol., 2004, 42, 803-807.

137 B. H. Babu, B. S. Shailesh and J. Paddikala, Fitotherapia, 2001, 72, 272-277.

138 K. Kato, S. Terao, N. Shimamoto and M. Hirata, J. Med. Chem., 1988, 31, 793-798.

139 Y. Gow-Chin and C. Hui-Yin, J. Agric. Food Chem., 1995, 43, 27-32.

140 U. M. R. Kunda, S. K. Balam, B. R. Nemallapudi, S. S. Chereddy, S. K. Nayak and S. R. Cirandur, Chem. Pharm. Bull., 2012, 60, 104-109.

141 P. Miszczyk, D. Wieczorek, J. Gałęzowska, B. Dziuk, J. Wietrzyk and E. Chmielewska, Molecules, 2017, 22, 254265.

142 P. Miszczyk, I. Turowska-tyrk, P. Kafarski and E. Chmielewska, Molecules, 2017, 22, 450-461.

143 N. G. Singh, C. Kathing, J. W. S. Rani and R. L. Nongkhlaw, J. Chin. Chem. Soc., 2014, 61, 442-446.

144 S. F. Hojati and A. S. Kaheh, Jordan J. Chem., 2019, 14, 1727.

145 H. Witzel and U. Pindur, J. Heterocycl. Chem., 1988, 25, 907910.

146 J. Yu, Y. Hu, Q. Huang, R. Ma and S. Yang, Synth. Commun., 2000, 30, 2801-2806.

147 S. Fox, R. Hudson and R. W. Boyle, Tetrahedron Lett., 2003, 44, 1183-1185.

148 M. Wormann and M. E. Maier, $R S C A d v ., 2019$, 9, 1531415317.

149 R. Calmanti, E. Amadio, A. Perosa and M. Selva, Catalysts, 2019, 9, 534.

150 Y. N. Mabkhot, A. Barakat and S. Alshahrani, J. Mol. Struct., 2012, 1027, 15-19.

151 L. M. Shorr, J. Am. Chem. Soc., 1954, 76, 1390.

152 O. J. Klejnot, Inorg. Chem., 1963, 2, 825.

153 M. E. Childs and W. P. Weber, J. Organomet. Chem., 1975, 86, 169.

154 J. S. Yadav, B. V. S. Reddy and V. Geetha, Synth. Commun., 2002, 32, 763-769.

155 A. Ahmad and L. F. Silva Jr, Synthesis, 2012, 44, 3671-3677.

156 I. A. Khan, M. V. Kulkarni, M. Gopal, M. S. Shahabuddin and C. M. Sun, Bioorg. Med. Chem. Lett., 2005, 15, 35843587.
157 H. Liu, C. S. Tomooka and H. W. Moore, Synth. Commun., 1997, 27, 2177-2180.

158 D. R. Chaffey, T. E. Davies, S. H. Taylor and A. E. Graham, ACS Sustainable Chem. Eng., 2018, 6, 4996-5002.

159 Z. Zhang, T. Hashiguchi, T. Ishida, A. Hamasaki, T. Honma, H. Ohashi, T. Yokoyama and M. Tokunaga, Org. Chem. Front., 2015, 2, 654-660.

160 R. S. Varma and D. Kumar, Tetrahedron Lett., 1998, 39, 9113-9116.

161 H. Egami, S. Tamaoki, M. Abe, N. Ohneda, T. Yoshimura, T. Okamoto, H. Odajima, N. Mase, K. Takeda and Y. Hamashima, Org. Process Res. Dev., 2018, 22, 1029-1033.

162 G. V. Kryshtal, G. M. Zhdankina, N. V. Ignat'ev, M. Schulte and S. G. Zlotin, J. Fluorine Chem., 2016, 183, 23-29.

163 E. Brenna, C. Fuganti, F. G. Gatti, M. Passoni and S. Serra, Tetrahedron: Asymmetry, 2003, 14, 2401-2406.

164 H. M. Kumar, S. Joyasawal, B. V. Reddy, P. P. Chakravarthy, A. D. Krishna and J. S. Yadav, Indian J. Chem., Sect. B: Org. Chem. Incl. Med. Chem., 2005, 44, 1686-1692.

165 Y. Tamura, T. Yakura, Y. Shirouchi and J.-I. Haruta, Chem. Pharm. Bull., 1985, 33, 1097.

166 T. Yoshino and H. Togo, Synlett, 2004, 2004, 1604-1606.

167 T. Sakamoto, F. Shiga, A. Yasuhara, D. Uchiyama, Y. Kondo and H. Yamanaka, Synthesis, 1992, 746-748.

168 A. A. Padmapriya, G. Just and N. G. Lewis, Synth. Commun., 1985, 15, 1057-1062.

169 C. J. Borths, J. Chan, B. J. Burke and R. D. Larsen, Synlett, 2009, 2009, 3139-3142.

170 Y. Tamura, T. Yakura, Y. Shirouchi and J.-I. Haruta, Chem. Pharm. Bull., 1985, 33, 1097-1103.

171 F. Malmedy and T. Wirth, Chem.-Eur. J., 2016, 22, 1607216077.

172 T. Seidensticker, D. Möller and A. J. Vorholt, Tetrahedron Lett., 2016, 57, 371-374.

173 R. Kumar and P. M. S. Chauhan, Tetrahedron Lett., 2008, 49, 5475-5479.

174 R. A. Swaringen Jr, J. F. Eaddy and T. R. Henderson, J. Org. Chem., 1980, 45, 3986-3989.

175 H. G. Bonacorso, C. A. Cechinel, M. R. Oliveira, M. B. Costa, M. A. Martins, N. Zanatta and A. F. Flores, J. Heterocycl. Chem., 2005, 42, 1055-1061.

176 A. Ladépêche, E. Tam, J.-E. Ancel and L. Ghosez, Synthesis, 2004, 2004, 1375-1380.

177 E. Pérez-Mayoral, R. M. Martín-Aranda, A. J. López-Peinado, P. Ballesteros, A. Zukal and J. Čejka, Top. Catal., 2009, 52, 148-152.

178 R. Kumar and A. K. Chakraborti, Tetrahedron Lett., 2005, 46, 8319-8323.

179 Y. Du and F. Tian, Synth. Commun., 2005, 35, 2703-2708.

180 W. Gong, B. Wang, Y. Gu, L. Yan, L. Yang and J. Suo, Synth. Commun., 2004, 34, 4243-4247.

181 H. Mansilla and M. M. Afonso, Synth. Commun., 2008, 38, 2607-2618.

182 R. A. Ugarte and T. W. Hudnall, Green Chem., 2017, 19, 1990-1998.

183 I. Kharkongor and B. Myrboh, Tetrahedron Lett., 2015, 56, 4359-4362. 
184 R. A. Swaringen Jr, D. A. Yeowell, J. C. Wisowaty, H. A. ElSayad, E. L. Stewart and M. E. Darnofall, J. Org. Chem., 1979, 44, 4825-4829.

185 M. B. Gazizov, S. Y. Ivanova, S. N. Ibragimov, K. S. Gazizova, R. A. Khairullin and K. A. Medvedeva, Russ. J. Gen. Chem., 2016, 86, 2132-2134.

186 M. B. Gazizov, S. Y. Ivanova, N. Y. Bashkirtseva, O. D. Khairullina, R. A. Khairullin and O. V. Gazizova, Russ. Chem. Bull., Int. Ed., 2017, 66, 1230-1233.

187 M. B. Gazizov, R. F. Karimova, O. M. Chernova, K. M. Gazizov, E. R. Khazeeva and O. G. Sinyashin, Russ. J. Gen. Chem., 2006, 76, 1172-1174.

188 P. H. Nelson and J. T. Nelson, Synthesis, 1992, 1992, 12871291.

189 J. S. Yadav, G. Kondaji, M. S. R. Reddy and P. Srihari, Tetrahedron Lett., 2008, 49, 3810-3813.

190 A. Kumar, S. Kumar, R. K. Gupta and D. Kumar, J. Chem. Res., 2007, 2007, 680-682.

191 M. S. Khanna, O. V. Singh, C. P. Garg and R. P. Kapoor, Synth. Commun., 1993, 23, 585-590.

192 I. Németh, A. Kiss-Szikszai, T. Z. Illyés, A. Mándi, I. Komáromi, T. Kurtán and S. Antus, Z. Naturforsch., B: J. Chem. Sci., 2012, 67, 1289-1296.

193 M. S. Khanna, Org. Prep. Proced. Int., 1994, 26, 125-127.

194 H. M. C. Ferraz, T. O. Vieira and L. F. Silva Jr, Synthesis, 2006, 2006, 2748-2752.

195 L. F. Silva Jr, R. M. F. Sousa, H. M. C. Ferraz and A. M. Aguilar, J. Braz. Chem. Soc., 2005, 16, 1160-1173.

196 H.-J. Kabbe, Justus Liebigs Ann. Chem., 1962, 656, 204.

197 H. M. C. Ferraz, L. F. Silva Jr and T. O. Vieira, Tetrahedron, 2001, 57, 1709-1713.

198 C.-H. Liao, F.-N. Ko, T.-S. Wu and C.-M. Teng, J. Pharm. Pharmacol., 1997, 49, 1248.

199 (a) H. M. C. Ferraz, A. M. Aguilar and L. F. Silva Jr, Synthesis, 2003, 2003, 1031-1034; (b) H. M. C. Ferraz, A. M. Aguilar and L. F. Silva Jr, Tetrahedron, 2003, 59, 5817-5821.

200 A. McKillop, J. D. Hunt, F. Kienzle, E. Bigham and E. C. Taylor, J. Am. Chem. Soc., 1973, 95, 3635-3640.

201 H. M. C. Ferraz, L. F. Silva Jr and T. O. Vieira, Tetrahedron, 2001, 57, 1709.

202 H. M. C. Ferraz, A. M. Aguilar and L. F. Silva Jr, Synthesis, 2003, 2003, 1031.

203 H. M. C. Ferraz, A. M. Aguilar and L. F. Silva Jr, Tetrahedron, 2003, 59, 5817.

204 G. G. Bianco, H. M. C. Ferraz, A. M. Costa, L. V. CostaLotufo, C. Pessoa, M. O. de Moraes, M. G. Schrems, A. Pfaltz and L. F. Silva Jr, J. Org. Chem., 2009, 74, 25612566.

205 P. Abley, J. E. Byrd and J. Halpern, J. Am. Chem. Soc., 1973, 95, 2591.

206 H. Sekizaki, M. Ito and S. Inoue, Bull. Chem. Soc. Jpn., 1978, 51, 2439.

207 L. Wang, J. Sheng, H. Tian and C. Qian, Synth. Commun., 2004, 34, 4265-4272.

208 A. R. Katritzky, R. P. Musgrave, B. Rachwal and C. Zaklika, Heterocycles, 1995, 41, 345-352.
209 G. Aridoss and K. K. Laali, Eur. J. Org. Chem., 2011, 2011, 2827-2835.

210 S. F. Hojati, B. Maleki and Z. Beykzadeh, Monatsh. Chem., 2011, 142, 87-91.

211 I. Mohammadpoor-Baltork, A. R. Khosropour and S. F. Hojati, Monatsh. Chem., 2007, 138, 663-667.

212 I. Mohammadpoor-Baltork, A. R. Khosropour and S. F. Hojati, Catal. Commun., 2007, 8, 1865-1870.

213 B. Karami, S. Nikoseresht and S. Khodabakhshi, Chin. J. Catal., 2012, 33, 298-301.

214 K. Nikoofar and S. M. Dizgarani, Iran. Chem. Commun., 2018, 6, 62-69.

215 A. Mobinikhaledi, M. Zendehdel, F. Goudarzi and G. R. Bardajee, Synth. React. Inorg., Met.-Org., Nano-Met. Chem., 2016, 46, 1526-1531.

216 H. Wang, Y. Xia, S. Lv, J. Xu and Z. Sun, Tetrahedron Lett., 2013, 54, 2124-2127.

217 B. Kaboudin, F. Kazemia, M. Pirouza, A. Baharian Khoshkhoo, J. Kato and T. Yokomatsu, Synthesis, 2016, 48, 3597-3602.

218 F. Fouad, D. R. Davis and R. Twieg, Liq. Cryst., 2018, 45, 1508-1517.

219 J. L. Malavolta, L. M. Frigo, S. Moura, D. C. Flores and A. F. C. Flores, J. Braz. Chem. Soc., 2017, 28, 2106-2116.

220 M. M. Ghorab, F. A. Ragab, S. I. Alqasoumi, A. M. Alafeefy and S. A. Aboulmagd, Eur. J. Med. Chem., 2010, 45, 171-178.

221 G. S. Gadaginamath and S. R. Pujar, Indian J. Chem., Sect. B: Org. Chem. Incl. Med. Chem., 2003, 42, 2896-2900.

222 M. R. Mahmoud, W. S. I. Abou-Elmagd, H. A. Derbala and M. H. Hekal, J. Chem. Res., 2012, 36, 75-82.

223 V. Polshettiwar and R. S. Varma, Tetrahedron Lett., 2008, 49, 879-883.

224 C. Ainsworth, J. Am. Chem. Soc., 1955, 77, 1148.

225 H. G. Bonacorso, G. R. Paim, L. M. F. Porte, E. P. Pittaluga, M. A. P. Martins and N. Zanatta, Arkivoc, 2012, 8, 214-225.

226 A. K. Yadav, G. R. Sharma, P. Dhakad and T. Yadav, Tetrahedron Lett., 2012, 53, 859-862.

227 E. Kanaani and M. Nasr-Esfahani, Monatsh. Chem., 2018, 149, 543-550.

228 A. M. Kamal, S. M. Radwan and R. M. Zaki, Eur. J. Med. Chem., 2011, 46, 567-578.

229 T. M. Potewar, S. A. Siddiqui, R. J. Lahoti and K. V. Srinivasan, Tetrahedron Lett., 2007, 48, 1721-1724.

230 M. Esmaeilpour, J. Javidi, F. N. Dodeji and M. M. Abarghoui, J. Mol. Catal. A: Chem., 2014, 393, 18-29. 231 C. N. S. S. P. Kumar, D. K. Parida, A. Santhoshi, A. K. Kota, B. Sridhar and V. J. Rao, MedChemComm, 2011, 2, 486-492.

232 D. Habibi, M. Nasrollahzadeh, L. Mehrabi and S. Mostafaee, Monatsh. Chem., 2013, 144, 725-728.

233 H. Naeimi and S. Mohamadabadi, Dalton Trans., 2014, 43, 12967-12973.

234 H. Naeimi, F. Kiani and M. Moradian, Green Chem. Lett. Rev., 2018, 11, 361-369.

235 M. Maham and M. Nasrollahzadeh, Appl. Organomet. Chem., 2019, 33, e5097.

236 H. Naeimi, F. Kiani and M. Moradian, Iran. J. Catal., 2013, $3,243-247$. 
237 M. Esmaeilpour, J. Javidi and S. Zahmatkesh, Appl. Organomet. Chem., 2016, 30, 897-904.

238 M. Nasrollahzadeh, M. Sajjadi, M. R. Tahsili, M. Shokouhimehr and R. S. Varma, ACS Omega, 2019, 4, 8985-9000.

239 D. Habibi, H. Nabavi and M. Nasrollahzadeh, J. Chem., 2012, 2013, 1.

240 T. M. Potewar, S. A. Siddiqui, R. J. Lahoti and K. V. Srinivasan, Tetrahedron Lett., 2007, 48, 1721-1724.

241 A. K. Gupta, C. H. Song and C. H. Oh, Tetrahedron Lett., 2004, 45, 4113-4116.

242 D. Habibi, M. Nasrollahzadeh and T. A. Kamali, Green Chem., 2011, 13, 3499-3504.

243 D. Habibi, M. Nasrollahzadeh and T. A. Kamali, Green Chem., 2011, 13, 3499-3504.

244 S. N. Dighe, K. S. Jain and K. V. Srinivasan, Tetrahedron Lett., 2009, 50, 6139-6142.

245 D. Kundu, A. Majee and A. Hajra, Tetrahedron Lett., 2009, 50, 2668-2670.

246 F. Darvish and S. Khazraee, Int. J. Org. Chem., 2015, 5, 7580.

247 Y. Zhou and M. K. Denk, Tetrahedron Lett., 2003, 44, 12951299.

248 V. S. Rao, A. K. Gupta, P. Giridhar and B. S. Reddy, Synth. Commun., 2000, 30, 2625-2628.

249 A. S. Nagarajan and B. S. R. Reddy, Synlett, 2010, 2010, 2311. 250 R. Toche, V. Medhane, A. Desai, A. Avhale, D. Kendre and M. Jachak, J. Indian Chem. Soc., 2006, 83, 1039-1040.

251 P. Ploszaj, A. Junka, B. Szponar, M. Maczynski, S. Ryng, M. Bartoszewicz and A. Piwowar, Acta Pol. Pharm., 2018, 75, 637-647.

252 S. Guccione, A. Raffaelli, G. U. Barretta, L. M. Scolaro, S. Pucci and F. Russo, Eur. J. Med. Chem., 1995, 30, 333-337.

253 F. Russo, S. Guccione, G. Romeo, L. Monsu'Scolaro, S. Pucci, A. Caruso, V. Cutuli and M. A. Roxas, Eur. J. Med. Chem., 1992, 27, 73-80.

254 G. Resnati, Tetrahedron, 1993, 49, 9385-9445.

255 K. L. Kirk, J. Fluorine Chem., 2006, 127, 1013-1029.

256 G. Lal, S. Pez and G. P. Syvret, Chem. Rev., 1996, 96, 17371756.

257 J. Mann, Chem. Soc. Rev., 1987, 16, 381-436.

258 K. Burger, U. Wucherpfennig and E. Brunner, Adv. Heterocycl. Chem., 1994, 60, 1-23.

259 Biomedicinal Aspects of Fluorine Chemistry, ed. R. Filler and Y. Kobayashi, Kondansha and Elsevier Biomedical, Tokyo, 1982.

260 J. T. Welch and S. Eswarakrishnan, Fluorine in Bioorganic Chemistry, Wiley, New York, 1991.

261 Biomedical Frontiers of Fluorine Chemistry, ed. I. Ojima, J. R. McCarthy and J. T. Welch, American Chemical Society, Washington, DC, 1996, ACS Symposium Series 639.

262 S. Narizuka and T. Fuchigami, Bioorg. Med. Chem. Lett., 1995, 5, 1293-1294.

263 T. Hiyama, Organofluorine Compounds: Chemistry and Applications, Springer, Berlin, 2000.

264 M. R. Shaaban, J. Fluorine Chem., 2008, 129, 1156-1161.

265 K. Gewald, Chem. Ber., 1966, 99, 1002-1007.
266 N. A. Hassan, Molecules, 2000, 5, 826-834.

267 K. Gewald and M. Henschel, J. Prakt. Chem., 1976, 318, 663.

268 C. G. Dave and R. D. Shah, Molecules, 2002, 7, 554-565.

269 C. G. Dave and R. D. Shah, J. Heterocycl. Chem., 2000, 37, $757-761$.

270 C. G. Dave and R. D. Shah, J. Heterocycl. Chem., 1998, 35, 1295.

271 C. J. Shishoo, M. B. Devani, G. V. Ullas, S. Ananthan and V. S. Bhadti, J. Heterocycl. Chem., 1981, 18, 43-46.

272 A. E. Rashad, O. A. Heikal, A. O. H. El-Nezhawy and F. M. E. Abdel-Megeid, Heteroat. Chem., 2005, 16, 226-234.

273 M. A. A. Elneairy, M. A. M. Gad-Elkareem and A. M. AbdelFattah, Phosphorus, Sulfur Silicon Relat. Elem., 2006, 181, 1451-1466.

274 S. H. Abdel-Hafez, S. A. Abdel-Mohsen and Y. A. El-Ossaily, Phosphorus, Sulfur Silicon Relat. Elem., 2006, 181, 22972305.

275 I. Devi and P. J. Bhuyan, Synlett, 2004, 2004, 283-286.

276 (a) M. Y. Gavrilov, G. N. Novoseleva, M. I. Vakhrin and M. E. Konshin, Khim.-Farm. Zh., 1996, 30, 39; (b) M. M. Ghorab and A. Y. Hassan, Phosphorus, Sulfur Silicon Relat. Elem., 1998, 141, 257.

277 (a) G. L. Anderson, J. L. Shim and A. D. Broom, J. Org. Chem., 1976, 41, 1095; (b) E. M. Grivaky, S. Lee, C. W. Siyal, D. S. Duch and C. A. Nichol, J. Med. Chem., 1980, 23, 327.

278 (a) S. Furuya and T. Ohtaki, Eur. Pat., EP608565, 1994, Chem. Abstr., 1994, 121, 205395; (b) D. Heber, C. Heers and U. Ravens, Pharmazie, 1993, 48, 537-541.

279 R. H. Bradbury, G. A. Breault, P. J. Jewbury and J. E. Pease, US Pat., US6593326B1, 1998.

280 L. N. Bheemanapalli, R. R. Akkinepally and S. R. Pamulaparthy, Chem. Pharm. Bull., 2008, 56, 13421348.

281 W. T. Ashton, R. D. Brown, F. Jacobson and C. Walsh, J. Am. Chem. Soc., 1979, 101, 4419.

282 S. TumkeviCius, Liebigs Ann., 1995, 1703-1705.

283 J.-C. Castillo, D. Estupiñan, M. Nogueras, J. Cobo and J. Portilla, J. Org. Chem., 2016, 81, 12364-12373.

284 N. Sachdeva, A. V. Dolzhenko and W. K. Chui, Org. Biomol. Chem., 2012, 10, 4586-4596.

285 J. Světlík and T. Liptaj, J. Chem. Soc., Perkin Trans. 1, 2002, 1260-1265.

286 K. Ighilahriz, B. Boutemeur, F. Chami, C. Rabia, M. Hamdi and S. M. Hamdi, Molecules, 2008, 13, 779-789.

287 K. Laxminarayana, C. Rajendiran and K. Mukkanti, Der Pharma Chem., 2012, 4, 517-522.

288 B. P. Bandgar, P. E. More and V. T. Kamble, Chin. J. Chem., 2009, 27, 1123-1126.

289 A. R. Khosropour, I. Mohammadpoor-Baltork and H. Ghorbankhani, Tetrahedron Lett., 2006, 47, 3561-3564.

290 M. Wang, Z. Song and T. Zhang, Synth. Commun., 2011, 41, 385-391.

291 M. Wang, Z. G. Song and T. T. Zhang, Chem. Heterocycl. Compd., 2010, 46, 581-584.

292 M. M. Heravi, N. Javanmardi, H. A. Oskooie and B. Baghernejad, Bull. Chem. Soc. Ethiop., 2011, 25, 305-308. 
293 L. Wu, W. Ma, L. Yang and F. Yan, Asian J. Chem., 2010, 22, 6053-6058.

294 W.-L. Wang, X.-X. Liu, T. Zhang, J.-M. Zhang and J.-H. Zhou, J. Chem. Soc. Pak., 2016, 38, 1196-1202.

295 M. Dabiri, M. Baghbanzadeh and A. S. Delbari, J. Comb. Chem., 2008, 10, 700-703.

296 D. Kumar, P. S. Jadhavar, M. Nautiyal, H. Sharma, P. K. Meena, L. Adane, S. Pancholia and A. K. Chakraborti, RSC Adv., 2015, 5, 30819-30825.

297 K. Rad-Moghadam and L. Samavi, J. Heterocycl. Chem., 2006, 43, 913-916.

298 W. Szczepankiewicz and N. Kuźnik, Tetrahedron Lett., 2015, 56, 1198-1199.

299 S. I. Bhat, U. K. Das and D. R. Trivedi, J. Heterocycl. Chem., 2015, 52, 1253-1259.

300 K. T. Potts and G. Brugel, J. Org. Chem., 1970, 35, 34483451.

301 A. L. Paulsen and R. Madsen, Heterocycles, 2004, 63, 2051.

302 D. Habibi, H. Sahebekhtiari, M. Nasrollahzadeh and A. Taghipour, Lett. Org. Chem., 2013, 10, 209-212.

303 S. Padmanabhan, N. L. Reddy and G. J. Durant, Synth. Commun., 1997, 27, 691-699.

304 M. Nasrollahzadeh, M. Enayatia and M. Khalaj, RSC Adv., 2014, 4, 26264-26270.

305 J. C. Jaen, L. D. Wise, T. G. Heffner, T. A. Pugsley and L. T. Meltzer, J. Med. Chem., 1991, 34, 248-256.

306 V. M. Rao, G. L. V. Damu, D. Sudhakar, V. Siddaiah and C. V. Rao, Arkivoc, 2008, 11, 285-294.

307 B. Maleki, M. Baghayeri, S. M. Vahdat, A. Mohammadzadeh and S. Akhoondi, RSC Adv., 2015, 5, 46545-46551.

308 H. Sharghi, M. Mozaffari, J. Aboonajmi, M. M. Doroodmand, P. Shiri and M. Aberi, ChemistrySelect, 2018, 3, 13534-13540.

309 F. Rezaei, M. A. Amrollahi and R. Khalifeh, Inorg. Chim. Acta, 2019, 489, 8-18.

310 P. Černuchová, G. Vo-Thanh, V. Milata and A. Loupy, Heterocycles, 2004, 64, 177-191.

311 F. A. Abu-Shanab, J. Sulfur Chem., 2006, 27, 433-440.

312 M. F. Farhat, A. M. M. EL-Saghier, M. A. Makhlouf, K. M. Kreddan and A. B. Elmezoughi, J. Sulfur Chem., 2007, 28, 563-572.

313 M. M. Heravi, N. Nami, N. Seifi, H. A. Oskooie and R. Hekmatshoar, Phosphorus, Sulfur Silicon Relat. Elem., 2006, 181, 591-599.

314 A. M. Hussein, A. A. Harb and I. A. Mousa, J. Heterocycl. Chem., 2008, 45, 1819-1823.

315 Y. M. Elkholy, F. A. Abu-Shanab and A. W. Erian, Phosphorus, Sulfur Silicon Relat. Elem., 2000, 167, 151-159.

316 N. M. Elwan, J. Heterocycl. Chem., 2004, 41, 281-284.

317 H. Abdel-Ghany and A. Khodairy, Phosphorus, Sulfur Silicon Relat. Elem., 2000, 166, 45-56.

318 E. I. Al-Afaleq and S. A. Abubshait, Molecules, 2001, 6, 621638.

319 A. A. Amer, Phosphorus, Sulfur Silicon Relat. Elem., 2008, 183, 2330-2343.

320 W. M. Basyouni and K. A. H. M. El-Bayouki, J. Chem. Res., 2005, 2005, 356-360.
321 A. M. S. El-Sharief, J. A. A. Micky, N. A. M. M. Shmeiss and G. El-Gharieb, Phosphorus, Sulfur Silicon Relat. Elem., 2003, 178, 439-451.

322 A. A. Fadda, H. A. Etman, M. Y. El-Seidy and K. M. Elattar, J. Heterocycl. Chem., 2012, 49, 774-781.

323 S. A. Al-Issa, Asian J. Chem., 2006, 18, 2145-2150.

324 N. M. Nahas and A. A. A. Hafez, Heterocycl. Commun., 2007, 13, 381-386.

325 A. E. Abdel-Rahman, E. A. Bakhite and E. A. Al-Taifi, Pharmazie, 2003, 58, 372-377.

326 A. H. Bedair, H. A. Emam, N. A. El-Hady, K. A. R. Ahmed and A. M. El-Agrody, Il Farmaco, 2001, 56, 965-973.

327 S. A. El-Assiery, G. H. Sayed and A. Fouda, Acta Pharm., 2004, 54, 143-150.

328 A. A. El-Maghraby, G. A. M. El-Hag Ali, A. H. A. Ahmed and M. S. A. El-Gaby, Phosphorus, Sulfur Silicon Relat. Elem., 2002, 177, 293-302.

329 A. Shaabani, S. Keshipour, S. Shaabani and M. Mahyari, Tetrahedron Lett., 2012, 53, 1641-1644.

330 K. A. Nazish, A. Rauf, A. Sharif, E. Ahmed, F.-U. H. Nasim, A. Yaqoob and A. M. Qureshi, J. Chem. Soc. Pak., 2015, 37, 1047-1055.

331 A. Yousefi, R. Yousefi, F. Panahi, S. Sarikhani, A. R. Zolghadr, A. Bahaoddini and A. Khalafi-Nezhad, Int. J. Biol. Macromol., 2015, 78, 46-55.

332 A. M. Salaheldin and M. K. Alphy, J. Heterocycl. Chem., 2008, 45, 307-310.

333 A. F. A. Khattab, D. V. Tinh and W. Stadlbauer, J. Prakt. Chem., 1996, 338, 151-156.

334 M. Seidel, G. C. Van Tuyle and W. D. Weir, J. Org. Chem., 1970, 35, 1662-1664.

335 A. K. Osipov, A. A. Anis'kov and A. Y. Yegorova, Russ. J. Org. Chem., 2017, 53, 210-214.

336 A. V. Komkov, M. A. Prezent, A. V. Ignatenko, I. P. Yakovlev and V. A. Dorokhov, Russ. Chem. Bull., Int. Ed., 2006, 55, 2085-2090.

337 B. Holló, V. M. Leovac, P. Bombicz, A. Kovács, L. S. Jovanović, G. Bogdanović, V. Kojić, V. Divjaković, M. D. Joksović and K. M. Szécsényi, Aust. J. Chem., 2010, 63, 1557-1564.

338 J. Balog, Z. Riedl and G. Hajós, Tetrahedron Lett., 2013, 54, 5338-5340.

339 F. P. L. Lim, G. Luna and A. V. Dolzhenko, Synthesis, 2016, 48, 2423-2428.

340 C. W. Whitehead and J. J. Traverso, J. Am. Chem. Soc., 1955, 77, 5872-5877.

341 A. Z. Halimehjani, M. H. Shayegan, S. S. Poshteh, V. Amani, B. Notash and M. M. Hashemi, Tetrahedron Lett., 2015, 56, 7124-7127.

342 B.-L. Wang, H.-T. Gao and W.-D. Z. Li, J. Org. Chem., 2015, 80, 5296-5301.

343 M. V. N. Reddy, J. Kim and Y. T. Jeong, J. Fluorine Chem., 2012, 135, 155-158.

344 M. Periasamy, N. Kishorebabu and K. N. Jayakumar, Tetrahedron Lett., 2007, 48, 1955-1958.

345 H. Park, Y. Kwon, J. E. Shin, W.-J. Kim, S. Hwang, S. Lee and S. Kim, Synthesis, 2017, 49, 2761-2767. 
346 R. Paolesse, L. Jaquinod, M. O. Senge and K. M. Smith, J. Org. Chem., 1997, 62, 6193-6198.

347 C. Tardieux, F. Bolze, C. P. Gros and R. Guilard, Synthesis, 1998, 1998, 267-268.

348 C. B. Reese and H. Yan, Tetrahedron Lett., 2001, 42, 55455547.

349 U. Pindur and H. Witzel, Arch. Pharm., 1990, 323, 427-432.

350 S. Khaksar, S. M. Vahdat, M. Gholizadeh and S. M. Talesh, J. Fluorine Chem., 2012, 136, 8-11.

351 R. Gu, A. Hameurlaine and W. Dehaen, J. Org. Chem., 2007, 72, 7207-7213.

352 Z. Hassen, A. B. Akacha and B. Hajjem, Phosphorus, Sulfur Silicon Relat. Elem., 2003, 178, 2349-2356.

353 M. J. Dooley, R. J. Quinn and P. J. Scammells, Aust. J. Chem., 1989, 42, 747-750.

354 S. K. Meegalla, D. Doller, R. Liu, D. Sha, R. M. Soll and D. S. Dhanoa, Tetrahedron Lett., 2002, 43, 8639-8642.

355 J. Warkentin, Acc. Chem. Res., 2009, 42, 205-212.

356 (a) H. Minato and T. Nagasaki, J. Chem. Soc. C, 1966, 377379; (b) C. W. Jefford, A. W. Sledeski, J.-C. Rossier and T. Boukouvalas, Tetrahedron Lett., 1990, 31, 5741-5744.

357 J.-P. Croisetière and C. Spino, J. Org. Chem., 2018, 83, 56095618.

358 P. A. Clarke, P. B. Sellars and N. M. Nasir, Org. Biomol. Chem., 2015, 13, 4743-4750.

359 G. H. Elgemeie, A. H. Elghandour and A. M. Hussein, Synth. Commun., 2004, 34, 3293-3302.

360 J. S. Yadav, B. V. S. Reddy, L. Chandraiah, B. Jagannadh, S. K. Kumar and A. C. Kunwar, Tetrahedron Lett., 2002, 43, 4527-4530.

361 J. S. Yadav, B. V. S. Reddy, C. Parisse, P. Carvalho and T. P. Rao, Tetrahedron Lett., 2002, 43, 2999-3002.

362 H. Miyazaki, K. Honda, M. Asami and S. Inoue, J. Org. Chem., 1999, 64, 9507-9511.

363 V. R. Shah, J. L. Bose and R. C. Shah, J. Org. Chem., 1960, 25, 677.

364 N. S. Bhatt, A. K. Shah, R. V. Raval and V. Thakor, Curr. Sci., 1984, 53, 1289-1290.

365 H. Maamar, J. Heterocycl. Chem., 1993, 30, 1155.

366 M. Chavda, A. Shah, S. Bhatt, K. Deo and P. Kundu, Arzneim.-Forsch./Drug Res., 2003, 53, 196-200.

367 J. Barluenga, A. Mendoza, F. Rodríguez and F. J. Fañanás, Angew. Chem., Int. Ed., 2009, 48, 1644-1647.

368 M. C. Mayorquín-Torres, M. Flores-Álamo and M. A. Iglesias-Arteaga, Tetrahedron Lett., 2017, 58, 35003504.

369 C. Alarcón-Manjarrez, R. Arcos-Ramos, M. Flores-Álamo and M. A. Iglesias-Arteaga, Steroids, 2016, 109, 66-72.

370 H. Miyazaki, K. Honda, M. Asami and S. Inoue, J. Org. Chem., 1999, 64, 9507-9511.

371 J. S. Yadav, B. V. S. Reddy, M. Aruna, C. Venugopal, T. Ramalingam, S. K. Kumar and A. C. Kunwar, J. Chem. Soc., Perkin Trans. 1, 2002, 165-171.

372 J. S. Yadav, B. V. S. Reddy, C. V. Rao and K. V. Rao, J. Chem. Soc., Perkin Trans. 1, 2002, 1401.

373 R. Merten and G. Müller, Chem. Ber., 1964, 97, 682-694.
374 S. Prado, Y. L. Janin and P.-E. Bost, J. Heterocycl. Chem., 2006, 43, 1605-1608.

375 M. Kočevar, S. Polanc, M. Tišler and B. Verček, Synth. Commun., 1989, 19, 1713-1719.

376 M. A. Al-Haiza, M. S. Mostafa and M. Y. El-Kady, Molecules, 2003, 8, 275-286.

377 A. H. Bedair, N. A. El-Hady, M. S. Abd El-Latif, A. H. Fakery and A. M. El-Agrody, Il Farmaco, 2000, 55, 708-714.

378 M. Bakos, Á. Gyömöre, A. Domján and T. Soós, Angew. Chem., Int. Ed., 2017, 56, 5217-5221.

379 D.-Q. Zheng, Y. Jing, B.-Y. Zheng, Y.-F. Ye, S. Xu, W.-S. Tian, H.-Y. Ma and K. Ding, Tetrahedron, 2016, 72, 2164-2169.

380 P. W. Anzalone, A. R. Baru, E. M. Danielson, P. D. Hayes, M. P. Nguyen, A. F. Panico, R. C. Smith and R. S. Mohan, J. Org. Chem., 2005, 70, 2091-2096.

381 J. S. Yadav, B. V. S. Reddy and P. Srihari, Synlett, 2001, 2001, 673-675.

382 E. Merişor, J. Conrad, C. C. Malakar and U. Beifuss, Synlett, 2008, 2008, 903-907.

383 N. Maulide and I. E. Markó, Org. Lett., 2007, 9, 3757-3760.

384 J. J. Lee and G. A. Kraus, Tetrahedron Lett., 2013, 54, 23662368.

385 R. J. Fletcher, W. B. Motherwell and M. E. Popkin, Chem. Commun., 1998, 2191-2192.

386 P. Bunse, E.-U. Wurthwein and B. Wunsch, Eur. J. Org. Chem., 2018, 2018, 1806-1812.

387 Y. Sempere and E. M. Carreira, Angew. Chem., 2018, 130, 7780-7784.

388 A. Brodzka, D. Koszelewski, M. Zysk and R. Ostaszewski, Catal. Commun., 2018, 106, 82-86.

389 D. Koszelewski, M. Zysk, A. Brodzka, A. Żądło, D. Paprocki and R. Ostaszewski, Org. Biomol. Chem., 2015, 13, 1101411020.

390 J. I. Trujillo and A. S. Gopalan, Tetrahedron Lett., 1993, 34, 7355-7358.

391 A. W. Schwabacher and A. D. Stefanescu, Tetrahedron Lett., 1996, 37, 425-428.

392 S. A. King, J. Org. Chem., 1994, 59, 2253-2256.

393 K.-I. Tadano, T. Murata, T. Kumagai, Y. Isshiki and S. Ogawa, J. Carbohydr. Chem., 1993, 12, 1187-1202.

394 K.-I. Takao, H. Saegusa, G. Watanabe and K.-I. Tadano, Tetrahedron: Asymmetry, 2000, 11, 453-464.

395 K.-I. Takao, H. Saegusa and K.-I. Tadano, J. Carbohydr. Chem., 2001, 20, 57-69.

396 T. Okano, T. Michihashi and J. Kiji, Appl. Organomet. Chem., 1995, 9, 473-478.

397 A. Roy, M. Rahman, S. Das, D. Kundu, S. K. Kundu, A. Majee and A. Hajra, Synth. Commun., 2009, 39, 590-595.

398 H. Mansilla, Synth. Commun., 2006, 36, 2195-2201.

399 M. J. Climent, A. Corma, S. Iborra, M. C. Navarro and J. Primo, J. Catal., 1996, 161, 783-789.

400 A. Ziyaei-Halimjani, N. Azizi and M. R. Saidi, J. Sci., Islamic Repub. Iran, 2005, 16, 37-41.

401 C. C. Silveira, S. R. Mendes, F. I. Ziembowicz, E. J. Lenardão and G. Perin, J. Braz. Chem. Soc., 2010, 21, 371-374.

402 S. H. Lee, J. H. Lee and C. M. Yoon, Tetrahedron Lett., 2002, 43, 2699-2703. 
403 R. Chen and L. Wang, RSC Adv., 2015, 5, 20155-20159.

404 D. J. M. Lyons, R. D. Crocker, D. Enders and T. V. Nguyen, Green Chem., 2017, 19, 3993-3996.

405 S. V. Ley and H. W. M. Priepke, Angew. Chem., Int. Ed., 1994, 33, 2292-2294.

406 R. Gopinath, Sk. J. Haque and B. K. Patel, J. Org. Chem., 2002, 67, 5842-5845.

407 N. M. Leonard, M. C. Oswald, D. A. Freiberg, B. A. Nattier, R. C. Smith and R. S. Mohan, J. Org. Chem., 2002, 67, 5202-5207.

408 Y.-R. Ma, T.-S. Jin, S.-X. Shi and T.-S. Li, Synth. Commun., 2003, 33, 2103-2108.

409 O. Takazawa, K. Kogami and K. Hayashi, Bull. Chem. Soc. Jpn., 1984, 57, 1876-1881.

410 M. A. P. Martins, G. P. Bastos, A. P. Sinhorin, A. F. C. Flores, H. G. Bonacorso and N. Zanatta, Synlett, 1999, 6, 789-791.

411 J. K. Stille, H. Su, P. Brechot, G. Parrinello and L. S. Hegedus, Organometallics, 1991, 10, 1183-1189.

412 J. Pospech, A. J. J. Lennox and M. Beller, Chem. Commun., 2015, 51, 14505-14508.

413 (a) W. Kantlehner, T. Maier and J. J. Kapassakalidis, Liebigs Ann. Chem., 1981, 1981, 70-84; (b) K. Utimoto, Y. Wakabayashi, Y. Shishiyama, M. Inoue and H. Nozaki, Tetrahedron Lett., 1981, 22, 4279-4280; (c) S. Kirchmeyer, A. Mertens, M. Arvanaghi and G. A. Olah, Synthesis, 1983, 1983, 498-500; (d) J. H. Babler and C. J. Marcuccilli, Tetrahedron Lett., 1987, 28, 4657-4660; (e) T. Hiyama, H. Oishi, Y. Suetsugu, K. Nishide and H. Saimoto, Bull. Chem. Soc. Jpn., 1987, 60, 2139-2150.

414 S. Kotani, M. Sakamoto, K. Osakama and M. Nakajima, Eur. J. Org. Chem., 2015, 2015, 6606-6609.

415 G. Casiraghi, G. Casnati and M. Cornia, Tetrahedron Lett., 1973, 14, 679-682.

416 H.-S. Byun and R. Bittman, Synth. Commun., 1993, 23, 32013204.

417 Y. Geng, H. M. Faidallah, H. A. Albar, I. A. Mhkalid and R. R. Schmidt, Eur. J. Org. Chem., 2013, 2013, 7035-7040.

418 M. Asaoka, N. Sugimura and H. Takei, Bull. Chem. Soc. Jpn., 1979, 52, 1953-1956.

419 J.-L. Montchamp, F. Tian, M. E. Hart and J. W. Frost, J. Org. Chem., 1996, 61, 3897-3899.

420 R. V. Hoffman and J. M. Salvador, Tetrahedron Lett., 1991, 32, 2429-2432.

421 J. Morris, D. G. Wishka, G. P. Luke, T. M. Judge and R. B. Gammill, Tetrahedron, 1997, 53, 11211-11222.

422 D. E. DeMong and R. M. Williams, Tetrahedron Lett., 2002, 43, 2355-2357.

423 A. McKillop, B. P. Swann, M. E. Ford and E. C. Taylor, J. Am. Chem. Soc., 1973, 95, 3641-3645.

424 E. C. Taylor, R. L. Robey, K.-T. Liu, B. Favre, H. T. Bozimo, R. A. Conley, C.-S. Chiang, A. McKillop and M. E. Ford, J. Am. Chem. Soc., 1976, 98, 3037-3038.

425 E. C. Taylor, R. A. Conley, D. K. Johnson and A. McKillop, J. Org. Chem., 1977, 42, 4167-4169.

426 D. J. Crouse and D. M. S. Wheeler, Tetrahedron Lett., 1979, 20, 4797-4798.
427 T. W. Hart and F. Scheinmann, Tetrahedron Lett., 1980, 21, 2295-2296.

428 B. M. Smith and A. E. Graham, Tetrahedron Lett., 2007, 48, 4891-4894.

429 S. Manojveer and R. Balamurugan, Eur. J. Org. Chem., 2015, 2015, 4254-4260.

430 S. Manojveer and R. Balamurugan, Chem. Commun., 2014, 50, 9925-9928.

431 S. R. Koppolu and R. Balamurugan, New J. Chem., 2017, 41, 1186-1192.

432 K. R. Kunz, E. W. Taylor, H. M. Hutton and B. J. Blackburn, Org. Prep. Proced. Int., 1990, 22, 613-618.

433 B. C. Tlach, A. L. Tomlinson, A. G. Ryno, D. D. Knoble, D. L. Drochner, K. J. Krager and M. Jeffries-EL, J. Org. Chem., 2013, 78, 6570-6581.

434 J. J. Lee, J. Kim, Y. M. Jun, B. M. Lee and B. H. Kim, Tetrahedron, 2009, 65, 8821-8831.

435 S. J. Maddirala, V. S. Gokak and L. D. Basanagoudar, J. Heterocycl. Chem., 2004, 41, 7-11.

436 A. Kudelko, K. Jasiak and K. Ejsmont, Monatsh. Chem., 2015, 146, 303-311.

437 M. S. Khajavi, S. S. S. Hosseini and F. Sefidkon, Iran. J. Chem. Chem. Eng., 1997, 16, 68-71.

438 K. K. Gnanasekaran, B. Nammalwar, M. Murie and R. A. Bunce, Tetrahedron Lett., 2014, 55, 6776-6778.

439 S. M. H. Al-Majidi, J. Saudi Chem. Soc., 2014, 18, 893-901.

440 J. Štetinová, R. Kada and J. Leško, Molecules, 1996, 1, 251254.

441 J. F. Mike, J. J. Inteman, A. Ellern and M. Jeffries-EL, J. Org. Chem., 2010, 75, 495-497.

442 S. Khaksar, A. Heydari, M. Tajbakhsh and S. M. Vahdat, J. Fluorine Chem., 2010, 131, 1377-1381.

443 M. M. Heravi, N. Montazeri, M. Rahmizadeh, M. Bakavoli and M. Ghassemzadeh, J. Chem. Res., 2000, 2000, 584-585.

444 Y.-C. Chi and C.-M. Sun, Synlett, 2000, 2000, 591-594.

445 F. Wang, M. Tran-Dubé, S. Scales, S. Johnson, I. McAlpine and S. Ninkovic, Tetrahedron Lett., 2013, 54, 4054-4057.

446 W. Huang and R. M. Scarborough, Tetrahedron Lett., 1999, 40, 2665-2668.

447 Z.-H. Zhang, T.-S. Li and J.-J. Li, Monatsh. Chem., 2007, 138, 89-94.

448 Z.-H. Zhang, L. Yin and Y.-M. Wang, Catal. Commun., 2007, 8, 1126-1131.

449 I. B. Dzvinchuk, A. V. Turov and M. O. Lozinskii, Chem. Heterocycl. Compd., 2006, 42, 929-934.

450 V. Nair and F. Zhang, Molecules, 2013, 18, 11576-11585.

451 R. P. Frutos, T. Tampone, J. A. Mulder, Y. Xu, D. Reeves, X.-J. Wang, L. Zhang, D. Krishnamurthy and C. H. Senanayake, Tetrahedron Lett., 2011, 52, 2465-2467.

452 D. Tomalia and J. N. Pmge, J. Org. Chem., 1973, 38, 39493951.

453 M. Aouali, D. Mhalla, F. Allouche, L. El Kaim, S. Tounsi, M. Trigui and F. Chabchoub, Med. Chem. Res., 2015, 24, 2732-2741.

454 M. S. Kerr, J. R. de Alaniz and T. Rovis, J. Org. Chem., 2005, 70, 5725-5728. 
455 S. S. Chuprun, A. V. Protas, O. S. Fedorova, D. D. Vaulina, R. N. Krasikova, E. A. Popova and R. E. Trifonov, Russ. J. Org. Chem., 2016, 52, 1863-1865.

456 V. A. Ostrovskii, M. S. Mazur, V. V. Mikhailenko, N. A. Aksenov and A. V. Aksenov, Chem. Heterocycl. Compd., 2016, 52, 849-851.

457 S. V. Voitekhovich, Y. V. Grigoriev, A. S. Lyakhov, L. S. Ivashkevich and O. A. Ivashkevich, Dalton Trans., 2016, 45, 13406-13414.

458 S. N. Dighe, K. S. Jain and K. V. Srinivasan, Tetrahedron Lett., 2009, 50, 6139-6142.

459 S. V. Voitekhovich, A. N. Vorob'ev, P. N. Gaponik and O. A. Ivashkevich, Chem. Heterocycl. Compd., 2005, 41, 999-1004.

460 H. Wang, F. Wei, Q. Chen, X. Hu and X. Niu, J. Chem. Res., 2016, 40, 570-572.

461 Y. Satoh and N. Marcopulos, Tetrahedron Lett., 1995, 36, 1759-1762.

462 W.-K. Su, Z. Hong, W.-G. Shan and X.-X. Zhang, Eur. J. Org. Chem., 2006, 2006, 2723-2726.

463 D. Srinivas, V. D. Ghule and K. Muralidharan, RSC Adv., 2014, 4, 7041-7051.

464 G. P. Sagitullina, A. K. Garkushenko, E. G. Atavin and R. S. Sagitullin, Mendeleev Commun., 2009, 19, 155-156.

465 Sh. H. Abdel-Hafez, Eur. J. Med. Chem., 2008, 43, 1971-1977. 466 Z. Arghiani, S. M. Seyedi, M. Bakavoli and H. Eshghi, J. Heterocycl. Chem., 2015, 52, 1099-1107.

467 A. Aidouni, S. Bendahou, A. Demonceau and L. Delaude, J. Comb. Chem., 2008, 10, 886-892.

468 Y. Kotaiah, N. Harikrishna, K. Nagaraju and C. V. Rao, Eur. J. Med. Chem., 2012, 58, 340-345.

469 A. E. Abdel-Rahman, E. A. Bakhite, O. S. Mohamed and E. A. Thabet, Phosphorus, Sulfur Silicon Relat. Elem., 2003, 178, 89-106.

470 A. A. Harb, A. M. Hussein and I. A. Mousa, Phosphorus, Sulfur Silicon Relat. Elem., 2006, 181, 2247-2261.

471 A. H. M. Hussein, M. A. M. Gad-Elkareem, A. B. A. A. M. ElAdasy and I. M. Othman, Phosphorus, Sulfur Silicon Relat. Elem., 2009, 184, 2263-2280.

472 Z. A. Hozien, A. A. Abdel-Wahab, K. M. Hassan, F. M. Atta and S. A. Ahmed, Pharmazie, 1997, 52, 753-758.

473 S. Sheikhi-Mohammareh, A. Shiri and M. Bakavoli, J. Chem. Res., 2015, 39, 403-406.

474 M. Mohadeszadeh, M. Rahimizadeh, H. Eshghi, A. Shiri, M. Gholizadeh and A. Shams, Helv. Chim. Acta, 2015, 98, 474-481.

475 H. Moradi, H. Eshghi and M. Bakavoli, J. Chem. Res., 2016, 40, 276-279.

476 A. V. Sergievskii, O. A. Krasnoshek, S. F. Mel'nikova and I. V. Tselinskii, Russ. J. Org. Chem., 2002, 38, 915-917.

477 J. A. Bekhit, H. T. Y. Fahmy, S. A. F. Rostom and A. M. Baraka, Eur. J. Med. Chem., 2003, 38, 27-36.

478 S. M. I. Badr, Turk. J. Chem., 2011, 35, 131-143.

479 S. Bondock, W. Khalifa and A. A. Fadda, Eur. J. Med. Chem., 2007, 42, 948-954.

480 A. R. Porcari and L. B. Townsend, Synth. Commun., 1998, 28, 3835-3843.
481 A. M. A. Hameed, A. M. Nour-Eldin, M. M. Ibrahim and K. U. Sadek, Chem. Sci. Int. J., 2015, 8, 1-5.

482 K. M. Dawood, A. M. Farag and N. A. Khedr, Arkivoc, 2008, xv, 166-175.

483 M. E. A. Zaki, Molecules, 1998, 3, 71-79.

484 H. N. Hafez, A. G. Alshammari and A.-R. B. A. El-Gazzar, Acta Pharm., 2015, 65, 399-412.

485 N. Montazeri, M. M. Heravi, F. Tajfirooz and N. Nazari, Monatsh. Chem., 2017, 148, 691-694.

486 I. Zemanová, R. Gašparová, F. Kraic, D. Kružlicová, T. Maliar, A. Boháč and G. Addová, Arkivoc, 2017, 2017, 184-193.

487 S. B. Rajur, A. Y. Merwade, L. D. Basanagoudar and P. V. Kulkarni, J. Pharm. Sci., 1989, 78, 780-782.

488 F. P. L. Lim, L. Y. Tan, E. R. T. Tiekink and A. V. Dolzhenko, RSC Adv., 2018, 8, 21495-21504.

489 M. M. Heravi, F. F. Bamoharram, G. Rajabzadeh, N. Seifi and M. Khatami, J. Mol. Catal. A: Chem., 2006, 259, 213-217.

490 M. M. Heravi, M. Rahimizadeh and M. Ghassemzadeh, Indian J. Heterocycl. Chem., 2006, 15, 387-388.

491 M. M. Heravi, M. Bakavoli, M. Rahimizadeh, G. Rajabzadeh and M. Ghassemzadeh, Russ. J. Org. Chem., 2008, 44, 12331234.

492 M. Z. A. Badr, A. A. Geies, M. S. Abbady and A. A. Dahy, Phosphorus, Sulfur Silicon Relat. Elem., 2004, 179, 25812593.

493 S.-L. Cao, M. Zhang, Y.-P. Feng, Y.-Y. Jiang and N. Zhang, Synth. Commun., 2008, 38, 2227-2236.

494 M. Adib, E. Sheikhi and H. R. Bijanzadeh, Synlett, 2012, 2012, 85-88.

495 A. Nasreen and R. M. Borik, Orient. J. Chem., 2014, 30, 761768.

496 D. Shi, L. Rong, J. Wang, Q. Zhuang, X. Wang and H. Hu, Tetrahedron Lett., 2003, 44, 3199-3201.

497 A. Davoodnia, M. M. Heravi, E. Golshani, M. Bakavoli and L. Dehabadi, J. Chem. Res., 2007, 2007, 257-258.

498 A. A. Mohammadi, S. Taheri and S. Askari, J. Heterocycl. Chem., 2017, 54, 484-488.

499 E. Marinho, R. Araújo and F. Proença, Tetrahedron, 2010, 66, 8681-8689.

500 M. M. Heravi, S. Sadjadi, N. M. Haj, H. A. Oskooie, R. H. Shoar and F. F. Bamoharram, Tetrahedron Lett., 2009, 50, 943-945.

501 F. F. Bamoharram, M. M. Heravi, M. Roshani and M. Monabati, Asian J. Org. Chem., 2011, 23, 511-514.

502 M. Bakavoli, B. Reihani, M. Rahimizadeh and M. Nikpour, Phosphorus, Sulfur Silicon Relat. Elem., 2006, 181, 99-104.

503 B. V. Rao, S. Manmode and S. Hotha, J. Org. Chem., 2015, 80, 1499-1505.

504 S. A. Thadke, M. Neralkar and S. Hotha, Carbohydr. Res., 2016, 430, 16-23.

505 C. Uriel, P. Rijo, A. S. Fernandes, A. M. Gómez, B. FraserReid and J. C López, ChemistrySelect, 2016, 1, 6011-6015.

506 A. Mallick, Y. Mallikharjunarao, P. Rajasekaran, R. Roy and Y. D. Vankar, Eur. J. Org. Chem., 2016, 2016, 579-588. 
507 S. A. Thadke, B. Mishra, M. Islam, S. Pasari, S. Manmode, B. V. Rao, M. Neralkar, G. P. Shinde, G. Walke and S. Hotha, Nat. Commun., 2017, 8, 1-9.

508 A. Y. Shaikh, G. Sureshkumar, D. Pati, S. S. Gupta and S. Hotha, Org. Biomol. Chem., 2011, 9, 5951-5959.

509 B. V. Rao, S. Manmode and S. Hotha, Carbohydr. Res., 2015, 417, 103-108.

510 M. L. Wolfrom, J. W. Spoors and R. A. Gibbons, J. Org. Chem., 1957, 22, 1513-1514.

511 P. M. Vadhadiya and C. V. Ramana, Org. Lett., 2015, 17, 1724-1727.

512 D. Mukherjee, S. K. Yousuf and S. C. Taneja, Tetrahedron Lett., 2008, 49, 4944-4948.

513 M. V. Panova, N. M. Podvalnyy, E. L. Okun, P. I. Abronina, A. O. Chizhov and L. O. Kononov, Carbohydr. Res., 2018, 456, 35-44.

514 N. M. Podvalnyy, A. O. Chizhov, A. I. Zinin and L. O. Kononov, Carbohydr. Res., 2016, 431, 25-32.
515 N. M. Podvalnyy, P. I. Abronina, E. L. Zdorovenko, A. O. Chizhov, A. I. Zinin, V. I. Torgov and L. O. Kononov, Russ. Chem. Bull., 2014, 63, 497-500.

516 T. Uchino, Y. Tomabechi, A. Fukumoto and H. Yamada, Carbohydr. Res., 2015, 402, 118-123.

517 W. Zhu and Z. Li, Synth. Commun., 2000, 30, 3823-3828.

518 E. J. Corey and N. Raju, Tetrahedron Lett., 1983, 24, 55715574 .

519 Y. Norimura, D. Yamamoto and K. Makino, Org. Biomol. Chem., 2017, 15, 640-648.

520 H. J. Shirley, M. Koyioni, F. Muncan and T. J. Donohoe, Chem. Sci., 2019, 10, 4334-4338.

521 C. H. Alves Esteves, C. J. J. Hall, P. D. Smith and T. J. Donohoe, Org. Lett., 2017, 19, 5248-5251.

522 (a) M. Kawatsura and J. F. Hartwig, J. Am. Chem. Soc., 1999, 121, 1473-1478; (b) D. A. Culkin and J. F. Hartwig, Acc. Chem. Res., 2003, 36, 234-245; (c) G. A. Grasa and T. J. Colacot, Org. Lett., 2007, 9, 5489-5492. 